\title{
Digital Materiality, Heritage Objects, the Emergence of Evidence, and the Design of Knowledge Enabling Systems
}

\author{
by \\ Kay Mary Sanderson
}

\begin{abstract}
A thesis
submitted to the Victoria University of Wellington in fulfilment of the requirements for the degree of Doctor of Philosophy
\end{abstract}

Victoria University of Wellington 2017 



\section{ABSTRACT}

Beneath the problem of achieving digital convergence in the heritage sector is a problem of deeply entrenched discourses generated in a physical paradigm where objects kept in heritage sector institutions were treated as goods to be divided, and where notions about the nature of those goods, their use, and practices facilitating their use, were imagined in terms of the norms for each institution type. The digital paradigm provides new opportunities, amongst them the possibility of creating intersecting digital knowledge spaces designed to aid processes of enquiry and meaning-making and to maximise possibilities for rational and justifiable knowledge formation about predictable and still to be imagined topics of enquiry. Achieving that vision calls for research that seeks to understand the process of knowledge formation, that hunts out the strengths and weaknesses in existing bodies of thought, and that works, through its modes of transmission, to instil the understanding necessary for a shared knowledge-oriented body of theory and practice to emerge. The research reported in this thesis responds to these needs. It was conducted by a former archives practitioner taking a fresh look at her own discipline's body of thought, and reflecting on its utility across the whole heritage sector.

An open and exploratory research question was posed: What can be learnt about archives domain thinking, heritage objects and their evidentiality, and the design of knowledge enabling systems by exploring how evidence emerges during a historical research process?

The research design combined close examination of the archives domain's explicit and implicit thinking with a case study in the form of a deeply reflective historical enquiry that was committed to tracking down and tracing seemingly relevant objects (both physical and digital), and their meaningful ways of being related, across institutional and conceptual boundaries. The researcher did not plan to go into 'the wild', but word got out, and 'the wild' came to her. The research, in other words, was conducted in the space archival science's continuum thinkers refer to as the fourth dimension - the societal plurality, where assumptions embedded in institutionalized thought can be deeply disturbed. 
The historical enquiry was centred on Frederick Burdett Butler (1903-1982), an eclectic 'collector' and local historian who built his own museum/archive/library/gallery/ information resource in New Plymouth, New Zealand. A misfit in New Zealand's historically-oriented professional community, he nevertheless amassed a massive collection which, during his life-time and since his death, has been widely dispersed. Parts are in collecting institutions and parts are in 'the wild'. Much is in hiding.

Three major problems in archives domain discourse were identified as potential stumbling blocks in the search for sector-wide theory. These are addressed in three theory-building chapters, each of which is framed around a line of enquiry followed in the researcher's attempt to form knowledge of Fred. One of these problems is the prevalence in the domain of a fuzzy and 'othering' object-privileging concept of record, but little awareness of continuum theory's concept-privileging notion of records as logical entities, which means there is also little awareness of the relevance of the continuum notion for richer, more flexible, and potentially convergent descriptive practice. The second is the existence of unresolved debates about the nature of evidence and its importance in relation to the concept of record. The third is dichotomous thinking about the nature of objectivity and subjectivity, a problem that has caused debates about the nature of records, the value of an evidence-oriented domain discourse, and the epistemic character of descriptive practice; also, it has played a part in the 'othering' of libraries. A final chapter reflects on the implications of the research for the design of knowledge enabling systems and on possibilities for archival science's continuum theory to connect with similar bodies of thought emerging in other disciplines.

The research paradigm is grounded in humanities, social science, and philosophical scholarship which draws attention to inter-dependence and co-evolution in time and over time, and which challenges habituated perceptions of dichotomies. Critical realism, a third way philosophy of knowledge, was the primary philosophical and methodological underlabourer. 


\section{TABLE OF CONTENTS}

LIST OF FIGURES — ix

LIST OF TABLES - X

ACKNOWLEDGEMENTS $\quad$ xi

PREFACE - xiii

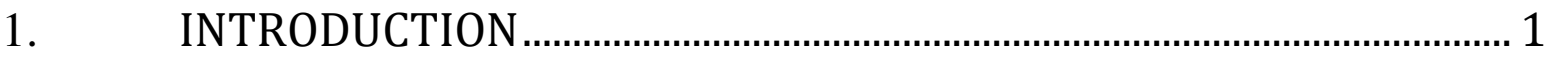

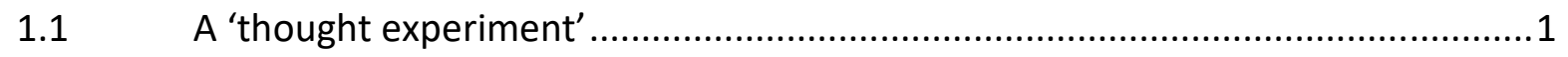

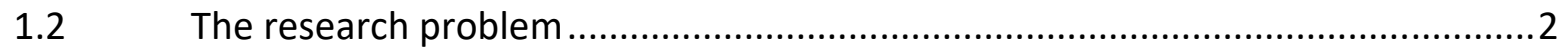

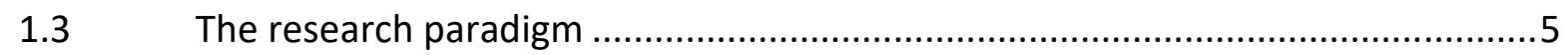

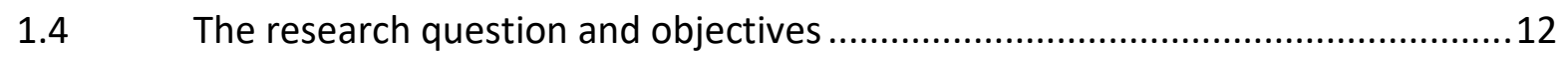

1.4.1 The intent of the research - a double agenda 12

$\begin{array}{ll}\text { 1.4.2 The research question and objectives } & 12\end{array}$

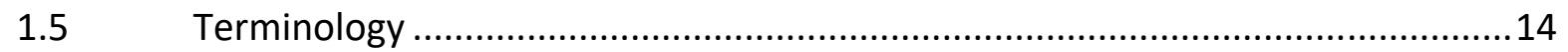

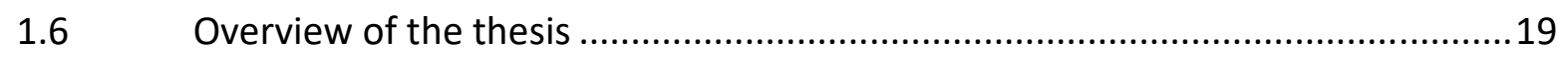

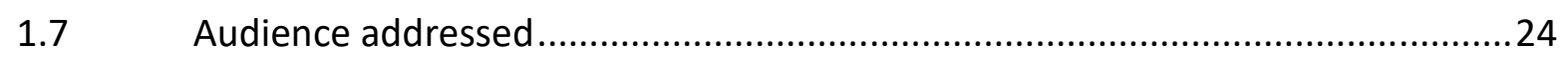

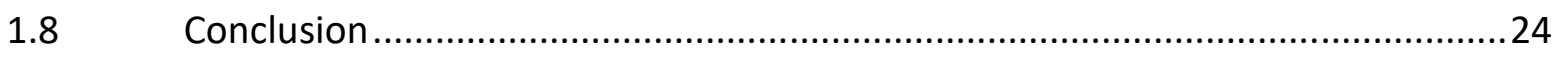

2. CRITICAL REALISM AND THE RESEARCH DESIGN ...........................27

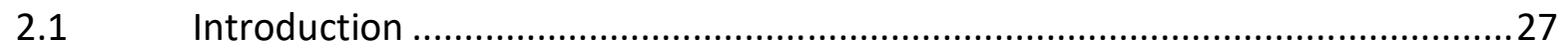

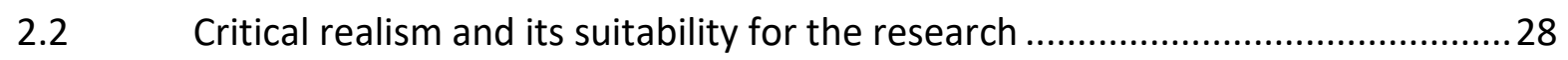

2.3 Critical realism as an emergent and open philosophy.................................... 31 
2.4 The logic at the core of critical realism

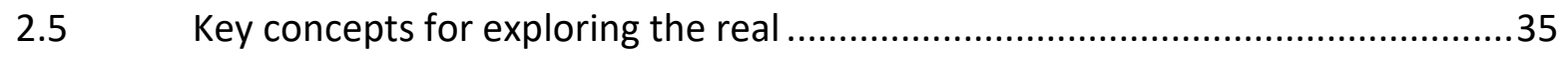

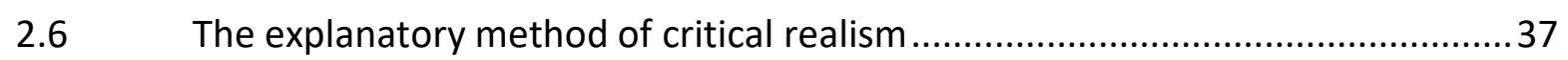

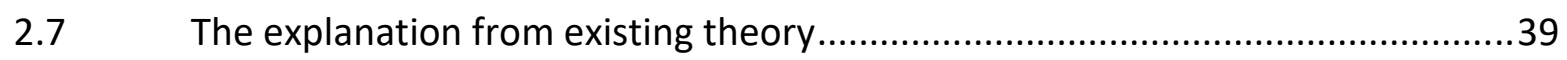

$\begin{array}{ll}2.7 .1 \text { A discourse analysis } & 39\end{array}$

2.7.2 The discourse analysis method 39

2.7.3 The initial discourse population $\quad 42$

2.7.4 Conducting the discourse analysis and reconfiguring the discourse population $\quad 45$

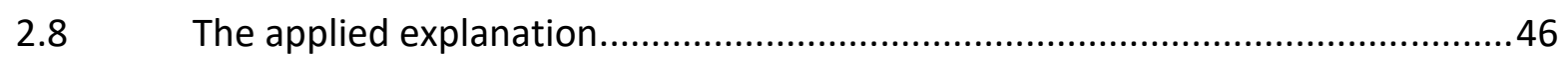

$\begin{array}{ll}\text { 2.8.1 A case study and critical reflection } & 46\end{array}$

2.8.2 The case study's scope $\quad 48$

$\begin{array}{ll}2.8 .3 \text { Practising critical reflection } & 49\end{array}$

2.8.4 Frederick Burdett Butler - A brief biography $\quad 50$

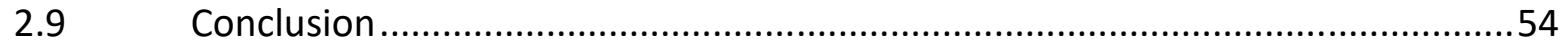

3. AN EXAMINATION OF ARCHIVES DOMAIN 'THEORY' ......................55

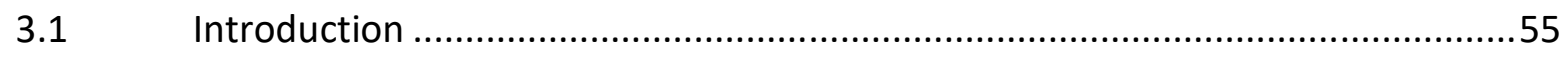

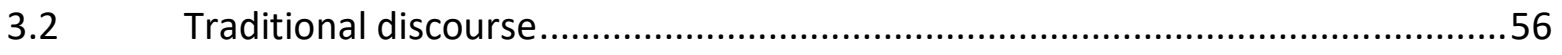

$\begin{array}{ll}3.2 .1 \text { Overview } & 56\end{array}$

3.2.2 Conceptualising records - physical objects and 'format-neutrality' 59

$\begin{array}{ll}\text { 3.2.3 Conceptualising provenance } & 62\end{array}$

3.2.4 Provenance, record, aggregation, and description 62

3.2.5 Conceptual absolutes and conceptual bundling 64

3.2.6 The library as other 65

3.3 Continuum theory in late twentieth and early twenty-first century discourse ...83

3.3.1 Departures from the traditional 83 
3.3.2 Upward's records continuum model and its reception - 1996 - 2000

3.3.3 Continuum theory - monistic diversity, multi-polarity, and spacetime

3.3.4 Archival description in the continuum paradigm

3.3.5 Debates over the record-as-evidence paradigm - continuum theory positioned, misplaced, excluded, and repositioned

3.4 Conclusion

4. “DOCUMENTS SELDOM SPEAK IN THE NUDE”: OBJECTIVITY AND SUBJECTIVITY

4.1 Introduction .135

4.2 Fred in the nude?

4.3 Objectivity - Connotation-laden and in need of redefinition

4.4 Evidence of an interest in nudism? Letting the objects object

4.5 Accounting for subjectivity when practising objectivity

4.6 Subjectivity as emergent and grounded

4.7 Just gossip? Grounding a 'gut feeling' in objective reality. .151

4.8 Snapped in the nude - The mediation of reality .158

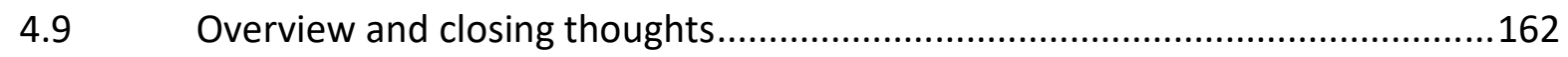

4.9.1 New concepts and terms 162

4.9.2 Differentiation between rational and intuitive thought 165

4.9.3 The possibility of truth? Records as "timeless facts"

4.10 Conclusion

5. LOOKING FOR LOVE: THE EMERGENCE OF EVIDENCE 
5.2 Truth in a tragic love story?

5.3 Pluralisation - Processes of making public

5.4 What is evidence? Where does it come from and where does it go?

5.5 Conclusion

6. SEEING AND BEING: THE CONSTRUCTION OF RECORDS AND CORNUCOPIAS OF EVIDENTIAL POSSIBILITIES 207

6.1 Introduction 207

6.2 Rediscovering the recordness of a digital orphan 209

6.3 Expanding recordness

6.4 Concepts, perceptions, and states of being in the construction of records.......216

6.5 Packages, parts, and provenance in the construction of records .221

6.6 Packaged packages and points of connection in the construction of records ...228

6.7 Overview and reflections on the record-evidence relationship .232

6.8 Conclusion .239

7. THE DESIGN OF KNOWLEDGE ENABLING SYSTEMS AND CONCLUDING COMMENTS.

7.1 Introduction

7.2 Reflections on the design of knowledge enabling systems

7.2.1 Introductory comments on relevant research objectives.

7.2.2 The ability to witness and (continuum-informed) recordkeeping functionality

7.2.3 Pathways through time and points of interaction 
7.2.4 Authority, objectivity, and interoperability

7.2.5 Aggregations, flexibility, and scalability - patterns, intuitive 'reading', and user interfaces.

7.3 The contributions of the thesis. 254

7.3.1 Two perspectives 254

7.3.2 Discussion of contributions with reference to the research objectives 255 7.3.3 Discussion of contributions with reference to problems and gaps in archival science literature 260

7.4 Thought and practice in the societal plurality - Intersections and potential ways of becoming .264

REFERENCES 271 


\section{LIST OF FIGURES}

Figure 1. Trespass notice written by Fred Butler and addressed to H.W. Insull....

Figure 2. Fred Butler swimming at Bell Falls, 10 February 1929.

Figure 3. Surf Life Saving Club members, circa 1930 .159

Figure 4. Part of a page from Volume One of Fred Butler's Mount Egmont albums with photographs of Fred Butler and Bernard Aris 176

Figure 5. Photographs of Molly and Hilda Haldane 177

Figure 6. Fred Butler with Hilda and Molly Haldane, 30 June 1925. 178

Figure 7. Fred Butler with Hilda and Molly Haldane, 30 June 1925. 179

Figure 8. Cropped section of a photograph of the "NP [New Plymouth] Amateur Photographic Society of Egmont, 3 June 192[?]". 180

Figure 9. Mrs Haldane feeding the hens at Tahurangi House. 183

Figure 10. Screen dump of Te Papa's Collections Online display of item C.003368.......209

Figure 11. Print of Tahurangi House and annotation in Fred's album. 211

Figure 12. Notes regarding intellectual property matters inside front cover of Volume One of Fred Butler's Mount Egmont albums 211

Figure 13. Magnified view of part of the digital image of item C.003368 depicted in Te Papa's Collections Online. .212

Figure 14. A reversed and rotated copy of the annotation near the top of the digital image of item C.003368 depicted in Te Papa's Collections Online. 213

Figure 15. The annotation beneath the print of Tahurangi House in Volume One of Fred Butler's Mount Egmont albums. 213 


\section{LIST OF TABLES}

Table 1. Questions I framed for the initial discourse analysis. 


\section{ACKNOWLEDGEMENTS}

Many people have played a role in the production of this thesis, some by providing intellectual stimulus, others by providing direct and indirect practical support. I am grateful to them all, most especially those who have shared the whole journey. I would particularly like to thank my supervisors Sydney Shep, Reader in Book History at Victoria University of Wellington, and Dr Dan Dorner, recently retired Senior Lecturer at Victoria University of Wellington. Together they provided stimulating ideas, robust (but always open-minded and respectful) argument, level-headed practicality, and unfailing confidence in my ability to complete a rather difficult piece of writing in rather difficult circumstances. Their patience, compassionate support, and advocacy on my behalf were deeply appreciated. Many thanks also to other staff, students, and former students at Victoria University of Wellington who have provided support, stimulus, and friendship over the years of my enrolment. I am especially grateful to Professor Peter Whiteford, Professor Jane Bryson, Emeritus Professor Rowena Cullen, Usha Varatharaju, and Associate Professor Gillian Oliver, now at Monash University in Melbourne.

I would like to say a huge thanks to Frances and Sereena Burton for sharing their knowledge of Frederick Butler and material from that part of Fred's collection still in their custody. I would also like to thank Frances and Sereena for their friendship. Getting to know them (and enjoying trips to their bach on Rangitoto Island) has been a highlight of my PhD experience. Others to whom I am grateful are those staff and former staff at Puke Ariki and Te Papa who assisted me as I delved into my case study research. Most especially I would like to thank Diana Gibbons, Bill Howard, Andrew Moffat, Lucy Macfarlane, Anita Hogan, and Athol McCredie. Thanks also to Dean Flavell, Maori Cultural Heritage Manager, Tauranga Heritage Collection. I am also grateful to Emeritus Professor Eric Ketelaar, Professor Wendy Duff, Dr Frank Upward, Dr Victoria Lemieux, Dr Joanne Evans, Geoffrey Yeo, Barbara Reid, Michael Piggott, and Rory Litwin. At one stage or another over the past few years all have taken time out of their busy lives to discuss ideas, offer encouragement, recommend readings, or provide reading material which it was difficult for me to access. 
Finally, thanks to all those family members, friends, and colleagues who have in one way or another supported and encouraged me as I inched towards completion. Most especially, I would like to thank Emeritus Professor Barry Welch, Pat Welch, Associate Professor Anna Redden, and Dr Brian Sanderson. I would also like to thank my mother, Mary Sanderson, for 'soldiering on' without me while I completed my thesis, and acknowledge the support and encouragement of my late father, Sandy Sanderson. Thanks too to Simon and Philip for putting up with a distracted and somewhat neglectful mother. Last, and mostly, I am grateful to my husband Michael Hodder, who has kept the boat afloat' for far too many years. Without fail, he has been understanding, encouraging, and patient. If not for him, this thesis would never have begun and could never have been completed. 


\section{PREFACE}

"What we know depends on the practices of communication by which the knowledge comes to us" (Chandler, Davidson, \& Johns, 2004, p. 1).

Chandler et al. (2004) made this claim in their introduction to an issue of Critical Inquiry which published papers from a digital humanities symposium concerned with exploring the materiality of knowledge transmission. Their objective was to begin a discourse which would explore knowledge transmission in relation to digital technologies. They drew their inspiration from Francis Bacon's 1605 treatise On the Advancement of Learning. In this work Bacon berated the quality of thought at the time. He attributed blame to the oral and written methods by which knowledge was received and communicated. Arguing knowledge should be acquired from empirical studies, he scorned dilettantism, the entrenchment of classical learning, and rhetoric (Bacon, 1998-2005; Findlen, 1997). He referred to these methods of communication as ars tradendi. Spedding and Ellis's 1879 translation of On the Advancement of Learning rendered ars tradendi as arts of transmission. Chandler and his colleagues chose this phrase as the theme for their symposium. Bacon's arts of transmission, they said, included "devices like the printing press" as well as "skills and crafts that must be learned and transmitted from generation to generation" (Chandler et al., 2004, p. 2). They claimed the same factors - technologies, practices and discourses, and even "basic activities like speaking and listening" (Chandler et al., 2004, p. 1) - are at work today, and that there is a need for research which looks at digital technologies and knowledge transmission from this perspective. Knowledge, they said, cannot be separated from the ways we develop it, organize it and pass it on. 


\section{INTRODUCTION}

\subsection{A 'THOUGHT EXPERIMENT'}

This thesis reports the conception, progress, and findings of a 'thought experiment'. The term thought experiment was used by Bruno Latour when describing his large scale multimedia exhibition Making Things Public (Latour \& Sánchez-Criado, 2007, p. 370). For Latour co-curating the exhibition was a way of doing "field work on one mode of existence" (interview transcript in Blok \& Jensen, 2011, p. 156). It gave him the opportunity to test hypotheses and explore representational tools through practice and material engagement - "to practice [sic] the exhibition as a medium" (Blok \& Jensen, 2011, p. 157). The intent of this exhibition was to interest people in the techniques of representation so that they would begin to understand how different assemblages of things ${ }^{1}$ lead to differing perceptions of what matters (Latour \& Sánchez-Criado, 2007). Fundamental to this way of thinking is an understanding that no thing stands alone imbued with a fixed meaning or significance. Rather, meaning or significance emerges from combinations of things and the ways in which they are seen to be related - or to have been related - to other things.

The 'thought experiment' reported in this thesis is similar to Latour's in that it explores the representational power of assemblages. It is also similar because, unlike most thought experiments, it is not purely discursive but instead understands thought as embodied and materially situated. However, it differs from Latour's in that it is as interested in assemblages of words and concepts as in assemblages of 'material' objects.

The assemblages of interest to me are those that exist and potentially could exist in libraries, archives, and museums. In these settings attention may - and usually does focus on the consciously collected objects. However, behind the scenes ways of thinking, ways of talking, and habits of practice play a part in determining the nature of physical

\footnotetext{
${ }^{1}$ The word thing is used as Latour uses it, which is to enable reference to any thing (e.g., a person, a inanimate physical object, a digital object, a word, a concept, or a type of behaviour) without bringing into play pre-conceived assumptions about the nature of the thing. It opens the way for disentangling a discussion about the nature of certain things from the words and categorical assumptions normally associated with those things and for exploring the ways in which things become connected and mutually implicated.
} 
and digital assemblages of those collected objects; and, so, subtly influence how they are perceived and how they can be used.

Another set of assemblages in which I was interested were those researchers create, in their minds as they conduct their research and, perhaps differently, in their writing. I wanted to get inside the mind of a researcher so that I could study the process of compiling assemblages closely enough to detect how the heritage sector's assemblages affect the possibilities for researchers to create theirs. I wanted to learn which aspects of heritage sector thinking and practice are helpful and which are not - and I wanted to be able to clearly articulate the reasons why. Therefore, whereas Latour used the activity of mounting an exhibition and the material engagements associated with that activity as stimuli for his 'thought experiment', I have used historical research activity and material engagement with the things encountered during that activity as stimuli for my 'thought experiment'. ${ }^{2}$

Because of my lengthy involvement in the archives domain (as a practitioner, a teacher, and now as a scholar) I was aware of the enormity of this task. ${ }^{3}$ Amongst archivists, there is no single way of thinking or single understanding of ideal practice. Nor is there uniformity in actual practice. On the contrary, the domain is riddled with diversity and there is a huge body of critical literature. The same appears to be true for the other domains in the heritage sector. Therefore I chose to focus attention on a single domain, choosing my domain of primary affiliation because I believed my pre-existing knowledge and experience would enable me to look deeper and produce more valuable findings than would be possible if I chose one of the others.

\subsection{THE RESEARCH PROBLEM}

This research did not begin with a single problem so much as with an awareness of multiple problems which appeared to be connected. At the most general level there is the

\footnotetext{
2 Throughout the thesis I use the word research to refer to knowledge-building activities focused on understanding some previously unknown aspect of reality as it really was and where "unstructured problems and ill-defined solutions are the norm" (Yakel \& Torres, 2003, p. 58). Such research is undertaken by many people for many reasons and with varying levels of skill.

${ }^{3}$ Throughout the thesis I use the term archives domain to refer to the whole body of thought and practice associated with archival institutions, records, archives and recordkeeping practitioners, and the discipline of archival science. I use the terms library domain, museum domain, and heritage domains in a similar fashion.
} 
problem of achieving digital convergence across the library, museum, and archive domains. Related to that is the problem of reaching agreement regarding the purposes of digitally converged systems; and related to that is the problem of how best to construct systems that achieve those purposes. These problems are simple to state but extraordinarily difficult to discuss at a cross-domain level because they are compounded and confounded by differing worldviews, modes of practice, and discursive traditions, not only between the domains but also within the domains. Collaboration in the design of digital systems, therefore, does not simply challenge each domain to communicate more effectively with the others; it also challenges each domain to look more closely and critically at its own traditions of thought and practice, and to clearly identify the user activities - including the cognitive activities - its systems are intended to enable.

The ultimate purpose of the future digitally converged systems my research imagines is that they are knowledge enabling. My research does not begin with a definite view on what the features of a knowledge enabling system would be. However, it does begin with an assumption that insight into how knowledge is enabled by systems can be found in the discourse of the archives domain. This is because one of the oldest and most recurring themes in that discourse is the notion that records have evidential characteristics and that descriptive practices have something to do with the capture and persistence of that evidentiality. ${ }^{4}$ A problem presented by this discourse, however, is that the word evidence is frequently used in the archives domain as a means of differentiating records from purportedly other heritage objects and as justifying non-participation in heritage sector digital convergence. This is a problem which needs to be considered in relation to disputed concepts of record and a mix of vagueness and disagreement regarding the extent to which the notion of record is inextricably bound up with the nature of the descriptive practices associated with it. Another, yet still related, problem is a tendency in some parts of the domain's critical discourse to disconnect thinking about evidence from thinking about records and descriptive practice. To some extent this disconnect is attributable to dichotomous understandings of the words objectivity and subjectivity, yet another problem in the domain - and one which spirals back into the problems associated

\footnotetext{
${ }^{4}$ I use the word record throughout the thesis to refer in general terms to the entities around which the archives domain orients itself. I leave the word undefined in all other respects. Further discussion of my use of this term can be found later in this chapter under the heading "Terminology".
} 
with cross-domain thinking and communication because of an archives domain tradition of differentiating between purportedly objective records and purportedly subjective 'library materials'.

The critical realist, Colin Wight, observed that it is a mistake to think everything in reality is necessarily intelligible (Wight, 2004, p.205). His observation seems applicable to many discourses, including that of the archives domain. In time and over time concepts, problems, and words become enmeshed, and only sometimes in rational and explicit ways. As the discourse expands, new variants of concept-word enmeshment are added as old words are used in new contexts. Ambiguity creeps in because those old words with their new meanings still carry connotations acquired in past contexts of use. Repeated enough the old words become essential parts of a discourse creating a sense of what is and what matters yet by-passing the question of whether the 'sense' makes sense. These features of discourses are widely recognised in humanities scholarship and social science theory (Gee, 2005; Ginzburg, 2013; Joseph \& Roberts, 2004; Sayer, 2000; Sewell, 2005; Smail, 2008, pp. 77-78)). Peppered with continuities and discontinuities, connections and disconnections, precision and ambiguity, definitions and assumptions, the archives domain discourse as a whole is a tangle possibly too dense to ever be properly unravelled. Problems intersect, often in very subtle ways, and the 'solution' to one problem may well give rise to another. I illustrate this in Chapter Three where I identify the archives domain problems addressed in this thesis within a discussion of relevant literature analyzed using critical realist concepts and a discourse analysis method developed by James Gee (both introduced in Chapter Two). At this point it is enough to say that, when I began my research, I indentified descriptive practice, the conceptualization of records, the conceptualization of evidence, and epistemological dichotomies as entangled matters of concern within the domain and for my research.

One further problem within the archives domain warrants mention in this introduction. This is the 'problem' of continuum theory. ${ }^{5}$ In Chapter Three I begin an argument that this body of thought, perceived as problematic by many in the domain (myself included when

\footnotetext{
${ }^{5}$ I use the term continuum theory throughout this thesis to refer to the body of thought developed by Frank Upward and a small number of his Australian associates (most relevant within my thesis are Sue McKemmish, Barbara Reed, Michael Piggott, and Chris Hurley).
} 
I began this research), has the explanatory power necessary to cut through problems raised elsewhere in the domain's discourse in relation to the conceptualization of evidence, the conceptualization of records, and the cross-domain problem of categorization. One thing I have learnt in the course of my research, and hope to show in the course of this thesis, is that sometimes the real problem is not the problem we perceive, but the way we are looking at the thing we think to be problematic.

\subsection{THE RESEARCH PARADIGM}

One strategy for looking at things differently is to look through the eyes of others who do not privilege the things we privilege, make the same assumptions, or draw boundaries in the places we have become accustomed to drawing them. In other words we can adopt a new paradigm and we can use this new paradigm to both look out at the world and also look more deeply into how we had previously been habituated to looking at ourselves and the things that are close to us. As I said in section 1.2, this research was conceived in part because of my awareness that a number of problems within the archives domain seemed to intersect and together contribute to a problem in the heritage sector. An additional stimulus was exposure to a body of (largely humanities) scholarship I had not previously encountered, which let me look at the archives domain problems through new eyes.

This body of scholarship focuses on questions relevant to the meeting of material cultures and digital technologies. It has generated research and theory supporting the argument that the materiality of digital objects has a tendency to disappear from view in 'information age' discourses that represent the digital as virtual (Day, 2004). ${ }^{6}$ Consequently better understanding of the interface between material cultures and digital technologies is needed. Scholarship of this nature can be found in the humanities, the social sciences, and the information sciences (Chandler et al., 2004; Day, 2004; Hand, 2008; Hayles, 1999, 2012; Kirschenbaum et al., 2009; Manoff, 2006; McGann, 2001; Rabinovitz \& Geil, 2004; Sassoon, 1998, 2007a; Van der Weel, 2011; Vandendorpe, 2009). This body of work concerned with the digital in relation to the material led me to other compatible scholarship not focused on that particular issue but sharing the same

\footnotetext{
${ }^{6}$ The words information age are enclosed in single quotation marks because, as Day (2004) pointed out, the very notion that the current era is more deserving of being called an information age than are earlier periods characterised by significant advances in communication technologies is problematic (p. 77).
} 
worldview, most notably the work of Bruno Latour and critical realism, a formal philosophy of knowledge which originated in the work of Roy Bhaskar and which has been further developed by Bhaskar and a community of critical realist scholars.

In this section I briefly introduce the worldview underpinning all this work - my research paradigm - and also introduce themes especially relevant to my thesis, included amongst them an explanation of how I use the term digital materiality which appears in the title of my thesis. Critical realism, which served as the primary philosophical and methodological under-labourer for my research, is discussed in detail in Chapter Two and, therefore, touched on only lightly here. ${ }^{7}$

The worldview shared by the body of scholarship that makes up my research paradigm is one of complex inter-dependence and co-evolution; one where the specificity of single occurrences challenges generalisation; and where habituated perceptions of dichotomies such as between the social and the natural, mind and body, the conscious and the unconscious and, of course, between the physical and the digital do not hold true - reality demands new forms of explanation.

Much of this scholarship discusses 'cultures' and the different phenomena which exist within, and together constitute, a culture. The concept of culture relevant to this work has been expressed in various terms but in all cases it is broadly construed. Hand (2008), for example, defined a culture as "a contingent arrangement of artefacts, knowledge, discourses, and practices within a given site" (p. 5) while Sewell (2005) described cultures as "landscapes of meaning" where the sign systems of language "are interlocked in practice with other structures - economic, political, social, spatial, and so on" (Sewell, p. 87). Both argued the necessity of probing deeply in attempts to build understanding of any specific culture. Latour (2005) took much the same line: words such as culture are social constructs; they explain nothing; rather they call for explanation (p. 97).

The world is "a multitude of points and connections" extending across time and through space, and each thing that exists is defined by its network relations (Blok and Anders, $p$. 49). Every thing in the network has potential to act (to play a role in causing something to happen) - "intellectual technologies", Latour (2005) argued, are "as important as gears,

\footnotetext{
${ }^{7}$ The term under-labourer is explained in Chapter Two.
} 
levers, and chemical bonds" (p. 196). Therefore, explaining cultures, and explaining phenomena and behaviours within cultures, calls for investigation of what is (or has been) at play in shaping the phenomena or behaviours of interest.

Latour's idea that anything may potentially play a role in causing something to happen is not unusual within the context of my research paradigm. Recognising that even words and habits of thought can have significant real world effects (Chandler et al., 2005, pp. 12; Joseph \& Roberts, 2004, pp. 1-2; Sewell, 2005, pp. 85-88) demonstrates the importance of not overlooking the commonplace when seeking out the things that shape cultures and influence the trajectory of technological development (Hand, 2005, p. 5). It is also important to keep in view the fact that cultures do not exist in isolation. They overlap, sharing component parts so that there is constant interaction - a "dialectical dance" between cultures as well as within cultures (Sewell, 2005, p. 92).

Sewell (2005) understood cultures as material semiotic communities, his gaze falling on the nature of discourse and how it works to hold a culture together. He claimed a process of differentiation is inherent in the use of signs and symbols because a sign or symbol always refers to one thing and not to other things. Through differentiation, the sign or symbol is defined in a given context and this makes it possible to talk about the thing referred to with a degree of precision. For "meaning is to exist at all," he said, "there must be systematic relations among signs and a group of people who recognize those relations" (Sewell, 2005, p. 87). At some level "users of a culture" - or a "semiotic community" share the same set of conceptual oppositions and this enables "mutually meaningful symbolic action" (Sewell, 2005, p. 86). However, the coherence of semiotic structures and the communities which form around them is normally thin and the boundaries of these "landscapes of meaning" are "relative and constantly shifting" (p. 93). Sewell argued this thin coherence demonstrates "that what are taken as the certainties or truths of texts or discourses are in fact disputable and unstable" (p. 87).

The disputable and unstable nature of facts is central to Latour's work. He has argued that facts are often not the objective accounts of reality we take them for, but are "black boxed" constructed orders which become engrained in the thinking of certain groups at certain times and so mediate that group's perception of reality (Blok \& Jensen, 2011, pp. 
$35,121)$. When this happens, the group's perception of a thing which exists in the world does not equate to the thing's whole objective reality. Instead it is a fusion of the thing that is and our beliefs about it, a hybrid, part material and part conceptual.

Throughout the thesis I expose the archives domain as having many of the characteristics of a thinly cohered "semiotic community". The evidence of this thin coherence is both in the existence of consciously disputed theory and practice, and also in the amount of conceptual ambiguity and inconsistency hidden behind a shared vocabulary. Further to this, the domain's discourse is riddled with "conceptual oppositions", some of the most significant of which, I will argue later in the thesis, stand in the way of effective crossdomain communication.

The idea that digital technologies, discourses, and practices co-exist and co-evolve with analogue technologies, discourses, and practices (Hand, 2008, p. 45) has profound implications for knowledge workers because, as Chandler et al. (2005) - cited in the preface to this thesis - pointed out, knowledge cannot be separated from the ways we develop it, organize it, and pass it on - "what we can know depends on the practices of communication [including the mediating technologies] by which the knowledge comes to us" (p. 1).

In the digital humanities the problem of attempting to understand the effects of different technologies on human cognition and possibilities for future knowledge has attracted significant attention. Driving this is a desire to design technologies so that they maximise human potential to generate knowledge while minimising design features that may have the effect of stimulating erroneous perceptions and interpretations. These are ambitions which resonate with the frequently occurring argument in traditional archives domain discourse that certain practices (notably, the preservation of provenance and documentary context, and also - prior to the normalisation of appraisal - an emphasis on the epistemic importance of wholeness) are essential for ensuring that records are kept in their 'proper' contexts so that, when later used, they can be 'correctly' understood. They continue to resonate in contemporary discourse relevant to digital recordkeeping and in records continuum discourse. 
This archives domain discourse differs from the digital humanities discourse in that it rarely discusses the perspective of the one who is doing the interpreting - the reader or meaning-maker (Duff, Monks-Leeson \& Galey, 2012, p. 76). Also, it rarely focuses attention on the cognitive effects of technologies or on "what the material characteristics of a record add to our understanding of the information in that record" (Rekrut, 2005, pp. 28-29). Questions of this nature and the reader perspective are, however, attracting significant attention in the digital humanities. Hayles (2012), Van der Weel (2011), and Vandendorpe (2009) have all argued the need to understand the potential and the limitations of different ways of reading alongside the question of the effects of technologies in enabling those ways of reading. ${ }^{8}$

"Narrative", for example, "excels in constructing causal models, exploiting complex temporalities, and creating models of how (other) minds work" (Hayles, 2012, p. 16). By encouraging linear reading, the narrative form gives the author significant control (though not by any means total control) over the meanings the reader takes from the text. Works designed for linear reading encourage deep immersion in the text, but can also encourage passive thinking (Vandendorpe, pp. 22-51). Reader passivity in combination with the closed worldview and sense of causality that emerges from the sequential linking of a selection of events and explanations in a narrative is problematic when the quality of knowledge is at stake. Hayles (2012), recognising this, challenged the humanities' tradition of assigning primary value to knowledge shared in narrative form. She argued humanities scholars should experiment more with databases as a means of communicating their work. "Database elements", she said, "can be combined in many different ways, depending on how a reader wants to navigate the interface" (p. 38). ${ }^{9}$ The effect is to "liberate contradictory and refractory threads in the material from the demands of a historically based argument, where they were necessarily smoothed over in the interests of coherence" (р. 38). Further to this, she pointed to significant differences between relational databases and object-oriented databases. Significant amongst those

\footnotetext{
${ }^{8}$ Vandendorpe (2009) distinguished between linear reading (e.g., the way a novel would normally be read) and tabular reading (e.g. the way a dictionary is read or an index is used). The distinctions drawn by Hayles (2012) are between close reading, hyper-reading (browsing and skimming), and distant reading (the use of algorithms to mine vast quantities of data for subsequent human interpretation).

${ }^{9}$ This is the reader-controlled way of reading Vandendorpe (2009) terms tabular.
} 
differences is the difficulty relational databases have showing change through time in comparison to object-oriented databases which

imply a metaphor of objects in the world that can spawn progeny and inherited traits, merge with other objects, and aggregate into groups. This makes it possible to chart their movements through time in ways that make time an intrinsic property rather than something added on at the end. (p. 15)

Although Hayles (2012) and Vandendorpe (2009) focused significant attention on technologies as active agents in generating predispositions to read in certain ways and to understand the read material in certain ways, they also recognised that the reader is an active participant in the communication-comprehension process. The reader always brings something extra to the reading (even the reader of a novel) and in some cases may read in a different manner and for different purposes (therefore, finding different significances and meanings) to those envisaged by either the author of the work or the designer of the mediating technology (Vandendorpe, 2009, pp. 40-45). Hand (2008), thinking specifically about the use of digital technologies, made the same point, observing that they are often used in ways which were not intended by their creators. When that is the case, he said, future design frequently responds to use. "Technical design, the use environment, and the uses", therefore, should be thought of as "mutually constitutive" (p. 69).

When one focuses attention on connectivity (rather than separateness) and on the longview (rather than the present moment), as all the scholarship discussed here does, any assumption that the concept of materiality is limited to the explicitly physical is problematic. Hayles (2012) articulated a more subtle appreciation of the nature of materiality:

On the level of conscious thought attention comes into play as a focusing action that codetermines [emphasis added] what we call materiality. That is, attention selects from the vast (essentially infinite) repertoire of physical attributes some characteristics for notice, and they in turn constitute an object's materiality. Materiality, like the object itself, is not a pre-given entity but rather a dynamic process [emphasis added] that changes as the focus of attention shifts. (p. 14) 
Superficially Hayles' description of materiality appears to be more a description of the perception of materiality. However, the context in which she made this statement, the hint of a space-time dynamic at work in the final sentence, and her use of the words "codetermines" and "dynamic process" make it clear that she saw both the perceiver and the perceived object acting together to bring about certain outcomes - potentially outcomes for the object as well as for the perceiver because our perceptions of materiality (of what is significant, what is similar, and what is different) feed into our discourses and our practices, and play a large part in determining our actions, and so shaping the things we create or alter in the course of our interactions with them. Conversely the actions we take on things have consequences for our perceptions because perception, being generated in part by the characteristics of the things we see, may change if the things - or the contexts in which we see them - change. Quite simply reality is complex - the physical is infused with the ideational and the ideational infused with perceptions we would not have if not for our encounters with the physical. It is in reference to this way of thinking that the term digital materiality is used in the title of this thesis.

This body of scholarship had significant implications for both my perception of the research problem and for the design of my research. It provided a rationale for thinking of the materiality of digital heritage objects as resting, not only in the physicality of the technologies we employ to create and use them, but also in many 'concepts' that come to be embedded in digital heritage objects. The 'concepts' to which I refer derive from the physicality of object types and technologies ubiquitous in past times (but perhaps less so in the present). Embedded in practice and in discourse - often beneath the level of consciousness - these physical world 'concepts' are carried into the present, where they contribute to the shaping of digital objects. This, in turn, pointed to the value of holistic research which takes into account how things are related and mutually implicated. This body of scholarship also warned me to be wary of the slippery relationship between words and concepts, and to be wary of my own and others' pre-existing assumptions and perceptual limitations. It pointed to the value of looking at the familiar from new angles and in new contexts in order to see more and see differently. Lastly, it gave me the idea of thinking about evidence as emergent during research (for an archivist, this is a new 
angle), possibly emergent because of the way of reading; and that gave me the idea of thinking about digital systems being ideally designed not only to carry things from the past and present into the future, but also to facilitate, perhaps even stimulate, that way of reading.

\subsection{THE RESEARCH QUESTION AND OBJECTIVES}

\subsubsection{The intent of the research - a double agenda}

The research is situated in the broad problem area of digital convergence in the heritage sector. Its intent is to contribute to an emerging, very thinly cohered, cross-domain discourse concerned with the epistemic adequacy of cultural heritage systems and also concerned with the epistemic adequacy of the theory informing the design and use of those systems. The research seeks to make this contribution by critically exploring interrelated issues in the archives domain in order to build understanding of how fit various archives domain discourses and concepts are for the purpose of cross-domain collaboration in the building of knowledge enabling systems. In doing this, the research seeks to also contribute to relevant discourses within archival science.

\subsubsection{The research question and objectives}

In an essay titled Our Words, and Theirs the historian Carlo Ginzburg observed there to be "a tension between our questions and the answers we get from the evidence" because, while our questions inevitably affect what we see to be significant in the evidence, "the evidence may well modify our initial questions" (Ginzburg, 2013, p. 105). This observation sits well in relation to my research paradigm and also in relation to my research experience.

My research was stimulated by awareness that descriptive practice, the conceptualization of records, the conceptualization of evidence, and epistemological dichotomies are entangled matters of concern in the archives domain. It was also stimulated by awareness of the relative paucity of archives domain literature relevant to collecting archives and user perspectives. My awareness of these issues stemmed from prior experience as a practitioner and teacher in the field. Cross-domain communication and systems design were issues of particular interest to me due to the fact that, as a practitioner, I had frequently worked as an archivist in librarian-dominated organisations. Within such 
discussions, arguments that archival principles should be observed when describing records are often countered with claims that, from a user perspective, distinctions between records and other 'types' of information are of no consequence, especially when the information objects are digital. Such assertions are frustrating for archivists and simplistic when seen in light of the literature I discussed in relation to my research paradigm.

When I encountered critical realism (discussed in Chapter Two) during the planning stage of my research, I recognised the possibility of designing conceptually open exploratory research which treated all these issues as entangled matters of concern, not only for the archives domain, but also for the heritage sector more generally. Such research promised to be richly rewarding in terms of its contributions to knowledge in the archives domain and to emerging cross-domain discourse concerned with issues of epistemic adequacy in relation to the digital.

To set a sense of direction for the research, I framed four objectives:

- to contribute to knowledge about the nature of evidence, especially how it emerges during a historical research process;

- to contribute to understanding of how the theoretical concepts and idealised practices of the archives domain work, or could work, to facilitate the emergence of evidence;

- to contribute to understanding of how actual practices and technologies facilitate - or possibly hinder - the emergence of evidence;

- and to contribute to understanding of the fitness of archives domain concepts and terminology for cross-domain communication and the development of a discourse which cuts across the domains.

These objectives identified evidentiality and archives domain discourse relevant to description as matters of central interest for my research. In other respects they were worded to enable conceptually open exploratory research. This was necessary as all the critical discourses from which my research paradigm drew told me my understanding of what is and what matters would change as my body of knowledge expanded. The objectives set a sense of direction and identified (in very general terms) the contributions 
I anticipated my research could make. How far I would go towards addressing each was something I could not pre-determine.

In contrast to the research objectives, which were relatively stable from the start, the research question went through numerous iterations before I was satisfied that my wording had the cross-domain applicability and conceptual openness needed for the exploratory research I envisaged. The question I finally posed was:

What can be learnt about archives domain thinking, heritage objects and their evidentiality, and the design of knowledge enabling systems by exploring how evidence emerges during a historical research process?

This question must be understood in relation to my research paradigm. In particular, the phrase archives domain thinking must be understood as enabling openness rather than pretending to totality. Other words and phrases which must be understood in specific ways are explained section 1.5 .

It was only in the course of the research that I identified the specific aspects of "archives domain thinking" on which my thesis focuses most attention. Problems and gaps in archival science discourse that have been explicitly addressed in the thesis are discussed in section 2.2 of Chapter Two and at various points in Chapter Three (they are summarized in section 3.4). In Chapter Seven I discuss the contributions my thesis makes to archival science and to emerging cross-domain discourse concerned with the epistemic adequacy of cultural heritage systems and the theories and practices that shape those systems.

\subsection{TERMINOLOGY}

Within the thesis, when I require a term to be understood in a specific way, I single it out for attention at the time when it first comes into use, explaining it either in the text or a footnote. My explanations indicate whether the specific meaning applies to every use of the term throughout the thesis or only to its use within the current context.

Some of my terminological choices - those used in my research question, for example are most meaningful when they are understood in relation to the conceptual problems I am attempting to solve through their use. My thesis keeps two theory-focused narratives 
flowing. One is archives domain specific. The other is conceptually open. Each calls for language capable of generalising in ways which serve the purposes of that narrative line. In the case of the research question conceptual openness was paramount. The terms archives domain thinking, heritage objects, knowledge enabling systems, and research were used in ways intended to achieve that end. Explanations of each term follow. After explaining these terms, I discuss the terminological problem with which I contended in those parts of the thesis where the things archivists think of as records are referred to, and where the differing ways in which archivists conceptualise those things are discussed.

The phrase archives domain thinking is open in two ways. Firstly, it is a way of avoiding predefinition of what the relevant thinking will be in direct reference to. This is important because assumptions about one thing are often implicit in writing that explicitly discusses something else; and the way in which things are positioned in relation to each other can be revealing. The thinking that is relevant, therefore, is any that is relevant to the other phenomena named in the research question and considered in relation to the primary research problem.

The second way in which the phrase archives domain thinking is open is that, besides encompassing deliberate theorising and consciously expressed thought, it also includes 'thought' that is transmitted in relatively non-conscious ways. Key examples would be the assumptions behind recurring metaphors in the domain's discourse and the domain's practical knowledge - that is knowledge (including ambiguous and inadequate knowledge) from the past which may no longer attract conscious reflection but which, having become embedded in practice or in objects carrying traces of earlier practices, persists so long as those practices and objects persist.

The term heritage object serves a need to refer to a nebulously bounded set of physical and digital objects in the aggregate and with minimal conceptual pre-loading. Any physical or digital object can be thought of as a heritage object if it carries something from the past into the present or is intended to carry something of the rapidly passing present into the future. Besides being applicable to the objects collected and received by libraries, archives, and museums, the term can also potentially be applied to physical and digital objects created by such institutions (e.g., inventories, indexes, catalogues, and 
metadata) and to physical and digital objects that have never been in heritage institutions. The term is also open to the possibility that there may be objects within objects and objects intersecting with other objects. So, not only is the whole set nebulously bounded; so too are many of the things in it.

I coined the term knowledge enabling systems after testing and discarding the words metadata, description, and finding aids. In the course of the research each of these words proved problematic for reasons outlined below.

Firstly, there is a logical disconnect between the idea that metadata describes the record to which it is 'meta' and the idea promoted by numerous recordkeeping and archival science theorists that the actions archivists take in relation to records shape those records (Brothman, 1991, p. 91; Cook, 2001a, pp. 4, 7, 22; Duff \& Harris, 2002; Evans et al., 2011, pp. 136-137; Harris, 1997, pp. 135-136; Jimerson, 2011, p. 373; Kaplan, 2002, pp. 216-217; Ketelaar, 2001; MacNeil, 2008; McKemmish, Piggott, Reed, \& Upward, 2005, p. xii; McKemmish, Upward, \& Reed, 2009, p. 4455; Nesmith, 2002, 2005; Sassoon, 2007a, p. 137; Schwartz, 2002, pp. 157-159; Trace, 2002, pp. 139-140), in which case 'metadata' must logically be understood as co-constituting the record rather than external to the record. The research paradigm and concept of materiality developed in relation to the paradigm indicates that it is not only records that are shaped by 'descriptive' activities and 'metadata'; the same is true for all heritage objects. This is one problem presented by the word description. A second relates to the question of exactly what it is that is being described. Frequently, at least in the case of physically bounded record objects, metadata that appears to describe such an object actually describes aspects of the context known, inferred, or heard to have been around that object at an earlier time. ${ }^{10}$ This question of what is actually being described loops back to the earlier problem of whether metadata describes or co-constitutes a record, and that in turn raises questions about exactly what a record is and how it is bounded. These issues are explored in Chapters Three and Six. At this point I raise them simply to explain why I preferred not to use the problem-laden word description in my research question.

\footnotetext{
${ }^{10}$ The term record object is borrowed from records continuum theorists who have argued that there is more value in thinking of records as logical constructs than as "physical realities" (McKemmish et al., 2009, p. 4455), which is the way in which records have traditionally, and are still commonly, conceptualised.
} 
Clearly in light of the above comments about the word description, metadata needs to be understood as serving a variety of purposes in relation to the 'data' to which it is attached. This is widely recognised and not in itself a reason for deciding to use the term knowledge enabling systems rather than metadata in my research question. ${ }^{11}$ My main concern about the word metadata stems from my belief that the way it is commonly used in the heritage collecting sector creates a predisposition for thinking of metadata as distinct from, even if related to, a heritage object and for thinking of that heritage object (rather than the metadata) as necessarily the thing of primary interest. This way of thinking assumes fixed categories. It assumes that metadata is always metadata and never itself the centre of attention, and does not account for the fact that one heritage object (or set of heritage objects) may serve as 'metadata' to another. Berners-Lee's vision of a semantic web comprised of re-usable uniquely identified data units open to being linked to by any other data unit offers an alternative way of thinking (Berners-Lee, 2009). Logically this would situate all that is metadata in one context of use as simply being data when seen in relation to the Web as a whole. In this paradigm differentiation between 'data' and 'metadata' is not absolute, but contingent and need-related.

There is a further reason why I decided the words metadata and description were inappropriate for my research question. A pre-occupation with both is common in archives domain discourse whereas user interfaces, like other matters relating to the use of records, have attracted relatively little attention (Duff, 2010, pp. 115-116). Being habituated to this way of thinking at the beginning of my research, I referred only to metadata in the first draft of my research question. However, during my case study I became aware that user interfaces have significant cognitive effects with consequences for the emergence of evidence during historical research. This led to my seeking a term broad enough to encompass front end as well as back end aspects of systems design.

I worked with the term finding aids for a time, but felt it to be too limited for my purposes because archives domain discourse tends to give as much (and often more) prominence to the role metadata plays in enabling authentication and meaning-making (Bunn, 2011;

\footnotetext{
${ }^{11}$ According to ISO 23081 Metadata for Records, for example, metadata is used "to support, identify, authenticate, describe, locate and manage" the information resources of organisations "to meet business, accountability and societal requirements" (International Organization for Standardization, 2007, p. 3).
} 
Duff \& Harris, 2002; Evans, McKemmish \& Reed, 2009; Hurley, 2005a; MacNeil, 2008, 2009; Sassoon, 1998; Schwartz, 2002; Yeo, 2010a) as it does to the role metadata plays in enabling finding (whether of objects or of 'information'). Writing that refers to the purpose of archives description as enabling finding (and which pays no attention to meaning-making and authentication) tends to be authored by archivists closely associated with the library domain (e.g., Light, 2008; Murtomaa, 2000) which tends to privilege finding type activities in its discourse as has been observed by Collins (2009), whose PhD research (in the discipline of anthropology) entailed an ethnographic study of the Library of Congress during the late 1990s. He found librarians to be primarily concerned with information seeking behaviour, rather than "the 'practice' of information", by which he meant how they interact with and make meaning of the documents they access (pp. 109112). The user tasks identified in the library domain's new cataloguing standard RDA (Resource Description and Access) - find, identify, select, obtain (Danskin, 2009, p. 3) suggest his observation to be still valid. Manoff, a librarian closely connected with the digital humanities community, is another who has commented on the library domain's limited perspective on the nature of information and its use. She argued librarians need to be more aware of the ways in which library practices affect how research can be conducted and the knowledge it can produce (Manoff, 2006, pp. 312, 323).

I coined the term knowledge enabling systems in order to transcend these problems by focusing instead on what I perceived as the ultimate purpose (in relation to historical research) of the heritage collecting sector's systems. I toyed with the idea of calling them evidence enabling systems but the word evidence itself is heavily burdened with problematic connotations (which will be discussed in Chapters Three and Five). Besides, "The field of evidence is no other than the field of knowledge" (Bentham, as cited in Furner, 2004, p. 233). That being the case, each of these concepts can be taken as implying the other. I also thought carefully about the word enabling, wondering whether it overstated what systems might aspire to do. Perhaps it does, though so long as it is coupled with a critical realist understanding of knowledge, it seems appropriate. For a critical realist knowledge is always fallible because there is always a gap between a knowledge claim and the reality it references (Morgan and Olsen, 2007, pp. 260-261). I use the phrase knowledge enabling systems broadly with the intention that metadata 
creation practices as well as digital infrastructure should be understood as co-constituting a system.

My use of the word research follows on from this understanding of knowledge. It assumes a genuine desire to understand some aspect of reality, but it acknowledges the fact that (for a variety of reasons) some research goes further than other research towards closing the gap between the knowledge claim made and the reality referenced.

Although explanation or definition at relevant moments in the thesis is my primary method for making the meaning of my chosen terms clear, one more major problem with which my terminology has had to contend warrants discussion here. This is the problem presented by the terminological and conceptual diversity that characterises the archives domain's references to and thinking about the objects that are of central interest to the domain (variously referred to as archives, records, documents, manuscripts, papers, etc.). There are points in the thesis where specificity in relation to this diversity is important. At those times I use whatever term is true to the situation (generally this will be the term used and perhaps defined by a specific author) making it clear that I am doing so. There are other points in the thesis where generalisation is needed, but not the kind of generalisation used in the research question which aspires to transcend the discourses of the heritage domains; rather, generalisation that retains a sense of archives domain specificity. I use the word record for this purpose. I leave it undefined, somewhat ambiguous. This gives me a way of referring in general terms to the objects around which the domain orients itself and about which it talks, but talks only in thinly cohered ways.

\subsection{OVERVIEW OF THE THESIS}

In Chapter One I have introduced my research as a 'thought experiment' concerned with a number of inter-related problems in the archives domain which I believed, when I designed my research, contributed to the problem of achieving effective cross-domain communication and design of knowledge enabling systems. I then explained my research paradigm which draws from discourses in the social sciences and humanities that focus attention on issues of inter-dependence and co-evolution in time and over time, and that challenge habituated perceptions of dichotomies, arguing that reality demands new forms of explanation. Following this I stated the objectives of my research and posed my 
research question. Explanation of how key terms in the research question and thesis should be interpreted followed along with advice to my readers that other terms required to be understood in specific ways will be explained either in the main text or in footnotes when first used.

In Chapter Two I discuss my research design. I begin by introducing critical realism, the philosophy of knowledge which served as my primary philosophical and methodological under-labourer. Critical realism is a well-developed formal philosophy of knowledge which provides analytical concepts specifically designed to harness the epistemic strengths and overcome the epistemic shortcomings of the positivist and interpretivist traditions. Drawing attention to archival science literature concerned with conceptual problems that have arisen from the co-existence of dichotomous epistemological paradigms, I argue that critical realism's potential as a 'third way' philosophical paradigm deserves testing. I also argue that, because critical realism is explicitly concerned with the question of how rationally justifiable knowledge emerges, it can play a double role in research concerned with the conceptualization of evidence and with the question of how archival description might be practised if its end purpose is understood to be knowledge enabling.

Following this introduction to critical realism and justification for its use, I describe the analytical concepts provided by critical realism and its explanatory method. I then describe how I applied that method by designing my research so that it would be comprised of an exploration of existing formal and informal archives domain theory and a case study. I explain that, in exploring existing theory, I engaged with a select body of literature and used a critical discourse analysis method and critical realist conceptual analysis. Selection criteria are discussed and the manner in which I interrogated the literature is explained. The objectives of this stage were to improve my understanding of thought patterns within the archives domain from the late nineteenth century through to about 2010 (when my research proposal was approved), to seek out rationally justifiable theory (relevant to the research problem) already present in that part of the discourse with which I engaged, and to identify issues to be further investigated during the case study. 
The case study centred on the New Zealand collector Frederick Burdett Butler (19031982). In conducting the case study, I took the stance of a researcher investigating the life of Fred Butler and the dispersal of his 'collection' so as to gain insight into how descriptive practices and technology designs impact on evidence emergence, and so as to also reflect from a researcher perspective on theoretical issues identified as being of interest during the analysis of existing theory. By adopting the stance of a reflective practitioner, I was able to closely follow my own meaning-making process and identify in fine-grained detail the sources of my emerging knowledge and the effects of institutional practices and systems. Chapter two includes a brief overview of Fred's life, which pays particular attention to the building and dispersal of his collection.

Chapter Three reports the findings of my analysis of existing formal and informal theory. It discusses only a portion of the literature with which I engaged, privileging those works that were most significant in giving shape to my thesis. It identifies questions I explore, and provides concepts I work with in the theory-building that follows in subsequent chapters. It represents my understanding of archives domain discourse and of what matters (for my research) in that discourse at the time the final version of my thesis was taking shape. It is divided into two major parts. The first focuses on traditional theory as I saw it to manifest in the manuals of Muller, Feith, \& Fruin (1940); Jenkinson (1922); and Schellenberg (1956, 1965). The second centres continuum theory in a discussion of contemporary theory. The discussion of traditional theory focuses on the entanglement of notions of document, record, aggregation, provenance, and practice. It also draws attention to epistemic and non-epistemic factors (e.g., the differentiation of government archives from libraries) that played a part in giving shape to traditional archives domain thinking. Drawing attention to common characteristics of the manuals and also to significant differences, it argues foundations for future problems within the domain were laid within these manuals.

One of those problems is a widespread (but not universal) assumption that differentiation between organisational records and personal records and between organisation-oriented theory and person-oriented theory is a fundamental necessity. Another is the entrenchment of an objectivity-subjectivity dichotomy. This dichotomy, first put to use by government archivists for the purpose of othering libraries, had, by the late twentieth 
century, become a cause of disputation within the archives domain where, because dichotomous thinking itself was not addressed, parallel objectivity-oriented discourses and subjectivity-oriented discourses emerged. The former was significantly concerned with contemporary recordkeeping (especially government recordkeeping), the accountability of organisations, and the need for trustworthy records; while the latter was significantly concerned with records received from the past (especially personal records), the 'reading' of records, variable perceptions of their significance and meaning, and factual uncertainty. The word evidence was caught up in this mix. Having been relegated to the realm of outmoded and epistemically unjustifiable positivism by archival science's 'postmodern' theorists and having also been much used and narrowly used in the discourse concerned with the keeping of government records for accountability purposes, it was eschewed - or simply avoided - by theorists suspicious of objectivist claims, and by collecting archivists for whom the notion of accountability and other concepts expressed in language heavily weighted with business-world connotations lacked self-evident relevance. $^{12}$ Those who rejected the record-as-evidence notion also typically rejected continuum theory, which is a post-structuralist meta-theory developed by a small group of Australian archivists in the mid-1990s and which is explicit in pinning the concept of record to the notion of evidence.

In conducting my analysis of archives domain literature, I realised that continuum theory has a fundamental logic very similar to critical realism's. It is reality-oriented, sensitive to space-time variability, respectful of the unknown, open to extension, logical, and ontologically consistent. Significantly (within the context of my research), it differentiates between processes and purposes, rather than between institutional types and the 'types' of materials typically associated with the different heritage and information domains. For all these reasons, it is conceptually far better equipped to facilitate cross-domain

\footnotetext{
${ }^{12}$ The word postmodern is problematized because, in archives domain discourse as elsewhere, it has been used to refer to a heterogeneous body of critical theory and critical theorists who have variously selfidentified as postmodern or explicitly rejected the label. Hardiman (2009) suggested that, for these reasons, it "should always appear in quotation marks, explicit or assumed" (p. 28). I have chosen to explicitly problematize the term for these reasons and also because in my own text I use it primarily to refer to theory that privileges subjectivity to such an extent that the possibility of objectivity is ruled out. This is problematic because Frank Upward has self-identified as postmodern, yet the continuum paradigm seems more epistemologically balanced (more third way) than that implied by the discourse I have identified as 'postmodern'.
} 
communication and co-operation than is mainstream 'theory', which is grounded in a tradition of typing objects for purposes of either claiming or othering. Therefore, in Chapter Three, I identified misunderstanding and misrepresentation of continuum theory and disengagement from continuum discourse as major problems with which my research needs to be concerned. Also, I recognised that my research had (coincidentally) been conceptualized and designed in ways that would enable it to help fill some relatively empty spaces in continuum discourse.

All the problems identified above are addressed in the thesis, either directly as major themes in Chapters Four to Six, or by means of the conceptual orientation of the research and the choice of case study. I illustrate continuum theory's value and relevance for the whole heritage collecting sector in each of these chapters by putting highly relevant concepts from continuum theory to work in my writing and, where appropriate, correlating them with conceptually equivalent terms from the other discourses with which I have worked.

In Chapter Four I focus on the objectivity-subjectivity dichotomy and the question of whether it can be dissolved. In addressing this question, I draw on critical realist theory, theory developed by Bruno Latour, and recent findings from the cognitive sciences. This chapter, which is deeply concerned with processes of observation, interpretation, and meaning-making, builds foundations for Chapters Five, Six, and Seven.

In Chapter Five I draw on the foundation laid in Chapter Four to explore the question of how evidence emerges in the conduct of historical research (one part of the research question I posed in section 1.4). I take a particular interest in the types of relationships that serve evidential purposes. Also in Chapter Five I use continuum spacetime notions and critical realist concepts to address metaphysical issues, relevant to the conceptualisation of evidence, that have been raised by theorists who have been critical of the notion that evidentiality is of such central importance to the concept of record that it should be regarded as definitional.

In Chapter Six I explore the other dynamic in the record-as-evidence debate. I look at the question of how records emerge, explore the conceptual and perceptual dynamics at work in their emergence, and illustrate the meaning and value of continuum theory's 
argument that records should not be thought of as "physical artifacts" defined "in terms of their format or media", but instead thought of as "logical objects" differentiated from "other forms of recorded information" only on the basis of "their evidential qualities, purposes, and functionality" (McKemmish, et al., 2009, p. 4447). Then, reflecting back on the findings of Chapter Five, I address the question of how closely the continuum concept of record aligns with the concept of evidence as I came to understand it in the course of my research.

In Chapter Seven I conclude the thesis by discussing what has been learnt from the research about the design of knowledge enabling systems and by reflecting on my research findings from two perspectives: firstly, in light of the research objectives and, secondly, as contributions to archival science. I also briefly discuss continuum theory in relation to similar bodies of thought emerging in other information and cultural heritage domains, and make suggestions for further research.

\subsection{AUDIENCE ADDRESSED}

This thesis has been written for an archival science audience and also for a cross-domain audience. I anticipate it will be of interest to those working in the discipline of archival science to extend the reach of continuum theory, improve descriptive practice, explore the concept of record, and develop a concept of evidence relevant to the domain. I anticipate it will also be of interest for theorists in the library, museum, and information science disciplines who are working on the development of epistemically robust theory for guiding the development of digitally converged knowledge enabling systems in the heritage sector.

\subsection{CONCLUSION}

In this chapter I introduced the research as a materially grounded 'thought experiment' conceptualised at the intersection of a number of practical and theoretical problems in the archives domain and relevant to the problem of designing converged knowledge enabling systems in the heritage sector. I also introduced the research paradigm, objectives, and question. I discussed terminology at some length, explaining to readers of the thesis not only how I was using terms, but also why I had made certain terminological 
choices. I explained that my research question should be understood in relation to that discussion.

My discussion of terminology in this chapter was a first step towards developing understanding of archives domain thinking and reflecting on the fitness of archives domain concepts and terminology for cross-domain communication and the development of a discourse which cuts across the domains (one of the research objectives I identified in section 1.4). The chapter finished with an overview of the thesis and a statement about the audience addressed.

In discussing the research paradigm, I referred briefly to critical realism saying it served as the primary philosophical and methodological under-labourer for my research. Chapter Two introduces critical realism and its explanatory method, and then discusses the design of my research. 


\section{CRITICAL REALISM AND THE RESEARCH DESIGN}

\section{$2.1 \quad$ INTRODUCTION}

In Chapter One I introduced my research as a materially grounded 'thought experiment' conceived at the intersection of a number of practical and theoretical problems in the archives domain which contribute to a heritage sector cross-domain problem of difficulty in communicating across domain boundaries and collaborating effectively in the design of cross-domain knowledge enabling systems. Working from the premise that archives domain thinking, taken as a whole, would include both beliefs that stand in the way of effective cross-domain collaboration and also knowledge of fundamental importance for the design of knowledge enabling systems, I posed the following open and exploratory research question: What can be learnt about archives domain thinking, heritage objects and their evidentiality, and the design of knowledge enabling systems by exploring how evidence emerges during a historical research process?

I explained that this question, the objectives of my research, and my terminological choices should all be understood in relation to my research paradigm. I also explained that the worldview articulated in scholarship comprising my research paradigm is one of complex inter-dependence and co-evolution where the specificity of single occurrences makes generalisation difficult. In this worldview habituated perceptions of dichotomies such as between the social and the natural, mind and body, the conscious and the unconscious and, of course, between the physical and the digital do not hold true - reality demands new forms of explanation.

In discussing my research paradigm, I referred briefly to critical realism saying it served as my primary philosophical and methodological under-labourer. In the current chapter I introduce critical realism and its explanatory method and justify the privileged position critical realism has been given in my research. I then explain how I applied critical realism's explanatory method in my own research. 


\subsection{CRITICAL REALISM AND ITS SUITABILITY FOR THE RESEARCH}

Critical realism is a philosophy of knowledge first articulated in two books published in the 1970s by the Indo-British philosopher Roy Bhaskar (1944-2014). ${ }^{13}$ In Bhaskar's view the role philosophy serves in relation to research is that of an under-labourer. This term, first used by John Locke (1632-1704), conveys the notion that the concepts provided by philosophy complement those found in disciplinary theories. It explicates the "higher order or abstract features, which are normally not topicalised in, but rather only tacitly presupposed by, our [research and theory building] practices" and which, therefore, are often "confused" within scholarship focused on the objects and matters of core concern to specific disciplines (Bhaskar, 2013, p. 12). At a very general level philosophy defines what can be known and the means of acquiring that knowledge (Dobson, 2002); or, as Locke himself put it, philosophy clears "the ground a little ... removing some of the rubbish that lies in the way of knowledge" (Locke, as cited in Dobson, 2002).

Bhaskar's original philosophical mission was to remove some of the rubbish associated with the positivist and interpretivist paradigms. He argued research conducted within these paradigms tended to generate incommensurable theories that stood in the way of advancing knowledge. Also, he argued, both paradigms struggled to sustain a realist position in the face of critique (Bhaskar 1998a, pp. x-xi). Variously rejecting, drawing from, and building on positivist and interpretivist philosophies, critical realism positions itself as a third way. By various means, but most significantly by combining an "ontological insistence on the existence of objective natural and social realities with recognition of the socially constructed and fallible character of scientific knowledge", it has constructed a foundation which allows it to transcend "the polarized terms of much debate between ... [the positivist and interpretivist] positions" (Elger, 2010, p. 254).

Critical realism's concept of the real is broad. It stretches out from the concrete to also include such things as concepts, words, social conventions, and personal habits. It reaches

\footnotetext{
${ }^{13}$ These books were A Realist Theory of Science (1975) in which Bhaskar examined and critiqued existing philosophical thought relevant to the natural sciences and developed a new philosophical position he called "transcendental realism", and The Possibility of Naturalism: A Philosophical Critique of the Contemporary Human Sciences (1979) in which he extended his thinking into the social sciences, on this occasion dubbing his philosophy "critical naturalism". The two terms were subsequently combined to produce the name critical realism (Groff, 2004, p. 10).
} 
back in time to include the past realities that created the conditions for present realities (Archer, 1998, pp. 196-197), and also implies a future moment and future realities emergent from those of the present. In critical realism the real is whatever is. It is "an infinite realm of possibility" that can never be equated with - or limited to - our thoughts about it (Wight, 2004, p. 206). By arguing that the social world emerges from, and interacts with, the natural world, critical realism sustains "a materialist understanding of social and historical processes" (Benton, 2007, p. xii); and in its rejection of mind-body dualism, it sustains a view of thought as embodied (Nellhaus, 2004, pp. 103-104). With these characteristics critical realism is an easy fit with my research paradigm.

Because in the archives domain there are troubling discrepancies between a traditional and persisting positivist discourse and a more recent interpretivist discourse, critical realism is potentially a rewarding philosophical stance to take in archival science research. On two occasions in the past decade Sue McKemmish and Anne Gilliland have drawn attention to significant differences in positivist and interpretivist understandings of records and recordkeeping, and have argued the need for archival science research to move "beyond the binary oppositions" associated with these paradigms (Gilliland \& McKemmish, 2004, p. 170; McKemmish \& Gilliland, 2013, p. 91). Picking up on similar comments made by Verne Harris (2001a, p. 42), they have argued there is a place for elements of both paradigms and speculated that the "liberation" of archival science research "may well lie in the challenge of applying the apparent opposites of interpretive and positivist approaches to studying archival phenomena". The "creative tension generated", they suggested, may "lead us to yet other ways of seeing" (Gilliland \& McKemmish, 2004, p. 170; McKemmish \& Gilliland, 2013, p. 91). Commenting on this situation, Bunn (2011) observed, "Although there would appear to be broad consensus within the field that positivism used to be the dominant paradigm, there is, however, much less agreement about what has replaced it" (p. 164). Given that growing numbers of researchers in fields other than archival science are finding "the programmatic stance of critical realism attractive because it offers a warrant for existing research approaches that do not conform to either positivist or social constructionist protocols" (Elger, 2010, p. 254), perhaps the merits of critical realism as a replacement warrant investigation. 
Though critical realism has been promoted (and sometimes used) for research in the information sciences (examples include Carlsson, 2009; Dobson, 2002; Dobson, Myles \& Jackson, 2007; Fox, 2009; Kaponen, 2008; Mingers, 2002; Smith, 2006; Wikgren, 2004; Wynn \& Williams, 2012), it has (to my knowledge) not previously been discussed in archival science discourse, let alone used as an under-labouring philosophy in archival science research. I was initially attracted to it, not because I was looking for a warrant for a method, but because I recognised its mix of realism and relativism as necessary for my research problem (realism, because the concept of evidence is meaningless without it, and relativism because the relativist arguments made in archival science's critical discourse are too compelling to be ignored). The use of critical realism as under-labourer for my research, therefore, can be thought of as an experiment with this third way paradigm, a test of its fitness for archival science's purposes - at least, for those of its purposes that are addressed in my research.

Bunn (2011), whose doctoral research sought to build an understanding of archival description as a practice, explored the "the middle road" by using grounded theory method supplemented by theory from the field of cybernetics. Reflecting on her research experience, she likened taking this particular middle road to "walking a tightrope between decision and indecision and retaining the ability to act whilst being in a constant state of uncertainty and doubt" (p. 223). She saw this "tightrope" as one archivists also must walk when practising description (p. 232) because the fundamental problem with which she saw archival description to be wrestling is "the question of how it is possible to describe the world around us, 'to understand the regularity of the world we are experiencing at every moment, but without any point of reference independent of ourselves that would give certainty to our descriptions and cognitive assertions' (Maturana and Varela, The Tree of Knowledge 241)" (Bunn, 2011, p. 233). Enabling (albeit imperfect) understanding of the "regularity of the world" is what critical realism sets out to do. In choosing it as my under-labouring philosophy, I had a double agenda because at the same time as using it to guide the practice of my research, I envisaged also exploring its utility for underlabouring in the knowledge enabling 'descriptive' work undertaken by heritage sector practitioners. 
With all the above in mind, my description of critical realism below is provided both as background for my research strategy, but also to lay foundations for later recommendations regarding practice and for later discussions of how critical realism can be used to complement and extend continuum theory and to build bridges between continuum theory and other, seemingly competing, critical theory.

\subsection{CRITICAL REALISM AS AN EMERGENT AND OPEN PHILOSOPHY}

In discussing the problem of research paradigms, McKemmish and Gilliland (2013) drew attention to a variety of 'post' ways of seeing that have developed as challenges to "the dualism inherent in positivism versus interpretivism" (p. 91). Positioning critical realism in relation to other ways of seeing, including other 'post' ways of seeing is important because the philosophy is too often interpreted by those who do not engage with it deeply as self-affirming, closed and making hegemonic claims when, in fact, openness to other theories and philosophies and internal critique are amongst its key characteristics (Elder-Vass, 2010, p. 202). In the decades since Bhaskar's first two books were published, ideas in those books have been explored, critiqued, disputed, extended, and refined by a philosophically-oriented community of critical realist scholars associated with a number of disciplines, and in which Bhaskar continued to be active until his death in 2014. "Only a small band of critical realists still defend every turn in Bhaskar's thought", Elder-Vass (2010) observed, "The rest of us reserve the right to take what we find useful from Bhaskar's work without committing ourselves to the rest" (p. 201).

As it evolves, critical realism continues its engagement with the discourses emerging from the also-evolving positivist and interpretivist paradigms. Though it subjects those discourses to close analysis, often exposing logical flaws and untenable ontological ramifications, it also draws from them when they can be used to fill gaps or demonstrate flawed thinking in critical realist discourse. For these reasons, critical realism should be thought of as an open body of philosophical discourse (Elder-Vass, 2010, p. 202) which persists as significantly cohered because certain logically connected fundamental tenets (or theses) are agreed. Though it invites critique, it maintains that critique must always reason logically from these fundamentals and that it is only if they can be exposed as not 
holding good in real life situations that critical realism itself can be said to be flawed (Bhaskar, 2013, p. 9).

In the title to this section I described critical realism as an emergent philosophy. The word emergent is used here, as it is in critical realism, to refer to a phenomenon that exists because of a synchronic or diachronic relationship with other phenomena, ${ }^{14}$ but which is so intrinsically different from those other phenomena that it cannot be described as simply a sum of their parts, or even as a sum of parts of their parts. The emergent phenomenon has powers that are different to those of any of the phenomena in which it is grounded and which, therefore, make it capable of causality, including reacting back on the phenomena in which it is grounded (Collier, 1994, pp. 110-111; Elder-Vass, 2007, p. 161).

Elder-Vass (2007) argued that distinctive structure is what ultimately differentiates an emergent phenomenon from any phenomenon in which it is grounded, and that, while some emergent phenomena are fleeting, others persist because their structure has "morphostatic" powers. However, they persist only for so long as they can withstand the effects of contact with entities in their environment that have "morphogenetic" powers capable of destabilising existing structures. ${ }^{15} \mathrm{He}$ went on to propose:

that we can describe emergence as the outcome of a process by which a set of morphostatic causes, which may be both internal and external, sustain a set of lower level entities in relationships that constitute them into a stably organised higher level entity that can as a result exercise powers that are not possessed by its component entities either in isolation or in an unstructured aggregation. (p. 163)

The relevance of this thinking in relation to problems in archival science will be obvious to anybody at all conversant with the field. At this point, however, explanation of critical

\footnotetext{
${ }^{14}$ The biological as emergent from the molecular is an example of synchronic emergence. An example of diachronic emergence would be the authorized minutes of a meeting as emergent from the meeting they minute and from the documentation practices of the social group conducting the meeting.

${ }^{15}$ The terms morphostasis and morphogenesis were imported from general systems theory into sociology by Walter Buckley and then into critical realism by Margaret Archer. Morphogenesis refers to "those processes which tend to elaborate or change a system's given, form, state, or structure" (Buckley, as cited in Archer, 2013, p. 146). Morphostasis refers to "those complex system-environmental exchanges that tend to preserve or maintain a given form, organization or state" (Archer, 2013, p. 146).
} 
realism as an emergent phenomenon is the matter of concern. In that context too the relevance of Elder-Vass's thinking should, by now, be mostly self-evident. What remains to be discussed is the morphostatic power of critical realism's core logic, the internal structure that has enabled it to attract and retain a community of scholars and to maintain its essential character despite four decades of internal and external critique.

\subsection{THE LOGIC AT THE CORE OF CRITICAL REALISM}

Critical realism's core theses are "ontological realism, epistemological relativism, and judgmental rationalism" (Groff, 2004, p. 10). Explicitly grounded in realist ontology, a fundamental premise of critical realism is that epistemological possibilities emerge from ontological realities. A number of important things flow out of that premise. One is that the nature of the reality that is being studied has a bearing on how it can be studied, and even on whether it can be studied at all - reality, as Bhaskar observed, cannot be empirically experienced in its entirety. ${ }^{16}$ Furthermore, reality "has the ontic [emphasis added] characteristic of complexity" (Morgan \& Olsen, 2007, p. 261), and cannot be assumed to have "necessary intelligibility" (Wight, 2004, p.205). ${ }^{17}$

Another thing that flows out of that initial premise is that the reality of the researcher's positioning in space and time has epistemological consequences because such things as motivation, access to financial resources, acceptance or non-acceptance of pre-existing theory (or less formal thought) in relation to the research phenomena, access to evidence, and the effects of technologies that mediate the researcher's experience of the evidence all play a role in determining the nature of the knowledge that is produced. In short, epistemological relativism is "unavoidable" if one takes a realist stance (Wight, 2004, p. 202). Therefore, the "proper attitude" towards knowledge is to accept that it is fallible (Morgan \& Olsen, 2007, p. 257). However, critical realism's ontologically necessary ${ }^{18}$ acceptance of epistemological relativism does not logically lead to the belief that there is no basis for making universal generalisations as is argued to be the case in

\footnotetext{
${ }^{16}$ This premise is fundamental to Bhaskar's matrix of ontological depth which is discussed in section 2.5.

${ }^{17}$ The word ontic is a commonly used in critical realist writing to emphasize that what is being discussed is a thing as it really is (as opposed to what we might perceive or think the thing 'really' is).

${ }^{18}$ Necessary is another word commonly used in critical realism. When it is used it indicates that whatever is necessary to a thing is so intrinsic to that thing's essential nature that it would not be what it is without that necessary component. In other words, 'realism' which does not accept epistemological relativism as necessary is not realism.
} 
hermeneutics, phenomenology, and social constructivism (Mingers, 2002, p. 298). On the contrary, if epistemology is explicitly grounded in a realist ontology, a correspondence theory of truth is necessitated; ${ }^{19}$ and, although prior acceptance of the fallible nature of knowledge prevents us from claiming actual correspondence, it is still both reasonable and logical to maintain that some knowledge claims will correspond more closely with the ontic reality they reference than others. Epistemological relativism in critical realism, therefore, must be understood not as "the relativity of truth [i.e., anything goes] but the truth of relation" (Deleuze, as cited in Latour, 2005, p. 95). ${ }^{20}$

What follows on from this is a commitment to judgmental rationalism, which can be understood both as a high-level statement about research method and as a commitment by the researcher to an objective stance, though clearly not to a naive empiricist form of objectivity. In the context of the type of research I have done, this is probably best understood as maintaining awareness of the possibility that the evidence at hand might be explicable in numerous ways (including some which do not occur to the researcher) and also of the possibility that new evidence may raise serious doubts about earlier 'certainties'. Practising research in this way calls for close attention to one's own biases, a form of self-discipline which it can be very tempting to 'relax' in certain situations (for example, if it means abandoning an entertaining or emotionally appealing narrative, or if it means making a case contrary to one that is widely accepted), as my case study examples in Chapter Four and Chapter Five will demonstrate.

Judgmental rationalism also has high level implications for method. Because critical realism maintains our perceptions and interpretations of empirical reality are coloured by our pre-existing theories and assumptions, it is rational to prioritize conceptualisation in critical realist research and to do so by assessing the judgmental rationalism of existing thought (including competing theories) in relation to the research phenomenon. "How we

\footnotetext{
${ }^{19} \mathrm{~A}$ correspondence theory of truth is one which argues that $\mathrm{x}$ is true if it corresponds with "how the world is" (Morgan and Olsen, 2007, p. 258).

${ }^{20}$ Bruno Latour is not a critical realist. However, in many respects his thinking is similar to critical realist thinking (even though his terminology is quite different, and even though his early work gave the impression he had adopted a social-constructionist non-realist stance). I draw on Latour's work at various points in the thesis, most especially in Chapter Four where his explicit engagement with the concept of subjectivity complements critical realist pre-occupation with objectivity.
} 
'carve up' and define our objects of study", Sayer (2000) observed "tends to set the fate of any subsequent research" (p. 27).

\subsection{KEY CONCEPTS FOR EXPLORING THE REAL}

In this section I look at how critical realism carves up and defines the world for research purposes. As previously stated, as an under-labouring philosophy, critical realism complements disciplinary knowledge by focusing attention, not on the phenomena of core concern to individual disciplines, but on "higher order or abstract features" of reality relevant to the process of knowledge formation in all disciplines, yet often "presupposed" and "confused" in disciplinary research (Bhaskar, 2013, p. 12). Two sets of concepts are of fundamental importance. One - that of a transitive dimension which exists as part of, and also in relation to, an intransitive dimension - serves the purpose of keeping the researcher ever mindful of the gap between a perception and the reality perceived. The other - Bhaskar's matrix of ontological depth - identifies, relates, and differentiates abstract realities relevant to the process of working from empirical experience of a phenomenon (or empirical experience of its effects) towards an understanding of its structure and "generative mechanisms" - the qualities which enable it to act in the way it does (Smith, 2006, p. 201).

The term transitive dimension is used by critical realists to signify knowledge claims and products (and even just perception); and the term intransitive dimension is used to signify reality itself. This means that the whole of the intransitive dimension is equivalent to reality (everything that is, just as it is, knowledge claims included). When used as highlevel abstractions, these terms draw attention to the fact that the quality of 'being' is shared by all things that exist, but the quality of 'aboutness' is intrinsic to only some things. When used in reference to specific phenomena, the terms transitive and intransitive provide a way of articulating the way in which two phenomena stand in relation to each other when one of those phenomena references the other by means of a knowledge claim, belief, or perception. In effect, the phenomenon 'saying something about' is actualising its transitive dimension characteristics and by doing so, it situates the phenomenon it references as intransitive in relation to that particular act of referencing. 
These relational concepts force the researcher to attend to the gap between the observer and the observed and the nature of the relationship between the two.

In the paragraph above I italicized the word actualising in order to link discussion of the intransitive and transitive dimensions to Bhaskar's matrix of ontological depth which posits three overlapping domains which need to be differentiated in discussions of the research process. These are the domains of the empirical (experiences), the actual (events), and the real (structural mechanisms). In this view intransitive reality is understood to be comprised of structural mechanisms, each of which may or may not have the quality of being empirically self-evident. In imagining this, it is useful to think about clusters of structural mechanisms aggregated in such a way that together they comprise some higher level entity. In any given situation when certain of these higher level entities come into contact, some of their structural mechanisms will actualise while others will remain latent. The term domain of the actual is used to refer to these 'comings together' (events, in critical realist terminology). This domain is critically important for analysis as it is where the emergence of new entities occurs and also, often, where structural mechanisms not empirically self-evident in themselves manifest their presence, thereby creating potential for researchers to 'discover' their nature by means of retroductive reasoning about what they must be like in order to have those effects in that situation. ${ }^{21}$ This 'discovery' must be regarded as potentially fallible and corrigible because not every mechanism that is actualised so as to have causal effects with regard to some event or in some context of emergence can be assumed to manifest its presence in a way that can be empirically apprehended. The domain of the empirical, therefore, is a subset of the domain of the actual, which is a subset of the domain of the real.

Because not everything that exists in the domain of the real or that actualizes in the domain of the actual can be assumed to manifest its presence in a way that can be empirically apprehended, critical realism stresses that researchers in the social sciences must understand their research takes place in the open system that is reality. In an open system causation cannot be thought of in terms of "the standard Humean 'successionist'

\footnotetext{
${ }^{21}$ Retroduction is the term used by Bhaskar to refer to the type of reasoning that works from an observed, but unexplained, phenomenon to "hypothetical mechanisms that, if they existed, would generate or cause that which is to be explained". It involves the gradual testing and elimination of hypotheses and is essentially the same as C.S. Peirce's concept of abduction (Mingers, Mutch \& Willcocks, 2013, p. 797).
} 
view that involves regularities among sequences of events" (Sayer, 2000, p 13). Instead the focus must be shifted "to explicitly describing causality by detailing the means or processes by which events are generated by structures, actions, and contextual conditions involved in a particular setting" (Wynn \& Williams, 2012, p. 789) which then opens the way for theorising at a more general level about causation in terms of tendencies for certain things to act in certain ways when in certain contexts (Smith, 2006, pp. 199-205).

Together the concept of interacting transitive and intransitive dimensions and Bhaskar's matrix of ontological depth describe "the regularity of the world" (Maturana and Varela, as cited in Bunn, 2011, p. 233) when the aspect of the world that is of concern is the ongoing process of knowledge production and transmission. These concepts can be used in complex interpretive situations to enable fine-grained analysis of one's own and others' meaning-making processes. When used for critique of existing theory (critical realist or disciplinary), they help the researcher identify and categorize tacit assumptions, biases, silences, and ontological ramifications. I use them in that way throughout the thesis, but especially in Chapter Three. When put to use during empirical research, they create a predisposition for paying close attention to the meaning-making process and stimulate the researcher to identify with a relatively high degree of precision the mechanisms at play as meaning emerges. My use of them in that way is most pronounced in Chapters Four, Five, and Six. They are particularly helpful for locating the objectivities in subjectivities and the subjectivities in objects, as I will demonstrate in Chapter Four. Often, for the sake of easy reading, I replace these critical realist terms with the words aboutness (transitive dimension) and being (intransitive dimension).

\subsection{THE EXPLANATORY METHOD OF CRITICAL REALISM}

Elger (2010) is one of a number of scholars who have observed that "much of the advocacy of critical realism has remained at a high level of abstraction" (p. 254) and that there is relatively little critical realist research or methodological guidance (Elger, 2010; Wynn \& Williams, 2012; Yeung, 1997). At the level of research method, as at the level of theory, critical realism aspires only to under-labour, to ensure that research, though inevitably "theory-laden", is not also "theory-determined" (Sayer, 1998, p. 122). Insisting that observation is never neutral, its explanatory method requires that research be 
conducted in two stages, an analysis of existing theories followed by a practical exercise during which the researcher has empirical experience of the research object (Lawson, 1998, p. 164; Collier, 1994, pp. 162-164). However, the methods used during each stage are not prescribed. Rather, it is accepted that methodological pluralism follows on logically from critical realism's argument that the ontic characteristics of the research phenomenon have consequences for how it can be studied. Therefore, critical realist research can use - or adapt for use - any research method developed in the positivist or interpretivist paradigms so long as it is appropriate for the phenomenon and the context in which it is being studied (Elger, 2010, p. 254; Fairclough, Jessop \& Sayer, 2004; Jones, 2004; Mingers, 2004; Wynn \& Williams, 2012, pp. 795-806; Yeung, 1997).

Building on the idea that, if a thing is real, others who have experienced that thing will have (perhaps useful) knowledge of it, the purpose of the first stage in critical realist research is to test the judgmental rationalism of existing theories relevant to the research phenomenon. This is a form of theoretical triangulation because multiple theories (especially competing theories) are analyzed (Yeung, 1997, p. 64). In the process of analyzing existing theories, the researcher's pre-existing understanding of those theories is also tested. (As I indicated in Chapter One, my understanding of continuum theory was radically altered as a consequence of the deep reading required during this stage). The analysis of existing theories potentially challenges, alters, and extends the researcher's understanding of the research phenomenon. It also identifies matters requiring further investigation and lays a foundation for articulating the research findings in relation to a range of existing theories already in the field, negating, affirming, connecting, or extending them as may be warranted and creating the potential for existing theory to be re-formulated as emergent third way realist theory - and third way just might be the natural way for archivists, if the archival science musings discussed earlier in this chapter are anything to go by.

The outcome of the exploration of existing theory is a well-reasoned abstract understanding of the research phenomenon - a "working hypothesis about what exists" (Smith, 2006, p. 199). In my thesis I refer to this "working hypothesis" and the process whereby it was generated as the explanation from existing theory. The researcher takes this "working hypothesis about what exists", along with any questions that have been 
identified for further exploration, into the second stage of the research, during which practical engagement with the research phenomenon is required. This second stage is referred to as the applied explanation. It tests, deepens, and extends the explanation from existing theory, leading to a 'final' theoretical explanation (i.e., final within the context of the research because of the emphasis critical realism places on fallibility and corrigibility).

\subsection{THE EXPLANATION FROM EXISTING THEORY}

\subsubsection{A discourse analysis}

According to Fairclough et al. (2004) "critical realism has tended to operate with an insufficiently concrete and complex analysis of semiosis". Its tendency "to take symbol systems, language, orders of discourse, and so on for granted", they said, has led to "central features of the social world" being excluded from analysis (pp. 38-39).

In the first stage of my research I addressed this 'blind spot' in critical realism by using discourse analysis methods alongside the analytical concepts provided by critical realism. Discourse analysis methods were doubly important because tendencies to take the meanings of words for granted have been amongst the root causes of the problems in archives domain discourse which I discuss in this thesis. Therefore, in analyzing, archives domain 'theory', I was as interested in identifying habitual unquestioned 'concepts' and thought patterns as I was in assessing the judgmental rationalism of deliberate and explicit theoretical writing.

\subsubsection{The discourse analysis method}

In advocating the use of discourse analysis methods for critical realist research, Fairclough et al. (2004) said traditional discourse analysis methods are unsuitable because they do not sufficiently take into account "extra-discursive" matters which have causal effects in producing a discourse and in shaping its consumption, re-production, and re-use (pp. 3839). Elaborating further, they explained, analysis requires that discourses be located "within their necessary dialectical relations with persons (hence minds, intentions, desires, bodies), social relations, and the material world - locating them within the practical engagement of embodied and socially organised persons with the material world" (p. 27). 
Though traditional discourse analysis methods are not sufficient for critical realist research, critical discourse analysis methods are seen to have much to offer because of their sensitivity to diachronic and synchronic matters of context (Fairclough et al, 2004, pp. 38-39; Jones, 2004, p. 43). ${ }^{22}$ Jones (2004) observed that because critical discourse analysis works to "unpack communication itself along the lines of structures and mechanisms, it also allows for an understanding of how other social structures are maintained and transformed in and through various forms of languages and discourses" (p. 43). James Gee, whose critical discourse analysis method I used, is one who has paid close attention to matters of this nature.

Gee (2005) described language and context as being "like two mirrors facing each other and constantly and endlessly reflecting their own images back and forth between each other" (p. 97). He, therefore, advocated a reflexive method of analysis which does not concern itself simply with language but also deals with social context.

Gee's use of the term social context is similar to Sewell's use of the term culture (discussed in Chapter One). Social contexts, like cultures, are "landscapes of meaning" (Sewell, 2005, p. 87). They include not only individuals and institutions, but also "tools, technologies... values, attitudes, beliefs, and emotions" (Gee, 2005, p. 7). Gee's method, therefore, seeks "to balance talk about the mind, talk about social interaction and activities, and talk about society and institutions" (p. 6). It explores discourses as situations "in which people take on certain sorts of identities or roles..., contract certain sorts of relationships with each other..., and use certain sorts of sign systems and forms of knowledge". In discourses, Gee said, "people and things take on certain meanings or significance... things are connected or disconnected, relevant or non-relevant to each other in various ways; and various sorts of social goods are at stake in various ways" (p. 97).

Gee (2005) saw discourses to rest on certain "building blocks":

\footnotetext{
${ }^{22}$ The academic discipline of discourse analysis consists of two strands: the critical and the non-critical. The non-critical "prioritises semiology, textual linguistics, and natural language". Critics of this approach say focusing "mainly on 'text in itself" plays "down social struggle and power relations" and fails to discuss production, distribution, and consumption. Critical discourse analysis, on the other hand, "is concerned with uncovering relations of power and ideology and their effects on social identities and relations" (Jones, 2004, p. 45).
} 
- the things which are significant in the discourse and the type of meaning or significance attached to them;

- the activities which the participants in the discourse are engaged in;

- the identities which the participants in the discourse are projecting;

- the relationships which are being enacted;

- the politics implied by the discourse (e.g. status, power);

- the ways in which things are presented as connected or disconnected; and

- the "ways of knowing" (shared meanings taken for granted by the discourse group) which are operative during the discourse. (pp. 10-13)

Each of these building blocks, Gee (2005) said, should be explored during a discourse analysis. As a starting point for analysis, he suggested twenty-six questions which could be used (pp. 110-113). However, he said they should not be used pedantically because the tools and strategies used in research must always fit the specific context of the research. Those which prove irrelevant, he said, can be dropped, and new questions can be added if other ways of exploring the building blocks should be needed (pp. 110-113). His method, in short, is a "thinking device", not a set of rules to be followed (p. 6).

In practice, it was as a "thinking device" which supplemented the thinking devices provided by critical realism that I found Gee's method most useful. While his questions were extremely useful for building a broad appreciation of how the archives domain's "landscape of meaning" has evolved, I found them too general and too context-focused to meet all my needs. When used alone, they seemed to keep my analysis always one step removed from what the discourse was actually saying (whether consciously or unconsciously) about the phenomena of primary interest for my research. After working with Gee's questions for a short time, I felt I needed more balance between analysis of the content and analysis of the context as a first step in formulating an understanding of how the two worked together. Therefore, I devised some content-focused questions (see Table 1).

These questions helped me search out, within single texts, definitions and dichotomies relevant to my research problem and to identify how (and if) they were justified. They also helped me explore the connections and disconnections explicit and implicit within 
each text. Gee's "building blocks", which I continued to work with, let me look at a bigger picture (and at single texts within that bigger picture) so that I could recognise connections and disconnections between texts and over time.

Table 1: Questions I framed for the initial discourse analysis.

\section{Questions I framed for the initial discourse analysis.}

How are archives/records defined?

What characteristics are associated with archives/records?

How are personal papers referred to?

If personal papers are distinguished from archives/records, how are they distinguished?

If personal papers are likened to archives/records, how are they likened?

How are archives/records distinguished from (library) collections?

How are books described?

How are three-dimensional, non-documentary objects described?

Are there other comments relevant to formats?

What, if anything is said about evidentiality (or similar concepts?)

How should archives/records be arranged?

Why should they be arranged that way?

Is anything said about how personal papers should be arranged? If so, what?

Why should they be arranged that way?

How is the process of arrangement related to concepts of evidentiality and archives/records?

How should archives/records be described?

Why should they be described that way?

How is the process of description related to concepts of evidentiality and archives/records?

How should personal papers be described?

Why should they be described in that way?

Other points of interest?

\subsubsection{The initial discourse population}

My initial discourse population (of sixty works) was identified early in 2010. A number of factors worked together to guide my selection. Firstly, there were the broad topic areas of interest for my research; namely, the concept of record, the concept of evidence, and descriptive practice. Secondly, there was the fact that one of the motivations underpinning my research was a desire to explore these topics in ways that are relevant to 
collecting archivists. Thirdly, there was the critical realist requirement that research should engage with competing theories.

The critical realist researchers Morgan and Olsen (2008) have argued that epistemic privileging, which is inevitable in research, affects research outcomes. ${ }^{23}$ When the nature of such privileging is made explicit by the researcher, the research can be judged in terms of its own frames of reference and future research can correct or extend those findings by expanding the frames of reference. In other words, by exposing the nature of her epistemic privileging, the researcher lays a foundation for future bridge-building - the possibility of commensurable, rather than incommensurable research activity. Because there is a huge body of work in the archives domain which explicitly or implicitly reveals thought about the nature of records and their evidentiality or which is concerned with descriptive practice, it was inevitable that epistemic privileging would occur in my selection of a very small portion of that whole to serve as my discourse population. As I said above, I made a conscious decision to privilege the writing of collecting archivists and writing highly relevant to collecting archives (e.g., about personal papers). A consequence of that decision was an equally conscious decision to exclude from my discourse population any work generated within the context of the University of Pittsburgh's Electronic Records Project, the University of British Columbia's Preservation of the Integrity of Electronic Records (hereafter InterPARES) Project, or Monash University's SPIRT (Strategic Partnerships with Industry - Research and Training) Recordkeeping Metadata Research Project and Clever Recordkeeping Metadata Project due to the fact that I understood those projects to privilege contemporary organisational records. I also understood them to privilege legal discourse regarding the nature of evidence. I excluded this work so I could focus my full attention on evidentiality as emergent during historical research and on collecting institutions in the cultural heritage sector.

This epistemic privileging was off-set, to a limited extent, by decisions I made in order to meet the critical realist requirement that attention be given to competing theories and viewpoints. One way in which this occurred was because my selection of writings on archival theory and on personal records included a number of articles written by Frank

\footnotetext{
${ }^{23}$ Morgan and Olsen's work is discussed in detail in Chapter Four.
} 
Upward and Sue McKemmish, two of the most significant continuum theorists. This meant that I engaged with the theory underpinning the Monash University projects even though I did not engage with the work that emerged directly from those projects. Another way in which it occurred was because my selection of writings on archival description included a number of articles written by Peter Scott and by Chris Hurley. Scott's thinking about description is typically hailed as a pre-cursor to contemporary continuum-informed approaches. Hurley, a member of the continuum community, has extended the logic underpinning Scott's work. In addition, he was a member of the SPIRT Recordkeeping Metadata Project reference group and of the Clever Recordkeeping Project advisory group.

Other ways in which I attempted to meet the critical realist requirement that research consider competing theories and viewpoints was by including a mix of traditional works and late twentieth and early twenty-first century critical work. The traditional works were virtually all practice manuals. I included manuals written for collecting archivists as well as the well-known manuals of Muller, Feith, \& Fruin; Jenkinson; and Schellenberg, which were written primarily for government and organisational archivists. Critical theorists (outside the core continuum community) who I included were Terry Cook, Verne Harris, Elisabeth Kaplan, Heather MacNeil, Jennifer Meehan, Laura Millar, Tom Nesmith, Ala Rekrut, Joanna Sassoon, Joan Schwartz, and Geoffrey Yeo (as well as various others who have co-authored articles with the afore-mentioned).

In summary, my initial discourse population was a conceptually broad, yet epistemically biased and relatively small sample, of the large body of archives domain literature which, explicitly or implicitly, says something about the definition and characteristics of archival records, about their evidentiality, and about their description. Collecting archives and cultural heritage perspectives were privileged in the sense that writing directly relevant to those contexts comprised a significant part of the discourse analysis population whereas writing produced within the context of the archives domain's most significant late twentieth and early twenty-first century enquiries into the evidential character of records and recordkeeping practice was excluded. 


\subsubsection{Conducting the discourse analysis and reconfiguring the discourse population}

I approached my initial discourse analysis population chronologically beginning with Muller, Feith and Fruin's 1898 manual (albeit the 1940 English translation of their second edition). I used a form focused on Gee's building blocks and the additional questions I had posed rigorously for the analysis of all the works in my initial list published up to the 1980s. This was a time-consuming approach, but it entrenched habits of awareness and attention to how arguments are constructed, the purposes they serve, and how words and thoughts move (not necessarily together) from one text to a later one. Over time, these habits became a way of reading which, like inter-textuality, blurred the distinction between my discourse analysis population and other literature that came to my attention and prove to be relevant.

As my research advanced, my interest in some of the material in my initial discourse population waned (the manuals produced for collecting archivists, for example, were very practice-focused and revealed little of interest for my research). Newly published articles by Geoffrey Yeo, on the other hand, suggested his research interests paralleled my own, so I followed his work. Also, I became very interested in continuum theory due to the fact that the articles by Upward in my initial discourse population gave me reason to think continuum theory had much in common with critical realism and could, therefore, be put to work in much more diverse and interesting ways than I had previously recognised. Though I read continuum writing more extensively than I first anticipated, for the most part, I continued to practise the epistemic privileging that excluded its major metadata projects. I also became very interested in two books authored outside the archives domain which came to my attention as a consequence of following citations in articles authored inside the domain. These were Moore's Restoring Order: The École des Chartes and the Organization of Archives and Libraries in France, 1820-1870 and Schum's The Evidential Foundations of Probabilistic Reasoning (1994).

Though, during the research, I engaged with a large volume of published work, only a portion of that work is cited in the thesis. An even smaller portion is discussed analytically. The works that have been singled out for attention in the thesis are those 
which were most relevant to the lines of argumentation I develop and which were most influential in shaping my thinking.

\subsection{THE APPLIED EXPLANATION}

\subsubsection{A case study and critical reflection}

The empirical component of the research - in critical realist terms, the applied explanation - took the form of a case study during which I adopted the stance of a reflective historical researcher seeking to build knowledge about the New Zealand collector Frederick Burdett Butler (1903-1982) and his (now dispersed) collection, and the complementary stance of an archival science researcher reflecting critically on how that knowledge was being built and on any implications for the matters of interest identified in my research objectives and during the discourse analysis.

The case study method is frequently used for both archival science and critical realist research (Elger, 2010, p. 254; McKemmish \& Gilliland, 2013, p. 94). Wynn and Williams (2012) argued it to be the best method for exploring the interaction of structure, events, actions, and context when the objective is to identify and explicate causal mechanisms ( $p$. 795). Case studies enable an individual situation, institution, or process to be studied and understood in complex detail (Gilliland-Swetland, 2000, p. 267) and are particularly valuable "when the boundaries between phenomenon and context are not clearly evident" (Yin, 2009, p. 13). For all these reasons a case study seemed appropriate.

As I said above, I designed my case study to enable multiple levels of analysis, as is common in case study research (Eisenhardt, 1989, p. 354). I used my enquiry into the life of Fred Butler and the nature (and dispersal) of his collection as a vehicle for an empirical investigation into how evidence emerges and, in particular, into how heritage sector systems facilitate or obstruct evidence emergence and knowledge building activity. I also used it as a vehicle for testing and extending the theoretical insights resultant from, and problems identified during, my analysis of existing theory.

I chose the dual stance described above because I was seeking close understanding, from a historical researcher perspective, of how evidence emerges - I wanted to get beneath the level of document (the typically smallest item of interest to archivists) so as to identify, as precisely as possible, the sources of emergence and the ways in which those 
sources were seen to be related when they were seen as evidence. In planning my research, I had considered the alternative method of interviewing historical researchers. However, I was concerned interviews would yield only superficial results. I have a background in historical research myself (a Master of Arts by thesis in the discipline of history and also experience gained in the course of conducting family history and local history research) and was aware that, whilst researching, I had rarely paused to reflect this closely on my sources and my own meaning-making processes. I assumed this was likely to also be true for other historical researchers. This assumption was supported by material I had read relevant to my research paradigm, which argued that we all tend to perceive what we have previously perceived and talk about what we have become accustomed to talking about, so that talk and perception reinforce each other and work together to limit our awareness and also to limit our ability to describe, or even attach significance to, anything vaguely perceived on the margins of our consciousness (Collins, 2009, pp. 109-112, 133; Day, 2004, p. 77; Van der Weel, 2011, p. 37). This being the case, I felt it unlikely that interviewees, reflecting retrospectively on their research experiences, would be able to provide the insights I was seeking into how the material heritage objects, the descriptive practices, and the systems they encountered had facilitated or hindered the progress of their research. I felt it even more unlikely that they would be able to reflect on the potential consequences of different practices and designs such as those promoted by archival science's critical theorists. I was also concerned about the limits of my own awareness and about my ability to translate concepts articulated in archival science into language that might allow researchers to recognise experiences during their research activity which manifested those archival science concepts. For all these reasons I reached the conclusion that the deep theory-informed reflection I was seeking would require a case study during which I either followed a single researcher very closely or positioned myself as the researcher. I chose the latter, largely out of concern that following a single researcher closely enough to know in detail why the researcher was thinking what he or she was thinking and doing what he or she was doing would be excessively intrusive. ${ }^{24}$

\footnotetext{
${ }^{24}$ This approach might, however, work well as a collaborative action research project. Insights resulting from the collaboration could potentially enrich both disciplines.
} 
Eisenhardt (1989) advised that, because a researcher can expect to explore only a limited number of cases in any depth, it is sensible to select cases which manifest "extreme situations and polar types" and where the phenomena of interest are "transparently observable" (p. 537). Ginzburg (2013) made a similar point when discussing cases that have "generalizing potential". "Anomalous cases", he said, "are especially promising, since anomalies ... are richer, from a cognitive point of view, than norms, insofar as the former invariably includes the latter - but not the other way round" (p. 109). A dynamic of norms and anomalies exists in the archives domain's thinking about the nature of records. As Yeo (2008) observed, records are typically understood as a category in terms of "prototypes" and "boundary objects". The norms are the records of governments and those kept in-house by large organisations. The anomalies include personal papers and other 'manuscript' material and items that differ in genre and media type from the norm of government records (pp. 122-124). These anomalous or "boundary object" records (if they are records) are typically found in collecting archives and in the special collections of libraries and museums. ${ }^{25}$

\subsubsection{The case study's scope}

By placing Fred Butler and his collection at the centre of my case study, I also placed the databases of, and materials held by, collecting archives, libraries, and museums at the centre of my research. I delimited my case study by resolving to seek out only material held in institutional repositories. I made this decision because the metadata and digital systems of those repositories were of central interest for my research - I anticipated that pursuing Butler's story via records in private hands would contribute nothing to achieving my research objectives.

On a small number of occasions, when conducting the case study, I abandoned this delimitation. Philosophically, I should never have imposed it because, in practice, historical research takes place in an open system. Attempting to explore the process within an artificially closed system distorts the reality. Like many historical researchers (Duff \& Johnson, 2003, p. 90; Johnson \& Duff, 2005; Yakel \& Torres, 2007), I found my

\footnotetext{
${ }^{25}$ Similar thinking to that of Eisenhardt (1989) and Ginzburg (2013) can be found in critical realism where the "primacy of the pathological" (cases where the phenomenon of interest is not behaving in its normal way) is advocated (Collier, 1994, p. 165).
} 
interests intersected with those of others and that this led to the sharing of ideas and knowledge and - in my case - to awareness of the nature and content of material in private hands.

Though in the course of my research I engaged with a wide range of materials relevant to Fred Butler and his collection, only some of these materials - and some of the many lines of enquiry I followed - are discussed in the thesis. In order to improve the narrative coherence and readability of the thesis, I focused my attention on a small number of intersecting lines of enquiry capable of supporting the theory-building work I do in the thesis. Those I chose have a human-interest component in addition to being conceptually rich.

In section 2.8 .4 , in order to provide context for the lines of enquiry described in the thesis, I share an overview of what I learnt about Fred and his collection in the course of the case study.

\subsubsection{Practising critical reflection}

In the early stages of the case study I collected a huge amount of data (largely as digital images) and also kept supplementary notes recording my thoughts about the materials with which I was engaging, about how I was interpreting those materials, and why. I also printed out (and annotated) screen displays of interest. My reflections on archives domain concepts were included in those notes and annotations.

Much of the close analysis I discuss in the thesis occurred at a later stage (often whilst writing early drafts). It drew on the data and reflections I had previously compiled and also sometimes extended them. In the course of a highly recursive reflective and datagathering process, there were many occasions when some perceptual experience would bring to mind some item previously seen, which had not at first seemed significant. On returning to that item, I would discover more in it than previously recognised. When this occurred, there was often a flow-on effect, sometimes leading to new database searches or requests for digital copies of material in repositories I had visited (and not visited). As a consequence the case study lines of enquiry described in Chapters Four, Five, and Six were, in large part, conducted as I was writing early drafts of those chapters. The minutiae of my evidence discovery and meaning-making processes were captured directly 
into my drafts. This was also true for many of my reflections on theory and descriptive systems (though some were transferred from notes made at an earlier time when I was fully focused on the case study).

The critical realist researchers Morgan and Olsen (2008) argued that by exposing all the factors that have influenced a researcher's reasoning, the researcher makes it possible for others to assess the quality of the knowledge she has produced and to build on that knowledge in their own research. They claimed objectivity, which must be understood in terms of an "open ended process of active knowledge formation" (p. 116), rests on this foundation. In those chapters in which I report on my case study findings, I follow these practices of thick-description of my meaning-making processes in relation to the 'objects' (including personal experience and the fuzzy space of my own psyche) in which they were grounded. The exercise was revealing on two counts. One was that it provided grounds for arguing that a good deal of supposed 'subjectivity' can be traced to evidential sources external to the self. The other was that it made me aware of 'forces' in myself and in the storytelling practices of history which work against objectivity. By exposing both, I contend that, although I placed myself at the centre of this case study research, my stance was objective when seen within the critical realist paradigm. In saying that it was objective, I am not saying that it was complete or infallible. On the contrary, in critical realism, incompleteness and fallibility are assumed to be the default position for knowledge contributions. Objective practice, as described above (and in greater detail in Chapter Four), enables corrigibility and extensibility.

\subsubsection{Frederick Burdett Butler - A brief biography}

Besides being a collector, Fred Butler was a local historian, a musician, a hiker, a craftsman, and photographer. He accumulated materials created in the course of these, and other, activities alongside those he purchased, found, or otherwise acquired for his collection. His collecting interests were wide-ranging, both in terms of scope and object type. In an article published in New Plymouth's The Daily News on 17 January 1970 he was cited as saying, "My interest in history begins in New Plymouth and spreads outwards" ("Historic material lost", 1970). Peter Shaw, who met Fred towards the end of the 1970s, recalled him saying that he collected everything except "Chinoiserie" (Shaw, 2006, September 15). Books made up a large part of Fred's collection, one his ambitions 
from an early age having been to acquire a copy of every book ever published in New Zealand. He estimated that, when his collection was at its height, it contained approximately 80,000 books ("Historic material lost", 1970). He had paintings by Constable, Durer, Goldie, and Gully, fine furnishings such as a Chippendale four poster bed, and rare musical instruments. He collected household furnishings and equipment associated with the early settlers of Taranaki, photographic equipment, and parts of old buildings (the door of the first New Plymouth jail was re-used as his bedroom door). Amongst the paper items in his collection were Taranaki Provincial Council records (which he rescued by stealth at night when the building they were in was about to be demolished), family bibles, and birthday books ("City gains a treasure: Tauranga Museum's priceless collection", 1977). His collection of taonga Māori ${ }^{26}$ is said to have been "of national significance, certainly of Taranaki significance" ("Butler Collection", n.d., Archaeopedia New Zealand website). ${ }^{27}$

Today Fred is best known for his encyclopaedic collection of approximately 3000 wallpaper-covered 'scrapbooks'. These so-called scrapbooks are extraordinarily complex in terms of their physicality, their content, and the ways in which they have been valued and organised. In general they began life as novels, school textbooks, unused diaries and other bound volumes which Fred re-used by turning them upside down and pasting into them newspaper clippings and other material (e.g. raffle and lottery tickets). When filled, the 'scrapbooks' were covered in wallpaper (usually), named, sometimes numbered, sometimes embellished with a bookplate and a title page, and - for a time - indexed. ${ }^{28}$ Some, however, contain minutes and other records of organisations to which Fred belonged. Others contain records Fred himself created (e.g., daily rainfall and temperature measurements). A large number contain manuscript transcriptions of early Taranaki newspapers. Some of the volumes transition from one use to another related, but somewhat different, use. Some are numbered in such a way that they can be seen in series that have undergone such a transition. I refer to these volumes as scrapbooks

\footnotetext{
${ }^{26}$ Taonga is a Māori language word used as a collective term for things which are culturally treasured by the indigenous people of New Zealand.

${ }^{27}$ Dean Flavell, who Archaeopedia New Zealand cited as the source of this information, advised by private email dated May 5, 2011 that his own source was the 31 March 1978 Directors' report for the Tauranga District Museum Historical Village.

${ }^{28}$ There are approximately 20,000 cards in the index Fred created for his scrapbooks.
} 
because that is how they have come to be known - and, since 2007 when they were brought to the attention of the international art world (and many others) by the photographic artist Ann Shelton, they have become quite well-known. I problematize the term scrapbook, however, because they are not typical of the scrapbook genre and many (such as the volumes of manuscript transcriptions) are not scrapbooks at all.

For Fred the work of collecting, transcribing and compiling began as a hobby which, as a young man, he fitted around his working life. By the mid-1930s he seems to have been dedicating substantial parts of the working week (if not the whole of it) to his collecting, information compiling, and local history activities. ${ }^{29}$ There is evidence in the 'scrapbooks' that by 1939 he was employing staff to assist with the work. Notes at the back of the volumes show who they were, the hours they worked, and the rates they were paid. During these years Fred also wrote historical articles for local newspapers and his book Early Days, Taranaki, which he self-published in 1942.

Initially Fred housed his collection in his parents' home at Gill Street, New Plymouth; but, following the death of his mother in 1960, he moved everything - the house as well as the contents - to a three acre property on Sentry Hill on the outskirts of New Plymouth. There he began a major building project, extending the family home by adding on two other relocated houses. His collection filled this 40 room building and overflowed into two cottages also on the property. The scale of this building project led to financial problems, and in 1961 Fred agreed to sell a large number of items from his collection (including many of his 'scrapbooks' and their index) to the New Plymouth Council to be added to the collections of the Taranaki Museum. ${ }^{30}$

Ongoing financial problems in the years that followed caused Fred to sell increasingly large parts of his collection, often to private collectors. In 1970 he sold books, manuscript material and 'scrapbooks' to the Hocken Library in Dunedin which immediately on-sold them to the New Plymouth Council, the acquisition on this occasion going to the New

\footnotetext{
${ }^{29}$ In 1970 Fred claimed that he had "worked for fifty years of... [his] life, from 5am to 11pm, every day of the week" building his collection ("Historic material lost," 1970)

${ }^{30}$ Correspondence relating to this sale is highly suggestive of the Museum, having first established the extent of Fred's debt, offering him the sum needed to 'bail him out' (Allen, 1961, June 22; Taylor, 1961, June 20).
} 
Plymouth Library. ${ }^{31}$ Throughout this period, however, Fred's aspiration was to find an organisation willing to purchase the entire collection and keep him on as curator. In March 1977 he negotiated such an agreement - he and his collection were relocated in "seven large trucks" to the Tauranga District Museum Historical Village. ${ }^{32}$ Within a year the arrangement had soured, and in July 1978 Fred removed himself, and a diminished collection, to a large house he purchased in Thames. ${ }^{33}$ In 1982 Fred had a stroke while trying to remove his books from danger during a flood. He died soon after.

Throughout his collecting years Fred appears to have traded in antiquities, regularly selling some items and acquiring others. It seems he had always been a trader as well as a collector. As he aged and his financial difficulties began to weigh more heavily, he sold more. In his final years at Thames he was selling bundles of books (often containing his bookplate) for small sums from the verandah of his home (Shaw, 2006, September 15). Today Fred's material legacy is dispersed amongst public and private collections throughout New Zealand and, reputedly, the world. Some, including most of Fred's correspondence and diaries, has remained in the family, and some - considered worthless - has been destroyed. The largest known aggregation of things associated with Fred Butler is at Puke Ariki in New Plymouth. This institution was formed in 2003 when the New Plymouth City Council merged its visitor centre, the former New Plymouth Library, and the former Taranaki Museum into a single organisation housed in a single building.

\footnotetext{
${ }^{31}$ There has been some suggestion anecdotally that the sale to the Hocken Library was a 'set-up' arranged by the New Plymouth Librarian and the Hocken Librarian with the intention of acquiring this material for the New Plymouth Library. The purported subterfuge was necessitated by the fact that Fred had fallen out with so many of the councillors and personnel associated with the New Plymouth Council that he was refusing to sell his collection locally. It has also been suggested that Fred may have been aware of the behind the scenes manoeuvring and happy to play along so long as the appearance of him standing on principle was maintained. Newspaper reports from the time and documents I have seen leave me uncertain as to whether either suggestion has any validity. Significantly, the New Plymouth Librarian did not seek approval for funding until after the sale. and it was only after receipt of a grant from the Taranaki Savings Bank in October 1970 that payment was made to the Hocken Library ("City Council buys historical items", 1970; New Plymouth City Council Finance Committee, 1970, 19 January; "Historic material lost", 1970; Shipherd, 1970, 16 January, 21 January, 2 October, 14 October, 23 October; “Sold outside Taranaki”, 1970).

32 In a newspaper article published at the time, Fred claimed that only about one tenth of his original collection remained in his possession at this stage ("Taranaki history goes to Tauranga," 1977)

${ }^{33}$ Negotiating a way out of the contract resulted in some items being given up to the Tauranga District Museum Historical Village. Fred claimed other items were lost due to carelessness (e.g., a chest of documents left out in the rain) and unscrupulous disregard for the terms of the contract (e.g., sales to second hand dealers) (Book Row: Collection on the Move, 1978).
} 
The merger brought together the parts of Fred's collection which had previously been acquired by the Taranaki Museum and the New Plymouth Library.

\subsection{CONCLUSION}

In this chapter I introduced critical realism, a philosophy of knowledge compatible with my research paradigm, which I used as the primary philosophical and methodological under-labourer in my research. I also drew attention to archival science literature which suggests a third way theory of knowledge such as critical realism is highly appropriate for research in archival science, especially for research involving conceptual analysis of evidence and evidentiality and seeking insights into how archives description might be practised if its end purpose is understood to be knowledge enabling.

Following my introduction to critical realism I described my research design which, as required by the explanatory method of critical realism, analysed existing theory in order to develop a conceptual lens for exploring the research phenomena through practical experience of those phenomena. For the analysis of existing theory, I used a critical discourse analysis method along with critical realist concepts to examine a body of literature which, though in many ways conceptually broad, privileged cultural heritage and collecting archives perspectives. The second part of the research was a case study, during which I took the stance of a historical researcher investigating the life of Fred Butler and the dispersal of his collection, in order to be able to reflect closely on theoretical issues identified during the analysis of existing theory and on the question of how descriptive practices and technology designs impact on evidence emergence. I explained that both aspects of my research had a recursive character. My perception of what literature was most relevant and my interpretations of that literature evolved as the research progressed, and especially when I was writing the thesis. Similarly, much of my fine-grained case study analysis occurred during the period of writing.

In Chapter Three I report my analysis of archives domain thinking as I saw it to be manifested in the body of literature in which my thesis is most deeply grounded. In doing so, I situate my research in relation to problems and gaps in the literature and identify issues that are primary foci for attention in Chapters Four, Five, and Six. 


\section{AN EXAMINATION OF ARCHIVES DOMAIN 'THEORY'}

\subsection{INTRODUCTION}

In Chapter Two I introduced critical realism and described my research design which is based on critical realism's explanatory method. I explained this method requires that research comprise an examination of existing theory followed by practical engagement with the research phenomena. The intended outcomes of the examination of existing theory are a well-reasoned abstract understanding of the research phenomena and identification of matters not adequately covered in existing theory and, therefore, warranting investigation through practical engagement with the research phenomena. The examination of existing theory also lays a foundation for articulating the research findings in relation to theory already in the field.

In Chapter Two I also explained that the body of literature I selected for analysis was only a fragment of the archives domain's whole discourse relevant to the research phenomena. In making my selection, I said, I had - at least, up to a point, privileged collecting archives and cultural heritage perspectives, as well as writing by and for practitioners.

The current chapter reports on my analysis of the body of literature with which I engaged. It does not discuss all works I examined. Instead, it focuses attention on those I found to be of most interest to my research and in which, therefore, my thesis is most deeply grounded.

The chapter is divided into two main sections. The first discusses traditional discourse, primarily as I saw it to be manifested in the widely read manuals of Muller, Feith, and Fruin (1940); Jenkinson (1922); and Schellenberg (1956, 1965). It focuses on two aspects of this discourse: the conceptual bundling of thought about the nature of records, provenance, aggregations, and practice; and the means whereby libraries, librarians, and 'library materials' were othered. The second major section centres continuum theory in a discussion of contemporary discourse. The objective of this section is both to introduce those continuum concepts with which I work in later parts of the thesis and to situate the 
theory's emergence, development, and reception within the broader discourse, most especially within discourse concerned with the cultural heritage aspects of archival work. Misunderstood and misrepresented from a very early stage in its development, continuum theory has been othered by a significant part of the archives domain's heritage-oriented community. In particular, its explicit linking of records and evidence has been resisted. Literature relevant to that dispute is discussed. Points of overlap with continuum theory and points of disconnection are identified. Also identified are problematic assumptions in the non-continuum literature and still to be filled gaps in the continuum literature.

\subsection{TRADITIONAL DISCOURSE}

\subsubsection{Overview}

The origins of contemporary archives domain thought and practice are commonly traced back to nineteenth century Europe. It was during this century that national archives began to be established and that archivists working in those institutions were forming a distinct professional identity (Cunningham, 2005, pp. 28-30; Eastwood, 2010, p. 5; Horsman, 1999, pp. 1-9; Schellenberg, 1956, pp. 3-5, 169-179). A concept of record, and formal definitions of records, emerged in this setting in relation to a need to define the nature of public records in relation to private records, in particular the circumstances in which private records became public records (Milligan, 2005), and in relation to a need to differentiate archives from museums and, more especially, from libraries. ${ }^{34}$ By the $1970 \mathrm{~s}$ this body of thought, practice, terms and metaphors - referred to in this thesis as traditional discourse - dominated archives domain discourse in the Western world. It continues to shape thought and practice today.

The authors of three widely distributed manuals (all of which were included in my initial discourse population) are commonly regarded to have been the primary shapers of the traditional discourse (Cook, 1997, pp. 20-29; Eastwood, 2010, pp. 5-10). The first of these manuals to be published was Muller, Feith, and Fruin's 1898 Manual for the Arrangement and Description of Archives. Initially published in Dutch, it was subsequently published in German (1905), Italian (1908), and French (1910). In 1920 a second Dutch edition was

\footnotetext{
${ }^{34}$ The word archives is used here and elsewhere in this chapter to refer to archival institutions.
} 
published. This was translated into English and published in the United States in 1940. Footnotes in the English translation identified points of difference between the Dutch version and the French version (significant because French archivists tended to have a more inclusive concept of record). I analyzed a copy of the 1968 reissue of the 1940 English version. The editors noted in their preface that the second Dutch edition differed from the first only in minor ways.

The other two foundational manuals were authored and published in English (though also subsequently translated and widely spread). The first was A Manual of Archive Administration Including the Problems of War Archives and Archive Making, authored by the English archivist Hilary Jenkinson and published in 1922. This was the first manual published in English. The 1940 translation of the 1898 Dutch manual was the second. The third was Theodore Schellenberg's Modern Archives: Principles and Techniques. Published in the United States in 1956, Modern Archives promoted concepts and practices significantly different to those assumed or promoted in the earlier foundational works. In 1965 The Management of Archives, also by Schellenberg, was published. In this book Schellenberg was particularly attentive to the matter of explaining the similarities and differences between archives and libraries, and between archival records and personal and private manuscripts. Given the relevance of this book to my research, I discuss it along with the three works already mentioned.

These manuals, though different in many ways, have a number of common features which have attracted the attention of late twentieth and early twenty-first century archival science theorists. One, much commented on in the 1990s, was the extent to which physicality and a preoccupation with matters of custodianship had shaped traditional concepts and practices (Bearman, 1994; Brothman, 1991; Cook, 1994; Harris, 1997; McKemmish, 1994; Upward \& McKemmish, 1994). One consequence of this was a physical object privileging notion of record (McKemmish, 1994) which pre-supposed unpublished textual documents to be the norm and, therefore, privileged objects of that type (Sassoon, 2007a; Schwartz, 2002; Yeo, 2008, p. 122). Another was a tendency for archivists to focus their attention on those records that had entered, or were on the cusp of entering, the custody of an archives repository. This tendency became the norm in the domain's English language discourse after differentiation between "records" and 
"archives" [i.e., archival records] was embedded in a life-cycle model developed by archivists in the United States (Dingwall, 2010, p. 140-144) and fore-grounded in Schellenberg's Modern Archives (Schellenberg, 1956, pp. 15-16).

Other characteristics of the traditional discourse to which critical theorists were later to draw attention were the extent to which it made objectivist claims about both records and the practices of archivists (Brothman, 1991; Cook, 1994, 1997, 2001a; Harris, 1997; Kaplan, 2002; Ketelaar, 2001; Schwartz, 2000); the fact that many of its key concepts were ambiguous, derived through circular reasoning, or by conflating multiple concepts (Hurley, 2005b, pp. 61-62, 65); and the fact that it attached central importance to the record-as-object rather than to the processes shaping the "becoming" (McKemmish, 1994, p. 200) of the record and determining in what contexts and how well it would later be able to serve as evidence.

A feature of the traditional discourse that has attracted less attention is the fact that museums, libraries, and historians were repeatedly cast as 'others'. This theme was so persistent that a concept of the other - particularly, the library other - co-emerged with the domain's talk about itself and the objects it claimed for itself. The "fuzzy" notion of record predominant amongst archivists today (Yeo, 2008) has its origins in this discourse of othering. So too does today's widespread belief that records fall into two distinct categories: the organisational/official and the personal. The origins of that belief do not rest in essential difference, but in discourse that served the purpose of othering libraries:

The literature on the relationship between archives [i.e., official records] and manuscripts [i.e., personal and private documents] might remind some military observers of the tactical considerations that govern the gradual establishment of control over additional sectors of occupied territory. Early archivists, in effect, assumed that manuscripts were hopelessly lost to the librarians, and as part of their battle to prevent the same thing from happening to archives they emphasized the differences between historical manuscripts and archives. (Brubaker, 1966, p. 507)

It would be a mistake to think of the traditional discourse as having been either static or cohered at any single point in time. Rather, the discourse I refer to as traditional should 
be understood as a body of linguistic and conceptual tendencies of varying epistemic value that came together in varying combinations over time in multiple discursive contexts and for multiple reasons. Along the way, there was a good deal of linguistic continuity coupled with conceptual slippage. Careful deliberation on epistemic matters played a part in the discourse's becoming, but so too did competing concerns, perceptual biases, inconsistencies, fallacious reasoning, and epistemic claims of a rhetorical but unjustifiable character. This gave rise to vagueness and ambiguity, to circular reasoning and to difficult questions, implied but not asked in the discourse such as, 'Does a relationship with activity make a book a record?' and, 'If newspapers are not records because newspapers tend not to be impartial evidence, how can it be said that records are impartial evidence, when a newspaper can be a record if kept with the records of the newspaper's publisher?'

Before addressing these questions directly, I look at the nature of the discourse that prompted me to ask them.

\subsubsection{Conceptualising records - physical objects and 'format-neutrality'}

In an overview of archives domain discourse, Eastwood (2010) said that "thinking about the nature of archives [records, in the terminology of this thesis] has been at the heart of the orientation of the archival body of knowledge" (p. 3). He also observed that the domain's discourse "assumes [that when we are speaking about records] we are speaking about a determined body of material" (p. 4). Based on the findings of my discourse analysis, I agree with him on both points; though I would add that neither statement is true for continuum theory.

Despite all this talk about records, a definition acceptable to all archivists has been elusive (Yeo, 2007, p. 315). The problem as Yeo (2008) saw it was that, in the minds of most archivists today, the category of record is fuzzily imagined in terms of "prototypes" and "boundary objects". Records are conceptualized in relation to a suite of prototypical characteristics, which in varying combinations are seen to afford recordness. Those things with relatively few prototypical characteristics are viewed as "boundary objects". Further complicating the situation is the fact that different archivists, and different groups of 
archivists, have different mental prototypes and, therefore, different notions of record characteristics (pp. 122-126).

To understand how this situation came about, one needs to look at the traditional discourse and the circumstances in which the domain's fuzzy concept of record emerged.

As I said earlier, an object privileging concept of record was pervasive in the traditional discourse. What I mean by this is that actual physical objects, bonded and bounded by their physicality, were said to be records or to not be records. This foundational assumption sat somewhat uneasily in relation to formal definitions that invariably pointed to a certain type of provenance (discussed in section 3.2.3) as also being a factor in determining whether a physical object was or was not a record. Up to a point - or, rather, up to varying points - the tenor of traditional definitions was to maintain that provenance trumped format, with the result that over time definitions of records and discussions about the nature of records came to claim format-neutrality, encouraging archivists to assume their thinking and their practices were also format-neutral. ${ }^{35}$ However, the situation has never been quite that simple. Rather, 'format-neutrality' has co-existed, and continues to co-exist, with format privileging and format blindness (Sassoon, 2007a; Schwartz, 2002).

The concept of format-neutrality rested on the notion that documents in all formats could be records. That word document, however, is not as simple as it might appear. This is because it was used in a number of ways in the traditional discourse. Muller et al. (1940) used it much as it is commonly used today; i.e., broadly and vaguely, but in a way that assumed text and commonly used text-bearing materials (notably paper) to be at the heart of the concept. One knows this, not because they said so, but because they allowed for the possibility of books being records, but were explicit in excluding all "antiques and similar objects" such as would normally be in museums (pp. 14-15). Conceptually, formatneutrality for them, therefore, was neutrality only with regard to a sub-set of all possible forms. Further complicating the situation was the fact that, though in theory, they were format-neutral with regard to documents, they were not in practice. This is because they

\footnotetext{
${ }^{35}$ The word format has been widely used in the archives domain in ways that conflate notions of media type and notions of genre. I use it in the same sense here.
} 
saw no point in keeping books in an archive, not even those which were technically records by virtue of provenance and provenance-determined documentary relationships. The library, they said, was the "natural depository" for the book (p. 16).

Jenkinson's use of the word document differed from Muller et al.'s in that he extended its meaning to include "material evidences annexed" to documents in record aggregations (Jenkinson, 1922, pp. 5-7). This meant things not normally thought of as documents became 'honorary' documents by virtue of a certain type of provenance and by virtue of association with normal types of documents with the same provenance. In effect, such "material evidences" acquired document and record status simultaneously, becoming documents because they were records, rather than records because they were documents. Jenkinson's stance in relation to publications was conceptually the same as Muller et al.'s towards books. In general, publications were excluded from the category of record, but they could become records by virtue of provenance and provenancedetermined documentary relationships (Jenkinson, 1922, p. 8). Whether Jenkinson believed books with contextualising relationships of this type should be kept in archives or sent to libraries is not discussed in his manual. Keeping them in archives would be consistent with the logic of the paradigm he developed, but one cannot assume that paradigm was the only one shaping his thinking. The possibility that an older paradigm might also have come into play can be read into his reflections on differing views in continental Europe about what the types of things that could be records. In those reflections, he noted the director of the French National Archives, whose view was particularly inclusive, excluded from the category of record only historical, scientific, and literary works ("les oeuvres"), all of which were taken to belong in libraries (Jenkinson, 1922, p. 2).

What can be seen in both these approaches to the conceptualisation of documents in relation to the concept of record is format privileging. Depending on the paradigm at work, things that were not documentary norms were either completely excluded from the conceptual category of record or included but only by virtue of both association with 'normal' documents and a certain type of provenance which the norms and the anomaly 
shared. ${ }^{36}$ Complicating the matter further was the fact that, at least in Muller et al.'s paradigm, actual physical things that were conceptually included could, for practical purposes, be excluded, meaning that the category of record as it materialised in archives repositories and inventories did not correspond precisely with the category of record as it was conceptualised.

\subsubsection{Conceptualising provenance}

As I said above, provenance played a significant part in the conceptualisation of records. Provenance is complex. If conceptualised in relation to my research paradigm, it would entail notions of person, place, inscription technologies, behavioural norms, linguistic heritage, and much more. In the archives domain's traditional discourse, however, only one aspect of provenance was treated as significant. This view of provenance - or concept of provenance - conflated two entity types. One was a type of activity: administrative activity. The other was the human entity (e.g., an organisation, a family, an individual) performing that activity and retaining custody of the records created and received in the course of the 'performance'. Because the retention of custody is another type of activity, the conflation is complexified because, in effect, it bound together two 'high-level' types of activity and one human entity engaged in the performance of those activities. If two other things are taken into account, the conflation is revealed to be more complex still. One of those things is the fact that I have used the word administrative as a 'catch-all' for activities ranging from the exercise of executive, regulatory, and juridical powers through to clerical and other support services. The other is the fact that the notion of custodianship at work in the concept encompasses notions of receipt and creation. These too are forms of activity, each quite distinct from the other. That distinction, however, was made immaterial by the over-riding importance attached to custodianship. Of course, the concept of creation is itself a conflation of many more specific types of 'creation' activity. Needless to say, those distinctions were also rendered immaterial.

\subsubsection{Provenance, record, aggregation, and description}

This conflated notion of provenance has been present in the traditional discourse's best known definitions of - and discussions about - the entity type that was regarded as the primary focus for description. This entity type was an aggregation known by various

\footnotetext{
${ }^{36}$ Schellenberg (1956) used the word documents in his definition of records, but did not discuss its meaning.
} 
names including the fonds d'archives (French), the archief (Dutch), and the archive group (Jenkinson). The term most commonly used today is the fonds, so, for the sake of consistency, I will use that term whenever I refer to aggregations of this type.

Muller et al. (1940) described the fonds (archief, in the original Dutch version) as:

the whole of the written documents, drawings and printed matter, officially received or produced by an administrative body or one of its officials, in so far as these documents were intended to remain in the custody of that body or that official. (Muller, et al., 1940, p. 13)

Because the fonds is defined by provenance, in rare cases it was not an aggregation at all, but a single surviving document (Muller, et al., 1940, p. 14). The fact that a fonds could be a single document had a flow-on effect because the custodianship and use aspects of the fonds singleton's provenance were assigned more importance than authorship. This meant that the provenance of a received letter which happened to be the only document in a fonds would be attributed to the recipient, not the writer.

The same notion of provenance (albeit expressed differently) is present in Jenkinson's definition of documents that "may be said to belong to the class of Archives". Such a document, he said,

is one which was drawn up or used in the course of an administrative or executive transaction (whether public or private) of which itself formed a part; and subsequently preserved in their own custody for their own information by the person or persons responsible for that transaction and their legitimate successors [emphasis in original]. (Jenkinson, 1922, p. 11)

That notion of provenance appears again in Schellenberg's definition of records:

All books, papers, maps, photographs, or other documentary materials, regardless of physical form or characteristics, made or received by any public or private institution in pursuance of its legal obligations or in connection with the transaction of its proper business and preserved or appropriate for preservation by that institution or its legitimate successor as evidence of its functions, policies, 
decisions, procedures, operations, or other activities or because of the informational value of the data contained therein. (Schellenberg, 1956, p. 16)

A point of interest in Jenkinson's and Schellenberg's definitions is that they differ from Muller et al.'s in that they are focused on the objects within the fonds, rather than on the fonds itself. What both Jenkinson (1922) and Schellenberg (1956) did was use a concept of provenance that is highly meaningful in relation to a fonds as though it is equally significant - indeed has definitional significance - for the 'documents' (I use that term broadly, as Jenkinson did) comprising the fonds. In effect, that provenancial relationship (rather than any other type of provenancial relationship) constitutes the documents as records. If one reasons logically from these definitions, the conclusion one reaches is that records were as much conceptual as physical - as physical entities, they were only partially seen.

Ironically, the low level entities (the documents and 'honorary' documents) that Jenkinson (1922) and Schellenberg (1956) treated as being of primary importance in definitions of records were close to invisible in the inventories archivists created (often the only finding aid provided for researchers). This is because fonds-type aggregations were the primary focus for description and because description was hierarchical - it began with the largest entity (the fonds), then worked down through layers of aggregations (e.g., sub-fonds, series, sub-series), but rarely described the lowest level items at all (Jenkinson, 1922, p. 101; Schellenberg, 1956, p. 206).

\subsubsection{Conceptual absolutes and conceptual bundling}

It is interesting that the definitions of primary importance in the manuals of the archives domain came to focus on an entity that was almost invisible in praxis and on a provenancial relationship more significant for the aggregation in which that entity was seen than for the entity itself. Inevitably, much of the essence, including the provenance, of these low-level items went unacknowledged.

This turning of a blind eye resulted from, and perpetuated, a tendency to think in terms of closed categories and conceptual absolutes. Many concepts besides those of record and provenance were affected. Others of central importance were the fonds, the creator, original order, and authenticity. Similarly, the practice of conflating a mix of concepts 
within a single concept was not restricted to conceptualisation of records and provenance alone. It was also present in the other concepts I have identified as being of central importance (Brothman, 1991; Hurley, 1995b, Hurley, 2005a; MacNeil, 2008, 2009; Yeo, $2009,2012 a)$. The traditional concept of creator, for example, bundled together notions of aggregation and administrative activity; or, if one looks at it a little differently, it bundled together notions of receiving, authoring, using, and keeping, with all of these activities taking place in the course of the creator performing its administrative duties, but none of them being necessary to the concept of creator other than that of keeping, which was not in itself usually regarded as adequate reason for referring to a custodian as the creator. It also, of course, bundled the human entity performing the 'creating' activity in with the activity itself, but only in so far as that human entity was engaged in the privileged activity. This bundling was not particularly problematic when the creator was an organisation; however, it was a major conceptual limitation when the 'creator' was an individual or a family.

\subsubsection{The library as other}

All these conceptual tendencies within the traditional discourse seem to have arisen from a confused theory-praxis relationship. My reading left me with no sense of theory having pre-existed practice or practice having pre-existed theory. Over-all, my impression was that, throughout the period I studied, a mixture of epistemic concerns and competing real world concerns were at work in driving the co-evolution of theory and practice. Those competing concerns could be as minor as the problem of not being able to file one document in more than one place (Jenkinson, 1922, pp. 96-97; Muller et al., 1940, p. 157), as mundane as a mismatch between the quantity of records to be managed and the resources available (Jenkinson, 1922, pp. 39-41; Schellenberg, 1956, pp. 8, 206), and as political as shaping an archive to legitimize the principles of a governing elite (Fritzsche, 2005; Moore, 2008, p. 75).

Significant amongst those things that shaped the domain's traditional thinking was the need for archival institutions and archivists to carve out a space in relation to museums and their curators and, more particularly, in relation to libraries and librarians. The dynamics at work were captured in the passage from Brubaker (1966) I quoted near the end of section 3.2.1. Moore's description of a protracted tussle over the custody of a 
cabinet of genealogical manuscripts in mid-nineteenth century France (Moore, 2005, pp. 212-233) provides deeper insight. The cabinet "contained both documents produced by the royal government and documents produced by individual nobles and families" ( $p$. 215). In 1858 the Mérimée Commission, which had been set up to evaluate the collections and services of the Imperial Library with a view to bringing together in one place all objects "of the same nature, [and] serving the same [kinds of] studies" (p. 210), recommended the manuscripts be transferred to the Imperial Archives. The minister responsible took no action. In late 1860 , following an administrative change that saw control of the Imperial Library move from the Ministry of Public Instruction to the Ministry of State, a second commission (the Vaillant Commission) was set up, and it made the same recommendation. The upshot was an acrimonious dispute that went on until mid-1863 when a decision was finally made to leave the manuscripts in the Imperial Library.

Moore (2005) said, that in arguing the case for transfer of the manuscripts, Léon De Laborde, Director of the Imperial Archives, constantly shifted the debate into the realm "of abstract definitions" as he pressed for a definitive answer to the question of "if there were in the past, [and] if there ought to be in the future, archives and libraries, archivists and librarians" (p. 212). In a series of attacks and counter-attacks, a set of issues were raised. Firstly there was the question of the purposes libraries and archives served; and tangled up with that, the question of allocating materials in relation to those purposes. The Archive positioned itself as a centre for historical research and as the proper repository for all documents kept "in the public interest" (p. 215) that were "true and original remnants of the past" (p. 216). It conceded to the Library only secondary sources - "works about the past" (p. 216). The Library countered by arguing the Archive was in service to government administration rather than historical research. It, therefore, conceded to the Archive only recent administrative documents, arguing all documents it held that were considered to be historical should be transferred to the Library (p. 226).

In addition to attempts to resolve the issue with reference to the purposes of the institutions or the nature of document types, there was debate regarding the contextual relationships between documents. This was interesting because fighting in the Library's camp were Natalis de Wailly, best known to archivists as the "originator" of the 1841 
circular that "is the birth certificate of the idea of the fonds d'archives" (Duchein, 1983, p. 66) and Léon Lacabane, a highly respected archivist educated in the École des Chartes and the school's director at the time the Mérimée Commission reported its findings (Moore, 2005 , p. 213). ${ }^{37}$

The Archives argued the manuscripts should be handed over so they could be replaced in their "real fonds" (Moore, 2005, p. 219) even though only a portion of the manuscripts related to the Archives existing holdings. The Library employed the same imagery in an argument which claimed its manuscripts collection to be "an indivisible set of fonds" ( $p$. 225). Both sides employed the metaphor of the organic, likening their fonds to a living human body which it would be "barbaric" to "dismember" (pp. 220, 225). They also employed imagery relating to city planning. Removing the cabinet of manuscripts, the Library Director said, would be like "opening a street through the middle of the chancel of Notre Dame in order to maintain a straight line" (Taschereau, as cited in Moore, 2005, p. 224). Repeatedly, Laborde's claim that there were documents in the cabinet which should be restored to their real fonds was countered by the Library's claim "that the various components of the Department of Manuscripts (including the Genealogical Cabinet) were interrelated and complementary" (p. 225). Lacabane, who the Archives "asked to acquire" along with "the collection in his charge" (p. 213), put his weight behind this argument by firmly stating "he could only conduct his work within the context of the Library's collections" (p. 213).

What was at stake in this argument? Certainly, there were the documents themselves; but identity was too - the identity of the Archives expressed through the claims it made about its purposes and the identity of archivists as a distinct professional group. That the identity of self and the other was significant during this dispute is most transparent in Laborde's scathing comments about librarians - the "phalanx of celebrities that occupies the first rank in the world of letters" (p. 221), despite doing "little more than fetch books" (p. 222). Archivists, on the other hand, were those who had "done brilliantly on difficult

\footnotetext{
${ }^{37}$ According to Duranti (1993) fonds-focused description was prescribed in legislation in the Grand Duchy of Tuscany in 1822 and in the Papal State in 1839 (p. 50), so did not originate in France in 1841 as Duchein (1983) and others (Horsman, 1999, p. 6; Schellenberg, 1956, p.171) have claimed.
} 
examinations" and whose intelligence was fortified, views extended, and judgment honed by everything in an archive (Laborde, as cited in Moore, 2005, p. 222).

As a twenty-first century reader with a head full of records continuum concepts, I am tempted to think that opposing views of provenance, meaningful documentary relationships, and relevant ambient contexts were also at stake. The reason the Archives wanted Lacabane along with the manuscripts was because he was the 'finding aid', the one who best knew the content of the cabinet and, therefore, the one best positioned to know which documents should be returned to which fonds and also the one best positioned to assist historians in the task of locating and interpreting documents. The reason Lacabane argued against the transfer was because he saw the documents in the cabinet as nodes in a much larger network of meaningful relationships. I am speculating, but only to make the point that what people 'know' is often too complex for them to articulate. I, for example, would probably never have seen potential for interpreting the debate between the Imperial Archives and the Imperial Library in this way, let alone been able to articulate it, if not for the conceptual and linguistic tools developed by Chris Hurley (discussed in section 3.3.4).

Interestingly, Moore (2005) said the Imperial Archives was not practising fonds-focused description at the time of this dispute, but began to soon after (p. 219). Possibly Laborde, who was appointed as Director of the Archive in 1857, was already planning the move to fonds-focused description at the time of the dispute or perhaps the idea gelled in the course of the dispute. Either way, the idea spread and became so entrenched in the domain that the Australian archivist Peter Scott, who, during the 1960s and 1970s, had worked with colleagues at the Commonwealth Archives of Australia to develop a more flexible (and more realistically provenance-oriented) method, was severely criticized by the French archivist Michel Duchein - and implicitly by the editors of the editors of Archivaria (the journal of the Association of Canadian Archivists), who had commissioned translation of Duchein's article previously published in French. Duchein (1983) lent authority to the domain's traditions by stating unequivocally that "respect des fonds" was the "basic principle of archival science", not least of all (my words, not his) because its practice "most clearly distinguished [the archivist] from the librarian on the one hand and from the professional researcher or documentalist on the other" (Duchein, 1983, p. 64). I 
say "not least of all" because Duchein made these two assertions in the first two sentences of his abstract. Professional identity, it seems, still called for differentiation from other professional groups interested in the same types of material; and respect des fonds (or fonds-focused description), it would seem, has persisted for as long as it has, at least in part, because it is one of the foundations on which the domain's sense of a separate professional identity was built.

It was also, as I will argue in the remaining part of this section, a practical way of achieving moderate epistemic adequacy in archives description when records were physical and paper was the medium for constructing finding aids - the inventory provided the overview of the fonds and its documentary structure; the knowledgeable archivist (and the materials themselves, as I will argue throughout the thesis) cast light on finer grained relationships within the fonds and between fonds.

To me (an archivist who entered the profession 120 years after this French dispute), Laborde's discourse of differentiation was disturbingly familiar. The trope of the organic, the artificial-real (more commonly, artificial-organic) dichotomy, and the assumption that books are intrinsically different to records have been passed down through generations of archivists. All are at work, for example, in an article written by Jimerson (2002) which explains to librarians the nature of archival material and practices. Also, at work in Jimerson's article is the notion that fonds-focused description - referred to by Jimerson as "the principle of provenance", the term that became widely established in the domain's English language literature during the twentieth century - is "the basis of archival theory and practice" (p. 22). That these notions have been so persistent is not surprising. Whenever we are required to succinctly explain the essence of a body of thought, the words and phrases repeated over and over in pre-existing explanations tend to be the first to come to mind and the easiest to employ (so long as they fit with our beliefs). That a discourse of differentiation should have persisted is not surprising also because debates about the nature and allocation of recorded information and objects seen to be informing (hereafter informing objects), and about their description and meaningful contextualisation, seem to be unending (Brubaker, 1966; Oliver, 2010; Robinson, 2014; 
Rolan, 2015, p. 54; Sassoon, 2007b; Vitali, 2008). ${ }^{38}$ Wellington (2013) pointed out that a converged culture is likely to be a culture in which one paradigm dominates at the expense of others (pp. 298-299). Given that the epistemic adequacy of the dominant paradigms of other information cultures are also under scrutiny, that behavioural tendency is concerning when the quality of knowledge is at stake. ${ }^{39}$

In staking their claim for a distinct space and identity, archivists have gravitated between three matters of concern. There was, of course, the matter of distinguishing between materials that could be claimed to belong in archives and materials that archivists conceded belonged in libraries or museums. There were also epistemic concerns and the defence of practices archivists believed to be necessary if the meaning of a record was to be understood in relation to its prior use. In addition, there were very practical matters, in particular the growing mismatch between the volume of records to be managed and available resources. The weight given to each of these concerns by the domain's three foundational theorists varied. Muller et al. (1940) privileged epistemic concerns, but compromised them somewhat for the sake of efficient practice. Jenkinson (1922) was much more attentive to epistemic matters, so much so that his book can be read as an attempt to develop a holistic and logically coherent objectivity-oriented and objectivityenabling body of thought and practice. Schellenberg $(1956,1965)$ differed in that he significantly sacrificed the epistemic to the practical; and, if he recognised he was doing so, he did not acknowledge it.

\footnotetext{
${ }^{38}$ The term recorded information is a commonly used 'catch-all' in continuum discourse. I read it as being intended to include objects that carry neither text, nor image, nor other deliberately encoded information, but which have nevertheless been seen to provide information (i.e., to provide grounds for making some knowledge statement). Unfortunately, the term recorded information, at least for me, conjures up an image of dematerialised information. It comes across as excluding objects that are seen to be informing and as blind to the fact that the material carriers of recorded information may themselves be informing, perhaps providing different types of information to the 'text' they carry. Therefore, I use the term informing objects in addition to the continuum term recorded information. My intention is not to imply a limitation in fundamental continuum theory, but to make explicit a part of that theory that is often obscured in continuum discourse, but which is important within the context of this thesis.

${ }^{39}$ See Manoff (2006) and Day (2008) for critique of the library domain's work-privileging paradigm, Doerr (2003) for discussion of the difficulty systems engineers experienced in establishing "the logic of cultural concepts" during meetings leading to the development of the CIDOC CRM (the Conceptual Reference Model created by the International Council for Museums' International Committee for Documentation), and Day (2004) for his account of how contemporary "information age" discourse has erased pre-digital information discourses or positioned them as mere pre-cursors in a digitally-focused story of continuous progress.
} 
The distinction Muller et al. (1940) and Jenkinson (1922) made between records and aggregations of manuscript material in libraries rested in part on a distinction between administrative (a catch-all term as defined in section 3.2.3) activity and nonadministrative activity, and in part on differing processes of accumulation. Muller et al. (1940) gave the latter as a reason for excluding "so-called family archives" from the purview of archivists. "So-called family archives, being typically "a conglomeration of papers and documents ... gathered together in the strangest manner", lacked the "organic bond" of a fonds (p. 20). Jenkinson (1922) went even further in linking the concept of record to matters of process. He 'imagined' the record as being defined by the circumstances of its creation and its "organic bond" with the documents with which it was aggregated, and also by proof of "an unblemished line of responsible custodians [emphasis in original]" (p. 11), both before and after its receipt in the archive. For Jenkinson "responsible" custodianship in the archive meant the observation of certain practices (briefly described in the paragraph that follows). There were two conceptual spin-offs from this. One, which was implicit, was that the quality of being a record was something that could be lost. The other, explicitly stated, was that libraries were, in effect, archives, and librarians were, in effect, archivists, so long as they followed the practices Jenkinson promoted for the receipt and management of archival records (p. 41). Jenkinson made this explicit because he recognised established archives did not have the resources necessary to manage the volume of records created in the course of, and subsequent to, the First World War.

The practices Muller et al. (1940) and Jenkinson (1922) saw as being of fundamental epistemic importance were, in essence, as follows. Firstly, archivists were not to engage in processes of selection. Rather, they should receive (and keep) in their entirety those aggregations that were passed on to them from the agencies they served (Jenkinson, 1922, p. 41; Muller, et al, 1940, pp. 13-14). In addition, archivists were counselled to not mix the descriptions of fonds relating to different agencies and also to keep documents within fonds in the order given to them by the last agency to use them. This concept of 'original order' is easily articulated, but often very difficult to put into practice. Jenkinson's views on how it should be interpreted differed from those of Muller et al. Nevertheless, there was fundamental agreement that the order given to documents 
should be an order that was real in relation to the provenancial context of accumulation, rather than an order that blurred that context. Both works argued the case for retaining a self-evident systematic order; however, their authors had differing views on how 'original order' should be practised when that was not the case.

Behind Muller et al.'s and Jenkinson's advocacy for these practices was awareness that when documents are used by historians, it is not only the individual documents that matter, but also the relationships between documents (Jenkinson, 1922, p. 81-82; Muller, et al., 1940, pp. 81, 104). Removal (or non-acceptance) of documents and re-arrangement both change the nature of the whole. In The Evidential Foundations of Probabilistic Reasoning Schum (1994) said, "What we do not consider can hurt us" (p. 2). What he meant was that the completeness of the evidential base from which we reason matters because, in the absence of things relevant to our enquiry that would alter our understanding of the relevance and meaning of the evidence we have at hand, we all too easily form incorrect conclusions. In the late nineteenth century and early twentieth century Muller, Feith, and Fruin and Jenkinson already seemed to know this. They also seemed to know that completeness is relative to situated moments (and extended situated 'moments'); it is not an absolute (at least, it is not an achievable absolute). By advocating the receipt of entire aggregations and the retention of their boundaries and internal structures they were positioning archivists as ideally being neutral custodians of an evidential base for future research.

That achieving this neutrality in the practice of description was hugely challenging, is also something they recognised. One knows this because they discussed the problems of multiple sequential provenance (Jenkinson, 1922, pp. 85-87; Muller, et al., 1940, p. 157); multiple orders, and discrepancies between the orders imposed by filing systems and the 'accidental' orders that left traces of use (Jenkinson, 1922, pp. 96-97; Muller, et al., 1940, pp. 60-67); situations where there was only partial evidence of a past systematic order (Jenkinson, 1922, pp. 87-92; Muller, et al., 1940, pp. 60-67); and whether to return or not return to an earlier fonds those documents which, for varying reasons, had been removed from the custody of the agencies the archives served (Jenkinson, 1922, pp. 9-11; Muller, et al., 1940, pp. 98-99). They addressed these problems in the best ways they could devise, given their circumstances and their knowledge paradigms. They did not give 
precisely the same advice - Jenkinson (1922) paid more attention to preserving empirical evidence than did Muller et al. (1940). Despite variation and despite compromises, however, the practices promoted in both manuals tended towards neutrality, a point usually not acknowledged in 'postmodern' critique (e.g., Cook, 1997).

An objectivity-subjectivity dichotomy played a part in this early othering discourse. It was a minor, but nevertheless noticeable, theme in the Dutch manual where it was applied to the practices whereby aggregations of documents were formed - Muller et al. (1940) argued that, if archivists avoided "subjective" practices such as subject indexing (p. 152) or creating "conglomerations" such as "so-called family archives" (p. 20), their practice would be "objective" (p. 152) or "scientific" (p. 42), the resultant inventories would be "scientific and logical" (p. 152), and the aggregations described in those inventories would be "organic". The words scientific, logical, and organic can, therefore, be read as embedded with objectivist connotations. The effect of these statements was to other libraries on epistemological grounds as well as those previously discussed.

Whereas Muller et al.'s manual had distinguished between objective and subjective practices and had carried the notion of objectivity through to the (organic) aggregations formed from archives practices, Jenkinson (1922) focused on the documents themselves. In order to position records as impartial and authentic evidence (pp. 11-15), he eliminated from the category of record, but not from the category of evidence, documents carrying content that was unlikely to be impartial because it was comprised of "statements or expressions of opinion by persons who may, or may not, have been capable reasoners, in a position to know the facts, and unprejudiced" (p. 4), namely "reports of speeches..., the leaders in The Times, the official communiqués set out in the Press, the memoirs of the German Chancellor" (p. 4) - and documents "drawn up in the interest or for the information of Posterity [sic]" (p. 11). He also eliminated documents that had strayed from "responsible" custody on the grounds that they could be inauthentic (p. 15).

Jenkinson has often been cited in contemporary critical literature as the archetype of empirical positivism, probably because there are certain passages in his text that, standing alone or read superficially, give that impression. Cook (1997), for example, argued that Jenkinson's "notions that 'Truth' was revealed through archival documents or 
that the archivist was an unbiased 'keeper' of records and a 'selfless devotee of Truth' ... was simply mirroring the empirical Positivism common to the historiography with which he was deeply familiar and schooled" (p. 25). My critical realist reading of Jenkinson (1922), however, suggests a different interpretation may be warranted. My argument rests on three points. The first is that Jenkinson's differentiation of first-hand, impartial, and authentic evidence, on the one hand, and "supplementary" evidence (p. 4), on the other, was a form of probabilistic risk assessment, rather than a firm statement that one category was always impartial and authentic and the other always subjective. Jenkinson acknowledged that forgeries did sometimes find their way into archives (pp. 14-15) and that the content of textual records was not always impartial (p. 8). Also, he made no statement about the epistemic value of "supplementary" evidence, but observed that such judgments are best left to the historians who use that material (p. 4). It is also worth noting that the words objectivity and objective were used only once in his 243 page text, and that use was in relation to a planned war history (p. 9); the words subjectivity and subjective were not used at all; and the word truth was used only five times, and only one of those uses was in a general statement that records tell the truth (p. 12). What Jenkinson appears to have meant by that statement is discussed later in this section.

The second point is that Jenkinson's 1922 manual should be read as a statement of the ideal, rather more than a description of the actual. Jenkinson, himself, did not make that distinction. Therefore, his text teeters between the two, a not uncommon shortcoming in a larger discourse that has often failed to distinguish clearly between the ideal (a highlevel abstract concept or standard for practice) and the actual (diverse physical objects and physically expressed practices). It is only recently that archival science theorists have begun to draw attention to the fact that there is a difference between anticipatory standards towards which practice can aspire and reactive standards that mirror a common understanding of existing practice and existing systems (Oliver, 2014; Rolan, 2015, p. 53). That Jenkinson (1922) knew archivists often fell short of the standard he advocated is evidenced by his awareness of things archivists did that destroyed "Archive evidence" (i.e., altered the empirical character of documents and aggregations of documents as it had manifested prior to archival intervention). The archivist, he said, "has every responsibility, that no genuine evidence be lost nor false one manufactured" ( $p$. 
68). ${ }^{40}$ The importance he attached to the fixity of the empirical is seen most clearly in his concern that archivists should make their interventions transparent (pp. 70-73). Ironically, this is something 'postmodern' theorists (e.g., Cook, 2001a, 2001b; Duff \& Harris, 2002; Kaplan, 2002) urged archivists to do in freeing themselves from the inadequate practices of their (purportedly) positivist past.

The importance of fixing the empirical can be seen also in Jenkinson's instruction that documents received in aggregations with no discernible systematic order should be sequentially numbered prior to any re-arrangement the archivist might think meaningful. Jenkinson (1922) clearly believed the receipt order was the authentic evidence and that future users should be able to see that order (pp. 96-97). The archivist who chose to rearrange without taking this preliminary precaution was, Jenkinson said, "taking on a very grave responsibility" (p. 97). It was only when empirical evidence of an earlier order was present that preserving the acquisition order was not required (pp. 69-73). Attention to fixing the empirical was also evident in the extensive cross-referencing Jenkinson expected whenever the empirical evidence available to the archivist showed that assigning a document or set of documents to a single fonds or a single series would distort understanding of a more complex variety of documentary or provenancial relationships that had actually existed in the past (p. 86). The importance of the empirical, and of being able to return time and time again to something as it previously was, is critically important for knowledge building, a point I argue and demonstrate throughout the thesis.

My third point relates to the notion of truth as revealed by records. What did Jenkinson (1922) mean when he said "provided the student understands their [records'] administrative significance, they cannot tell him anything but the truth" (p. 12)? If one takes the critical realist approach of focusing on the ontological ramifications of Jenkinson's body of theory, one gains useful insight into the nature of the truth Jenkinson perceived records to reveal. This analytical method also brings to attention a subtle perceptual switch that was at work in archivists' perceptions of records as being different to books.

\footnotetext{
${ }^{40}$ The fact that Muller, et al.'s manual was also a statement of ideal practice, rather than an indicator of actual practice, has been explicitly discussed by Horsman, Ketelaar, and Thomassen (2003, pp. xx1v-xxv).
} 
A good place to begin is with a transcendental question of the type fundamental to critical realism: How can it be possible in the real world for a copy of The Times to be seen as having questionable epistemic value, but a copy of the same issue "filed in the Foreign Office" or "in the Office of the Newspaper itself" to be seen as authentic and impartial evidence (Jenkinson, 1922, pp. 5-8)? It is ridiculous to suggest the assertions made in the text change so that those which were biased, only half the truth, or completely wrong suddenly become impartial and correct representations of the real events and people about which they speak. It is equally ridiculous to think Jenkinson believed such a thing. Rather, the explanation must be that the person who made that seemingly contradictory claim switched his focus from the transitive dimension characteristics of the newspaper (the aboutness of its text) to its intransitive dimension characteristics (its state of being; and, for traditional archivists, its state of being within an administrative context of being).

What I am suggesting is that Jenkinson (1922) was half aware of, and attempting to articulate the notion of, a kind of truth or impartiality which rests in things regardless of the validity of any assertions they make. It is the kind of impartiality that allows texts to be read against the grain and aspects of a document's physicality to be seen as traces of past presences and past uses.

Implicit differentiation between the critical realist transitive and intransitive dimensions is also present in Jenkinson's statement:

The historian ... may examine, interpret, analyse, and arrange them [records] for the purposes of his treatise: they themselves state no opinion, voice no conjecture; they are simply written memorials ... of events which actually occurred and of which they themselves formed a part [emphasis added]. (Jenkinson, 1922, p. 11)

It is also at work in Jenkinson's definition of records which, though it used the word transaction, was phrased in such a way that it is clear the quality of being a record rests in a document's transactionality, not in assertions its text makes about transactions. "A document which may be said to belong to the class of Archives", Jenkinson (1922) said, "is one which was drawn up or used in the course of an administrative or executive transaction (whether public or private) of which itself formed a part [emphasis added]" ( $p$. 
11). Clearly, a document was not a record because its text said something about a transaction, but because it was itself a part of the transaction. Jenkinson said as much (pp. 4-5). "Impartiality", he went on to say, "is a gift which results from the first part of our definition of Archives" (p. 12). ${ }^{41}$ Logically, documents such as minutes of meetings, registers of inwards correspondence, and ledgers of accounts payable were records by virtue of their relationship with an administrative recordkeeping activity and administrative uses of those records, rather than by virtue of their secondary relationships with the transactions recorded in their texts. What is important in Jenkinson's definition, if one is looking at it in relation to his objectivist orientation, is not so much the word transaction, but the phrase "of which itself forms a part". Words like activity and use, therefore, need to be understood as fitting under Jenkinson's 'transactional umbrella'.

Before moving on, there is one more question worth asking: Can one take it as a given that, in 1922, Jenkinson thought documents that were not records did not also have this kind of truth? I think one cannot make that assumption, because (as I previously said) Jenkinson left assessments of the value of "supplementary evidence" to historians. What one can assume is that Jenkinson (1922) did not address the question himself because "supplementary evidence" (i.e., documents that were not records) was outside his purview.

Working within a limiting paradigm and with inadequate pre-existing concepts and language at his command, Jenkinson (1922) fell short of expressing the third way vision he seemed to be edging towards. Nevertheless, his manual's definition of records, its discussion of the characteristics of documents that made them records, and its advocacy of non-interventionist practices all suggest he was skirting around the idea that being is one thing and aboutness another - and that objectivity is an attribute of being and a stance one can take, but it is not necessarily to be found in the assertions made in texts, nor is it the sure outcome of an archivist's or a historian's act of interpretation.

\footnotetext{
${ }^{41}$ The second part of the definition was concerned with preservation in official custody. Jenkinson (1922) saw this as providing grounds for claiming the authenticity of the "Archive" (p. 12).
} 
Another point to note, in this discussion of epistemological dichotomies and the othering of libraries, is that archivists' othering of books tended to assume books to be defined by the aboutness of their texts - they were seen as works (Jenkinson, 1922, p. 2; Moore, 2005 , p. 216). Seeing books (and other publications) as works is common amongst readers and librarians because, for the most part, their texts are constructed to be works. To say something is a work is to focus attention on its linear "intellectual content", and to think about it in terms of the knowledge claims the author has made about some topic that has been intentionally addressed (Le Boeuf, 2005, p. 5; Smiraglia, 2001, pp. 4, 129-130). When Jenkinson (1922) defined records, he turned a blind eye to this view of the documents he allowed, by dint of custodianship and use, to be records. Content and its aboutness played a large part in his conceptualisation of the documentary other, but no part in his conceptualisation of records and only a secondary role in his recommendations for descriptive practice. The construction of fonds-focused and 'original order' revealing inventories was the primary descriptive task with which archivists were charged. They provided "the fairest opportunity to the Archive of saying what it has to say and to the student of understanding and profiting" (p. 80). Repository guides, calendars of documents, and name, place and subject indexes were all optional extras (pp. 108-113). Much the same was true for Muller et al. (1940), though they were far more sceptical about subject indexing (p. 152) and paid more attention to the manner in which calendars should be constructed. Interestingly, they differentiated the roles of calendars and inventories in transitive dimension / intransitive dimension terms. The calendar was to be "exclusively concerned as to who attests and as to what is attested" (p. 174). "The inventory", they said, is "a list of documents, the calendar a list of facts" (p. 175). In both cases the archivist's primary duty was to reveal past states of being. Aboutness was extraneous to the concept of record and largely outside the purview of archivists.

Schellenberg $(1956,1965)$ differed from Muller et al. (1940) and Jenkinson (1922) in that he was far less concerned with epistemic matters than with a practical need to reduce the volume of records coming into archives and to develop less labour-intensive arrangement and description practices than had been advocated in the earlier manuals.

For Schellenberg libraries were exemplars of efficiency and partners in the business of managing the ever increasing volume of recorded information (Schellenberg, 1965, pp. 4- 
$6,61)$. Nevertheless, he saw libraries as different. Furthermore, he saw norms of different documentary formats as being at the heart of that difference. Unlike Jenkinson (1922) who had, in effect, argued recordness to be emergent from a mode of practice, Schellenberg maintained that differences in "technique" existed only because they were required by the nature of the materials most common to each institutional type "publications" in libraries and "records" in archives (Schellenberg, 1965, pp. 4-5). Taking this line of argument further, he reasoned that because archival practices had developed in relation to a norm of unpublished textual documents, employing those practices for non-textual records (e.g., photographs, maps, and sound recordings) was unnecessary. Seeing these "specialized materials" in terms of their content rather than their previous contexts of use, he said, "the techniques of the library profession may be followed in arranging and describing them" (Schellenberg, 1965, p. 20).

Dichotomous assumptions about the nature of books/publications and records/unpublished documents had, as I have shown, been a part of the domain's discourse for at least a century. As Schellenberg was not departing from that tradition his discourse of othering continued the habit of imagining publications as works and secondary sources and records as "source or primary material" (Schellenberg, 1965, p. 119). Publications were "discrete" and "indivisible" physical entities that were "unitary" in their subject matter (Schellenberg, 1956, p. 23; 1965, p. 82). Records were "organic material" which had "collective significance in relation to activity"; they were "heterogeneous... in subject matter". Publications, on the other hand, did not have significance in relation to activity and were "homogeneous in subject matter" (Schellenberg, 1956, p. 120).

When it came to discussing personal papers, however, Schellenberg ran into a problem because, as well as urging archivists to learn from librarians, he was urging manuscripts librarians to learn from archivists. This led him to focus close attention on the question of which materials held in library manuscript collections - in particular, which aggregations of personal documents - were so much like the records of government that they too should be thought of as records. Rather than question the assumption that there was a personal other, he turned his attention to the task of developing theory that (in his view) confirmed that assumption. 
In the argument he constructed, three dynamics were at work in determining whether a document was or was not a record. Firstly, there was the norm of an unpublished textual document (Schellenberg, 1956, p. 21). Then, there was the imagining of "purposive and organized activity" (Schellenberg, 1956, p. 13) or "organized systemic activity" (Schellenberg, 1956, p. 15) and the imagining of an opposite: activity that was not "organized", "purposive" and "systemic". The opposite was, of course, reserved for individuals and families. "Archives [i.e., archival records] grow", Schellenberg (1956) explained, "out of some regular functional activity, historical manuscripts [i.e., personal papers], in contrast, are usually the product of a spontaneous expression of thought or feeling. They are thus ordinarily created in a haphazard, and not in a systematic manner' (Schellenberg, 1956, p. 18). The third dynamic at work was the imagining of a meaningful correlation between "systemic activity" and the character of both the document produced by that activity and the aggregation in which it came to rest. The bulk of an aggregation of private documents and the extent to which it was systematically arranged was taken as indicating whether its origins rested in "purposive", "systemic" and "organized" activity (Schellenberg, 1956, pp. 15-18; Schellenberg, 1965, p. 31); and documents originating from activity that was "purposive" etc. were claimed to be "further removed from personal bias and ... more accurate than... private papers" (Schellenberg, 1965, p. 92).

Paying no attention to Jenkinson's transactional thinking about the nature of impartiality, Schellenberg had spuriously reasoned the existence of a content-focused epistemological dichotomy grounded in a provenance-focused behavioural dichotomy. A question comes to mind: Does a letter of condolence written on pre-printed black-edged paper and repeating culturally established phrases for such occasions have its origins in organized, systemic and purposive functional activity or in a "spontaneous expression of thought or feeling"? This is not the kind of question Schellenberg $(1956,1965)$ asked, so I will let it sit.

In developing the line of reasoning described above, Schellenberg $(1956,1965)$ seems to have been attempting to give rather chaotic thinking founded on generalisations the appearance of being logically grounded. He was unable to redeploy Jenkinson's logic (assuming he was aware of it, which I suspect he was not) because that logic had revolved 
around the notion that the quality of being a record required significant correspondence between descriptive representation of an aggregation and the aggregation's pre-archival state. This did not work for Schellenberg because the practices he advocated were not the "responsible" practices advocated by Jenkinson (1922). They did not even measure up to the standard set by Muller et al. (1940).

One of the ways in which Schellenberg (1956) departed from tradition was by introducing an appraisal method that licensed archivists to select which records they would preserve. This method, already in use in the United States National Archives, allowed for records to be selected either on the basis of the "evidential value" of their content or on the basis of the "informational value" of their content. Records with "evidential value" were those concerned with "the organization and functioning" of the [public?] agency that produced" them (p. 139). ${ }^{42}$ Records with "informational value" were those containing information about "persons, places, subjects, and the like with which public agencies deal" (p. 148). This (transitive dimension) content focus had the effect of favouring testimonial evidence over trace. This testimony-privileging stance is self-evident in Schellenberg's claim that the operational records of government agencies are relatively unimportant because "normally most of the significant evidence relative to the operations of an agency is relayed upward through statistical or narrative reports, through correspondence and memoranda, and other summary records" (p. 146). It is also self-evident in his advice that the informational values of records could "be appraised piecemeal, for the records are judged solely on the basis of their content and not on their relation to other records produced by an agency" (p. 148).

This process of selection was subjective both in its design and in its implementation. Schellenberg (1956), however, maintained it to be "objective" (p. 141), the existence of a standardized system apparently being the mark of objectivity. This was quite different to Jenkinson's notion of impartiality.

Schellenberg (1956) also introduced a method for arrangement and description that deviated considerably from the relatively impartial practices of the past. Setting aside the

\footnotetext{
${ }^{42}$ As this is the only unqualified reference to an agency within a lengthy discussion of evidential value that refers repeatedly to public agencies, I assume that this cited phrase refers to public agencies, rather than agencies in general.
} 
traditional ideal of arranging and describing fonds in isolation and in their entirety, he advised that description should focus on administratively convenient aggregations of records, which he called "record groups". In practice, this meant large fonds were divided between different record groups and small fonds with similar, though varying, provenance were combined in a single record group (pp. 181-182; 187-188). Not stopping there, Schellenberg (1956) questioned the value of retaining the orders imposed by past record keeping systems. While in principle he supported the retention of systematic orders given to records by "the originating office", he said that, if the order was "unintelligible" or made "reference service very difficulty", the "archivist may devise another system" (p. 186). Re-arrangement was especially justified, he argued, when the records concerned were being preserved for their "informational value" (pp. 188-191). Also, as I previously said, he promoted the use of library practices for photographs and other "specialized materials" (p. 210).

Schellenberg's advice on descriptive practice gave licence to archivists, when working with records selected for their "informational value", and to manuscripts librarians, whose collections had only "informational value", to separate those records from the contextualising relationships that might be essential for assessment of their evidential affordances in relation to research topics. His choice of terms to explain his appraisal system was also unfortunate because, even though he explicitly said the words evidential and informational should not "be taken literally" and that the term evidential value, as he was using it, should be understood only within the context of the appraisal system and not as suggesting all records did not have evidential value in a more general sense ( $p$. 139), those words have been taken literally (e.g., Henry, 1998 and Fisher, 2009). Such misinterpretations generate a narrow concept of evidence and position evidentiality as relevant to only a sub-set of records and only to the testimonial evidence provided by their content. This was quite unlike Jenkinson's conceptualisation of evidence, which included both testimony and trace, and was much broader than his concept of record.

In discussing Jenkinson (1922) I drew attention to an interesting anomaly. I will end this discussion of Schellenberg's work with another. As I previously said, Schellenberg othered books by claiming they were isolated physical entities that did not take on meaning through aggregation in relation to activity. It is, therefore, ironic that, in demonstrating 
that original order can sometimes be meaningful, he used a biography shelved in the fiction section of Thomas Jefferson's library (Schellenberg, 1965, p. 102). What makes this example doubly interesting is that Schellenberg (1965) used it in the context of arguing that "methods of filing are unimportant to an archivist, except from the point of view of their utility in making records accessible" (p. 102). The placement of this book was, he claimed, an exception to that rule because there is an over-riding rule (my words, not his) that "idiosyncrasies in filing... are important only if the person who did the filing is important" (p. 102). Whether an important person could make a book a record is something he did not say; but, logically, that would seem to be the case.

What is happening here? Presumably in Schellenberg's paradigm, historians were interested in the thoughts of great men. In an age when historians are interested in the common woman or common man, perhaps filing orders and idiosyncrasies in those orders always have the potential to be important. And in an age when book production, book commerce and other book-related activities such as book collecting and book reading are matters of historical interest (Suarez, 2003-2004), perhaps books are always records, if that is the way they are being used and 'read'. Does that mean a textual record read in a linear fashion for information about some matter of interest to both the author and the reader is something akin to a book?

\subsection{CONTINUUM THEORY IN LATE TWENTIETH AND EARLY TWENTY-FIRST CENTURY DISCOURSE}

\subsubsection{Departures from the traditional}

In discussing the nature of the traditional discourse I drew attention to how notions of record, provenance, document, archival practice, and aggregation have characterised the discourse, yet been situated in relation to each other in variable ways. I also drew attention to things that were shaping the discourse, especially epistemic concerns, custodial claims, institutional and professional identity, limited resources but increasing volumes of records, and the inflexibility of physical aggregations and the physical inventories that described those aggregations. Another matter to which I drew attention was the persistence of old tropes in the form of words such as organic which have persisted and, therefore, lent the appearance of stability to the discourse even though their situated uses have not been stable. In the literature I analyzed, these words seemed 
to move from having situated metaphorical meanings to being more free-floating recurrent tropes that carried an air of authoritativeness acquired in earlier contexts of use, even though in other contexts of use their claim to that authority might have diminished. Finally, I drew attention to the fact that words repeatedly put to use to describe records, record aggregations, and the work of archivists tended to be matched with an opposite word that othered all things related to libraries, and that certain biases were at work in the domain's co-emerging discourses of definition and differentiation. These biases were the privileging of certain types of documents, the privileging of a certain view of provenance, and unacknowledged perceptual switching between seeing documents in terms of their intransitive dimension characteristics and relationships (which supported objectivist claims) and seeing them in terms of the transitive dimension characteristics of their (usually textual) content (which supported claims of probable subjectivity).

How does one generalize the nature of a discourse characterised by significant variability in time and over time, yet also in some respects stable and self-perpetuating? How does one generalize the nature of such a discourse when the meanings of its central concepts are compounds of variable related and subsidiary meanings and, therefore, vague and open to varying interpretations? How does one find a line of logic that works to describe a discourse which mixes fragments of logic with a tendency to 'cherry pick' from a suite of generalizations tailored to support any pre-existing assumption and, thereby, avoid confronting the fact that anomalous cases might call the validity of the assumptions into question? Finally, how does one generalize about a discourse when only a small part of that discourse has been examined?

One way is to focus analysis on matters of concern in the research 'moment' of the present, to identify relevant presences and absences in the known part of that past discourse, follow the ontological ramifications of its lines of argumentation, and then find a way of communicating one's findings in a narrative where the nature of one's selective and generalizing 'presentism' must attempt to respect the intransitive, and significantly unknown, truth of the past. This is what I attempted to do in section 3.2. 
Another approach would be to construct a relational model. This is what Frank Upward did in the mid-1990s (Upward, 1996, 1997). By that time the domain's discourse had become even more complex because three major changes were under way. These changes were: an increasing tendency for archivists to think of documents with personal provenance as belonging inside, rather than outside, the category of record; a marked rethinking of the nature of records and processes of record formation stimulated by the problems and opportunities associated with the digital; and a rapidly expanding body of critical literature, much of which was examining the domain through a 'postmodern' lens.

Transitioning from a paradigm which tended to exclude documents created in the course of personal non-administrative activity from the category of record to one that tended to include such documents was significant because it meant a provenancial association with administrative activity could no longer be used in determining what documents counted as records. This posed problems for definition because traditionally it had been the provenancial relationship that had most logically determined what counted as a record and what did not. The glossary of the first edition of the Australian Society of Archivists' Keeping Archives (Pederson, 1987) casts light on the difficult process of transitioning from a relatively narrow concept of record to one which was much broader both in terms of provenance entities and the types of activities engaged in by those entities. In Keeping Archives provenance is defined as "the office or person of origin of records, i.e. the entity which created or accumulated and used the records in the conduct of business or personal life" and as "the chain of custody which reflects the office(s) or person(s) that created, received or accumulated and used the records in the conduct of business or in the course of personal life" (pp. 363-364). ${ }^{43}$

With provenance conceptualised in such broad terms, sustaining the notion that the category of record was closed relied on definition of the reason why records were kept. Both Jenkinson (1922) and Schellenberg (1956) had included statements along those lines in their definitions (section 3.2.4). So too did Keeping Archives, which defined records as: "documents, containing data or information of any kind and in any form, created or received by an organisation or person for use in the course of business and subsequently

\footnotetext{
${ }^{43}$ A third part of this definition is concerned with the principle of provenance.
} 
kept as evidence of such business [emphasis added]" (p. 364). Though the situated meaning of the word business must be understood as the general 'business of life', the wording of this definition, nevertheless, shows the difficulty archivists were experiencing in transitioning from an organisation and administrative activity paradigm to a paradigm which also included the personal - the connotations of the word business speak more clearly to the traditional concept of record than they do to the personal, as does also the notion that documents must be "kept as evidence of such business" in order to be records.

Because there is no allowance for variability over time, the wording of Keeping Archives' definition of record suggests the keeping of records is always intentional and purposeful, never an act of forgetfulness or neglect. Similarly, these words are more suggestive of rational problem-oriented future use of records than of ongoing (perhaps fading) sentimental and emotional attachment, or simple appreciation of the aesthetic. The notion that records can be defined by the fact of being "kept as evidence of such business" also somewhat misrepresents the diverse character of custodial practices that occur in administrative environments - I have seen hundred year old records 'stashed away' under dripping pipes, valued not as evidence, but kept out of fear that destruction would contravene legislative requirements only half understood by those who are 'keeping' the records, out of unwillingness to dedicate staff time and financial resources to appraisal, and for the 'sentimental' reason of not wanting to transfer 'local history' to a distant national repository. ${ }^{44}$

Definitions, as Yeo (2007) said, are difficult (pp. 315-316). That is one of the reasons why Upward $(1996,1997)$ published a records continuum model which was deliberately not grounded in definitions (of records, provenance, documents, or anything else), but in an appreciation of variable space-time situated and changing relationality.

Another aspect of the changing archives domain discourse to which Upward's records continuum model responded was that which had begun to seriously address the

\footnotetext{
${ }^{44}$ The first edition of ISAD(G), the General International Standard for Archival Description, did not define records. Its definition of provenance as "The organization or individual that created, accumulated and/or maintained and used documents in the conduct of personal or corporate activity" (International Council on Archives, 1994) was more hospitable to the personal than that in Keeping Archives.
} 
challenges and opportunities associated with operating in a digital environment. A major message communicated by those engaged in this discourse was that traditional archives domain concepts and practices were inadequate foundations on which to build a digital future because they neither allowed archivists to maximise the potential of digital technologies nor provided intellectual and practical tools that enabled the identification of digital records and their capture and management through time (Bearman, 1992; Bearman, 1994; Bearman \& Lytle, 1986; Cook, 1994; McKemmish, 1994; Upward \& McKemmish, 1994).

Schellenberg's record group method of description had never had the unanimous support of archivists in the United States (Jones, 2003, p. xiii), let alone elsewhere. Peter Scott, working in the Commonwealth Archives of Australia, argued it produced "fictitious" and "false" descriptions (Scott, 1966, p. 495). Working from a Jenkinsonian foundation, but looking for a method that would more accurately represent "the real nature" (Scott, 1966, p. 496) of the contexts in which records were created, aggregated, and used, Scott parted from the tradition of creating "mono-hierarchical" descriptions (Cook, 1997, p. 38). By separating descriptions of record creating entities from descriptions of record entities (i.e., series of documents in this first incarnation of Scott's system) and allowing for oneto-one, one-to-many, and many-to-one relationships, he "shifted the entire archival description enterprise from a static cataloguing mode to a dynamic system of multiple interrelationships" (Cook, 1997, p. 38). In addition to recognising the epistemic value of precision with regard to chronology, Scott (a linguist by training) also began to disentangle the semantics of the domain's conceptually conflated notions of creator and provenance (Hurley, 1994, 2008).

Scott did not, however, shift "the entire archival description enterprise", as Cook (1997) put it. This is because few archives, other than government archives in Australia and New Zealand, adopted his method. Internationally, rejection of Schellenberg's record group more commonly took the form of a return to the fonds, so much so that the French term became a part of the English language discourse following the publication in Archivaria of Duchein's article arguing that respect des fonds was the fundamental concept in the archives domain and that the Australian system (misunderstood and misrepresented by Duchein) was “wrong” (Duchein, 1983, p. 72). 
The case against fonds-focused description, and for more relational practice such as that developed by Scott, was subsequently argued by Bearman and Lytle (1986). Lytle had previously conducted research comparing the utility for researchers of fonds-focused description (the "provenance method", as Lytle put it in 1980 when he published his findings) and content indexing (Lytle, 1980a, 1980b). In publishing his findings, Lytle (1980b) reported that both methods had performed poorly and, on average, equally so; that there was little over-lap in what the two methods retrieved; and that content indexing scored highly when there was correspondence between topics of enquiry and indexed topics, but the fonds-focused method was more likely to produce results when that was not the case (p. 193). Writing with Bearman six years later, Lytle predicted that, if the study were to be repeated in such a way that it compared content indexing with provenance-focused description grounded in a pluralistic notion of provenance, provenance-focused description would easily out-perform subject indexing (Bearman \& Lytle, 1986).

In 1992, immediately after the International Council on Archives' (hereafter ICA) Ad Hoc Commission on Descriptive Standards recommended the principle of fonds-focused description be endorsed in the forthcoming international standard, Bearman published a second article arguing that the international standard should adopt a whole life of the record documentation approach (capturing contextual information along the way), rather than endorse the existing practice of describing aggregations of presumed end products that have been bounded and internally structured as archivists have decided, rather than in the variable ways that may have existed in the past. "In focusing on description rather than documentation", he said, the Ad Hoc Commission was overlooking "the most salient characteristic of archival records: their status as evidence" (Bearman, 1992, p. 33).

Two years later Bearman published Electronic Evidence: Strategies for Managing Records in Contemporary Organizations in which he implicitly defined records as "evidence of a transaction". He argued archivists needed to become actively engaged in the creation of records and the design of systems in order to ensure that "information in computer systems is a record" because "most collections of electronic data, electronic documents, or information are not records because they cannot qualify as evidence" (Bearman, 1994, p. 2). In making these statements Bearman (1994) was expressing a general consensus of 
opinion forming amongst those seriously concerned with born-digital information and the epistemic adequacy of government records. The primary epistemic concern for that community was, of course, the fitness of records to serve as evidence of government activity. Before moving on, it is worth noting that describing records as "evidence of a transaction" is a little different to seeing transactionality as the essential quality of a record, as (I have argued) Jenkinson did.

I have not analyzed Bearman's work deeply enough to be able to say whether transactionality was also at the heart of his thinking. I do know, however, that the Jenkinsonian notion had been picked up and continued in Australian discourse - "Being records of transactions of which they themselves formed a part [emphasis added], Archives [i.e., records] are, in a particular sense, authentic and impartial" (Maclean, as cited in Schellenberg, 1965, p. 92). ${ }^{45}$

Australian archivists were quick to see a place for themselves in the discourse community concerned with planning for a digital future. This was not only because planning for a digital future was as much a concern for them as others, but also because fundamental elements of the 'new' way of thinking and practising had been taking hold in Australia (primarily within the context of government archives) since the 1950s and 1960s. The descriptive system developed by Peter Scott was one of these precursors to the digital era. The other was breaking from the tradition of seeing the role of the archivist as beginning only when records were no longer required for regular administrative use. That break was made by the Commonwealth Archives in the 1950s when the organisation recognised early involvement in the development of records management systems resulted in better systems and, when the time came for transfer to the Archives, easier integration with existing holdings (Maclean, 1959; Upward, 1994). This mode of practice, which came to be seen as essential for the capture and preservation of born-digital records, began to be advocated in North America in the second half of the 1980s. Following the 1986 publication of an article by Jay Atherton, it was dubbed "the continuum model" (Dingwall, 2010, pp. 144-147).

\footnotetext{
${ }^{45}$ Ian Maclean was Chief Archives Officer of Australia's Commonwealth Archives.
} 
Another late twentieth century departure from the traditional was an increasing tendency for 'postmodern' philosophy to be used as the lens through which traditional discourse and practice were perceived and critiqued. Brien Brothman and Terry Cook were significant in introducing 'postmodernism' to archival science. Their writing (Brothman, 1991, 1993; Cook, 1994), which drew heavily on the work of Jacques Derrida and Michel Foucault, called attention to the socially constructed and subjective character of records, archival practices, and archivists' actions. It also cast the domain's past (and, therefore, its mainstream present) as positivist. In a paper first presented at the 1993 conference of the Australian Society of Archivists (where Bearman also presented), Cook called on the profession to replace the paper and custodial mind-set, the positivist assumptions and practices, and passive orientation of its past with a pro-active, post-custodial and postmodernist new paradigm. He said this was needed as much for managing the paper records of the past as for managing born-digital material (Cook, 1994).

This forward thinking discourse was, Upward and McKemmish (1994) said, "grounded in a new [and much expanded] provenance theory" (p. 137) which was seen to be relevant across the whole spectrum of information resources and systems. ${ }^{46}$ This was a radical departure from the traditional assumption that archivists (recordkeepers in the new paradigm) were concerned only with that difficult to define subset of documents traditionally claimed to belong in archival institutions. Following through on the logic, they argued that broader engagement with others in the information sector (including librarians) based on a "new 'language of purpose' might contribute to the emergence of a new paradigm [not only for archivists, but also] for information management" (p. 140). In their vision of this new paradigm recordkeeping requirements would be incorporated into systems design. Clearly, in this imagined, but emerging, "interdisciplinary" and "pluralist" paradigm, Upward and McKemmish (1994) envisaged record qualities (serving evidential purposes) as co-existing with other qualities (serving other purposes) that an information object, or set of information objects, might have.

\footnotetext{
${ }^{46}$ Bearman and Lytle (1986) had previously argued the case both for an expanded notion of provenance and for archivists to "take a much more aggressive leadership role ... in the wider management of information resources" (p. 14).
} 
It was with these notions in mind that McKemmish (1994) argued the case for thinking of records in abstract, rather than physical, terms. "Even when they are captured in a medium that can be felt and touched", she said, "records as conceptual constructs do not coincide with records as physical objects" (p. 187). That this had always been the case is self-evident if one thinks back to the importance attached to a provenancial relationship (and sometimes to custody and the actions of custodians) in traditional definitions of records. It is even more self-evident if one focuses attention on the circumstances in which anomalous 'documents' such as books and museum-type objects were accepted as records. Record quality, it seems, has always been relational, even though sometimes evidence of the provenancial relationships (deemed necessary when the concept of provenance was narrow) was inscribed in single documents.

What happens when we are completely open in our thinking about the nature of information objects and we are both open and pluralistic in our thinking about what can potentially be a provenance entity and what type of relationship that entity might have with an information object? How would we conceptualise records? How would we conceptualise their boundaries? Would they even be bounded? And would the answer to all these questions depend on who is constructing - or 'seeing' - the record and where and when and why? These are questions explored in the thesis, especially in Chapter Six.

\subsubsection{Upward's records continuum model and its reception - $1996-2000$}

In section 3.3.1 I described the state of the discourse, and where Frank Upward was positioned in it, when he published his records continuum model in two articles that sought to "explore the continuum in time/space terms" (Upward, 1996, 1997). This records continuum model differed radically from the North American "continuum model". Upward replaced that linear "life of the records model" (Upward, 1996, p. 268) with a circular model designed to represent the complex, contingent, and variable (in time and over time) character and relationality (synchronic, diachronic, and recursive) of physical entities, digital entities, physical actions, systems, conceptual entities, verbal entities, processes, and purposes.

Upward's model was comprised of four concentric circles representing four "time/space" dimensions (create, capture, organise, pluralise) and four axes representing notions of 
fundamental importance for record and archive formation: the transactional axis, the evidential axis, the identity axis, and the recordkeeping axis. Spread along each axis were words relevant to the axis and the dimension that were intended to be read as conceptual and terminological space-holders (my words, not Upward's), general notions which, in any specific context, might vary a little terminologically and conceptually in relation to other word-concept pairings in that context. One has only to think about the many ways in which the words document, records and archive were used in the traditional discourse to understand what Upward was attempting to achieve, and why.

The inspiration for Upward's records continuum model came from Anthony Giddens' structuration theory, which, like Bhaskar's model of social transformation, had been developed to address the problem of competing social science theories which either emphasized individual agency at the expense of structure or structure at the expense of individual agency. Upward saw Giddens' theory as an answer to 'postmodernist' suspicion of 'grand theory' and as providing "an overview" that would enable commensurable responses, rather than "diverse responses" to "the 'multiple realities' of the virtual archives" (Upward, 1996, p. 274).

In addressing the dichotomy in social science theory, Giddens brought structure and agency together arguing "the structural properties of social systems are both medium and outcome of the practice they recursively organize" (Giddens, 2005, p. 121). The "active, practical consciousness" of social actors, he said, does not bring structures into being, but structures are continually recreated by actors "via the very means whereby they express themselves as actors" (Giddens, 2005, p. 123). Bhaskar's response to the same problem was almost identical. "Society", he wrote, "is both the ever-present condition (material cause) and the continually reproduced outcome of human agency. And praxis is both work that is conscious production, and (normally unconscious) reproduction of the conditions of production, that is society" (Bhaskar, 1998b, pp. 37-38). ${ }^{47}$ Inevitably I read Upward's use of structuration theory through a critical realist lens.

\footnotetext{
${ }^{47}$ This quotation comes from the third edition of Bhaskar's The Possibility of Naturalism. That edition was a reprint of the second edition (1989). I have not seen the first edition, so cannot say whether this passage also appears there.
} 
In critical realism structure is, in a sense, whatever existed prior to an action or event and played a part in shaping that action or event (and any outcomes). Structure, therefore, can serve to enable or constrain human action. Upward $(1996,1997)$ seemed to have been carrying this kind of thinking into records continuum theory, though his transformational aspirations led him to emphasize the enabling properties of structure. ${ }^{48}$ In essence, he was (in my reading) advocating conscious development of systems and modes of practice embedded with rigorous thought about what types of structures produce desirable knowledge outcomes, so that those systems and practices would work to structure the actions of individual recordkeepers and the outputs of their actions. He was also, of course, advocating the normalization of new structures for thinking.

Unfortunately, there were factors at work in the domain that limited the spread of Upward's theory and promoted misinterpretation of his work. Significant amongst the 'structures' that served to constrain understanding of the theory's space-time sensitive dynamics were two that had also served to stimulate the development of the theory. These 'structures' were: international discourse concerned with the problem of managing the born-digital and the role records played in relation to government accountability; and the domain's 'postmodern' discourse.

The terms and illustrative examples privileged in the records continuum model and in records continuum discourse 'spoke' more strongly to government archivists than they did to collecting archivists. As a consequence words such as transaction, function, and organization were widely interpreted in terms of their traditional business activity connotations rather than understood as the conceptual space-markers Upward (1996, 1997) had intended them to be. The fact that Upward's model shared the same name as the older linear continuum model would not have helped understanding, as those who heard talk of the records continuum in the context of government recordkeeping (which is the context in which such talk usually occurred) might well have not known of the separate existence and separate nature of Upward's continuum model.

\footnotetext{
48 The relative under-playing of the constraining effects of structure may also have been carried into continuum theory from structuration theory, which has been critiqued on the grounds that it underplays the constraining effects of structural factors and over-emphasizes individual freedom and voluntarism. Taking issue with that critique, King (2010) has argued this impression stems from the way Giddens mediated his theory, rather than from the theory's fundamental logic (p. 254).
} 
Henry (1998) was probably similar to many traditional archivists of the time in believing both the purported need for a new paradigm and the nature of that new paradigm were being dictated by the nature of the digital (p. 309). Her scathing attack on new paradigm discourse revealed that she was unaware the discourse was, in large part, generated by awareness of the epistemic limitations of traditional concepts and practices. As an archivist schooled in the Schellenbergian paradigm and as one who had mistakenly come to believe some records had informational value, but not evidential value, Henry (1998) was troubled by the way the new discourse fore-grounded the word evidence in its understanding of the essential nature of records, but othered the word information (pp. 314-315) - Bearman (1994), for example, had done this when he said most information systems were not recordkeeping systems because the information in them did not "qualify as evidence" (p. 2). As Henry (1998) understood it, this new way of thinking about the nature of records did not address the "cultural and humanistic" (p. 315). Rather, it excluded "personal papers and other similar documentary materials" which did "not document business transactions" (p. 315). "Supporters of a new definition of a record", Henry (1998) said, "usually do not discuss or analyze what's wrong" with the old definition or "what a collecting archives would do with" the new definition, "but, rather, declare what should be or is" (p. 316). She criticized new paradigm authors for their "confusing jargon and technobabble" (p. 325), and their tendency to cite only themselves and each other - and then "proclaim a growing consensus for their ideas" (p. 322). She saw them as disparaging, rather than educating, the archival mainstream (p. 325).

In a sense, Henry (1998) laid down a challenge to which I have responded in my research; but, only in a sense, because at the outset of my research I was on the margins of continuum theory - a little in, a little out, a little knowing, a little ignorant. Nevertheless, my experience and reading in the domain had led me to believe there was a need for translation between traditional and contemporary discourses and a need for translation in terms relevant to collecting archivists. More recently, my thesis writing experience has taught me how difficult it is to 'teach' what one is still exploring and seeking words, models, and lines of narrative to explain - and how very difficult it is to explore and 'teach' everything at once. 
The extent to which French philosophy and discourse promoting suspicion of metatheories was structuring the thinking of the archives domain's 'postmodernists' in the 1990s also worked against positive reception of Upward's theory. At the ICA Congress in 2000 Verne Harris, who had previously argued archives domain practice and discourse was "dominated by a Positivist paradigm which has been dominant for a long time and which cries out for interrogation" (Harris, 1997, p. 133) and who was clearly unaware that Australian continuum thinking was grounded in a model designed to acknowledge and enable diversity, launched an attack from that angle.

Discourses concerned with the functional requirements of electronic records, Harris said, treated the word record as synonymous with evidence and conceptualised evidence narrowly in terms of accountability (Harris, 2001a, p. 39). Singling out the continuum "record-keeping paradigm" as "arguably the most powerful" of these discourses, he accused those responsible (namely Upward, McKemmish, and Hurley) of claiming "for 'the record' a single ontology - the record is evidence of process, of activity, of transaction". They had forgotten, he said, "that the requirements for evidence are specific to time and place" (Harris, 2001a, p. 40). The implication was that Australia's continuum thinkers were perpetuating positivist fallacies.

The continuum "record-keeping paradigm", Harris (2001a) went on,

excludes the possibility that people (individuals, organisations, societies) generate and keep records for reasons other than 'evidence of process.' It excludes the possibility that qualities, or attributes, or dynamics, other than 'evidence' enjoy equally legitimate claims on the concept of 'record' - for instance, remembering, forgetting, imagining, falsifying, constructing, translating, fictionalising, narrating.... It forgets there are no hard boundaries between text and context, data and metadata, form and content, evidence and memory, the 'event' and the 'event's recording'. (p. 40)

That Harris's knowledge of continuum theory was superficial is self-evident. What he himself was attempting to communicate is less clear. His text is almost contradictory. In places it can be read as expressing concern that the concept of evidence was being understood in very limited ways, yet in other places, it can be read as implying that the 
word evidence refers only to that limited concept and, therefore, does not adequately define records. I find myself wondering whether he intended that "remembering, forgetting, imagining, falsifying, constructing, translating, fictionalising, narrating" should be understood as relevant to the nature of evidence or as totally other to evidence. I cannot second-guess Harris; however, the question of whether those behaviours are evidentially implicated is one I identified for exploration through my case study research. Also, of interest to me was Harris's assertion that "knowing the record ... as cornucopia of meanings is both unavoidable and legitimate" (Harris, 2001a, p. 41). What does it mean to say the record is a cornucopia of meanings? Could we say instead that records are cornucopias of evidential possibilities waiting to be recognised? This is also an idea explored through my case study research and discussed in the chapters that follow.

In a post-Congress discussion of Harris's presentation on the Aus-archivists listserv, Reed (2000, December 4) commented that Harris seemed to have fallen "into the trap of assuming that the strategies were the theory". "The richness of records continuum theory", she explained,

is far more sophisticated and embracive than any strategic tool or specific pragmatic response.... That the strategies are consistent with a theoretical framework (or in some cases an emerging theoretical framework) does not make them a complete articulation of the richness of that framework.

McKemmish (2000, December 4) added that the word evidence was used in the continuum model to signify a broad conceptual space - behind the word lay a "spectrum of substantive concepts" ranging "from the narrowly legalistic, to necessarily rigorous specification of requirements in computerised environments, to a synonym for records in the broadest sense." Reiterating the fact that continuum theory was not complete, but emerging, McKemmish (2000, December 4) went on to say,

Harris's insights on the terrain he calls the archival heartland can help us to ... build on and enhance our understandings of evidence and memory, bringing into play in our discourse and practice new insights from other disciplines, like organisational theory, historiography, sociology, anthropology and philosophy. 
This too is a challenge to which my research responds - though again, only in a sense, because I was not aware of this Aus-archivists' discussion until quite late in my research when, bewildered as to why Verne Harris had never identified as a continuum thinker, I did a Google search on the off-chance that it would 'turn up' something of interest.

\subsubsection{Continuum theory - monistic diversity, multi-polarity, and spacetime}

In the late 1990s Upward made a strategic decision to distance himself from the contemporary archives domain discourse so he could focus his attention on reading outside the discipline and bringing new ideas in via continuum theory (Upward, 2009, p. 3), which he and other continuum theorists saw to be an evolving body of thought (Upward \& McKemmish, 2001, p. 24). During the following decade, he drew on a range of philosophies (McKemmish, et al., 2009, pp. 4453-4454) to extend his thinking about spacetime and introduced conceptually appropriate terms for discussing spacetime. Those of particular interest to me are monistic diversity and multi-polarity. Both are fundamentally important to the logic of continuum theory and for understanding Upward's concept of spacetime, which is also important in the context of this thesis. In essence, monistic diversity allows for entities - as large as the whole of critical realism's intransitive dimension or as small as a word - to be conceptualised both as singular and diverse; and multi-polarity recognises that entities (whether large or small) can be approached from diverse angles for diverse reasons. In the paragraphs below I explain my understanding of Upward's spacetime thinking and where these concepts fit into that thinking.

Upward's concept of monistic diversity is grounded in two seemingly contradictory notions of spacetime. The first, borrowed from Herman Minkowski, is a notion of "significant oneness" (Upward, 2009, p. 10) that results from seeing space and time in union, rather than separately. Bringing the two together conceptually was argued by Minkowski to be necessary for preserving "an independent reality" (Minkowski, as cited in Upward, 2009, p. 10). Reading from a critical realist stance, I take this to mean that what is at stake is not independent reality itself, but human ability to conceptually and verbally distinguish between that reality and perceptions of it. In other words, in continuum theory, spacetime serves the same intellectual purpose as is served by critical realism's intransitive dimension. 
Upward (2009) deepened understanding of the nature of the spacetime oneness by introducing the Bergsonian notion of "moments in time" (Upward, 2009, p. 10). In other words, spacetime can be conceptualised in terms of both oneness and parts - but the parts do not exist outside of the oneness and the oneness exists only by virtue of its parts. How long is a moment? Potentially, a moment can be however long we choose to say it is; but at the lower end of the scale, a moment is as fleeting as a flicker, a word Upward (2009) borrowed from Deleuze and made prominent in the title of his thesis.

With all this talk about moments and flickers one can easily lose sight of the space in spacetime, and that was not Upward's intention. A flicker is a spacetime fragment whereand-when

everything tends to be spread out into an instantaneous, indefinitely divisible continuum, which will not prolong itself into the next instant, but will pass away, only to be reborn in the following instant in a flicker or shiver that constantly begins again. (Deleuze, as cited in Upward, 2009, p. 17)

When all these concepts are brought together spacetime - whether conceptualised as the ever-mutating absolute whole or as some fragment of that whole - teems "with diversity and difference" (Upward, 2009, p. 106). Spacetime, therefore, is "monistically diverse" (Upward, 2009, p. 106).

Incorporating Upward's notion of multi-polarity into the notion of monistically diverse spacetime complexifies the diversity of the spacetime whole in much the same way as critical realism's inclusion of the transitive dimension in the intransitive dimension complexifies the diversity of the intransitive dimension whole.

The notion of multi-polarity builds on the spacetime philosophical foundations described above, but was derived also from Samuel Alexander's "explanation of the way the spacetime continuum is by its very nature a force for the acceleration of complexity" (Upward, 2009, p. 10) and "Quentin Gibson's view of the increasingly perplexing idioms we have for conveying our experiences of spacetime" (Upward, 2009, p. 17). Our observation points (a term borrowed from Upward, 2009) are space-time situated moments comprised of perceptual flickers in the flow of spacetime, and the what, how, 
and why of our seeing are structured by both the monistic diversity of that moment and also by each preceding monistically diverse flicker.

When one incorporates the seeing into the being containing the entities referenced by the seeing and also containing the entities that stimulated the seeing, that totality of being - that whole spacetime oneness - becomes very complex indeed. It is a space of recursive, as well as synchronic and diachronic relationships. It is a space that is complete, yet one containing perception-generated 'sub-totalities' that are paradoxically both incomplete and complete - incomplete when seen in relation to the relevant part of the whole, but complete when seen in relation to the space-time situated perception that generated them. Similarly, it is a space where everything is true, yet some things are also false. I work with these ideas throughout the thesis.

Upward introduced the concept of multi-polarity, along with four more continuum models, in two articles published in 2005 (Upward, 2005a, 2005b). Like the records continuum model, these models were intended to serve as thinking tools that would facilitate commensurable practice and discourse. The target audience was "archivists as recordkeeping professionals" (Upward, 2005b, p. 18), so the intent can be further understood as stimulating archivists' awareness that, while recordkeeping distinguishes them, other activities in which they engage may be of even greater interest to other disciplines and other information and cultural heritage professionals. Recognising this opens the way for understanding that the entire sector can potentially be re-imagined and re-invented in relation to different processes rather than the typing of objects in relation to institutionalised norms. It also opens the way for archivists to understand they can learn from the knowledge that has accumulated in other parts of the sector and in other disciplines.

The new models were built on the same foundation of four concentric circles representing four dimensions as had been the records continuum model. Also like the records continuum model, they were underpinned by structuration theory and Giddens' notion of time-space distanciation. Upward (2005a, 2005b), however, used the term spacetime distanciation in recognition of the fact that he had re-invented Giddens' "four logical regions ... for discussing the dynamics of social change" (Upward, 2005a, p. 89) as 
four logical regions for discussing "recordkeeping and archiving processes" (Upward, $2005 a$, p. 90); i.e., the creation of recorded information, the capture of recorded information, the organisation of recorded information, and the pluralising of recorded information. The plural region (or fourth dimension), he explained, is a zone of many totalities and of competition (Upward, 2005a, pp. 91-92). Following Giddens' notion that "forms of totality impact on immediate contexts of interaction and our contexts of interaction shape our totalities" (Upward, 2005a, p. 89), he said,

if I was to draw the archivist's version as a dynamic visual model then recorded information could be seen spreading out from specific occurrences of interaction only to return to that region, shaping further actions within transaction cycles. The making and continuing access of memory banks would be part of those transaction cycles as would the making and remaking of the archive and archives (Upward, 2005a, p. 92).

The first of these new models (the information continuum) was concerned with how "recorded information is represented, recalled, and disseminated" (Upward, 2005a, p. 95). The second (the publication [access] continuum) was concerned with processes of "making something public" (Upward, 2005a, p. 97), words chosen because they by-passed the published-unpublished dichotomy (which readers may recall played a significant part in Schellenberg's argument that there are essential differences between records and library materials). One of the axes of this model, dedicated to the concept of "reach", works powerfully to convey the notion that 'publication' is a relative, rather than absolute notion.

The systematic control of data is the central concern of another of the models (the information systems [data] continuum). Upward (2005a) cautioned this model should not be understood as being concerned only with digital data and digital systems. Words too are data; so are sheds. Accepting this conceptual breadth, he argued, "helps give a much greater fullness to the systematic structuring of information objects" (p. 101). The last of these new models (the cultural heritage continuum), concerned with processes of culture making and "cultural enshrinement", foregrounds story-telling, narrative, and "the 
spacetime distancing processes by which stories are disembedded and carried through spacetime within different cultures" (Upward, 2005b, p. 22).

Upward's intention was that the models should be allowed to "dance" individually and together. In his own words:

The models consist of a few words placed in a logical relationship with each other as a framework for 'any era - any place' situational analyses. They are not typographies. I try to keep my written descriptions of them brief. What matters is their use. Nor do they 'type' anything at least not consciously and to the extent that it is possible for me to play zero-sum language games. The models have been specifically developed to do the opposite, helping practitioners and students to see how typing occurs in particular eras or places and to organise skills, knowledge and understanding around difference and diversity, not the sameness of one era or one place. (Upward, 2005a, p. 85)

It was after reading these articles (Upward, 2005a, 2005b) that I had my 'eureka' moment, by which I mean I realised continuum thinking was not about the closed category of things I, as a traditional archivist, had become habituated to thinking of as records. I realised that the idea I had been toying with - that a book could be thought of as a record by virtue of its provenance in authorship and the events leading to authorship (perhaps captured in part in the text), if it was read in that way - could be justified in continuum terms. A book, like the whole of spacetime, is monistically diverse. When continuum theorists describe records as logical entities or conceptual constructs, they are not describing that old and familiar set of things, but expressing an entirely new concept which recognises that any thing (or set of things) may at some time act as a record of something for someone.

\subsubsection{Archival description in the continuum paradigm}

Beginning in the mid-1990s, Chris Hurley began working from the foundation laid by Scott to improve thought and practice relevant to the description of records. His emphasis in a substantial body of work has been on flexible data structures, space-time precision, and 
semantic precision. ${ }^{49}$ He has gone beyond arguing against fonds-focused description and its privileging of a single provenance entity deemed to be the creator (by virtue of multiple and variable types of relationships with a record or body of records) to also argue archivists should extend their thinking about multiple provenance to include, not only the notion of multiple sequential provenance, but also the notion of multiple simultaneous provenance. Advancing descriptive practice, he has argued, calls for terminological and practical disentanglement of entity type and relationship type conflations (e.g., the traditional notions of creator and fonds), and for exploration and identification of the many and varied ways in which human and organisational provenance entities could be related to each other and related to record entities (at varying levels of aggregation), and of how record entities could be related to other record entities. This requires that archivists let go of old beliefs such as that single documents should not be described (Hurley, 2005a, p. 121), and that authorship is not, in its own right, a provenance-type relationship (Hurley, 2005a, pp. 120-121; 2005b, p. 55).

In exploring descriptive problems, Hurley has been much concerned about the incommensurability of metadata generated in different archival institutions. He has argued incommensurable metadata results from different provenance entities being privileged in descriptions of related bodies of records - i.e., bodies of records that are monistically diverse with regards to actual (intransitive dimension) provenance and related (in the intransitive dimension) by virtue of some aspects of their provenance, but separated in (transitive dimension) descriptions because of narrow and varying depictions of their provenance. ${ }^{50}$ Hurley coined the term parallel provenance to refer to the problematic dynamic at work in such situations.

The problem of parallel provenance has its roots in traditional dichotomization of the organisational and the personal and of the private and the public, and also in the tradition of conceptualising provenance as singular. It can occur within a single institution simply because different archivists make different decisions regarding which of several possible

\footnotetext{
49 Hurley's full body of work can be found in the Chris Hurley's Stuff website: http://www.descriptionguy.com/description.html. A portion is referenced in this thesis.

${ }^{50}$ Hurley has not employed the critical realist notions of transitive and intransitive dimensions, but I have inserted them because of their power for enabling conceptual clarity in discussion of descriptive practice and problems associated with that practice.
} 
provenance entities will be identified as the creator; and also between institutions and institution types (Hurley, 2005b, p. 53). It also occurs when different decisions are made regarding the persona of an individual that is privileged in a description - one person may, as Hurley (2005b) pointed out, have significance in relation to multiple organisations and aggregations of organisational records, ties to two or more families (and aggregations of their records), and numerous other personal relationships (and potential relationships with record aggregations associated with those other persons). The privileging in description of a certain persona or group of personas (e.g., the personal and familial, on the one hand, and the official and organisational, on the other) has consequences for how relevant context is conceptualised and described and for what other entities (record entities as well as provenance entities) will be associated with that person (pp. 70-71).

Hurley (1995a) coined the term ambient context (or ambience) to refer to the context that surrounds a provenance entity (p. 27) at the time when that provenance entity created, used, or otherwise engaged with the record entity (p. 22). He has argued in favour of the structured representation of entities that are ambient in relation to an identified provenance entity because knowledge of that context enables "external validation of provenance data" (p. 21). I have stressed that ambience is relational because this is not always self-evident in Hurley's prose, but it was his intention that ambience should be understood in this way - "ambience and provenance are not ... characteristics of entities but of relationships between entities" (Hurley, 1995b, p. 254), meaning that "an entity that is ambient in one relationship can stand as provenance in another" (Hurley, 1995a, p. 36).

Besides enabling external validation of provenance data, description of ambient context facilitates understanding of the record in terms of the circumstances surrounding its creation, annotation, or use (Hurley, 1995a, pp. 22-23). Also, because description of provenance entities affords access to records (Hurley, 1995b, p. 257), description of ambient entities generates more potential access points. Context (in the intransitive dimension), however, is rich and, and even when knowledge of it can be gained from observation of the empirical, "observation is impaired by the subjectivity of perception" (Hurley, 1995a, p. 36). This means that, just as different decisions are made about the 
identification of a provenance entity, different decisions are also made about identification of relevant aspects of ambience.

It is when related bodies of records are encapsulated within different ambiences - or "contextual frameworks" (Hurley, 2013) - that Hurley has seen the problem of parallel provenance to occur (Hurley, 2005b, pp. 70-71). It occurs because descriptive paradigms and systems lack the specificity and flexibility needed for depiction of records in relation to the numerous provenance and record entities and numerous provenancial circumstances with which they may have actually been associated. "Developing methods to deal with parallel provenance", Hurley (2005b) said,

involves an intricate twofold approach. On the one hand, there must be an assault on tradition - exposing limitations of views that are too narrow and confused. On the other hand, tradition must be defended against an undiscriminating application of any old contextualisation without regard for distinctions (whatever they may be) between those which confer true contextual understanding of the contingent circumstances in which records came into being and were used (and which they evidence) and those which do not. (p. 56)

\subsubsection{Debates over the record-as-evidence paradigm - continuum theory positioned, misplaced, excluded, and repositioned}

During the late 1990 s and early part of the twenty-first century the practical problem on which most continuum thinking focused was systems and standards development for contemporary organisational recordkeeping. In this field continuum thinkers had significant international influence (McKemmish et al., 2009, p. 4449). Their attempts to bring practitioners and theorists with more of an archival orientation into the continuum paradigm were less successful. Outside of Australasia mainstream archivists, still deeply informed by the traditional paradigm, were dismissive of the continuum notion that contemporary records management practice and archival practice could be addressed within a single set of recordkeeping standards (Upward, 2009, pp. 82-83). Also, inside and outside Australasia, Hurley's case for highly relational, semantically precise, and spacetime situated descriptive practice generated little change in actual practice (Hurley, 2008, p. 3). However, a wealth of suggestions for improvements to practice made by archival 
science's 'postmodern' theorists during the 1990s and 2010s also elicited little practical response (Cook, 2011, p. 618).

In 1996, just ahead of publication of the first article in which Upward introduced his records continuum model, an article, authored by McKemmish and demonstrating continuum theory's relevance for personal recordkeeping was published. ${ }^{51}$ The article, "Evidence of me", was deeply engaging. Speaking personally and as a practitioner, it was the first piece of continuum writing to stimulate my interest. In this article McKemmish looked to literary sources to cast light on the forces that drive personal recordkeeping behaviour (including record destruction). What stimulated my interest, largely because it was disconcerting, was the juxtaposition of writing as easy to read as any novel with an argument - made in the seemingly ill-matched language of organisational recordkeeping. I remember struggling with the idea that identification and categorisation of personal relationships might serve similar purposes in recordkeeping to that served by the identification of the functions of organisations. I was not at all convinced that any relationship could be typed in a single way, except in a legal sense. In seeing that as an issue, I was, of course, thinking in terms of absolutes, rather than space-time situated variations, mixes, and gradations.

There are things we do as readers. Speaking for myself (though I believe it is common), as a practitioner what I read was determined by what was readily available to me, which part of that available material interested me, and how much time I had for reading. I read single articles, rather than bodies of work by a single author or on a single subject. This meant that conceptually I was not always in the same space as the author (this is hard to achieve in many circumstances, especially when authorial inconsistency or metaphorical obscurity is contributing to the comprehension problem). I was, therefore, inclined to 'read' inappropriate meanings into familiar words and to 'skate over' unfamiliar words. Confirmation bias was an issue of which I was unaware - I tended to react positively to writing that seemed to confirm my prior thinking and negatively to all that was discordant. I still do. We all do (Bilalić, M., \& McLeod, 2014). Verne Harris did when he read "Evidence of me" (Harris, 2001b).

\footnotetext{
${ }^{51}$ McKemmish (1996) was published in the first 1996 issue of Archives and Manuscripts and Upward (1996) was published in the second.
} 
Harris (2001b) read "Evidence of me" from a Derrida privileging 'postmodern' stance. He commended McKemmish on having addressed an issue "of seminal importance" (p. 8) and on having flagged "her difference from narrow 'record-as-evidence' formulations" by recognising the importance of bringing "the dynamics of storytelling" (p. 11) into play and by suggesting that personal recordkeeping can be thought of as a "kind of witnessing" (McKemmish, 1996, as cited in Harris, 2001b, p. 11). That said, he claimed McKemmish had squeezed the concept of witnessing "into the claustrophobic space of recordkeeping functionality" (p. 12), She had not recognised, he said,

that witnessing is a terrain without horizon, always stretching beyond evidencing and memorialising, embracing (without hard boundaries between them) interrogating, constructing, resisting, imagining, narrating, fabricating, hiding (from), forgetting, healing, and so on (and on). That witnessing, contrary to its conventional usage, cannot submit to an economy of proof, certainty and information. As Derrida has said of 'testimony', 'there is no testimony that does not structurally imply in itself the possibility of fiction, simulacra, dissimulation, lie, and perjury'. (p. 12)

"Why", Harris (2001b) asked, "should the capacity to witness through personal records depend on the degree of 'functionality'" (p. 12)? This is a question to which I return in Chapter Seven.

What is clear to me, as I read Harris (2001b) from a continuum-informed stance (rather than my prior continuum-ignorant stance), is that his concept of evidence was much narrower than McKemmish's. He seems to have thought that in the continuum paradigm there was no space for uncertainty, variability, emotion, fiction, or poetry. Standing alongside Harris's narrow conceptualisation of evidence was a broad concept of record coupled with an incorrect assumption that McKemmish's concept of record was narrow and Eurocentric (p. 14).

Harris's deconstructive technique involved two manoeuvres. One was to draw attention to matters McKemmish (1996) had not addressed or had touched on only lightly and, thereby, imply that those absences in McKemmish's article were also absences in her thought and in continuum theory. The other was to cast McKemmish as perceiving too 
much in terms of hard boundaries and certainty. He saw her, for example, to be of the view that "the boundary between 'personal recordkeeping' and 'corporate recordkeeping'" was "self-evident", "clear, stable, and hard" (Harris, 2001b, p. 18). This was simply wrong - it revealed Harris was unaware of foundational continuum theory. Equally inappropriate was Harris's implication that McKemmish, in not having identified a specific stance or cultural space relevant to the case she was making, was suggesting the imposition of a formulaic space-time insensitive understanding of recordkeeping (Harris, 2001b, p. 13).

Harris's reading of "Evidence of me" was clearly shaped by ignorance of the spacetime dynamic at work in continuum theory as meta-theory; and, no doubt, also shaped by his own 'postmodernist' need to seek out examples of positivism. For all that, Harris (2001b) saw much to endorse in McKemmish (1996). Likening personal recordkeeping to a "wilderness", he drew attention to her "unswerving" "respect for wilderness", her belief that archivists might have to accept "they "cannot play much of a direct role in ... processbased aspects of personal recordkeeping" (McKemmish, as cited in Harris, 2001b, p. 20). Harris (2001b) asked whether they should even try - "it could be argued", he said, "that wilderness areas are best (con)served by preventing breaches" (p. 20). That may be, but when the 'wilderness' of the personal is institutionalized (as happens in collecting archives and whenever personal documents find their way into the 'public record'), how then is the 'wilderness' of the personal best conserved ? $^{52}$ This question brings us back to somewhere near the point where McKemmish (1996) began - what functionality is required from the recordkeeping systems of those institutions if the products of personal recordkeeping are to serve as "socio-historical evidence" (Hurley, as cited in McKemmish, 1996, p. 41)?

Harris (2001b) invited deconstruction of his own deconstruction (p. 11). Upward and McKemmish (2001) responded by "reconstructing the possibilities in 'Evidence of me"" (22). They pointed out that "Evidence of me" had been "an exercise in professional

\footnotetext{
${ }^{52}$ The word wilderness is problematized here because it implies the existence of distinct spaces, an institutional and professional space, on the one hand, and, on the other hand, a personal space wholly unaffected by institutionalized norms. This type of dichotomization is logically incompatible with continuum theory and with continuum writing on personal recordkeeping (McKemmish, 1996; McKemmish \& Piggott, 2013; Upward \& McKemmish, 2001).
} 
knowledge formation" which Harris had critiqued "in terms of general metaphysics" ( $p$. 24). In other words (my words), Harris had raised issues that were outside the purview of archivists and recordkeepers. As a post-structuralist theory, continuum theory was concerned with setting out the "rules" that "define the pragmatics of its transmission", with enabling the integration of narratives so the recordkeeping community could work out "its competencies, its purport, its meanings" (p. 25).

Continuum meta-theory is difficult to communicate in succinct terms. Over time continuum thinkers have experimented with terminology and style. In 2001 Upward and McKemmish were using music as an analogy. They wrote of the "rhythms" and "metre" of the continuum in an attempt to counter reader tendencies to interpret the model in terms of fixed and closed zones. They said Harris had not heard the "music resonating in the text" of "Evidence of me", and that had led to his reading being "at times discordant" with "the music of the infinite, of the continuum" (Upward \& McKemmish, 2001, p. 23). They followed up by explaining the fundamentals of continuum thinking in more concrete terms and invited Harris (and others) to engage more deeply.

Upward and McKemmish (2001) maintained that the "evidential quality" of a document is "integral" to its "'recordness", and that this means transactionality and contextuality are at the heart of "recordness". In records continuum discourse, they explained, "contextuality is concerned with the record's rich, complex, and dynamic social, functional, provenancial, and documentary contexts of creation, management, and use through spacetime" (p. 27). Transactionality, they said, should be understood "in terms of the many forms of human interaction and relationships that are documented in records of all kinds at all levels of aggregation" (p. 27). This is an ambiguous statement; one which could easily be read as referring to the aboutness of text. The words "documented in" give that impression, though I believe Upward and McKemmish also had in mind the type of transactionality I previously argued to be at play in Jenkinson (1922) - i.e., the idea that, in the simple fact of their being and their being-in-relation, records can be seen to 'document' (or evidence) something of the circumstances in which they were created and have been used. 
In the years immediately following this 'deconstruction' and 'reconstruction' of "Evidence of me" continuum thinkers continued to focus most of their attention on matters relating to contemporary recordkeeping. This, as Reed (2005) pointed out, meant little continuum literature addressing "the cultural dimensions of recordkeeping" (p. 177) was generated. Outside of the continuum community, on the other hand, a substantial volume of such literature was published. Unfortunately, little direct mention of continuum theory was made despite ongoing critique of recordkeeping discourse and its explicit privileging of evidentiality in its concept of record.

Brothman (2002) tackled this theme in an article in which he argued that talk of evidence had become widespread in the domain's discourse only in the past ten years (p. 312), and that "record keeping" claims that evidence could be created in the form of records were mistaken because they did not recognise that there is an essential "temporal" difference between the two concepts (p. 312). Records, he said, can be created, but evidence must be found - it "arises out of processes of social negotiation after the fact" (p. 334): "What evidence a record serves up - what it is evidence for - is something that only becomes manifest through later use, not during the present-centred act of record creation" ( $p$. 335).

The "record keeping" authorities Brothman (2002) cited were Bearman (1994), various drafts of the International Standards Association's standards for records management, and Luciana Duranti, who was leading the InterPARES project. None of Australia's continuum thinkers were included, so one cannot say that Brothman's critique of "record keeping" discourse was a critique of continuum theory. Nor can one say that it was not he, like others at the time (and still), may have understood the theory only in terms of its recordkeeping discourse. Either way, he argued that those participating in the "record keeping" discourse were purveying a single essentialist "strong sense" (i.e., closed and rigid) notion of record (p. 315). "Once questions of evidence predominate as primary preoccupations of the archival profession", he said, "issues of truth, truthfulness, and proof come to displace concerns about meaning, understanding, and interpretation" ( $p$. 331). 
An article by Duff and Harris, published later in 2002, commended Brothman and kept the same theme going. In "Stories and Names: Archival Description as Narrating Records and Constructing Meanings", Duff and Harris (2002) reflected on the nature and limitations of archival descriptive practice and on issues associated with standardisation, in the lead up to sharing their vision of a "liberatory" standard. They argued the case for a descriptive paradigm which could well have been argued from within the continuum framework; yet, by not discussing that framework and by representing the continuum discourse narrowly and completely misrepresenting some parts of that discourse, Duff and Harris implied they were imagining a future continuum thinkers did not imagine, and could not imagine unless they were to move out of the paradigm they were promoting. The records continuum model, for example, was described as "a model" developed by "Sue McKemmish and her colleagues", that "focuses on the role that functions, activities, and record-keeping systems play in the creation of records" (p. 269). There was no mention of space-time distanciation, of variability (of concepts, of words, of actions, of perceptions), or of the notion that records are "always becoming" (McKemmish, 1994, p. 200). There was, however, an oblique reference to Hurley (neither he nor the source was named). In arguing that the key purpose of archival finding aids is to enable a record to be understood and interpreted in relation to "the circumstances which existed at its creation and the changes since", Hurley (1998) had spoken of the need for them to be located in "a time-bound, evidential cocoon of meaning" (p. 74). Duff and Harris re-used that metaphor and, in doing so, misrepresented the discourse within which it had been generated:

A liberatory descriptive standard would not position archives and records within the numbing strictures of record keeping. These strictures position 'the record' as cocooned in a time-bound layering of meaning, and reduce description to the work of polishing the cocoon.... In contrast, a liberatory standard ... would posit the record as always in the process of being made, the record opening out of the future.... It would seek to affirm an open-ended process of making and re-making (Duff \& Harris, 2002, p. 284).

And that is precisely what McKemmish and other continuum theorists had been arguing. 
As Harris had in earlier articles, Duff and Harris (2002) associated "record keeping" and "evidential value" with "legal and corporate perspectives". They saw "the series system" as part of that purportedly narrow conceptual bloc. The notion of evidential value and Hurley's advocacy of highly relational (and not series-privileging) descriptive practice were said to show a lack of interest in user perspectives. Do users not want to be able to see a record in the context that surrounded it at the time of interest to the user? Duff and Harris did not address that question. Instead they seemed intent on presenting all those engaged in "record keeping" discourse as so concerned with imposing one meaning that they were in denial of the possibility of other equally valid viewpoints and interpretations. If this was how they saw continuum thinking (which, I believe, they really did not see at all), they saw it, not in its own cocoon of meaning, but in one of their own spinning.

Unfortunately, these second hand accounts - these misunderstandings and misrepresentations - of continuum thinking took on a life of their own. They became truths that were not truths, and became mixed with other persisting truths that were not truths. Fisher (2009), for example, argued "much contemporary archival theory is not relevant to the practice of private archives" (p. 24) and, therefore, different theory needed to be developed. He did not explain how he intended the term private archives to be interpreted. As I read it within the context of his article, he had borrowed it from Schellenberg, who my discourse analysis showed had used it inconsistently. Fisher (2009) seems to have been doing the same, using it, on the one hand, as a 'catch-all' for the organisational and personal records typically found in collecting archives and, on the other hand, to refer specifically to personal records. Ignorant of the part a politics of othering had played in the archives domain's traditional discourse, Fisher staked his claim that there are essential differences between public and private records in the authority of Jenkinson and Schellenberg who, in his reading, had done "much to define the theoretical characteristics of private archives" (p. 2).

In addition, Fisher (2009) saw the fact that perception of difference had persisted as proof of an enduring difference (rather than as proof of enduring attachment to a paradigm). Theorists who had urged archivists to move beyond institutional versus cultural dualisms, therefore, seemed to be in denial of differences which, from Fisher's perspective, were unquestionable. He named Terry Cook and Laura Millar (Canadian theorists whose 
thinking was relatively continuum-informed) and McKemmish. By connecting the words evidence, structure, functions, and accountability and, then, disconnecting that set of words from the words research, memory, heritage, and cultural value (p. 24), Fisher revealed himself to be conceptually disconnected from the deeper levels of theory driving continuum and near-continuum thinking. He revealed this also in his critique of "Evidence of me". He claimed McKemmish had been promoting an "easy answer" to the development of theory relevant to the personal; i.e., simply translating "the essential concepts of government recordkeeping ... to personal archives" (p. 4). In making this charge, he cited Harris's critique of "Evidence of me" (Harris, 2001b), but made no comment on Upward and McKemmish's reply to that critique.

Hobbs (2010) pursued a similar line of argument. She drew attention to the volume of literature that has seen personal records as essentially different to organisational records and suggested that those who have argued "in favour of a single conception of record" were rejecting everything "associated with the manuscript tradition" (p. 215). She focused a good deal of attention on McKemmish's "Evidence of me", Harris's deconstruction, and Upward and McKemmish's response; but in ways that suggested she was reading the continuum articles through Harris's eyes. She did not discuss foundational continuum theory or show any sign of understanding that theory. Instead, she cited passages from the continuum articles which used terminology with business and organisational connotations - e.g., rules, protocols, transactionality, function, business, and structure (which she clearly interpreted as referring only to the orderly arrangement of archival aggregations) - as though the words were sufficient in themselves to reveal continuum theory's conceptual space. Her treatment of Harris's deconstruction, on the other hand, was affirming. In discussing it, she highlighted language with connotations of the idiosyncratic and uncontrollable - e.g., dys-functionality, resisting, hiding (from), wildness, and wilderness - and uncritically repeated Harris's assertion that McKemmish's concept of record was "static" (pp. 217-219).

The general gist of the argument Hobbs (2010) made against McKemmish and Upward's continuum writing was that it "turns personal archives outward into what record we, as archivists, are creating of society" (p. 218). Hobbs saw a need "to redirect the debate toward the character and interiority of the individual rather than socially conditioned 
roles and behaviours" (р. 220). In saying this, Hobbs made no reference to Upward and McKemmish's discussion of interiority and exteriority, which argued (amongst other things) that others are in our stories, and we are in their stories - to think otherwise "would be to establish an unbearable binary opposition, another dead end" (Upward \& McKemmish, 2001, p. 42). However, I also missed their point in my first readings.

Following Harris (2001b), Hobbs (2010) argued "the evidentiary viewpoint" did not admit "the anomalous behaviour in personal recordkeeping and the 'wildness' in personal archives" (p. 221). "The term 'evidence", she said, "acts to render personal archives in the realm of the factual and juridical: it is a word that lodges us in the realm of public accountability by its very meaning [emphasis added]" (p. 221).

Four years earlier Jennifer Meehan, also a collecting archivist, had looked at the word evidence from a different perspective. Meehan (2006) saw evidence as

an important concept for archivists - both for its explanatory power (what it has to say about the nature and value of records, and about the purpose of the archival endeavour and the role of the archivist in society) and its normative power (how it contributes to shaping archival ideas of how to treat records and guiding practice). (p. 129)

Despite its importance, evidence, Meehan (2006) said, was not adequately understood in conceptual terms - on the one hand, its meaning was taken as self-evident and, on the other hand, it was narrowly conceptualized in relation to "legal rules, accountability, and corporate memory" (p. 127). Though recent writing "by those working outside the sphere of electronic records and organizational record-keeping, and by those exploring the ideas of postmodernism" had begun questioning "current conceptions of evidence and their predominance in archival discourse", she said, that writing had cast little "meaningful light" on "what evidence ... means for archivists." Instead a "sharp distinction" had been drawn "between records as evidence and records as memory". The former, she said, was aligned "with the record-creator's perspective" and the latter "with the record-user's perspective". Thinking in terms of "binary oppositions (either evidence or memory)", she said, has "kept us from fully considering the possible affinities between different, though not necessarily differing (in the sense of conflicting), archival ideas [of evidence]" (p. 130). 
Though I see the situation as more complex than Meehan (2006) described it, I agree that the conceptualization of evidence and evidentiality, which has been deeply explored in relation to the record-creator's perspective, has been inadequately explored in relation to the record-user's perspective. In the record-creating discourse the emphasis has been, quite rightly, on understanding what characteristics records need to be authoritative evidence of organisational activity - and, therefore, on "strong sense" notions of record, as Brothman (2002) put it. Records, however, "exist in all types of states, adequate, inadequate, complete, lacking etc." (Reed, 2015, July 10). For this reason, there is a need to deepen understanding of evidence and evidentiality in relation to emergence from inadequate and incomplete sources, if those who receive and use (rather than create) records are to see a place for themselves in the evidence-privileging paradigm. Also, like Meehan (2006), I see a need for reflection on where and how the evidence-creating, evidence-preserving, and evidence-discovery perspectives intersect.

In what she described as a preliminary enquiry, Meehan (2006) began the task of trying to develop a meta-concept of archival evidence, one which would bridge the divide between the contemporary record-creation perspective and the access provision perspective. Drawing on Anglo-American legal discourse, she argued that an archival concept of evidence might be thought of as a relation between a record and the event which gives rise to the record (p. 128). "The event", she said, "is an instance of factum probandum (the fact to be proved) and the record is an instance of factum probans (the fact that proves) and the relations between these two facts [emphasis in original] comprise matters of evidence" (p. 139). Meehan's intent in making this statement was not to suggest that one record is related to only one event; rather, "evidence signifies the various possible relationships between record and event" (p. 139). Making these relationships explicit, Meehan argued, is the common concern of all recordkeepers and archivists (p. 142).

Meehan's archival science paradigm was 'postmodern'-informed, but continuumunaware; her concept of record was traditional in that it assumed records to be distinct bounded objects, the recordness of which is afforded by external relationships. At one point Meehan (2006) asserted that a record is a "physical object" (p. 140). Probably this was a terminological slip. A terminological slip, of course, can also be a Freudian slip - 
Meehan was clearly imagining the born-digital record in light of a physical prototype, as both Yeo (2008) and Reed (in Cunningham, Miller, \& Reed, 2013) have argued is common. She paid no heed to the possibility that records might be conceptualised in terms of varying degrees of granularity.

Meehan's conceptual paradigm led her to two conclusions that, from a continuum perspective, need to be questioned. The first was her belief that evidential relationships cannot be contained within a record - she referred to Duranti (leader of the InterPARES project) as one who has argued evidential relationships can be inscribed in records (Meehan, 2006, pp. 139-140). The second was Meehan's belief that treating and using records as evidence "invariably" involves a process of inference (p. 141). This sits uneasily alongside Hurley's assertion that archivists' descriptions of relationships should be based on what is known and can be observed, and not on inference (Hurley, 1995a, p. 36). This point had, of course, previously been argued by Jenkinson (1922). Viewing inference as being this significant in relation to the documentation of record context also does not recognise that one reason the recordkeeping discourse has focused so much attention on capture of metadata at the time of record creation (and re-creation) is because it is when one is close to the action to be described that one is most able to observe that action (Evans, et al., 2009, p. 135). In other words, where the archivist/recordkeeper stands in relation to the events to be described has epistemic consequences which Meehan did not discuss.

In arguing their different stances in relation to observation and inference, Hurley (1995a) and Meehan (2006) dichotomised these perceptual processes. Hurley's stance was similar to Jenkinson's - it assumed the possibility of objective knowledge (not of everything, but of those things that can be empirically experienced). Meehan's stance was consistent with the commonly expressed 'postmodernist' claim that the knowledge that fills the "empty shells" of "standards, databases, templates, and models" will "always, by definition, be subjective and interpretive" (Cook, 2011, pp. 618-619). In other words, Hurley and Meehan imagined perception in terms of polarized epistemological paradigms. As a critical realist, I need to ask whether the difference between observation and inference is that clear-cut. Assuming there is a significant difference, and accepting that archivists (especially those describing historic records) do make inferences, there are other 
questions to be asked, such as whether archivists' inferences assist or mislead researchers and whether there are steps that can be taken to mitigate the effects of incorrect inferences.

Less problematic in relation to the continuum paradigm is Meehan's claim that making the relationships between records and events explicit is the common concern of all working in the field. Continuum theorists do not typically use the word event. ${ }^{53}$ However, they do argue the importance of making relationships between 'record entities' and provenance entities explicit. Their point of difference from Meehan (2006) is that they see the act of making space-time situated relationships explicit as necessary for the emergence of recordness as well as for the emergence of the record's evidentiality (McKemmish et al., 2009, p. 4451). Applied to physical entities (as well as digital entities) this implies a relationship (or set of relationships) that is external to that entity is internal to that entity when it is captured as a record - evidentiality and recordness, in other words, co-emerge. These are issues I discuss further in Chapter Six where I suggest that the act of making such a relationship explicit may be 'internal' ('capture' within the mind of a researcher) or, to varying extents and in varying ways, externalised.

Another point of similarity between Meehan's thinking and continuum thinking rests in her having drawn attention to the role inference about future uses and the nature of the descriptive metadata needed for enabling those uses plays in the development of standards and systems. Upward took essentially the same stance when he developed his process-privileging continuum models. Not surprisingly, Meehan (2006) argued the value of shifting "focus from the nature of the thing that serves as evidence ... to the nature of the process that uses (or treats) the thing as evidence" (p. 144). This is continuum thinking. So too is her claim that this shift of focus

serves to dissolve certain conceptual distinctions between public and private records, organizational records and personal papers, and textual and non-textual records, and provides a means to better account for the whole range of possible

\footnotetext{
${ }^{53}$ The word event, however, could be placed on the records continuum model's transactional axis. I discuss it further in Chapter Seven.
} 
archival material.... [and] also opens up space for considering prospective and retrospective notions of evidence, and for potentially reconciling the two. (p. 144)

Geoffrey Yeo is another who has discussed the conceptualisation of evidence. He did this in the first of two articles $(2007,2008)$ concerned with the nature of records and the problem of definition. Given this larger agenda, his motivation for discussing evidence as a concept differed from Meehan's. Whereas she was looking to extend understanding in order to bridge divisions within the domain, he used the fact that division exists as justification for defining records without reference to their evidentiality (he foregrounded the word representation instead). This means, in one sense, Yeo (2007) did not advance understanding of the concept of evidence. However, in another sense he did because, in problematizing the possibility of whether a unified conceptualisation of evidence could ever be achievable, he identified issues that would need to be addressed in any serious attempt to understand evidence at the level of meta-concept.

One issue to which Yeo (2007) drew attention was the existence of different views on whether evidence is an entity or a relationship. He cited Duranti as one who has argued that "evidence is not an entity, but a relationship ... between the fact to be proven and the fact that proves it" (Duranti, 2002, as cited in Yeo, 2007, p. 324), but pointed out that it is more common for the word evidence to be used to refer to "materials evidencing a proposition" (Wigmore, 1931, as cited in Yeo, 2007, p. 324). Meehan (2006), of course, also argued evidence to be a relationship. In that respect she did not differ from Duranti. Rather, her point of difference from Duranti was that Duranti believed the relationship could exist inside a record and Meehan believed it could not. So, is evidence an entity or is it a relationship - or, if it is both, how can that be explained? These questions are explored in Chapter Five.

In problematizing the record-evidence relationship, Yeo (2007) drew attention to disputation over the question of whether evidence can ever be said to exist except for in the context of some specific human need, use, or reading. The fact that, in a single context of enquiry, different people may have different views regarding the relevance and, therefore, evidential status - of a specific entity, he said, raises questions about the extent to which we can say anything has objective evidential characteristics. Agreement 
about the nature of evidence is highly problematic when some people dispute the validity of an evidential relationship that others stand by, or when an item of evidence's relevance to a matter it was once believed to cast light on is exposed as unfounded ( $p$. 325).

In discussing the conceptualisation of evidence, Yeo (2007) did not draw attention to the fact that an abstract concept is ontologically different to the actual phenomena in relation to which the abstraction has been framed. Failing to make this distinction is commonplace because often the word used to signify an abstraction (e.g., evidence) is often also used to signify the phenomena with which the abstraction is concerned. Diversity at the level of evidential engagement with the lower level phenomena does not necessarily mean that there is nothing broadly applicable that can be said at the higher abstract level. ${ }^{54}$ Yeo (2007) did not pursue that possibility. Rather, he concluded his discussion of the nature of evidence by saying consensus on the question of how the concept of record stands in relation to the concept of evidence "is unlikely" (p. 326). That statement was, of course, grounded in scepticism about the possibility of arriving at an agreed and objective understanding of the nature of evidence.

It was also grounded in a certain understanding of the nature of records. Like Meehan (2006), who he did not cite, Yeo (2007) appears to have been continuum-unaware. He did not discuss (or even allude to) the notion of record as logical entity or conceptual construct. Rather, like Meehan, he saw records as "specific entities encoded spatially and bounded at the time of their creation" (p. 324). This naturally led him to argue that, if "evidence is not an entity, but a relationship", then records could not be defined as evidence. If, on the other hand, the word evidence was taken to refer to "materials evidencing a proposition", there was a closer correspondence between the two concepts. However, he did not see this in itself as providing grounds for claiming evidentiality was such a significant characteristic of records that it should be treated as definitional. Following Brothman (2002), who had argued "evidence derives from the use of records" (Yeo, 2007, p. 325), Yeo suggested that evidence might be better thought of as an affordance of records than as a defining characteristic. When records are looked at in

\footnotetext{
${ }^{54}$ This is the major point made by Schum (1994).
} 
terms of their affordances, he argued, it has to be acknowledged that they are valued not only for the evidence they afford, but also for other "goods" (Yeo, 2007, p. 329) they are seen to provide. They are valued, for example, for their aesthetic qualities, as memory, and because they provide a sense of social or personal identity.

Yeo (2007) saw Harris's description of records as cornucopias of meanings as synonymous with his own notion of records as providers of many different goods (p. 330). He made no reference to Upward's concepts of monistic diversity and multi-polarity, and no attempt to work through semantic differentiation between functional diversity and diversity with respect to the contexts in which a record might be seen as meaningful. Nor did he consider the question of whether records might be able to afford goods such as meaning, memory, and a sense of identity precisely because records have evidential qualities. Also, he did not discuss the possibility that in suggesting records could be characterized "as persistent representations of activities or other occurrents, created by participants or observers of those occurrents or by their proxies; or sets of such representations representing particular occurrents" (p. 136), he was merely foregrounding the evidential characteristics of records without using the word evidence.

Gee (2005) warned that terminological sameness or difference is not in itself a reliable marker of conceptual sameness or difference. This is a point also made by Schum (1994), who argued that evidential concepts exist and are important in all disciplines, but are often expressed using words other than evidence (p. 5). I would suggest that, in the archives domain, the word provenance, which has always been centrally important both in relation to the concept of record and in relation to the arrangement and description of records, is such a word. In Chapters Five to Seven, I will demonstrate, with reference to my case study experiences, that the authenticity and granularity of provenancial relationships are fundamentally important for establishing the relevance of evidence. Verbally provenance and evidence are not included in Yeo's definition, but conceptually both are there.

One of the affordances of records on which Yeo (2007) did focus attention was information. As was the case with evidence, he was more motivated to problematize and raise questions about the validity of assigning the word information definitional 
significance in relation to the word record than motivated to reconcile different understandings and perspectives. Amongst other things, Yeo raised the question of how information as a concept stands in relation to evidence as a concept. This is a question that had previously been addressed (up to a point) by Furner (2004) in an article titled "Conceptual Analysis: A Method for Understanding Information as Evidence, and Evidence as Information". This article, cited by neither Yeo (2007) nor Meehan (2006), is primarily concerned with demonstrating conceptual analysis as a method. Therefore, it needs to be understood as preliminary in terms of its findings relating to the concepts it was exploring. Nevertheless, in a text focused more on conceptualisation of evidence than of information, Furner (2004) made a number of points pertinent to my research.

One point Furner (2004) made was that analysis of the conceptualisation of relevance in relation to archives domain evidential concepts could be more interesting than analysis of the conceptualisation of information (p. 235). My 'thought experiment' is not the type of comparative conceptual analysis Furner modelled. Other, than noting relevance tended not to be amongst the evidentiality-connoting words commonly used in archives domain discourse (words such as authenticity, reliability, and integrity take centre stage), I did nothing with Furner's suggestion other than let it sit in my mind as I conducted my case study research (which is how I dealt with much of the knowledge I acquired during the discourse analysis). As it transpired, relevance turned out to be a highly significant concept. I discuss it further in Chapter Five where I explore how evidence emerges, in Chapter Six where I explore the nature of records and the evidence-record relationship, and in Chapter Seven where I discuss my findings in relation to the design of knowledge enabling systems.

Two other concepts of value that came to me via Furner (2004) are evidence-as-trace and evidence-as-testimony. Unfortunately, Furner introduced them in the context of a very light discussion of the conceptualisation of evidence in archives domain literature, which included a questionable interpretation of Schellenberg's notions of evidential value and informational value. Furner (2004) said,

For Schellenberg, a record's evidential value is an index of its utility in documenting the circumstances of its creation, whereas its informational value 
reflects the importance of its symbolic content. The possibility of confusion is thus introduced by Schellenberg's use of the term "evidential" to refer only to evidence of a real (rather than documentary) kind. In historical scholarship and in the law, Schellenberg's distinction is an important one, but it is one that is drawn between different kinds of evidence (i.e., between real evidence-as-trace and documentary evidence-as-testimony) rather than between evidential and nonevidential values. (p. 245)

In my discussion of traditional discourse, I argued the notion of documentary evidence-astestimony underscored both Schellenberg's concepts of value. I cannot understand how Furner (2004) reached his conclusion, though I certainly agree with his secondary conclusion that the term informational value has led some archivists to believe that evidentiality as a general concept is relevant to only some records. Though Furner neither explained his reasoning nor cited a source, bringing attention to the fact that documents can be used as "real evidence-as-trace" or as "documentary evidence-as-testimony" was useful. ${ }^{55}$

Explicit differentiation between aboutness (testimony) and being (trace) is generally absent from the archives domain's record-centring discourse. Rather, transitive dimension and intransitive dimension dynamics tend to elide in the concept of record. Such elisions open the way for arguments at cross purposes that lead to dead ends. Questions such as whether records are objective or subjective and whether records are or are not trustworthy evidence can be debated forever when the parties to the debate do not recognise that one side is focused on the record's intransitive dimension ('record-astrace') and the other side is focused on its transitive dimension ('record-as-testimony').

Schum (1994) discussed the notions of evidence-as-testimony and evidence-as-trace in considerable detail. He positioned that discussion in the context of a "major question". That question is "How do I stand in relation to this evidence" (p. 93)? In continuum terms, this is a question addressing the issue of spacetime distanciation. The reason for asking it is because being able to examine the evidence oneself is quite different to having to rely

\footnotetext{
${ }^{55}$ Furner's information did not come from Cook (1997), who he cited twice elsewhere on the page where he made this statement. No other archives domain sources were cited on that page.
} 
on somebody else's testimony, assertion, or belief that an event occurred. Evidence one can examine for oneself is tangible, in Schum's terms. In critical realist terms, it is in the domain of the empirical. In law, Schum said, it is "called real evidence" (p. 93). Though such evidence can be examined, its meaning in relation to the matter of interest "is not always obvious" (p. 93) and, for a host of reasons, we may be wrong in our judgments about what such evidence reveals (p. 94).

Documents are amongst the things Schum (1994) listed as tangible evidence. However, documents are complicated because, though tangible evidence, they are often also testimonial evidence. When what is of interest in an enquiry is the testimony embedded in a document, "you stand to varying degrees more remote from the occurrence or nonoccurrence of events than you do when you have tangible evidence of those events" (Schum, 1994, p. 94). How the testimony is grounded plays a significant part in determining the degree of remoteness.

According to Schum (1994) testimony can be grounded in three different ways. Firstly, the person who "testifies about some event" could have made a "direct observation" or "had some direct sensory interface" "in some situation in which this event could either have happened or not" (p. 94). Because "testimony on the basis of direct observation can ... only concern past events or events that happen in the rapidly fleeting 'present' [Upward's flicker]" (p. 94), there are questions to be asked about the completeness of the perception as well as about the honesty of the witness.

The second way in which testimonial evidence can be grounded is in others' reports of their observations or even in "a chain of sources, some of which may not be other persons [e.g., somebody in the chain may report something they recall having read]" (p. 95). This gels with Yeo's notion that records are often comprised of "tiers of representation" (Yeo, 2010c, p. 104). It means that, as testimonial evidence, records are not always primary sources, or even necessarily secondary sources.

According to Schum (1994),

The number of occasions on which we have to make use of secondhand or $n$th hand information is truly astonishing. In some situations we hear testimony in 
which no primary source (a person making a direct observation) can be identified. We have a name for such testimony; it is called rumor or gossip (p. 95).

Do rumour and gossip have anything to do with evidence and evidentiality? This is not a question Schum (1994) asked; but it is one that can be carried into the case study research.

The third way in which Schum (1994) said testimonial evidence can be grounded is in inference. For example, a person may have "observed events $C$ and $D$, and so ... inferred or guessed that event E also occurred" (p. 95). Alternatively, the inference may be grounded in something other than direct observation of related events. It might, for example, be grounded in hearsay, in authoritative sources (e.g., tables of physical constants such as tidal occurrences), or in "accepted facts" (e.g., that "the population of New York City exceeds that of Omaha") (p. 97).

In other words, in assessing the credibility of the testimonial evidence contained in documents, what matters is not so much how geographically or chronologically distant from the matter of interest one is, as how testimony regarding the matter of interest is grounded and how it has been mediated.

Schum (1994), of course, had much more to say about evidence and reasoning from evidence. His book came to my attention only after I had conducted my case study research. Therefore, only parts of all he said on the subject of evidence have found their way into my thesis. He is referenced at various points in my text. Furner's conceptual analysis was necessarily shorter (32 pages as opposed to Schum's 545). However, it played a much greater part in my work. Rather than run through Furner's thoughts on the nature of evidence here, I discuss those that prove to be highly relevant to my own work in Chapter Five where they are brought into relation with my case study observations.

Before setting Furner (2004) aside, however, there is one more aspect of his work that warrants attention here. This is that he saw questions relating to objectivity, subjectivity, and epistemological differences as relevant to the conceptualisation of evidence. Matters of objectivity and subjectivity have, as I have demonstrated in this chapter, been recurring tropes in archives domain discourse where they have been positioned primarily in relation 
to discussions about the nature of records and discussions about the nature of the work done by archivists. Intriguingly, in contemporary discourse, talk of subjectivity has played little part in talk about the nature of evidence. Rather, evidence has tended to be construed in objectivist terms - hence its otherness in relation to a 'postmodernist' subjectivity-privileging concept of record. This is a (generally un-noted) conceptual and terminological reversal of the paradigm in which Jenkinson (1922) worked - he attached objectivity to the concept of record, but conceptualized evidence itself as sometimes being objective and sometimes being subjective.

Yeo (2010c) saw 'postmodernist' writing of this nature to have perpetuated "the kind of dualism that postmodernist orthodoxy usually wishes to disparage" (p. 108). I saw this too. In fact, I have found myself thinking that certain strands of archival science's 'postmodernist' writing may have been more instrumental in creating the dualism than have been the purportedly positivist authors they critique. I have certainly seen 'postmodernist' caricaturing of positivism playing a part in the process. ${ }^{56}$ Failure to reconcile objectivity with subjectivity - or, as Upward and McKemmish (2001) put it, exteriority with interiority (a more general notion, but one that is pertinent to discussions of objectivity and subjectivity) - generates incommensurable 'dead end' lines of argumentation. As I said in Chapter Two, it was awareness of this that led me to choose a third way theory of knowledge as my philosophical under-labourer.

When Furner (2004) recommended third way theories for future conceptual analysis of evidence, it was not with archival science's disputatious parallel discourses and 'dead end' lines of reasoning in mind. Rather, in his view, archivists, in framing an understanding of evidentiality, should take the epistemological paradigms of historians into consideration. Contemporary historians, he argued, are intuitively third way, even when their reasoning is empathetic:

Successful persuasion is often the result of the application of skills such as the ability to empathize with historical actors or to construct a powerful narrative; but equally as often (and typically simultaneously) [emphasis added] such success is

\footnotetext{
${ }^{56}$ Harris (1997), for example, defined positivism (pp. 132-133) in almost precisely the same terms as Furner (2004) defined a caricature of positivism (p. 243).
} 
reliant on the historian's demonstration that conclusions are justified by means of appeals to (what is taken to be) the evidence, and revised in the light of new evidence. So long as historians' products continue to be evaluated in this manner, it would seem to be appropriate to continue to seek clarification as to the ways in which evidence is (or could be) conceptualized in contexts of this kind. (p. 244)

In archival science literature little attention has been given to the challenge of transcending dichotomous notions of objectivity and subjectivity. The possibility and desirability of doing so appears to have been in Upward's and McKemmish's minds when they argued the importance of not dichotomising interiority and exteriority. However, it was merely hinted at, not teased out. Yeo (2010c) went some way towards transcending epistemologically dichotomous notions of record by bringing concepts from speech act theory into play. Most interesting for me are J.L. Austin's notions of performative and constative utterances.

A constative utterance states or alleges facts that are "presumed to be either true or false" (p. 94). A performative utterance performs an act (e.g. a document transferring ownership of property performs the act of transfer). As Yeo said, a record that serves to both "effect a transaction and to provide evidence of it" can be thought of as a performative utterance (p. 94). These terms are not conceptually dichotomous because constative utterances are always also performative utterances. As Yeo explained, if one says "grass is green", one is, in effect, saying "I state that grass is green" - the constative utterance performs an act of stating (pp. 96-97). In other words (my words), perceptually we can privilege the transitive dimension aspect of the text of a document (i.e., what it says about something else) or we can privilege the intransitive dimension aspect of that text (i.e., its fact of being, and of being an utterance). So a text, even when conceptualised independently from its carrier, can be both trace evidence and testimonial evidence.

After discussing Austin, Yeo (2010c) went on to introduce Searle's classification of speech acts. I will not discuss Searle's concepts because only one is significant within the context of my thesis. That one is Searle's notion of an assertive speech act. This is essentially equivalent to Austin's constative utterance - in an assertive speech act "a speaker or writer sets out a proposition, stating how things are, were or will be" (p. 97). This too 
refers to the transitive dimension - or aboutness or testimonial - aspect of a text. I bring Searle's term to attention because I use it at various points in my thesis in preference to Austin's more arcane term.

Yeo (2010c) argued (as would I) that, when the speech act inscribed in a document is seen as assertive (constative), the correctness of the utterance - of the facts stated - can be disputed. The assertion may or may not be true. When the speech act is seen as performative, it has the quality of inherent objectivity. We may dispute the authenticity of such a document or argue about its interpretation, but we cannot dispute the words stated in it. That said, there are certain assertions that can be taken as objectively true. Yeo (2010c) referred to them as timeless facts (p. 103), a term he applied to assertions of the type Schum (1994) referred to as accepted facts. What is significant about these assertions is that they are accepted as true because they refer to some verifiable (and much verified) characteristic of a stable empirically accessible reality. Is an archival record a "timeless fact" when it is seen as performative, as trace evidence, or in respect of its intransitive dimension characteristics? It would seem to be; and, seen that way, it is impartial.

Speech act theory goes some way towards providing "a middle way between the extremes of objectivist and interpretivist views" (Yeo, 2010c, p. 107). However, as Yeo pointed out, its utility is limited:

It has more obvious applicability to written (and humanly created) records than to visual records or to reports automatically generated by computers. It is most directly applicable to what I have elsewhere called 'elementary records' (records of occurrents at the lowest level). In the terminology of recordkeeping, speech acts may often appear to be steps within activities or transactions rather than transactions complete in themselves, and they probably approximate more closely to transactions than to the higher-level occurrents that archivists call functions or processes; it is not yet clear how far speech act theory could be applied to the construction of composite records representing occurrents at these upper levels. (Yeo, 2010c, pp. 106-107) 
Yeo (2010c) also said "speech act theory has little to say about later interventions in the life of the record or about its interpretation by later users; rather, it serves to aid our understanding of the birth of records" (p. 107). My case study experience suggests it has utility that extends beyond the birth of a document, but only in respect of verbal annotations, which are, of course, also speech acts. However, it does not seem to have anything to say about relationships between speech acts (at least, nothing Yeo disclosed). Nor does speech-act theory say anything about issues of objectivity or subjectivity relating to the carrier of a text or about the material aspects of its inscription. Given too much prominence in the conceptualisation of records, I fear, speech-act theory would reinforce long-lived text-privileging, media-blind perceptions of records and narrow thinking about where evidentiality is located within the highly variable, highly relational, and usually (but not always) content-carrying media archivists typically refer to as records. ${ }^{57}$

The critical realist concept of a transitive dimension which is part of an intransitive dimension addresses the same problem as Yeo (2010c) attempted to address by applying speech-act theory. The critical realist notions, however, are generally (rather than narrowly) applicable. This means they can be used in relation to all types of records, all their component parts, and all levels of aggregation in order to rationalise the objectivity or impartiality of simply being and the (often) co-existing potential subjectivity associated with having content that is about something. The critical realist concepts can also be put to work to enable analysis of all types of 'reader'-record interactions and recordprovenance entity relationships.

In essence, whether we work with Austin's notions of performative and constative utterances or with the critical realist notion of intransitive and transitive dimensions, we are using tools that recognise the significance of that very subtle perceptual shift which has played such a large part (yet has gone largely unrecognised) in the archives domain's traditional and 'postmodern' othering discourses. Austin's concepts do not serve to type records so much as to draw attention to the fact that how anybody types a record (or a

\footnotetext{
${ }^{57}$ Archivists working with photographs have been particularly critical of the archives domain's textprivileging assumptions about the nature of records and, therefore, what metadata needs to be included in descriptions of records and allowed for in the design of systems (Sassoon, 1998; Schwartz, 2002). Others have spoken about how a text-privileging perceptual habit has led to inadequate awareness that the material characteristics of textual records can yield evidence the text might not (Rekrut, 2005; Bartlett, 2011).
} 
book) depends on which of these perceptual stances they privilege. The critical realist notions do the same, but much more broadly. There is a spacetime dynamic at work in both, a small switch of perceptual orientation that is right at the heart of meaningmaking. When brought into relation with critical realism's domains of the real, actual, and empirical, the possibilities for analysis of perceptual processes - processes which interiorise the exterior and exteriorise the interior - expand because they make it possible for us to factor into account how we are looking (e.g., observing an object as it is, 'reading' meaning into an object, looking at the object in order to glean knowledge of something in which the object was directly or indirectly grounded, or seeking to understand something somebody else said about some matter of interest to us).

Though the speech-act theory concepts introduced by Yeo (2010c) are narrower than the critical realist terms, they are conceptually compatible. This means the act of translation into critical realist terms does not erase them, but instead recognises their utility for providing analytical depth in relation to a narrow range of phenomena. This is how Bhaskar said critical realism should work. It does not seek to replace the specificity of disciplinary discourse relating to phenomena of concern to that discipline. Rather, it affords tools for identifying 'theory' (concepts and lines of reasoning) that are (and are not) rationally justifiable within a discipline; and those tools then serve the purposes of bridging divides between verbally separated but conceptually related notions and of pinpointing conceptual otherness lurking beneath verbal sameness.

Translation into continuum terms is more difficult. As I have previously argued, the continuum spacetime notion seems to equate conceptually with critical realism's notion of an intransitive dimension. One reason for this conceptual equivalence is the fact that both terms seem to conceptualise knowledge products and knowledge formulation processes as being part of - rather than apart from - the whole of spacetime or the whole of the intransitive dimension. However, in my readings of continuum theory I have found no discussion of the analytical and communicative value of being able to discuss being and aboutness as conceptually distinct abstractions. Despite its silence on that subject, the spacetime logic underpinning continuum theory allows ample space for a transitive dimension concept to be included. More than that, continuum discourse seems to already be aware that the knowledge we have about some sub-totality in the spacetime totality is 
not the same thing as the sub-totality to which it refers. This awareness has to be read into continuum theory's fundamental concern with the quality of knowledge and with the evidential attributes of knowledge's building blocks. Because a transitive dimension is implied by continuum theory (and because of the theory's openness to expansion so long as the fundamental logic holds), I suggest including these critical realist terms in the continuum paradigm would be valuable. Their value and compatibility will be demonstrated repeatedly throughout the rest of this thesis.

Another similarity between continuum theory and critical realism is awareness of the significance of the unknown. This has always been implicit in continuum thinkers' concerns about inadequate evidence and also in the importance they attach to awareness of how perceptual possibilities are determined (and limited) by how we are situated in the spacetime whole. Upward (2009) indicated the unknown could be thought of as another spacetime dimension (p. 207), one that would be layered across the other dimensions. "Much of the interior of the records continuum", he explained, "is unknowable and there is certainly something out there beyond the fourth dimension, but what" (p. 113)?

A final similarity between continuum theory and critical realism to note is that continuum theory's notion of transactionality, if understood as referencing interactions, "specificities of occurrence", "planes of emergence", or "planes of immanence" (Upward, 2009, p. $121)$, is conceptually equivalent to critical realism's notion of a domain of the actual.

\subsection{CONCLUSION}

This chapter focused on my analysis of existing archives domain thinking ('theory' and theory) as I saw it to manifest in the body of literature in which my thesis is most deeply grounded. The analysis served three purposes: to test and improve my own knowledge of existing thinking; to lay conceptual foundations for the case study component of the research; and to identify matters of theory to be further investigated in relation to the case study materials and experience.

The analysis confirmed my initial impression that, in the archives domain, notions of record, evidentiality, and recommended practice are so deeply entangled that they are 
better studied relationally than in isolation. In addition it made me aware that dichotomous notions of objectivity and subjectivity are part of this relationally implicated mix. Indeed, they seem to be foundational. Outwards focused epistemological othering in the traditional discourse has served the purpose of differentiating all things archival from the purportedly non-archival things associated with competing others (especially library others). I found this notion of a definite non-archival other to have persisted in contemporary non-continuum discourse even though 'postmodern' theory has gone a long way towards switching the archival norm from objective to subjective (previously the norm of the 'other'). In contemporary discourse epistemological dichotomies have come to serve the purposes of internal othering. Traditional practice has been othered. In particular, Jenkinson's relatively well cohered body of theory and advice for practice has been othered. Similarly, contemporary evidence privileging discourse (including continuum theory) has been othered. The domain, as a consequence, is much divided and, in so far as it can be said to have a single world view, that world view is a variously interpreted somewhat haphazard and bias-laden amalgam of traditional and 'postmodern' notions. For the most part, contemporary discourse centres records. The category of record, however, is generally conceptualized in terms of "mental prototypes" and "boundary objects", but not in a stable and universal way. Rather, different communities of archivists tend to have different notions of a prototypical record (Yeo, 2008). In these circumstances division and disputation within the domain is inevitable and potential for epistemically robust cross-domain collaboration seems limited.

Continuum theory (as developed by Frank Upward, Sue McKemmish, and colleagues), on the other hand, was found to be ontologically sound. This theory rejects absolutist forms of othering, is sensitive to space-time diversity, and is so logically coherent that one can reason from the premises of existing continuum discourse to possible future continuum discourse. Continuum theory does not type objects for purposes of differentiation, instead it differentiates processes that serve different purposes (and, therefore, differentiation between physical and digital objects is contingent, not absolute). For that reason, it has a concept-privileging notion of record (whereby anything can be a record if it is used or intended to be used that way). This notion of record is quite a different from the traditional closed category object-privileging notion. Unfortunately, this difference is 
not widely recognised because continuum theory is poorly understood by all but a small number of people (Upward, 2009, p. 8).

Misunderstanding exists partly because, in its early stages of development, continuum theory was used primarily in relation to contemporary recordkeeping, and so came to be narrowly (and, therefore, incorrectly) understood by many who believed themselves to be continuum thinkers (Upward, 2009, pp. 30,33), as well as by that part of the archives community who were not hearing continuum discourse speaking to them specifically about matters that concerned them and in language with which they could identify. The 'postmodernist' search for relics of positivism also played a part in generating and perpetuating misunderstandings of continuum theory. Within a few years of Upward publishing his records continuum model and arguing that continuum theory had the bones necessary for it to serve as meta-theory, authoritative figures in the archives domain unjustifiably construed it as positivist and as binding a narrow concept of record to a narrow concept of evidence. Without being given serious attention, it was dismissed as unworthy of such attention. Repetition of both sets of misunderstandings entrenched misunderstanding.

Misunderstandings, and inadequate understandings, of continuum theory, coupled with polarized notions of objectivity and subjectivity, have contributed to contention regarding how the concept of record stands in relation to the concept of evidence. They have also generated differing views on how the documentation and description of records should (or can) be grounded. An ongoing pre-occupation with differentiation and an ongoing habit of thinking in terms of absolutes has held back the development of theory and practice that recognises and integrates differing viewpoints and perceptual orientations.

The fact that continuum theory has been seen as part of the problem, rather than as potentially providing means to solve the problem, stems in part from the fact that many of continuum theory's possibilities have yet to be explored and discussed in any depth. The multi-polar aspect of Upward's work has attracted little attention - Upward (2009) said it had "so far not been mentioned in any of the many expositions by others of the records continuum model" (p. 176). Also, at the time the bulk of my research was conducted, there was relatively little continuum literature relevant to the continuum's 
fourth dimension, the "pluralised space" of "shared experience" and "knowledge across communities" (Reed, 2005, p. 178); and relatively little attention had been given to drawing out continuum theory in ways that are directly relevant to collecting archivists. Personal recordkeeping behaviours had attracted some interest (McKemmish \& Piggott, 2013), but issues relating to research use and, in particular, processes of meaning-making and meaning-distribution had gone largely unaddressed, not only in continuum discourse (Upward, 2005b, p. 24; 2009, p. 274), but in the discipline more generally (Duff, MonksLeeson, \& Galey, 2012). ${ }^{58}$

In the early stages of my research I felt uncomfortable because in adopting a 'reader' perspective and proposing anything could be a record if it was 'read' that way, I saw myself to have moved into a conceptual space so far outside of the archives domain discourse (as I knew it at the time) that my work was in danger of being dismissed as both eccentric and irrelevant. Continuum theory, however, has given me an anchor. It seems I am putting to use its concepts of monistically diverse spacetime and multi-polarity. It also seems that by keeping my research conceptually open and selecting a case study with potential to take me into the databases of multiple institutions of multiple types, I have positioned myself well for reflection on the continuum's relatively unexplored fourth dimension. In addition, by designing my case study so I look from a historical researcher perspective at objects that are more easily conceptualized as personal than official, I have privileged matters as yet under-explored in continuum discourse, but of major interest to collecting archivists and mainstream archivists concerned primarily with providing services to support cultural heritage related uses of records. Unknowingly, it seems I conceptualized and designed my research in such a way that my thesis will go some way towards filling continuum discourse's relatively empty spaces.

During the discourse analysis I discovered that the possibility of future research such as mine has been anticipated by continuum theorists - "the view of the bank customer", Reed (2005) said, "is different from the view of the bank". Therefore, "we should ... be prepared to open up our thinking to possibilities", not in order to "displace or supercede a

\footnotetext{
${ }^{58}$ These matters have been attracting more attention in recent continuum discourse. That work, however, has not been included in this discussion because it played no role in shaping the theory I develop in this thesis.
} 
perfectly legitimate organisational interpretation of role, but [in order to] ... enable alternative readings of process to coexist". "Archiving systems", she said, "can be conceived as locator mechanisms or managers of meaning for records wherever they reside" (p. 183). In other words, I have found in continuum thinking, the ideas with which I began. I can stop 're-inventing the wheel' and instead put continuum concepts to work.

So, where does my thesis go from here?

Firstly, it draws on the case study component of the research and relevant theory to explore the question of how evidence emerges during a historical research process. It does this in the course of the next two chapters by using both case study experience and relevant theory to discuss matters relating to observation, perception, and meaningmaking and the roles objects, systems, and yet to be identified other things play in these intellectual processes.

Secondly, it explores problems in contemporary archival science theory which seem to have emerged from continuum-unawareness and conceptual mismatching. The major issue explored is the question of how the concept of record stands in relation to the concept of evidence. This question cannot be adequately addressed unless three related issues are first addressed. One is exploration of the continuum notion of record as logical entity or conceptual construct from a researcher perspective. To my knowledge, this has not previously been done. However, it needs to be done as one step towards countering critique of continuum discourse's evidence-privileging concept of record that has been grounded in an assumption that when continuum thinkers define records as evidence, they are referring to the same 'record things' that archivists with a traditional objectcentring and closed category notion refer to as records. The other two matters of theory I have identified as being inadequately explored, yet highly relevant to the question of how the concept of record stands in relation to the concept of evidence - and to my research more generally - are the objectivity-subjectivity dichotomy and the three-fold problem of understanding evidence from a discovery perspective, bringing that view of evidence into relation with the organisational recordkeeping view of evidence, and addressing the question of whether there is any useful and meaningful way of understanding evidence as a meta-concept. 
Each of the next three chapters is framed around one of these problems in archival science theory and around a line of enquiry followed during my case study research. Together they build foundations for addressing the question of how the concept of record stands in relation to the concept of evidence. They also provide insight into how systems (systematized practices as well as technological systems) can be designed to be knowledge enabling, the topic I address in my final chapter.

Chapter Four begins the process by arguing the case against thinking of objectivity and subjectivity as polarized opposites. 


\section{4. “DOCUMENTS SELDOM SPEAK IN THE NUDE": OBJECTIVITY AND SUBJECTIVITY}

\subsection{INTRODUCTION}

In Archive Fever, Derrida wrote of a "moment", an "ecstatic instance" when "stones talk", when the "origin... speaks by itself", when "the arckhe appears in the nude". ${ }^{59}$ At that moment the thing which speaks of the past is itself the past of which it speaks. There is no need for the "laborious deciphering of the archive" because the past "presents itself and comments on itself by itself" (Derrida \& Prenowitz, 1995, p. 58).

Upward and McKemmish (2001) borrowed this metaphor of the arckhe appearing in the nude to draw attention to the primary point Derrida was making which was that "documents seldom speak 'in the nude' to us" - "the same documents speak very differently to different observers" (p. 37). "Communications", Upward (2009) explained, "are clothed by the mind of the reader" (p. 121). The emphasis Upward and McKemmish (2001) and Upward (2009) placed on the reader's role in identifying the meaning of documents should not be understood as intended to convey the notion that the reader alone determines the meaning of a document. Rather, continuum logic leads to a view that the emergence of meaning from any communicative event (whether a conversation or the reading of a document) will always be the situated outcome of interacting factors associated with the 'authorship' of the communication, its mode of transmission, and the predispositions and motivations of the 'reader'.

This awareness of variability in interpretive experience sits uneasily alongside a persistent and widespread feeling that archival documents let us "literally touch the past" (Robinson, 2010, p. 503). As Upward (2009) said, "even allowing for our cynicism about ... our ... ability to freely mis-interpret them", we seem to "want to believe that objects can endure, and that they can be accessed and replayed in other times and places" (p. 162).

Lived experience seems to tell us that objectivity and subjectivity co-exist. Yet in many archives domain discourses these concepts have been situated as incommensurable

\footnotetext{
${ }^{59}$ The Greek word arckhe means source or origin.
} 
epistemological opposites. This has made it possible for them to be put to use to support a variety of other arguments involving differentiation and negation. Together, these arguments have shaped the domain's worldview. One example in the traditional discourse is the notion that records are objective, but library materials are subjective and, therefore, not records. Though 'postmodern' critique has demonstrated again and again that records have subjective characteristics, the idea that records have superior epistemic characteristics to library materials lingers (see, for example, Williams, 2006, pp. 7, 23). Another example, in contemporary discourse but with its origins in traditional discourse, is the notion that the subjectivity of personal records provides grounds for differentiating them from official records. That purported difference has served as justification for the dismissal of arguments that have employed records continuum logic to demonstrate that a hard and fast distinction between personal and official records does not exist in reality. As a consequence of that dismissal, the calls of the continuum community for more flexible descriptive systems - systems that come closer to representing reality as it actually was, rather than representing the imagined 'reality' of the differentiated closed categories to which archivists have become habituated - have also been dismissed.

In addition to the above, a number of contemporary problems exist because of a tendency to speak about records in terms of evidentiality and also in strong objectivist tones. This seems to have generated a tendency to conceptualise evidentiality itself in strong objectivist terms. Wherever this objectivist concept of evidence co-exists with a subjectivist understanding of records and archival activity, the word evidence tends to either not be used or the importance some communities within the domain attach to that word is openly attacked. Discourses which have side-lined talk of evidence also have a tendency to have side-lined records continuum theory which explicitly aligns its concept of record with the word evidence and which argues the formation of evidence to be the logical purpose of recordkeeping (Upward, 2005b, p. 22). Yet, as the opening paragraph of this chapter made clear, Upward and McKemmish, two of the key records continuum theorists, do not take an objectivist stance in their writing - at least, not in that extreme sense of negating the presence and effects of subjectivity.

This chapter responds to a perceived need to focus theoretical attention specifically on the words objectivity and subjectivity as a first step in addressing the problems listed 
above. In the course of the chapter, I dismantle the objectivity-subjectivity dichotomy by developing a more nuanced understanding of the perceiver (the subject) and the perceived (the object) and of the many ways in which the two become entangled. I draw on critical realist writings, Bruno Latour's thoughts about "reshuffling" objectivity and subjectivity, and recent research findings in the field of neuroscience. I illustrate my theoretical reflections by discussing them in relation to a line of enquiry followed during my case study research. This line of enquiry explores 'evidence' (problematized because I have yet to share my view on what evidence is) relevant to the question of whether Fred Butler practised nudism.

\subsection{FRED IN THE NUDE?}

Some people believe Fred Butler practised nudism. This belief has given substance to a story - with popular appeal - that an elderly Fred sunbathed nude on the veranda of his cottage in the Tauranga District Museum Historic Village. As it is told on Puke Ariki's website (Hoskin, 2004), this story leaves the reader with the impression that Fred's "insistence on sunbathing in the nude" was a significant factor in his inability to "fit in" and the reason why he did not stay on at the Village. The implication is that he was asked to leave because of his nude sunbathing. The story does not say this explicitly. Rather, the effect is achieved through omission. No other factors which may have been relevant to Fred's departure from the Tauranga District Museum Historic Village are mentioned. There is no reference to disputes over the care of the collection or to Fred's claim that the Tauranga Museum Trustees breached their agreement with him by selling items they did not want. There is no mention of lawyers being involved - though they were. There is only the story of Fred's nude sunbathing. Furthermore, only one source is cited for this story. That source is a gentleman named Russell Standish who, in the late 1970s, lived near Eltham in Taranaki. Eltham is just over 300 kilometres driving distance from Tauranga. It seems unlikely Standish was an eye witness to Fred's purported misdemeanour. In short, the story told on Puke Ariki's website repeats a story which probably repeats yet another story which possibly repeats still others.

The art historian Francis Pound is another who has claimed that Fred practised nudism. In an article in which he explored the idea that "the archive is... signature - a kind of 
'immense autograph'”, Pound (2006) suggested two of Fred's 'scrapbooks' which are labelled "Nudes" and "Nudists" would have had special personal significance for Fred because he himself "certainly ... practiced nudism on occasion". Pound substantiated this claim by grounding it in the story about Fred sunbathing nude on his cottage verandah: "In 1977 while he [Fred] was living in the Tauranga Museum Village as a kind of live-in historical actor" Pound asserted, "it seems there were complaints from scandalised visitors who had discovered him sunbathing naked on his veranda". The only source Pound cited was the story on Puke Ariki's website. In repeating it, he embellished it with details not present in that source - a date, the information that Fred was a "kind of live-in historical actor", and the image of "scandalised visitors". In short, Pound re-presented a story, which was itself a re-presentation of a story. He gave no hint of having paused to reflect on its trustworthiness and whether it really did provide grounds for the certainty he claimed. Instead, taking the story at face value, he used it to justify a claim that four of Fred's 'scrapbooks' - the ones entitled "Radiant Living", "Nudes", and "Nudists" - could "be subsumed ... into the same utopian category: that of the Naturist." The existence of the documentary evidence so constructed - for evidence is always, in one way or another, constructed (a point I will argue in Chapter Five) - served the purpose of reflecting the appearance of veracity back onto the anecdote.

This story about nude sunbathing at the Tauranga District Museum Historic Village was amongst the first things I was told about Fred Butler. It is one of those colourful stories which spread by word of mouth. It first came to me in that way and, since then, I have heard it many times. I expect Pound had much the same experience. The extra detail in his own re-telling may well be there because of the way somebody else told the story to him. Many people seem to have accepted it as truth. I did too at first.

Ann Shelton has observed that "there is a sense in which things become real through repetition" (Shelton, n.d.). In a way, her comment is apt because this story, like the story Piggott (2012) told about Bob Hawke purportedly swimming naked in the University House lily pond at Australian National University, has taken on a life of its own. However, there is also a sense in which what is real is always real, and what is not real is never real, irrespective of anything people say. Fred was real. His "signature" is everywhere. But was he a nudist? Although there are many people who seem willing to believe he was and that 
he caused offence by sunbathing naked in public, I am not convinced. When I looked at the documents Pound (2006) singled out as evidence, I saw them differently - just as Upward and McKemmish (2001) said so often happens when different people read the same documents. As for Standish's anecdotal evidence, I think it may well have been nothing more than gossip. In other words, Pound's evidence that Fred was a nudist was, in my eyes, evidence so weak that it hardly warrants being called evidence at all.

\subsection{OBJECTIVITY - CONNOTATION-LADEN AND IN NEED OF REDEFINITION}

One of the many ways in which the word objective is defined in the Oxford English Dictionary is synonymous with the critical realist notion of intransitivity: it is an adjective used in relation to that which "belongs to what is presented to consciousness, as opposed to the consciousness itself", that which is "external to or independent of the mind". The Dictionary notes that the word was used in this sense with increasing frequency in the nineteenth century, at first in philosophy, but as the century advanced increasingly in common language. As I argued in section 3.3.6, this seems to have been the sense in which Jenkinson (1922) used the word impartial in his writing about the nature of archival evidence. Confusingly the word objective is also used - and more commonly used in the twentieth century - to refer to "senses relating to objects, their function, and perception [emphasis added]", matters which critical realism regards as belonging in the transitive dimension. In short, the word carries contradictory meanings. On the one hand, the attribute of being objective cannot be ascribed to consciousness; on the other hand, it is.

Being mindful of "the gap between knowledge and the rest of reality" (Morgan \& Olsen, 2007, p. 257) is fundamental in critical realism. It is because that gap exists -because "the facticity of the world ... is in some sense indifferent to our accounts" (Morgan \& Olsen, 2007 , p. 257) - that knowledge claims can be incomplete, of varying validity in relation to that which they reference, and sometimes incorrect. Awareness of the gap and, therefore, of the objective existence of the referenced object is also the reason why there is potential for partial knowledge claims to be enriched and those which are mistaken to be corrected. This is because, for so long as the referenced object exists or objective (i.e., mind-independent) evidence of that object exists in the domain of the empirical, others have the opportunity to formulate their own understandings of the real nature of that 
object or to test the validity of claims that certain things evidence it in certain ways. What this means is that it is nonsensical, in any paradigm where belief in the fallibility of knowledge co-exists with belief that some knowledge claims can be better than others (because they correspond more closely with the reality they reference), to use the word objective in relation to a mode of enquiry in the belief that mode of enquiry will guarantee the discovery of full and accurate knowledge. Yet those who claim objects have the quality of objectivity and that objective stances can be taken in relation to the formulation of knowledge have frequently been accused of making these nonsensical assumptions, as, for example, Jenkinson was accused by Cook (1997).

Morgan \& Olsen (2007) have argued this situation exists in part because researchers who claim their stance is objective - albeit not in the belief that the knowledge they produce is necessarily either complete or infallible (e.g., critical realists) - have not explicitly identified the features of an objective stance. The consequence is that "acceptance or rejection of claims of objectivity" rests on how the word objectivity is interpreted in relation to "murky hidden notions or connotations" (p. 250). A further consequence is that those who claim to adopt objective stances may not be practising objectivity as well as they might if the concept was more clearly articulated. Focusing attention of the question of what constitutes an objective stance in a realist paradigm, Morgan \& Olsen (2007) maintained, is necessary if the word objectivity is to be freed from "the philosophical residue of various forms of positivism" (p. 250).

Bruno Latour, working in a realist paradigm similar to that of critical realism, has also argued the need to rethink objectivity. He came to that conclusion after realising his early work had often been interpreted as endorsing 'postmodern' non-realism. Latour (2004) said this work had been driven by his concern that over-stated assertions of objectivity misled the public, and that he had emphasized subjectivity and fallibility in order to draw attention to what was missing in those objectivist assertions. He had not anticipated his own work would be interpreted as maintaining all knowledge claims are equally fallible because they can be referenced only in relation to the subjects who produced them, and not in relation to the reality of the world. With hindsight, Latour (2004) realised 'postmodern' over-statement and positivist over-statement were equally problematic in 
the world of scholarship and equally dangerous when coming from the mouths of those who wield power in the world at large (pp. 226-231).

Aware that actor-network-theory has frequently been misused by researchers who have adopted it as a method but paid little attention to its philosophical underpinnings (Latour, 1996), Latour saw a need to spell out how objectivity should be practised - and subjectivity understood (a matter to which I will return later in the chapter) - if social science research is to produce "textual accounts" which do not put aside "the question of ... accuracy and truthfulness" (Latour, 2005, p. 126). Objectivity, he asserted, tracks objects and it gives objects "a chance to object [emphasis in original] to what is said about them" (Latour, 2005, p. 125).

In the section that follows, I look at the 'scrapbooks' Pound (2006) saw as evidencing Fred's active interest in nudism, and I ask whether, when seen through my eyes, these objects affirm or object to the meaning Pound gave them.

\subsection{EVIDENCE OF AN INTEREST IN NUDISM? LETTING THE OBJECTS OBJECT}

There were four 'scrapbooks' which Pound (2006) identified as evidencing the fact that Fred "practiced nudism on occasion": two labelled "Radiant Living" and the two labelled "Nudists" and "Nudes". Pound's inference that the "Radiant Living" volumes showed an interest in nudism rested in part on late twentieth century stories about the Schools of Radiant Living and in part on his assumption that the titles of the volumes labelled "Nudists" and "Nudes" could be interpreted as autobiographical in a literal sense.

I too would say that these volumes are in a sense autobiographical, but I disagree that their titles can be read as literally autobiographical. The "Nudists" and "Nudes" volumes are only two within a collection of some 3000 volumes. While some of the 3000 (for example, those labelled "Radiant Living") contain minutes and other documentary evidence of Fred's active involvement in community groups, most (including the two volumes with titles referring to nudity) contain only newspaper cuttings. The 3000 'scrapbooks' cover many topics and the number of volumes on each topic is clearly indicative of the attention that topic received in the newspapers Fred was clipping (there 
are over one hundred labelled "Crime", for example). Why read special autobiographical significance into two of those 3000 ?

For Fred the business of clipping, organizing, and pasting newspaper articles into 'scrapbooks' was a major enterprise. In 1961 Clyde Taylor, the Chief Librarian of the Alexander Turnbull Library, estimated that it would "take a $£ 700$-a-year clerk several years at least to achieve" the same output "assuming the requisite background knowledge" (Taylor, 1961, August 20). Not only did Fred employ assistants, he also ordered multiple copies of the two daily newspapers published in New Plymouth (Shipherd, 2000). This latter fact suggests he may have been clipping every article. The vast quantities of clippings I saw at Puke Ariki which had never been pasted into 'scrapbooks' lend weight to this conjecture as do all the stories I have heard about boxes of clippings being sent to the dump after Fred's death. The fact that Fred employed paid assistants also raises questions. Given this was the case, can we say with confidence that "the archive is... signature - a kind of 'immense autograph"'? I am inclined to think we can because Fred seems to me to have been the kind of man who would maintain control over all intellectual aspects of the enterprise, but I may be wrong.

The content of the volumes, as well as their documentary context, suggests they do not provide evidence of a special interest in nudism. Only some of the clippings in the volume labelled "Nudists" (which covers the period 1938 to 1954) are about nudism in the context of naturism. Also included are stories about people being left unclothed in embarrassing circumstances and about public authorities prohibiting the display of artworks depicting nudes. There are also jokes about naked women. As for the volume labelled "Nudes", there is nothing about either its title or its content that supports Pound's claim. This volume, begun in 1969, contains only a few pages of clippings. These report public outrage and official responses to nudity in many settings, including the stage shows Oh! Calcutta! and Hair and at a "love-in" at Oriental Bay, Wellington.

The time gap between the two volumes also does not appear to be significant in relation to a possible interest in nudism. A lack of coverage for the period 1961-1969 recurs throughout the 'scrapbook' series. This can be explained by the fact that Fred sold most of his 'scrapbooks' to the Taranaki Museum in 1961 and, presumably because of his 
impecunious state in the 1960s (he was no longer able to employ assistants), only recommenced pasting clippings into 'scrapbooks' in 1969 when the prospect of a sale to the Hocken Library was looming. The fact that the volume labelled "Nudism" ends in 1954, which is somewhat earlier than most of those sold in 1961, may be simply because the local newspapers did not publish much that he deemed relevant during that time or because he had not had time prior to the sale to paste into 'scrapbooks' all the clippings he had collected.

Until quite late in my research, all the above factors suggested to me that there was no case for arguing the "Nudists" and "Nudes" volumes provided grounds for believing Fred had a special interest in nudism. However, as my research progressed, I became aware that the objects were objecting to my certainty, not so strongly that I had to concede to having previously been wrong, but just enough to prevent me from completely ruling out the possibility that the volume labelled "Nudists" might indeed have been begun out of a special interest in naturism. The first clippings in this volume report on the formation of naturist groups throughout New Zealand in early 1938. Included amongst them are articles alleging the existence of nudist groups in Taranaki and nude bathing at beaches on the north Taranaki coastline, including New Plymouth's Ngamotu Beach.

Interpreting the significance of this early content is not straightforward. I formed the view that this 'scrapbook' may have been begun as a consequence of a personal interest in nudism by making analogies between it and the series of volumes with the title "Weather". What is interesting about the "Weather" series is that the early volumes contain not only weather reports clipped from newspapers, but also handwritten temperature, rainfall, and wind velocity data which Fred himself was recording on a daily basis. Over time, however, the handwritten data vanished and the series transitioned into containing only clippings of weather reports and other newspaper articles about the weather and weather-related events. Conceivably a similar transition occurred within the "Nudists" volume. I cannot say for certain. All I can do is point to the possibility that it might have and, therefore, there is some scope for entertaining the idea that this volume may indeed evidence an interest in nudism. 
As previously mentioned, the content of the volumes labelled "Radiant Living" differs from that of the volumes labelled "Nudists" and "Nudes" because, in addition to newspaper clippings, the two "Radiant Living" volumes include notices of meetings, minutes, receipts for membership payments, and a miscellany of other documents which show that Fred was actively involved in the Sutcliffe Schools of Radiant Living during the early 1940s. In other words, these volumes evidence with certainty a personal interest other than, and in addition to, Fred's life-long interest in compiling an information resource.

The documents in these volumes provide glimpses of Fred interacting with others in a web of relationships. We see his activities (or, at least, some of them) as a member of the New Plymouth School of Radiant Living. Also, through Fred's eyes and through the eyes of others responsible for the authorship of documents pasted into these volumes, we see the activities of the New Plymouth School and its interactions with Herbert Sutcliffe and the wider movement he led. These documents show a point of rupture when members of the New Plymouth School, Fred included, broke away from the Sutcliffe Schools of Radiant Living and formed an independent local group.

If one focuses on the continuation of a group engaged in an activity, rather than the continuation of a title, it quickly becomes apparent that the two volumes labelled "Radiant Living" are part of a logical sequence which includes four other volumes which are labelled "Health Centre", the name adopted by the secessionist group. The entire sequence covers the period 1941-1958. Reading these six volumes as evidence of Fred's involvement in the New Plymouth School of Radiant Living and the New Plymouth Health Centre provides grounds for an inference which is unlikely to be contentious. This inference is that Fred was interested in pursuing a healthy life-style in ways which were reasonably consistent with the philosophies of these groups. Why else would he have belonged to these groups for so long? However, do any of these volumes provide grounds for making an inference that Fred was a nudist? When I looked through them, I did not notice any reason to think so.

Pound's claim that the two "Radiant Living" volumes can be read as evidencing such an interest seems to have been based on prior knowledge or belief that nudism was a 
feature of Sutcliffe's Schools of Radiant Living. In order to explore the possibility that this might have been the case, I consulted published sources which described Sutcliffe, his philosophy, and the movement he led (Sargent, 2012; Stace, n.d.-a, n.d.-b). I chose sources which, in a traditional paradigm, would have been regarded as authoritative because they were either works of scholarship or sponsored by government (or both). Authoritative sources are not infallible. However, in the absence of evidence that they are biased, they serve as short-cuts to probable knowledge of reality. That is the way I used them in this enquiry. I found no references to nudism or naturism in these sources. This does not rule out the possibility that some members of the Schools of Radiant Living did practise nudism. It does suggest, however, that if there were some who did, it may have been incidental. One could look further for evidence of nudism amongst members of the Schools of Radiant Living, but even if such evidence were found, it would have little bearing on the question of whether Fred Butler practised nudism unless it was directly relevant to Fred (or at least the New Plymouth School).

Did the objects object to the meaning Pound (2006) assigned to them? Yes - and, no. It might be more accurate to say they had nothing to say on the subject of Fred's purported nudism, so I objected. Then again, one could say that absence spoke to me and I passed on the message.

\subsection{ACCOUNTING FOR SUBJECTIVITY WHEN PRACTISING OBJECTIVITY}

Critical realists, like Latour (2005), believe an important part of objective practice is the production of texts which are object-focused and so enable subjects to object on behalf of objects about which some other subject has had something to say. ${ }^{60}$ Taking empirical reality, one's own foundational concepts, reasoning processes, and communicative behaviour seriously enables corrigibility; and corrigibility is necessary for the advancement of knowledge when fallibility is taken to be the default status for knowledge. To claim objectivity, Collier (1994) said,

\footnotetext{
60 The word subject in this discussion should be understood as denoting a person describing some phenomenon, or holding a belief or making a knowledge claim about some phenomenon. The word object is used here to denote the phenomenon referred to in that description, belief, or knowledge claim. The application of these terms depends on a situated relationship which means that people can be objects and even that a single person can be both subject and object when that person says something about himself.
} 
is to lay one's cards on the table, to expose oneself to the possibility of refutation. It is to make it clear that one is talking about [emphasis in original] something, and saying that that 'something' is thus and not so; this makes it possible for others to point out features of that something which are not as claimed, and hence disprove your opinion. All claims to objective knowledge are vulnerable in this way. (pp. 1314)

Morgan and Olsen (2008) expanded on this by pointing out that in a critical realist paradigm laying one's cards on the table logically means exposing all the factors, including those typically referred to as subjective, that played a part in shaping the knowledge claim. "Stocks of knowledge", they said, "including values, theories of other kinds, and so on ... form part of the way in which the subject confronts alternatives" and, therefore, shape the knowledge the subject produces (p. 118). In other words, they took the view that the knowledge claim is emergent from the ontic reality in which it was formed and cannot be properly assessed unless it is understood within the context of that ontic reality. Much of what is described as subjective, they pointed out, is actually epistemic privileging, the unavoidable selection for attention of some aspects of reality (the whole of spacetime, in continuum terms) and not others. The 'subjectivity' associated with epistemic privileging in research that acknowledges fallibility and invites corrigibility is quite different to the subjectivity that manifests in an account of some aspect of reality framed entirely in relation to one's pre-existing beliefs about that reality. Epistemic privileging is a feature of both but, when the only thing a (purported) knowledge claim does is validate the subject's beliefs, that privileging is universalised. When, on the other hand, enquiry stems from a commitment to understanding reality as it actually is, and this commitment is coupled with an awareness that one is only ever looking at a fragment of all that might be relevant to a particular enquiry and that one is looking at that fragment from a particular position and through particular conceptual and material mediators, the existence of epistemic privileging is regarded as a limiting reality to be acknowledged, not as a defining reality to be universalised and re-created. In other words, objectivity values epistemic openness and expresses that value through openness about the nature of the privileging associated with the knowledge claims generated from any single viewpoint. 
Logically within critical realism, subjectivity must be regarded as emergent, situated, and causal. Being emergent and situated means there is potential for explaining it in terms of the objective (i.e., simply existing) phenomena in which it is grounded. Being causal means we need to explain it in that way if we do not want to be imprisoned by our own subjectivities or to be disempowered targets for the ill-founded negating subjectivities of others. Explaining subjectivity in terms of its emergence is also important for the incremental advancement of knowledge. It tackles the problem of disjuncture by constructing an interface that enables "genuine engagement" between subjects who see the same thing differently (Morgan \& Olsen, 2008, p. 254).

When Latour (2005) said that objectivity traces objects and allows them to object to what is said about them, he was working within a similar conceptual paradigm because he saw subjectivity itself as something that could be explained in terms of objects which could (to a significant extent) be traced. "Subjectivity", he said, "is not a property of human souls" but a property of a "gathering" (p. 218):

Cognitive abilities do not reside in 'you' but are distributed throughout the formatted setting [of which the subject is a part], which is not only made of localizers but also of many competence building propositions, of many small intellectual technologies. (Latour, 2005, p. 211)

\subsection{SUBJECTIVITY AS EMERGENT AND GROUNDED}

Because subjects are situated and resituated in relation to other things which are also constantly changing in relation to each other, subjectivity can no more be thought of as unchanging, than it can be thought of as ultimately grounded in the soul or psyche of the subject. For this reason, I suggest one useful way of understanding subjectivity is as a word which refers to the immediately present things (including memories, attitudes, etc.) which collectively cause a subject at any given time and in any given situation to perceive or understand something in one way rather than another.

Thinking about subjectivity in this way seems to be consistent with findings emerging from research in the field of neuroscience where it is now widely accepted that data acquired from sensory perception becomes meaningful only when it is integrated with 
data stored in memory. More specifically, it seems to become meaningful when it is abstracted in relation to abstractions previously formulated by the brain (Quiroga, Fried, \& Koch, 2013, p. 23). It seems, the brain, working beneath the level of consciousness, selects and references against working memory only a tiny portion of the data that is acquired through sensory perception.

Research conducted by Gilbert and Wu (2013) suggests this process may be triggered by the external perceptual stimulus, its surrounding context, and the behavioural context (especially what the body is doing). Together these things may stimulate the brain to select some contextualising working memories ahead of others. Those contextualising working memories stimulate the brain to select from the incoming data that which it registers as relevant to the situation. "For every feedforward connection [between cortical areas]", Gilbert and Wu (2013) said, "there is a reciprocal feedback connection" (p. 350), which suggests that meaning-making should be understood as occurring through the interaction of external (objective) stimuli, internalised (subjective) memory, and (physically expressed) behavioural context (p. 350-352). In other words, in any particular perceptual situation, this thing we think of as subjectivity and which we associate almost entirely with the interiority of an individual's mind may be activated by, and formulated in relation to immediate external stimuli and bodily motion and sensation. Borrowing words from Upward and McKemmish (2001), we could say that subjectivity forms and re-forms at "the creation/capture threshold", at the continuum model's " intersecting point between the interior and exterior" (p. 35).

In philosophy it has long been recognised that many important new ideas in science have come as flashes of insight or "imaginative reasoning" at times when the person to whom the idea has come has not been consciously focusing on the problem to which a solution is suddenly presented (Schum, 1994, p. 462). The term abductive suggestion, first used by the American philosopher Charles Sanders Peirce (1839-1914), is commonly used to refer to these moments of awareness which seem to come 'from out of the blue'. The fact that many ideas have been generated in this way has posed a problem in positivist paradigms which value consciously sustained rational reasoning but typically dismiss 'subjective' ways of knowing such as imagination and intuition (Shum, 1994, p. 461). The discoveries which are emerging from neuroscience research and which I referred to above, however, 
undermine the very idea that such a thing as totally conscious non-imaginative thought exists. Rather, every thought - every perception - seems to come to consciousness only after non-conscious neuro-cognitive activity which selects from and translates sensory data into a relatively familiar abstraction. Further to this, research in neuroscience and psychology is raising questions about "classic distinctions between cognition and emotion" (Dalgleish, Dunn, \& Mobbs, 2009, p. 363). Empathetic ways of knowing, it seems, may have more in common with rational ways of knowing than has traditionally been admitted.

If we think of all thinking as occurring in part as a consequence of non-conscious imagining, the distinction between ordinary everyday thought and a flash of insight begins to break down. Instead of thinking about flashes of insight as distinctive because they are imaginative and produced in non-conscious ways, we can think of them as distinctive because they are the imaginings we are most aware of as imaginings because they often come to us when we are not consciously focusing our attention on the problem they seem to solve - when we wake during the night or are gardening, for example. Given that Gilbert and $\mathrm{Wu}$ (2013) have suggested perception emerges in relation to bodily activity and external stimuli, how a thought can come to us in the absence of relevant external stimuli and behavioural context needs to be explained. Research on the brain's activity during sleep may offer a clue. According to Tononi and Cirelli (2013) sleep allows the brain to restore "to a baseline state the billions of neural connections that get modified every day by the events of waking life" (p. 28). Studies they have conducted over two decades suggest the sleeping brain "tries out" "imaginary scenarios" (a "neural free-for-all" we glimpse in dreams) selecting the "circuits that are 'fittest', either because they were activated strongly and consistently during wakefulness ... or because they were better integrated with previous, older memories" and weakening (perhaps pruning) those which "were only mildly enhanced during wakefulness ... or that fit less with old memories" (pp. 29-30). Tononi and Cirelli's research indicated this activity takes place in parts of the brain which were highly active during the day, which suggests sleep need is "localised" in the brain. "Recently, they said, "we have even found that prolonged or intense use of certain circuits can make local groups of neurons "fall asleep" even though the rest of the brain (and the organism itself) remains awake" (p. 31). This research, though new and in some 
respects still speculative, is interesting as it seems to explain why there are times when I abandon my work because the harder I try, the less able I am to make sense of the detail; why during a break away from my work when I am doing something that requires much less conscious attention, a pathway through the morass becomes apparent; and why sometimes an "imaginary scenario" - an abductive suggestion - can bring me to wakeful attention during the night (see Chapter Six).

What comes to attention as an abductive suggestion is not simply awareness of a possible answer to a problem (a hypothesis), but also awareness of evidence which appears to support that answer (Schum, 1994, p. 461). This makes abductive suggestions - 'gut feelings' included - useful starting points for enquiry because, though their emergence may have been subjective in the sense of being brain-centred, at least some of the evidence in which that emergence was grounded will exist outside of the brain, perhaps in forms which can be empirically examined so that their intuited relevance and meaning in relation to the hypothesized reality can be assessed.

Latour (2005) maintained that subjectivity, because it is grounded in things external to the subject, can be objectively studied. Subjects, he said, "depend on a flood of entities allowing them to exist" (p. 208) and, amongst those entities, are the "plug-ins" that "lend actors the supplementary tools - the supplementary souls - that are necessary to render a situation interpretable" (p. 209). Some of these "plug-ins are fairly easy to trace" (p. 208), but others (for example, "largely forgotten" "places, people, times, and events" and collective subjectivities embedded in clichés and novels) leave "a thin trace". Nevertheless, he said, "if we maintain our outlook, we can follow them as well" (pp. 208209).

If most of our thought processes are non-conscious, as is widely maintained in neuroscience (Dalgleish, Dunn, \& Mobbs, 2009; Gilbert \& Wu, 2013; Hayles, 2012, pp. 9495; Mclntyre, 1999, pp. 154-155, 2007, pp. 2-3; Quiroga, Fried, \& Koch, 2013; Turner, 2012, pp. 136-138), and if our brains grasp the gist, but not the detail, of the situations we encounter, as Quiroga et al. (2013) maintained, Latour's certainty that we can follow those thin traces needs to be questioned. In the next section I explore, from a practical perspective, the process of attempting to ground a 'gut feeling' in memories of 
specifically experienced realities and to objectify my 'subjectivity' - to exteriorise my interiority - by tracing those memories back to actual experiences.

\subsection{JUST GOSSIP? GROUNDING A 'GUT FEELING' IN OBJECTIVE REALITY}

Earlier in this chapter I said that, as my research advanced, I came to think the story about Fred sunbathing nude on his cottage verandah at the Tauranga District Museum Historic Village may have been nothing more than gossip. This was a 'gut feeling' that came to me quite suddenly when I 'saw' that story in relation to an alternative storyline I (my brain) had 'conjured up' as a consequence of having interpreted certain documents at Puke Ariki in relation to my experiential, observational, and 'second hand' knowledge of human behaviour. I realised that the social dynamic at play at the time when Fred is said to have sunbathed nude in public view would have been conducive to spreading gossip which socially othered Fred and which, if it did not exactly begin by saying Fred was in the nude, may have taken on that extra gloss in the re-telling.

The storyline I imagined was that Fred began life with a language disorder (an autism spectrum disorder). Language disorders typically manifest as limited receptive or expressive language ability, difficulty in reading others' emotions, and a tendency towards obsessive thinking and behaviour. Children with these problems frequently have difficulty with peer relationships and are punished by adults for socially inappropriate behaviours which the adults have incorrectly deemed to be deliberate and within the child's ability to control. Many children who have these disorders are highly intelligent in some cognitive areas. Those with language disorders may, for example, be visually or numerically gifted. Dual exceptionality (the term used to refer to those who are gifted in one area but suffer from a disability in another) has a tendency to cause frustration (if, for example, the child's language ability is not sufficient to communicate the knowledge he has acquired by means of visual intelligence). Frustration, in turn, may manifest as impatience or anger. Either way, there are negative social consequences. The outcome over time may be the development of an individual who simultaneously experiences low self-esteem and a sense of superiority, and who carries grudges at having been repeatedly under-estimated. Such individuals can be extremely self-referencing so that a lack of sensitivity towards others co-exists with hyper-sensitivity to perceived slights, which may or may not exist in 
reality. ${ }^{61}$ I imagined Fred in this position, as others who have knowledge of Fred's 'papers' and of autism spectrum disorders also have.

I imagined Fred to have been in this position partly because I had pre-existing experience of such disorders and societal responses to them, and partly because I had seen documents and heard stories about Fred which suggested what I had experienced might be relevant to Fred. If we think of individuals as being situated in intersecting societal totalities which are contained within larger societal totalities, then there is considerable overlap between my spacetime and Fred's, so much so that, as a young person, I may well have passed an elderly Fred in the streets of Tauranga or Thames. His 'norms', on the whole, would not have been very different to mine and certainly not very different to those of my maternal grandparents - indeed, when I met Frances Burton for the first time, we discovered a good deal of overlap in our social networks. ${ }^{62}$ Given the proximity of Fred's world and mine, there is a case for claiming that the knowledge I have formed of social behaviours in my own space-time may be relevant to what he was experiencing in his different, but not so distant, space-time.

Documents associated with Fred lend weight to the case, but do not prove it. Many either speak about or reveal Fred to have engaged in behaviour which could be explained by a language (or similar autism spectrum) disorder. Others specifically relevant to Fred's move to Tauranga cast light on the social dynamic at work at the time the nude sunbathing event is said to have taken place. Amongst the latter are newspaper reports and oral history recordings describing the types of problems which occurred after Fred's arrival at the Tauranga District Museum Historic Village. The relationship between Fred and the Museum Trustees deteriorated to such an extent that the Trust engaged lawyers and Fred resorted to 'litigation' through the newspapers. Documents relevant to the situation refer to issues relating to the care, use, and right to dispose of the collection. They reveal Fred's frustration with the poor storage conditions provided at the Village and the low level of curatorial knowledge of the Village's largely volunteer staff. There was

\footnotetext{
${ }^{61}$ I have chosen for purposes of privacy protection to not disclose the circumstances in which I acquired this knowledge. I have also chosen to not seek out authoritative sources on the subject for purposes of citation because that would falsify my description of my meaning-making experience.

${ }^{62}$ Frances was the daughter of Fred's cousin Doris. She first met Fred in the 1970s. Sereena, her daughter, was a child at that time - she was thirteen years old when Fred died in 1982. On Fred's death they and their parents inherited what remained of Fred's collection.
} 
clearly a clash of values between Fred the curator and the Museum as the provider of a participatory heritage experience (Burton \& Burton, 2007; "Book row: Collection on the move", 1978). If nude sunbathing was a problem, I found no reference to it (other than in the secondary sources discussed at the beginning of this chapter).

This absence in itself is interesting because one of the newspapers which reported on the confrontation between Fred and the Village Trustees was Truth, a widely read weekly publication which did not shy away from racy stories. It is also interesting because there is something about the nature and compilation of documents relevant to Fred and viewed by me when I was at Puke Ariki, that suggests somebody (or perhaps more than one person) in the New Plymouth Library and Taranaki Museum was following events in Tauranga and keeping newspaper clippings and other material that depicted Fred as prone to extreme behaviour in confrontational situations. I also formed the impression that this information was being circulated. I came to that view after finding multiple copies of a trespass notice originally typed by Fred on an old manual typewriter in about 1960. The copies were typed with an electric typewriter and were very similar in appearance to transcriptions and correspondence typed by Library and Museum staff during the late 1970 s.

An oral history recording of an interview with Peter Shaw, who befriended Fred soon after his departure from Tauranga, also provides information that tends to support the autism spectrum disorder hypothesis (Shaw, 2006, September 15). Shaw's impression, from what Fred had told him of the Tauranga episode, was that "anybody who tried to work with him [Fred] would ... have been doomed to failure.... It was all or nothing". That comment was followed by a question from the interviewer, who wondered whether Shaw thought Fred might have had an autism spectrum disorder. Shaw replied he did not "know enough about autism to comment". Shaw's ignorance makes his description of behaviours consistent with the autism spectrum disorder hypothesis all the more meaningful. "He would obsess over things", Shaw recalled. He was uncompromising and prone to rages, yet "well meaning and genial", suspicious of women, but not "a misanthropic kind of person". Then, tellingly in relation to my suspicion of a language disorder and dual exceptionality: "Mr Butler was clever", Shaw said, but "he used to mangle language and his mispronunciation of names was truly marvellous". Also, he "was completely self- 
obsessed" - "He didn't want to hear what I knew.... He never stopped talking.... He wanted company". This last comment could point to pure narcissism, but it could also be indicative of a severe receptive language disorder accompanying a less severe expressive language disorder. The problem of categorization is one that is debated in the field of psychology and diagnosis of individuals is, I have heard, extremely difficult. Given this complexity and the relative superficiality of my own body of knowledge, I am in no position to state with authority how Fred's behaviours would best be described in clinical terms. All I can do is point to a possibility (or range of possibilities) and to the evidence that led me to form that impression.

Though Shaw recalled Fred would work himself up into a rage whenever he talked about his time at Tauranga, the newspaper articles from this period talk about grievances, not rage. Off-setting the aboutness of their text, however, is the very fact of their being. When seen in relation to other documents showing Fred had a long history of fighting his battles in public, they seem to evidence rage because this was not the first occasion on which Fred had used public exposure of the other party's (purported) wrong-doings as a weapon of war.

The newspaper articles, in aggregate, seem to suggest Fred had little awareness that making confrontation public, especially when one has oneself lost emotional control, often has the effect of exposing the person who 'went public' to public condemnation or ridicule, as the case may be. To see the newspaper reports in this way, one must see them as widely dispersed public texts and in a documentary context that privileges the aboutness of text and centres on Fred. This is different to how one must see them when they are seen as evidence that Fred's former associates in New Plymouth were following his fortunes and very possibly swapping stories. For the newspaper articles to evidence in this second way, they must be seen as unique clippings and in a documentary context centred on the Taranaki heritage community. Russell Standish, the recorded source of the story about Fred sunbathing nude, was a member of that community (Hoskin, 2004).

One of the documents which contributed to my perception of Fred's personality - and, therefore, indirectly to my feeling that the nude sunbathing story might have been merely gossip - is pasted into the first of the 'scrapbooks' labelled "Radiant Living". It is a 
professionally printed open letter to Herbert Sutcliffe, founder and leader of the Sutcliffe School of Radiant Living. In March 1945 Fred mailed copies of this letter to members of the School all around New Zealand. In it, he accused Sutcliffe of arrogance and highhanded behaviour in his conduct towards members of the New Plymouth School.

This letter was sent following a series of events which had begun the previous December when Sutcliffe expelled a member of the New Plymouth School on the grounds that he was "not in harmony". A number of meetings followed including one where Sutcliffe was represented by his solicitor. Fred recorded these events in the first "Radiant Living" volume where he entered brief handwritten notes about what occurred at meetings and in the intervals between meetings. After one meeting Fred wrote, "Dr Sutcliffe present \& gave 50 minutes of self glorification about himself!" Soon after, a group of New Plymouth members, including Fred, formed a committee and issued Sutcliffe an ultimatum - they would remove Sutcliffe's name from the name of their organisation if he did not carry out their wishes by 31 January.

If Sutcliffe responded, it cannot have been in a way that satisfied the committee. A secession group was formed, and this group ultimately came to call itself the New Plymouth Health Society. However, before then, Fred sent his letter.

In speech-act theory terms, the letter can be seen as a document carrying an utterance which was simultaneously constative and performative, as the following extract shows:

By the way, at your last "act" here (on $25^{\text {th }}$ Jan) the particular two minutes of bitter unseemly language on your part was a revelation of a new side of your character - previously you had kept your effusions suitable for lady listeners; they found it very disgusting. (Letter from F.B. Butler to Herbert Sutcliffe, 1 March 1945, Butler Scrapbooks, Radiant Living Vol. 1, Puke Ariki)

The words in this letter, if looked at as being a constative utterance (or as being testimonial evidence, or in the critical realist transitive dimension), present Fred's perceptions of, and feelings about Sutcliffe (and about Sutcliffe's "lady listeners") as facts; but there is a gap between each asserted 'fact' and the reality to which it refers, and this gap leaves us unable to say for certain how Sutcliffe actually behaved or how the "lady 
listeners" really felt. What we can know with certainty is what Fred said and did. This is because the letter (seen as trace evidence or as being in the critical realist intransitive dimension) performed a speech act (i.e., it was a performative utterance). However, the speech act it performed was more than simply an act of stating - it performed an act of public shaming. Simultaneously - and, no doubt, unintentionally - it performed an act of self-exposure. The letter was a weapon, and those who read it in 1945 would have caught a glimpse of Fred wielding that weapon, just as those who read it today still do. It is a slice of the action carried from the past into the present. It is the arckhe appearing in the nude, the origin speaking for itself. Or, in the drier tones of Jenkinson (1922), it is impartial evidence of an event of which it itself formed a part.

Another documentary weapon created by Fred was a trespass notice Fred is said to have attached to his gatepost. A portion of that notice is depicted in Figure 1 below.

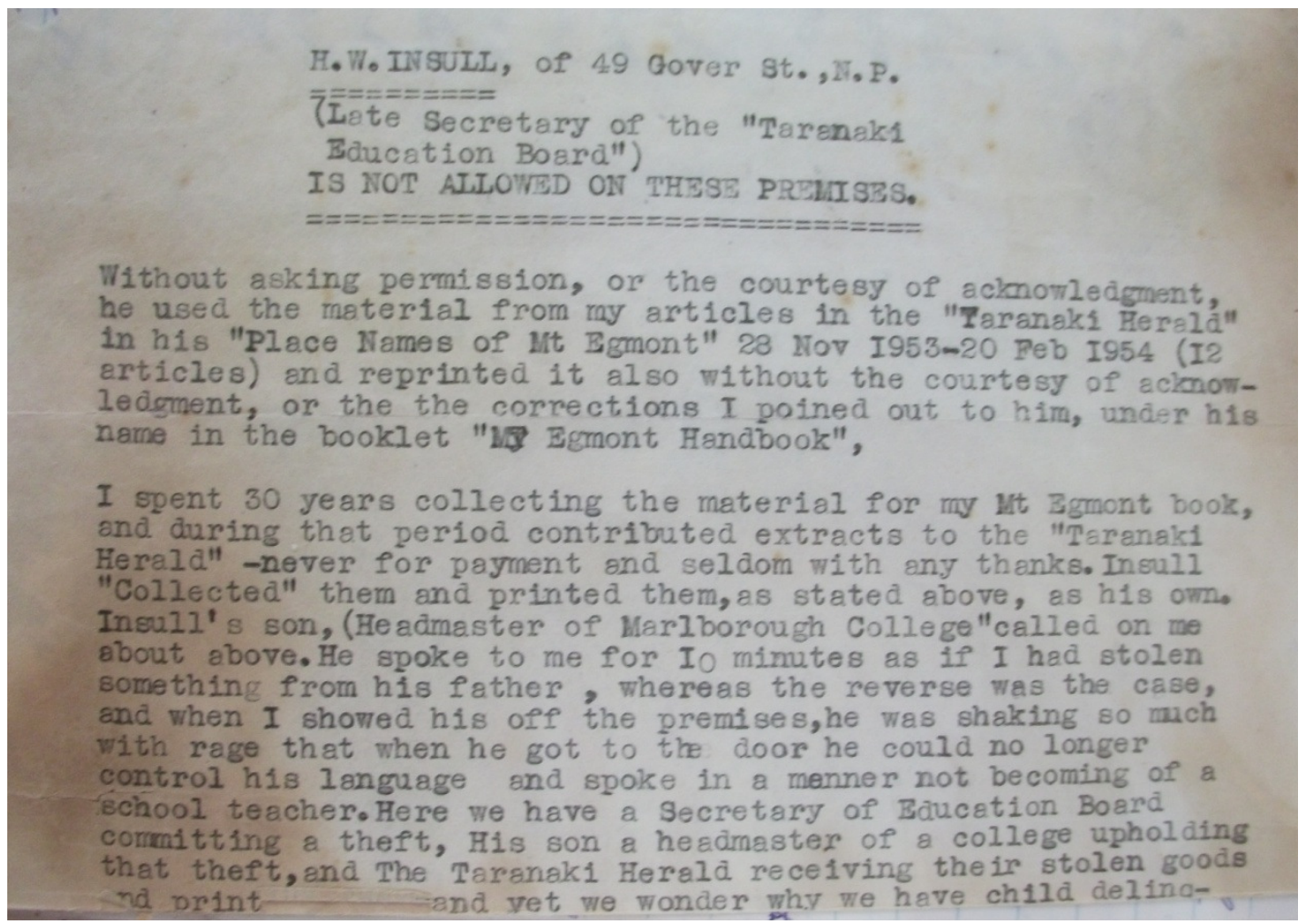

Figure 1. Trespass notice written by Fred Butler and addressed to H.W. Insull. ARC 2002-1031, Puke Ariki. 
Reading it, we again see Fred intentionally speaking through a document about the alleged wrong-doing of other people (on this occasion, H.W. Insull and his son), and in that speaking, unintentionally revealing his own nature by the way he spoke. ${ }^{63}$

Materially and textually, the trespass notice is objective evidence of Fred. Textually, it is also a constative utterance, 'subjective' (is it subjective if it is correct?) evidence about the behaviour of those Fred rebuked. We can only trust that 'subjective' evidence if we trust Fred's account of events. As objective evidence, on the other hand, the trespass notice speaks for itself.

The letter to Sutcliffe and the trespass notice are not the only documents in which I caught a glimpse of Fred acting in ways which revealed a compulsion to expose perceived wrong-doing and yet seeming to be completely unaware of how his attempts to expose others would reflect badly back on him. Newspaper articles published in New Plymouth in 1970, following Fred's sale to "the great Hocken Library", and in 1977, following the sale to the Tauranga District Museum Historic Village, reveal Fred as an aggrieved man who felt he had finally been vindicated after years of slights ("Historic material lost," 1970; "Taranaki history goes to Tauranga", 1977). They enumerate wrongs. In contrast, a photograph of young men from the Historic Village, packing up Fred's collection in anticipation of moving it north, seems infused with naive and optimistic innocence ("Taranaki history goes to Tauranga", 1977). So too does an article extolling Fred's accomplishments and the value of his collection, which was published in The Bay of Plenty Times soon after the move ("City gains a treasure: Tauranga Museum's priceless collection," 1977). As a knowing reader, I saw the optimism in these newspaper clippings and I saw disaster looming. I suspect many Taranaki readers in 1977 also did. I imagine them nodding knowingly the following year when The Truth reported the problems that

\footnotetext{
${ }^{63}$ I am uncertain about the date of this event and about the date Insull's booklet was published (searches of Puke Ariki's catalogue and heritage collections database did not retrieve it, nor did a search of the National Library's catalogue). The gatepost to which the trespass notice was affixed was at Signal Hill where Fred lived between 1960 and 1978. Insull died in 1962. The event, therefore, would have occurred early in the 1960s. It is interesting to note that the 1963 electoral roll listed Fred as an author whereas all earlier electoral rolls listed him as a clerk. Given that Fred's only book was (self) published in 1942 and his newspaper articles also date from this earlier period in his life, I am inclined to read the change of listed occupation as a demand for recognition prompted by awareness that others who were receiving recognition had used his material without acknowledgement. A.B. Scanlan was another Fred accused of intellectual property theft following the 1961 publication of Egmont, The Story of a Mountain. That accusation, and the way I established its truth, is discussed in Chapter Five.
} 
had ensued following Fred's arrival in Tauranga ("Book row: Collection on the move," 1978).

I imagine the gossip.

I imagine, but I do not know.

Imagining the action, like being told about the action, is not the same as seeing a slice of the action.

\subsection{SNAPPED IN THE NUDE - THE MEDIATION OF REALITY}

On 10 February 1929 Fred Butler wrote in his diary, "Bells Falls looked so good I stripped and had a swim and Dick snapped me in the nude with my camera". Frances Burton emailed me this sentence which she had transcribed from the diary (still in the family's possession). Attached to the email was a copy of a snapshot showing Fred swimming at Bells Falls (personal email from Frances Burton to Kay Sanderson, November 3, 2011). The snapshot, also dated 10 February 1929, is depicted in Figure 2 below.

Could Fred, in 1929, have described this state of undress as being "in the nude"? His swimming attire would be normal by today's standards. However, compared to what was normal for the place and time (see Figure 3), Fred was certainly 'unclothed'. Is being less clothed than is socially acceptable in public places the same as being "in the nude"? Was it the same for Fred in 1929?

The snapshot says one thing about Fred's attire when he went swimming at Bell Falls, while the text in the diary seems to say another. However, when one sees the snapshot in relation to the bathing costume norm of the times one is tempted to think that what the snapshot shows is exactly what Fred meant when he wrote that diary entry. The juxtaposition of these messages from the past teases the researcher. 


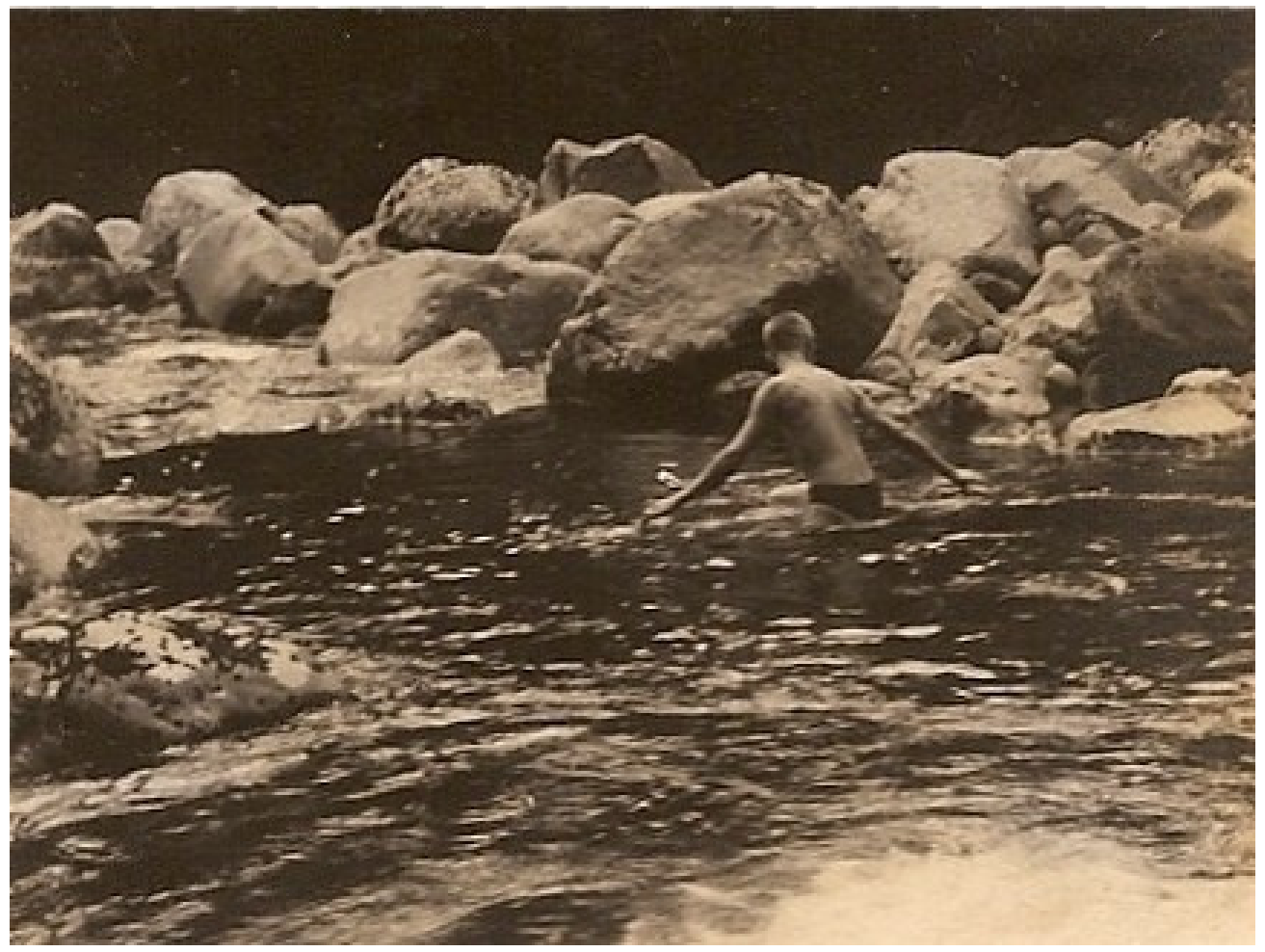

Figure 2. Fred Butler swimming at Bell Falls, 10 February 1929. Photograph from the private collection of Frances and Sereena Burton and reproduced here with their permission.

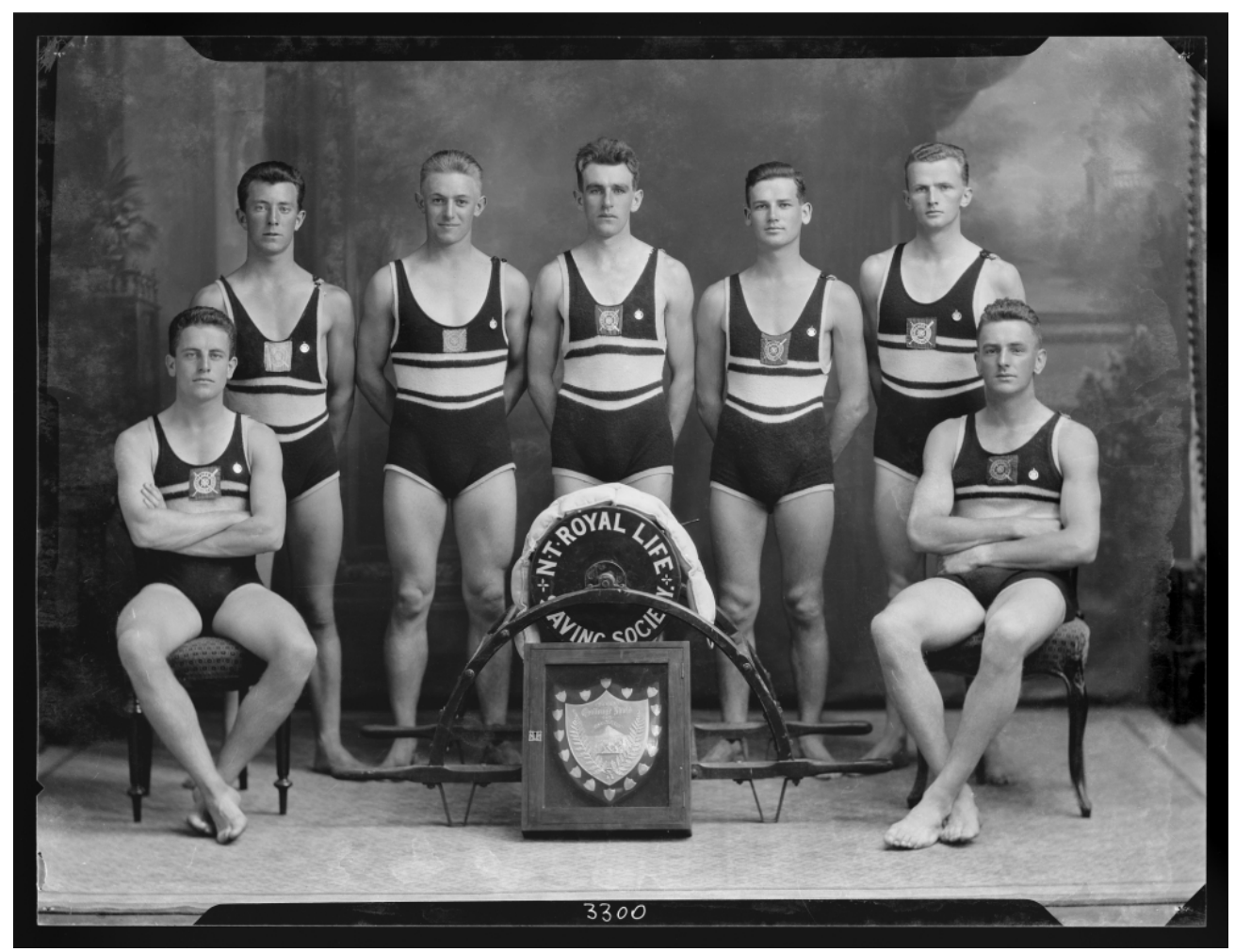

Figure 3. Surf Life Saving Club members, circa 1930, maker unknown, F.B. Butler/Crown Studios Collection. Gift of Frederick B. Butler, 1971. Te Papa (C.003300). 
In thinking about the interpretive possibilities open to a researcher seriously engaged in attempting to establish just what Fred meant when he wrote the word nude in his diary, it is useful to focus attention on the characteristics of the actors (including the technological actors) which, in coming together at a particular point in space and time, brought the diary entry and the snapshot into being. In its identification of 'creators' archives domain discourse relevant to description has privileged organisational and human actors but largely ignored the fact that technological and natural world actors also play a significant role in determining the characteristics of a record. Logically these things are provenance entities, in a sense, co-creators. Recognising their presence is important because the epistemic qualities of documented representations of reality are contingent on the characteristics of the mediators.

A box brownie (likely to have been the type of camera used to 'snap' Fred at Bell Falls) has very different ways of mediating reality to a paper diary and a pencil or fountain pen. The camera, like the human eye, works with light waves and light-sensitive materials so that the light waves (also co-creators?) produce an image of the reality from which they were refracted. What the camera 'sees', however, is not exactly the same as what the human sees because the camera itself does not attach meaning to reality and select for attention from all that is visually present only those things to which it has consciously or unconsciously attributed significance. This means that when a photographer frames a scene so as to capture an image of whatever has captured the photographer's attention, the image that is captured depicts with great accuracy and in significant detail all that was visually present at that moment in time and capable of being visually experienced through the camera's lens and from the photographer's viewpoint. Very little human agency is required for such an image to be created.

Pen and paper, by way of contrast, create no knowledge carrying object without the sustained agency of a historically situated human-being. As a consequence, text filters reality through the unconscious and conscious mind and then through conventionalised symbols which are selected and combined - sometimes in habitual ways and sometimes following careful deliberation - to take the form of written language. In short, so long as we think about norms and not exceptions, transitive dimension phenomena play a far 
greater role in the production of texts than they do in the production of photographic images, especially when those images are early twentieth century snapshots.

The snapshot, therefore, stands in a close to direct relationship with the swimming event it depicts. This is partly because of the way in which the snapshot was created and partly because the swimming event it depicts and the 'snapping' event, which captured a moment during that (possibly very eventful) swimming event, occurred in the same space and time. In a sense, the camera was an eyewitness to a part of the swimming event, and the snapshot - because of the way the photographic technology functions - lets us be eyewitnesses too. We see much of the reality the camera saw. When we read the diary entry, we do not see the reality Fred witnessed at first hand; we can only imagine it.

When it is not possible to see an event with our own eyes, the accounts we tend to trust most are those of eyewitnesses and participants (Yeo, 2010c, p. 103). I believe Fred had no intention to deceive when he wrote that diary entry. I believe that, by his own standards, he was "nude" at some stage during the swimming event. I trust Fred's honesty (on this occasion). However, I do not trust Dick's. In all probability Fred wrote the diary entry on the same day as the snapping and swimming events occurred or maybe a day or two after, if he and Dick were on an overnight tramp. Also, in all probability, he wrote it before the film in his camera was developed and printed - in other words, before he saw the snapshot of himself in the nude. Perhaps that snapshot never existed; perhaps Dick was just teasing, a trick which would only have worked if, at some stage during that swimming event, Fred was actually "in the nude", whatever that means. It might mean he was unclothed to the extent depicted in the snapshot or it might mean he was fully unclothed.

The problem is that I do not know what it means. What I do know is that the snapshot image lets me experience visually, almost at first hand, what was once a past visual reality whereas the text leaves visualisation to the imagination. The text stimulated a sense of certainty, but that sense of certainty dissipated when I saw the snapshot. This is a reminder that proximity in space and time matters - if I knew for certain that the snapshot depicted was the one to which Fred's diary referred, I could be certain of the nature of the reality about which the diary spoke. These two documents have 
complementary ways of evidencing the same past. Frustratingly, I cannot exploit that complementarity. Knowing that the diary and the snapshot have shared the same recordkeeping provenance since their creation does not bind them tightly enough. Nor does knowing that the day to which the diary entry refers (and on which it was probably written) is the same day as the image was captured.

\subsection{OVERVIEW AND CLOSING THOUGHTS}

In the course of this chapter I have used research from the field of neuroscience, the 'third way' theoretical writing of Bruno Latour and of the critical realist scholars Jamie Morgan and Wendy Olsen, and reflections on my case study experience to tackle the question of how provisional knowledge about past hypothesized realities and observational (and testable) knowledge about present realities (which have been used as evidence of hypothesized past realities) emerges during the meetings of subjects and objects. ${ }^{64}$ By doing so, I have challenged dichotomous understandings of the words objectivity and subjectivity. I have done this in two ways: firstly, by putting to use critical realist terms and terms used by Latour devised for the specific purpose of transcending the dichotomy; and secondly by using Latour's work and also research from neuroscience to argue that differentiation between rational and intuitive thought is not clear-cut.

\subsubsection{New concepts and terms}

I began the task of putting third way concepts and terms to use in Chapter Three when I analyzed Jenkinson's work by showing that the word truth could be used with reference to a knowledge statement or with reference to an object which has a kind of truthfulness in simply being what it is, even if the statements made in its text are not true. Critical realism's notion of an intransitive dimension (being) that contains a transitive dimension (knowledge about being) provides the situated semantic specificity needed for this form of differentiation. Its strength is that it does not differentiate purely on the basis of whether 'aboutness' is present or absent, but also on space-time situated relationality. In this way it allows knowledge statements themselves to be the referents of other knowledge statements and, therefore, to be intransitive dimension phenomena as well as transitive dimension phenomena. The terms constative utterances and performative

\footnotetext{
${ }^{64}$ Third way is problematized here because, to my knowledge, Latour has not described himself in that way.
} 
utterances, introduced from speech act theory by Yeo (2010c), serve the same purpose for text.

Terms such as fact, reality, truth, and objective, on the other hand, have been used in traditional and postmodern archives domain discourse (as in common language) to refer variously to transitive dimension phenomena such as knowledge statements (which, despite claims to the contrary, may not be true) and to the intransitive dimension phenomena that are the referents of those knowledge statements. Rather than acknowledging the gap between a knowledge claim and its referent, they span the gap. The resultant ambiguity provides ample scope for misinterpretation of authorial intent and for arguments at cross-purposes.

Another useful term introduced in this chapter is epistemic privileging. Its value is that it stops short any suggestion that serious thinkers believe they or anybody else can have knowledge of the whole of spacetime. It recognises that being situated in spacetime inevitably means that one has potential access only to a part of the whole of spacetime, and that one will want to engage with only a part of the available part because knowledge needs are focused, defined by problems one faces, by disciplinary concerns, etc. In archival science discourse, however, the concept of epistemic privileging has often been embedded in the words subjective or subjectivity (e.g., Cook, 2011, p. 616; Duff \& Harris, 2002, p. 275; Nesmith, 2002, p. 36). This is problematic because the words subjectivity and subjective have also sometimes been teamed up with words such as passion, human soul, and irrational (e.g., Cook, 2011, p. 24). On other occasions they have been used ambiguously (e.g., Kaplan, 2002, pp. 216, 218), seemingly spanning the whole gamut of subject-centred perception so that, in effect, the one word covers everything from bias rooted in self-affirming emotional irrationalism through to the epistemic privileging that is an inevitable aspect of all enquiry, even that which strives to be rational and openminded.

The term epistemic privileging breaks that semantic conflation - it clears away some of the rubbish that gets in the way of allowing us to acknowledge and clearly express the fact that subject-centred limitations play an inevitable part in objectivity-oriented 
enquiry. It can serve this purpose for a reader as well as a writer. Take for example the following passage from Ketelaar (2001):

Once we no longer assume that there is only one reality or meaning or truth, but many, no one better than the other, we can try to find these multiple meanings by interrogating not only the administrative context, but also the social, cultural, political, religious contexts of record creation, maintenance, and use (p. 141).

This passage reads almost as though Ketelaar (2001) was in denial of the existence of an intransitive dimension - or, at least, in denial of the possibility that some knowledge statements may better approximate the reality about which they speak than others. Ketalaar's over-all intention, however, was to draw attention to the complexity of the realities surrounding records and their uses, their 'readings' included. Bearing that in mind, it seems reasonable to infer that it was not the quality of knowledge statements about intransitive dimension reality Ketelaar had in mind when he said no "reality or meaning or truth" was "better than the other", but the epistemic privileging that occurs because people seek and form knowledge about intransitive dimension reality for many reasons and from many perspectives, and, therefore, carve off from intransitive dimension Reality smaller intransitive dimension realities. They do this because it is only those smaller realities that are meaningful to them and, therefore, the (intransitive dimension) truth they are seeking. Serious enquiry, Morgan and Olsen (2007) said, should always be respected as "truth-directed" (p. 258), as striving towards an ideal of correspondence between a knowledge statement and the reality to which the statement refers even as it recognises the improbability of ever achieving that ideal. Similarly, I believe, theory-building in archival science entails not only the development of new concepts, but also a search for words capable of communicating those new concepts.

Another term I found useful is "objectfullness" (Latour, 2005, p. 133). There is a word play embedded in Latour's use of this word. On the one hand, it refers to the fact that objects can (and should be allowed to) object to what we say about them; on the other hand, it refers to the fact that our knowledge claims, perceptions, and even our feelings are, in a sense, object-full (Latour, 2005, pp. 204-213). In continuum terms they interiorise the exteriority. I use it frequently in that way in the chapters that follow. To make my 
meaning clear I use the term object-full rather than Latour's objectfull. The corresponding notion of subject-full objects (my term, but Latour's idea) refers both to an interiorising of the exteriority and an exteriorising of the interiority. Fred's trespass notice, for example, captures within it aspects of Fred's thoughts and feelings, but because the trespass notice was made public, it exteriorised his interiority. These concepts play together in Latour's paradigm. He provided an answer to those who, like Hobbs (2010), do not see the interiority of one person's psyche as being deeply entangled with an exteriority that is embedded with the interiorities of others:

How many circulating clichés do we have to absorb before having the competence to utter an opinion about a film, a companion, a situation, a political stance? If you began to probe the origin of each of your idiosyncrasies, would you not be able to deploy, here again, the same star-like shape that would force you to visit many places, people, times, events that you had largely forgotten? ... And then there is the question of your inner feelings. Have they not been given to you? Doesn't reading novels help you to know how to love? Latour, 2005, p. 209)

\subsubsection{Differentiation between rational and intuitive thought}

The second dichotomy I tackled is that between 'rational' and 'intuitive' thought. In the course of the chapter I argued that imagination and non-conscious 'thinking' play a part in all thinking, the rational and truth-directed as well as the self-affirming and fanciful. I showed that feelings and empathetic thinking can be starting points for consciously conducted truth-directed enquiry that is objective in that it allows objects to object to what is said about them. Doing this allows me to argue that the real distinction between an objective stance and a subjective stance has nothing to do with where an idea comes from, but everything to do with how one tests that idea and whether one allows others to test one's findings.

In this paradigm, perception and the attribution of meaning result from encounters subjects have with objects (which may carry within them traces of the subjectivities or objectivities of other subjects and other objects). This means that 'subjectivity' is - like records in the continuum paradigm - always becoming (term borrowed from McKemmish, 1994, p. 200), always responding to both what is immediately present and 
to what is already embedded in memory. Memories are not accrued so much as reformulated in the process. Again, this thinking is consistent with the continuum paradigm - the subject's predisposition for perceptual awareness and attribution of meaning is both changed by each just-past flicker (term borrowed from Upward, 2009) of meaning-making and also changing in response to each flicker in the here and now. Knowledge emerges from the mix, shaped to varying extents by the objects in that mix and the subject's ever-altering predispositions.

When we use the word subjectivity, do we use it to refer to the perceptual and meaningmaking predispositions immediately prior to an encounter with an object or do we use it to refer to what emerges from the mix? This question needs to be asked because objectivity (understood as a truth-directed stance which gives the objects a chance to object) may play a part in shaping the subject's 'subjectivity' when subjectivity is understood purely and simply as the subject's perceptual and meaning-making space. It also needs to be asked because 'subjectivity', when understood as epistemic privileging of which the subject is aware, is always a factor in objective enquiry; but 'subjectivity', understood as epistemic bias which the subject does not acknowledge and of which the subject may not be aware, may also play a part. Given this complexity, is there any case for saying the presence of one (objectivity or subjectivity of some kind) cancels out the validity of claiming the presence of the other?

There were times during the case study research I described in this chapter when objects spoke so loudly and clearly that all who encountered them seemed to hear the same message. There were other times when they whispered vaguely, perhaps not really saying anything at all that was relevant to the meanings, or possible meanings, attributed to them. Can we say objectivity exists when the object seems to be clothing the mind of the reader more than the mind of the reader is clothing the object? Is subjectivity the reverse situation? If so, we need to recognise that, in the course of an extended enquiry, there are moments when one is the case and moments when the other is.

'Subjectivity' and 'objectivity' in truth-directed enquiry, it seems, are better thought of in terms of gradations, and as co-emerging and ever changing configurations, than as dichotomous absolutes. Perhaps the difference that matters is not the difference 
between objectivity and subjectivity, but the difference between enquiry that sustains a truth-directed stance and enquiry which does not?

Commitment to sustaining a truth-directed stance should be, Morgan and Olsen (2007, 2008) argued, the foundation on which a third way concept of objectivity is built. They used the term truth-directed because they believed a correspondence theory of truth to be necessary in a realist paradigm, but also believed that truth as actual correspondence must be "perpetually deferred":

Since how the world is can only be approached through knowledge claims that cannot be conflated with the world, a disjuncture arises that entails that knowledge claims be truth-directed in order to be meaningful but at the same time are to be understood to be only conditionally assertible as true; that is, truth itself as actualised correspondence remains perpetually deferred. (Morgan \& Olsen, 2007, p. 258)

\subsubsection{The possibility of truth? Records as "timeless facts"}

Morgan and Olsen's claim that truth as actual correspondence must be "perpetually deferred" (Morgan \& Olsen, 2007, p. 258) is debatable. The case study experience suggested actual correspondence can be achieved in the case of small assertions about the self-evident characteristics of empirically present things. Morgan and Olsen (2007) acknowledged this, but dismissed it as "not the interesting aspect of arguments about objectivity" (p. 263). Perhaps, however, it is the interesting aspect for those archivists and archival science researchers whose concern is more with providing epistemically adequate building blocks for knowledge formation than with the 'big knowledge' outcomes of extended research activity. It might also be more interesting in relation to sustained research enquiry than Morgan and Olsen realised. The case study experience described in this chapter suggests that degrees of certainty about the big questions rest on the degrees of certainty afforded by observations of small things like, for example, the situated meaning of the word nude when Fred entered it in his diary and the precise relationship between the snapshot and the diary entry.

This focus on the building blocks points to two other conceptual differentiations being important enablers of truth-directed enquiry. One is the difference between intransitive 
situated being and transitive accounts of that being. The other is the difference between the empirically present and the inferred. These are significant because one tends to feel a high level of certainty about the fragments of knowledge derived from observations focused on the intransitive dimension aspects of empirically present things. This is especially true when those things persist in a relatively stable state. Facts of this type (e.g., the distance between Moscow and Paris) are, as Yeo (2010c) put it, are "timeless" (p. 103). They are timeless because the (transitive dimension) fact can be and has repeatedly been verified in relation to the (intransitive dimension) reality. Similarly, in the course of conducting the case study research relevant to this chapter, I viewed digital copies of the 'scrapbooks' at the heart of the chapter on multiple occasions and interrogated them from many angles as different questions I could ask of them came to mind. A stable record, it would seem, is also a "timeless fact". Jenkinson (1922) recognised when he strove to develop methods that would fix the record's "facticity" (Morgan \& Olsen, 2007, p. 258); and Upward (2009) recognised it when, in light of the record's continuous becoming, he said there is a need to establish "observation platforms" (p. 20) that would enable repeatable views of related space-time situated objects.

The certainty one feels in relation to 'timeless facts' is not about the completeness of one's observations, but only about the correspondence between the observations one has made and the details on which those observations have focused. One tends to feel much less confidence in the inferences one makes from one's observations. Lack of confidence, however, is not always experienced. Sometimes one can feel certain of one's inferences, and only begin to experience uncertainty when one's interpretive context expands. The way my thoughts about the "Nudists" volume changed is an example. Other examples can be found in the case study line of enquiry I describe in Chapter Five. The lesson to be learnt here is that one should retain a degree of scepticism about one's inferences. The theory and case study experience discussed in this chapter (and also in Chapter Five) suggest we should also retain a degree of scepticism about the reliability of the stories others tell about realities they claim to have participated in, or to have observed, or about which they have been told by others. 


\subsection{ConClusion}

Standing alone, this chapter can be read as addressing a recognised problem in archives domain thinking which has, to date, received little attention. That problem is a tendency to use the words objectivity and subjectivity in vague, sometimes over-stated, but generally dichotomous ways which divide, rather than cohere, the discourse community. In this chapter I have shown that close analysis of how meaning emerges at the interface between the complexity of a subject and the complexity of the objects the subject encounters during a historical research process makes it possible to understand objectivity and subjectivity in more relational and nuanced ways than the domain's traditional or 'postmodern' discourses have allowed. I have introduced critical realist terms that acknowledge the gap between a knowledge claim and its referent and, therefore, avoid the ambiguity of terms that span the gap, in the sense that they can be used in reference to phenomena on both sides of that gap. I have also introduced terms used by Latour (2005) which are useful for discussing the interplay of complexly interiorised exteriorities and exteriorised interiorities. I have also argued the case against absolute differentiation between rational thought and intuitive thought (including empathetic and imaginative thought) as epistemological opposites. In addition, I looked at the notion of truth as actual correspondence between a knowledge claim and its referent and suggested that such correspondence is achievable, but only in the case of small assertions about the self-evident characteristics of empirically present things. I argued this to be significant for archivists and suggested that a stable record can be thought of as a "timeless fact".

Looked at within the context of my thesis as a whole the ideas developed in this chapter lay a foundation for the chapters that follow. This is because dualistic understandings of objectivity and subjectivity have become embedded in, and have made problematic, the archives domain's thinking about evidence, its thinking about the nature of records, and its thinking about actual and ideal practice. Transcending that dichotomy is, therefore, an important first step in exploring these other issues. In addition, this chapter has provided insight into how knowledge emerges. I add to those insights in Chapters Five and Six and discuss them in relation to the design of knowledge enabling systems in Chapter Seven. 
Chapter Five builds on the foundation laid in this chapter. It focuses on the problem of understanding how evidence emerges during historical research enquiries conducted in circumstances where subjectivity and the unknown are realities that cannot be avoided. Drawing on that understanding, on the theory developed in this chapter, and on continuum theory, it also addresses metaphysical questions that have been raised in contemporary archival science literature regarding the nature of evidence. 


\section{LOOKING FOR LOVE: THE EMERGENCE OF EVIDENCE}

\subsection{INTRODUCTION}

In traditional archives domain discourse central importance is attributed to the word record. The word evidence and its variants, on the other hand, have been significant only in some texts and, when used, have had varying meanings attached to them. In contrast, discourse concerned with contemporary organisational recordkeeping and continuum discourse have been so evidence-focused that the quality of being evidence is treated as the defining characteristic of records.

The concept of evidence in the contemporary recordkeeping discourse emerged in response to a need to identify the ideal characteristics of records and the functionality of recordkeeping systems when the purpose of those records is to serve as evidence of the activity of their creators (typically government organisations). The fact that this concept articulates an ideal in relation to a specific purpose, however, is not universally understood. As a consequence, continuum theorists, who have been prominent in the contemporary recordkeeping discourse, have been charged with promoting objectivist and narrowly focused concepts of both evidence and record with the intention they be understood as the only valid and useful ways of thinking about these phenomena in the domain as a whole.

Responses to this situation have taken three forms. One has been to explicitly reject the idea that the word evidence denotes a concept of central importance for the domain and, in particular, to reject the notion that evidentiality is significant enough in relation to the concept of record to be regarded as definitional. Another form of response has been to by-pass explicit discussion of evidence and, instead, include discussion of concepts with significant, but unacknowledged, evidential implications (e.g., subjectivity and meaningmaking) in discourses oriented around other words, the most significant being the word memory. The 'evidence-avoidant' character of this discourse has tended to reinforce the idea that the word evidence denotes a narrow and objectivist concept. The third form of response has been to argue the need for research explicitly focused on broadening the 
domain's understanding of evidence and evidentiality. To date, relatively little research of that nature has been conducted.

As a consequence of the way the domain's discourse has evolved, development of the concept of evidence and reflection on the nature of evidential practice has been lopsided. Significant attention has been given to the problem of creating evidence of known activities and looking at this problem from the perspective of a recordkeeper who is close to - perhaps even a participant in - the action to be evidenced. However, little attention has been focused on the problem of understanding the factors which enable evidence to emerge during historical research activity when record entities are ideally thought of cornucopias of evidential possibilities, many of which may not be apparent to archivists describing those records. Also, little attention has been given to the problem of bringing into the evidence paradigm the uncertainty, incompleteness, and subjectivity commonly acknowledged in contemporary historical research.

This chapter focuses on the problem of understanding evidence and evidentiality from this neglected perspective. Like Chapter Four, it lays foundations for discussing (in Chapter Seven) matters relating to 'descriptive' practice and the design of knowledge enabling systems. Its primary purpose, however, is theory development. To that end, it explores problems in conceptualising evidence that have manifested in, or been identified in, archival science's critical discourse. Does Brothman's claim that evidence cannot be deliberately created, but "arises out of processes of social negotiation after the fact [emphasis in original]" (Brothman, 2002, p. 334) hold good in light of the case study experience and the theory developed in Chapter Four? Can evidence be conceptualised as a relationship - as is common in archival science - when a thing one person sees as evidencing one matter might be seen by others as evidencing some quite different matter, or when the fallibility of perception is taken into account? Can we say that evidence exists when some people dispute the validity of an evidential relationship that others stand by, or when an item of evidence's relevance to a matter it was once believed to cast light on is exposed as unfounded? Similarly, does evidence exist if the matter it was once believed to cast light on turns out to have been nothing but a figment of imagination? Are there more meaningful ways of thinking about evidence in terms of relationships than simply thinking about it as a relationship? 
All these questions, raised in contemporary archival science literature and by my case study experiences, can be encompassed in a simple tripartite question: What is evidence, where does it come from, and where does it go? This question sets the stage for developing a concept of evidence which includes reflection on its emergence, ephemerality, persistence, and social reach.

The chapter begins with an excerpt from an oral history recording which provides anecdotal evidence of a tragic love affair. The line of enquiry which emerged as I attempted to validate, disprove, or otherwise explain this anecdotal evidence is then described. This is followed by theoretical reflection on the question posed in the previous paragraph. In answering that question I draw on my case study experiences, the theory developed in Chapter Four, continuum theory, and existing conceptual analyses of evidence which have entered the domain's discourse.

\subsection{TRUTH IN A TRAGIC LOVE STORY?}

Amongst the many items at Puke Ariki which relate in one way or another to Fred Butler is a sound recording of an interview with Frances Burton and her daughter Sereena. During this interview Frances responded to a question about Fred's relationships saying, "He did tell us once that he was going to get married, and the girl died the day before the wedding. We only heard it just the once" (Burton \& Burton, 2007, July, 26). Sereena added:

Maybe that's why he destroyed those diaries - because it had his courtship in it.... All his twenty-first year, it's been destroyed. He said that. There are certain little bits that he's copied into the back of one of the other ones. (Burton \& Burton, 2007, July 26)

My reaction on hearing these comments was a sudden switch from a relatively passive listening mode to one that was hyper-attentive. Something about the story, or about the way I received it, stimulated intense interest and also disbelief. The very idea of Fred having been engaged to be married seemed implausible in light of the picture I had formed of him at that point in my research. As for the part about the fiancée dying the day before the wedding, that seemed too clichéd and melodramatic to possibly be true. 
It struck me that the story may have been an outright lie - that Fred may have been amusing himself by seeing how big a fiction he could invent without being caught out (I had come across many references to Fred having been known for his sense of humour). It also struck me that Fred's story may have been a half-truth, the part about the fiancée's death being a fabrication which served the purpose of excusing Fred from explaining the real reasons why the relationship had ended. I imagined a troubled relationship and Fred's reputedly difficult personality perhaps being much of the trouble. All these thoughts came to me quickly in a flash of imaginative reasoning such as I described in Chapter Four and which I likened to abductive suggestion. Rationally - and a little later - I conceded that, melodramatic as the story was, it might have been completely true.

Though intrigued, I decided against putting effort into trying to establish whether that was the case. I reasoned that it would take considerable time and probably not deliver anything relevant to my primary research objectives. The difficulty with which I was faced was that I could imagine only two possible next steps. One was to examine Fred's diaries, something I did not want to do because they were in private hands and, in planning my research, I had made a decision I would delimit the case study by engaging only with 'institutionalised' objects. Setting aside the diaries, I could envisage only one other way forward. This was to act on the assumption that the events Fred described had happened during his twenty-first year, and to search local newspapers published that year for an engagement notice or perhaps an article describing the tragic death of a young woman. I would not have hesitated to search the newspapers, if they had been digitised. However, the prospect of browsing through twelve months of newspapers, looking for something that might not have happened during that twelve months (and which might not have happened at all), was daunting, particularly given that, a few days earlier, I had browsed through all the Taranaki Museum's accession registers looking for items received from Fred, and repeatedly found my attention wandering. I was, therefore, aware that, even if there was something to be found in one of newspapers, I might miss it.

Given these circumstances my decision not to seek out evidence relevant to the story Frances told was quickly made. I returned to browsing through the material relating to Fred Butler in Puke Ariki's collection. 
Lytle (1980a) observed browsing to be common during the early stages of research and when "subject questions" are broad. In such circumstances, he said, "the browser holds an uncertain image of his subject interest ... [and] probably changes his notion of what he wants as his search proceeds" (p. 68). My subject interest was certainly broad and, in some respects, quite vague. During that early stage, I was heavily focused on my research objectives. I was exploring the extent to which finding aid descriptions corresponded with the heritage objects themselves; I was thinking a lot about documentary relationships, multiple provenance, and the evidential effects of the ways in which heritage objects were constructed; and I was looking for material which would support discussion on the legitimacy of distinguishing artificial collections from personal fonds, books from records, and information from evidence. In contrast, the objectives of my historical research were vague. I was simply looking for material which would enable me to advance the primary research; and, because I was particularly interested in exploring multiplicity in relation to the evidential affordances and categorisations of heritage objects, I was as interested in the histories of those documented in, or associated with, Fred's collection as I was in the collector himself. Browsing was a way of familiarising myself with what was in the collection, and as I browsed I was building knowledge about Fred and about the creation and dispersal of his collection.

In scientific research lines of enquiry have been observed to often begin with the identification of an anomaly (Schum, 1994, p. 454). This seems to have also been the case for the line of enquiry I describe in this chapter. Frances's story about Fred's engagement caught my attention because, at the time I heard it, I pictured Fred as an aging, eccentric, and often cantankerous loner. The possibility that he may once have come close to being married simply had not entered my head. In truth, I had not even thought about him being young.

That perception was challenged by what I found when browsing through four large leather bound albums which Fred had labelled "Mount Egmont".

These albums were amongst the unprocessed items in Puke Ariki's archive. I had been given stack access and I found them piled horizontally on a single shelf, volume four at the top and volume one at the bottom. This physical arrangement led to me looking at them 
in reverse chronological order. That, in turn, led to me seeing significance in the chronologically first which I might not have noticed if I had not already browsed through the others.

The three later albums contained photographs taken by Fred mixed with pictures and texts clipped from a variety of sources. Many of the original photographs in these albums depicted scenery and vegetation on the mountain. Most were dated, and alongside some Fred had noted the time of day and place the photograph had been taken. People were only occasionally depicted in these photographs and the annotations rarely recorded the names of those photographed. In general, the content of the three albums (including images of Fred) fitted with the picture of an aging loner I had built in my mind's eye during my weeks of browsing.

The chronologically first volume, however, was startlingly different. When I opened it, I came face to face with the image of a young socially active Fred playfully enjoying the company of other people, people whose names he had usually recorded in his annotations. Fred's playfulness is evident in the photographs on the left and right in Figure 4 below, though only when they are seen together. The photograph on the left was taken by Bernard Aris and depicts Fred. That on the right was taken by Fred and depicts Bernard Aris. Both were taken on Dawson's Track on 16 June 1924. Playfulness is suggested (at least, to me) by the fact that Fred and Bernard have both adopted the same pose and are standing at almost exactly the same point on the track.

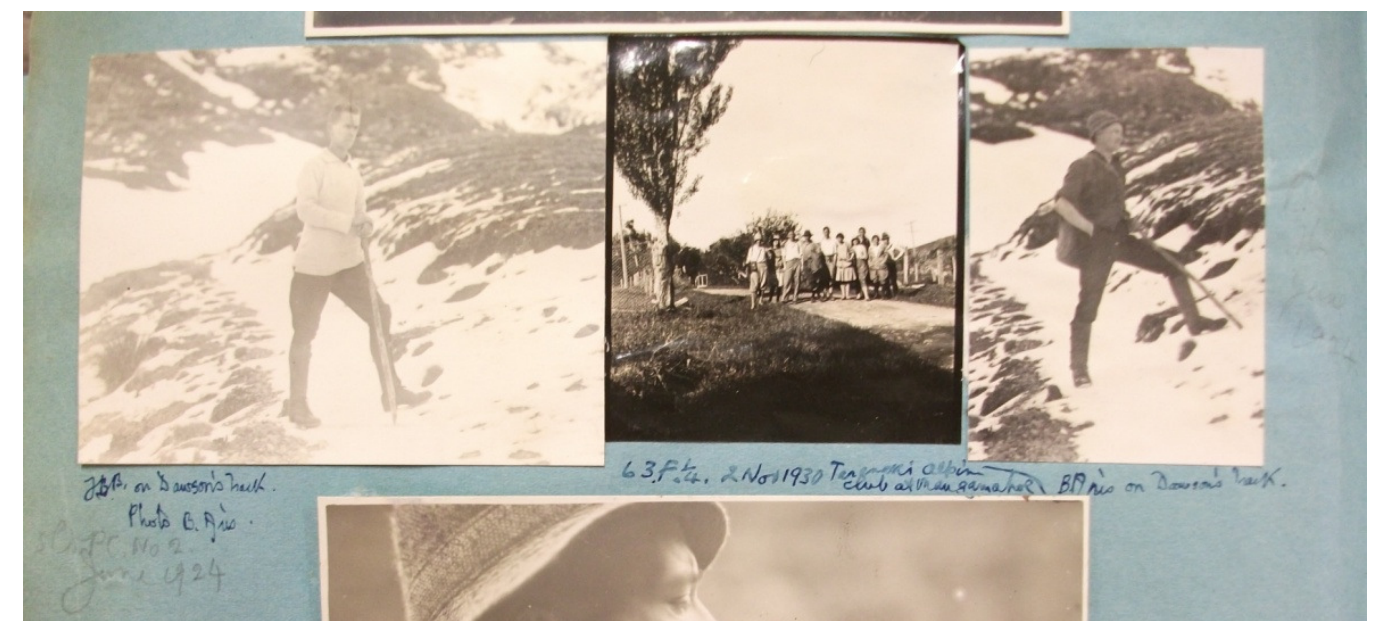

Figure 4. Part of a page from Volume One of Fred Butler's Mount Egmont albums at Puke Ariki with photographs of Fred Butler (on the left) and Bernard Aris (on the right). 
Amongst the photographs that captured my attention were those in which two young women named Hilda and Molly Haldane appeared. Some of these seemed to have a flirtatious quality. Collectively they had an air of domesticity, no doubt because they were accompanied by photographs depicting other members of the Haldane family (including a dog named Roy). These photographs gave me the impression Fred was very much at home with the Haldanes. Intriguingly, even though this album contained photographs up to 1930 , all the photographs of the Haldanes were dated between June 1924 and June 1925. This was Fred's twenty-first year.

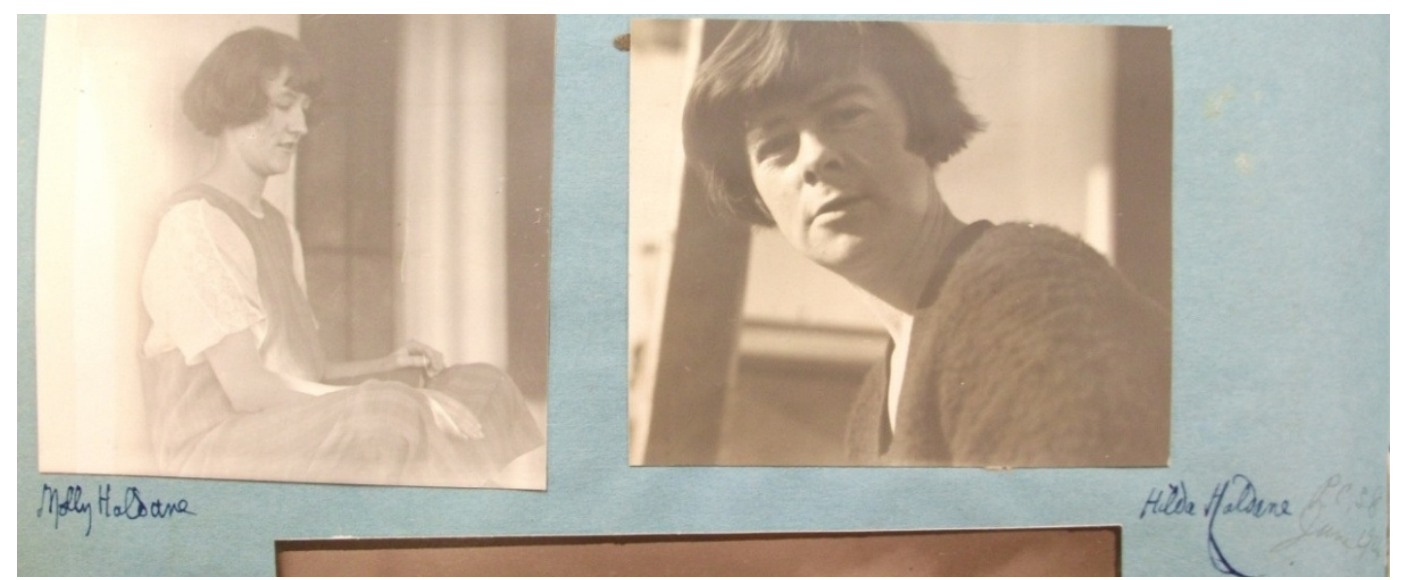

Figure 5. Photographs of Molly and Hilda Haldane. Note the embellished capital $\mathrm{H}$ in the annotation beneath the photograph of Hilda. Does this signify romantic day-dreaming or simply that Fred happened to be experimenting with a lettering style (something he seemed to be doing at this time in his life)? From Volume One of Fred Butler's Mount Egmont albums, Puke Ariki.

Photographs, as I argued in Chapter Four, can enable something close to an eye-witness visual experience of a past event. Snapshots like those depicted in Figures 4 to 8 let us read body language, something we do intuitively, and which research in affective neuroscience has established we do even following subliminal presentation of facial expressions and bodily movements (Dalgleish, et al., 2009, pp. 358- 360). My perception of these photographs as potentially evidencing a love interest in Fred's life was immediate - the body language spoke to me even before I read the annotations and saw the dates. What I intuitively read into them was an emotional affinity between Fred and Hilda. 


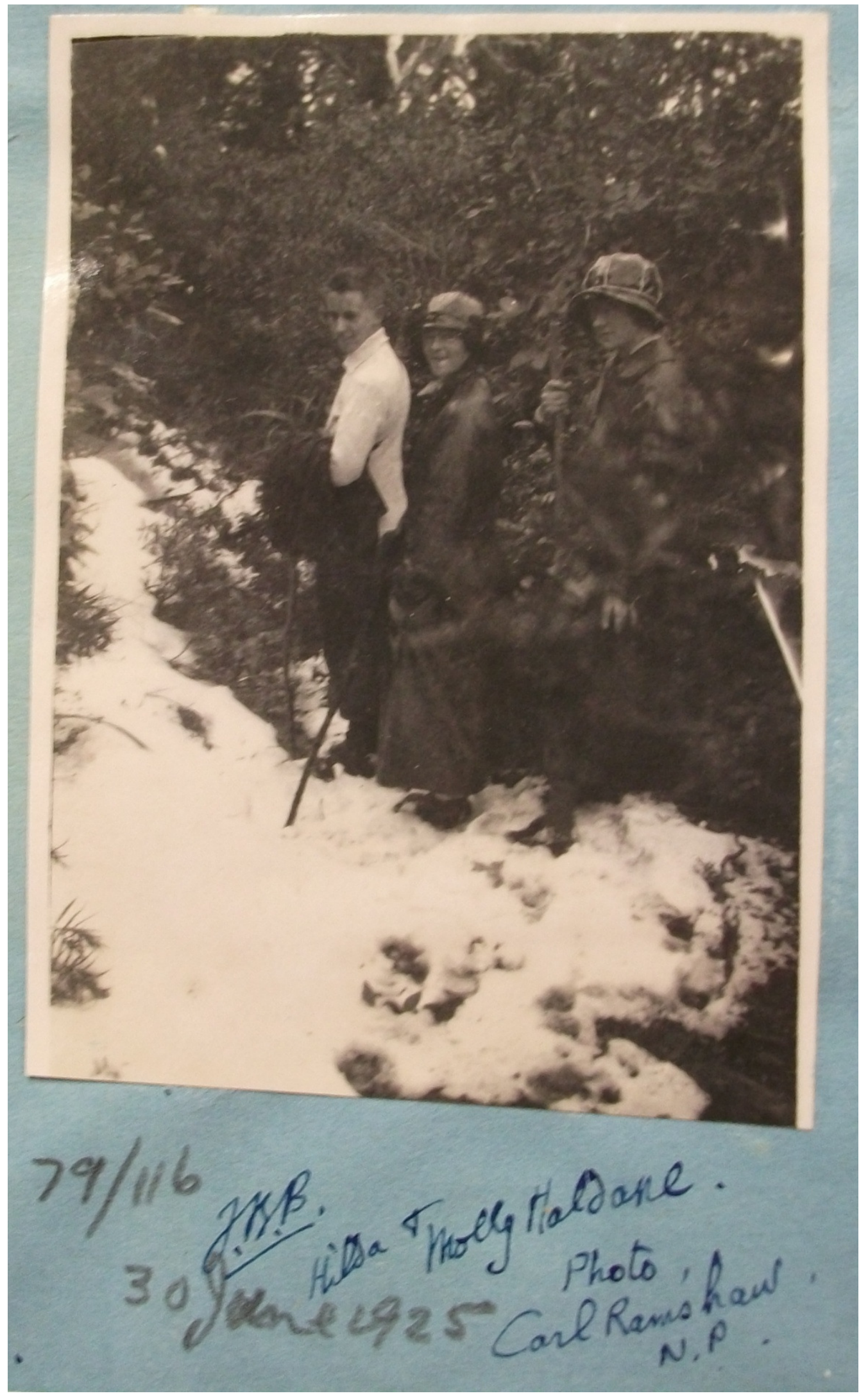

Figure 6. Fred Butler with Hilda and Molly Haldane. Photograph taken by Carl Ramshaw on 30 June 1925. Volume One of Fred Butler's Mount Egmont albums, Puke Ariki. 


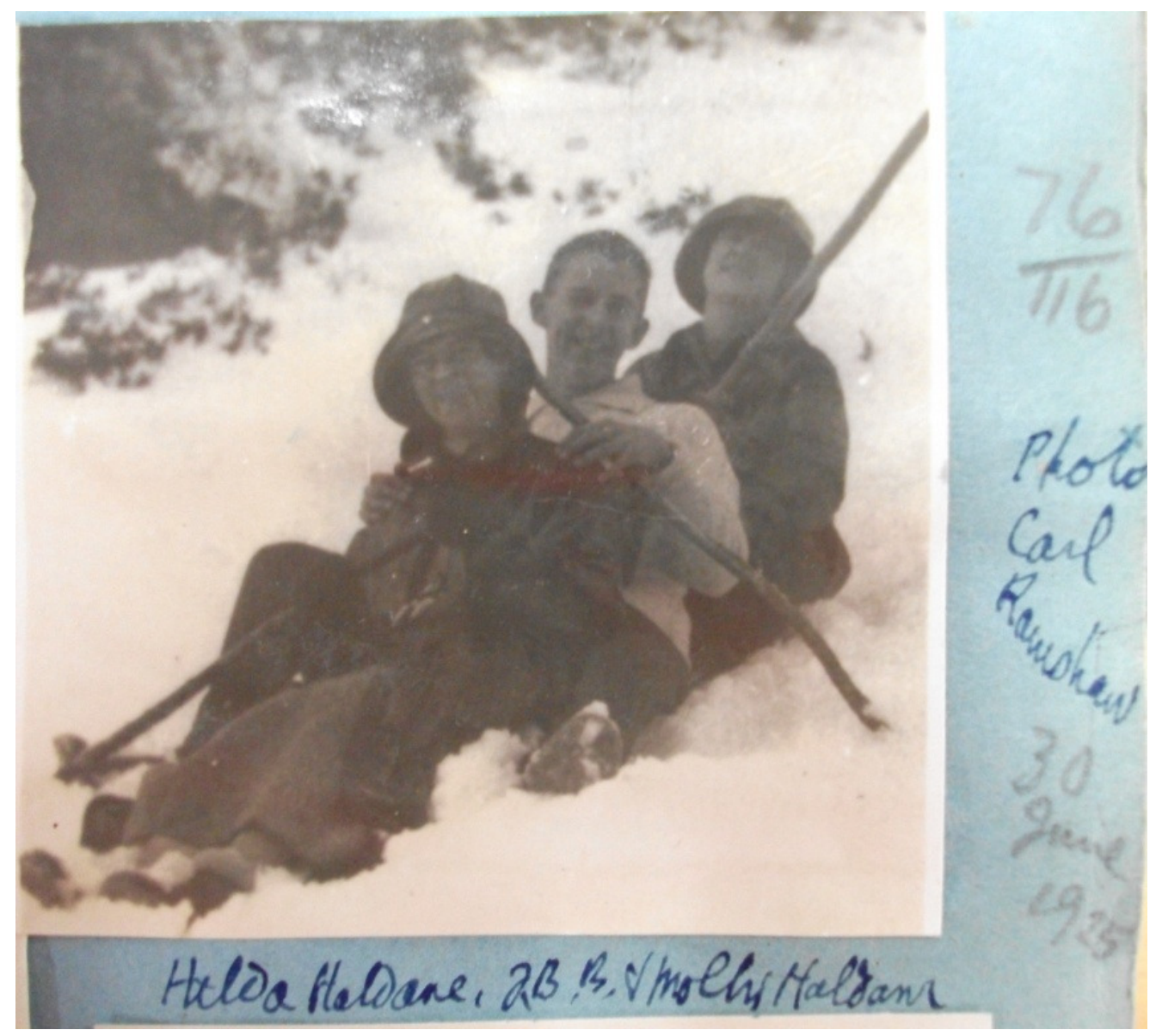

Figure 7. Fred Butler with Hilda and Molly Haldane. Photograph taken by Carl Ramshaw on 30 June 1925. Volume One of Fred Butler's Mount Egmont albums, Puke Ariki

These photographs were not evidence in the sense that they proved Fred had a special relationship with one or other of the Haldane sisters. Instead they served as evidence in two other ways. One was by suggesting a possibility or, to put that differently, by stimulating a hypothesis. The other was by enabling me to keep the enquiry going - the annotations gave me dates and names of people and places which I subsequently used as search terms - they were cornucopias of evidential possibilities.

It is widely recognised that evidence points to something beyond itself. Usually that something is observed to be a hypothesis, a fact that is proven, or an explanation (Furner, 2004; Meehan, 2006; Schum, 1994; Yeo, 2007). Less observed - though observed by Schum (1994, p. 22) - is the fact that things also serve evidential purposes when they point to search strategies it might be fruitful to follow in order to advance an enquiry in the hope of finding further evidence that can flesh-out, confirm, negate, or simply strengthen or weaken the views one has formed from evidence already found. 


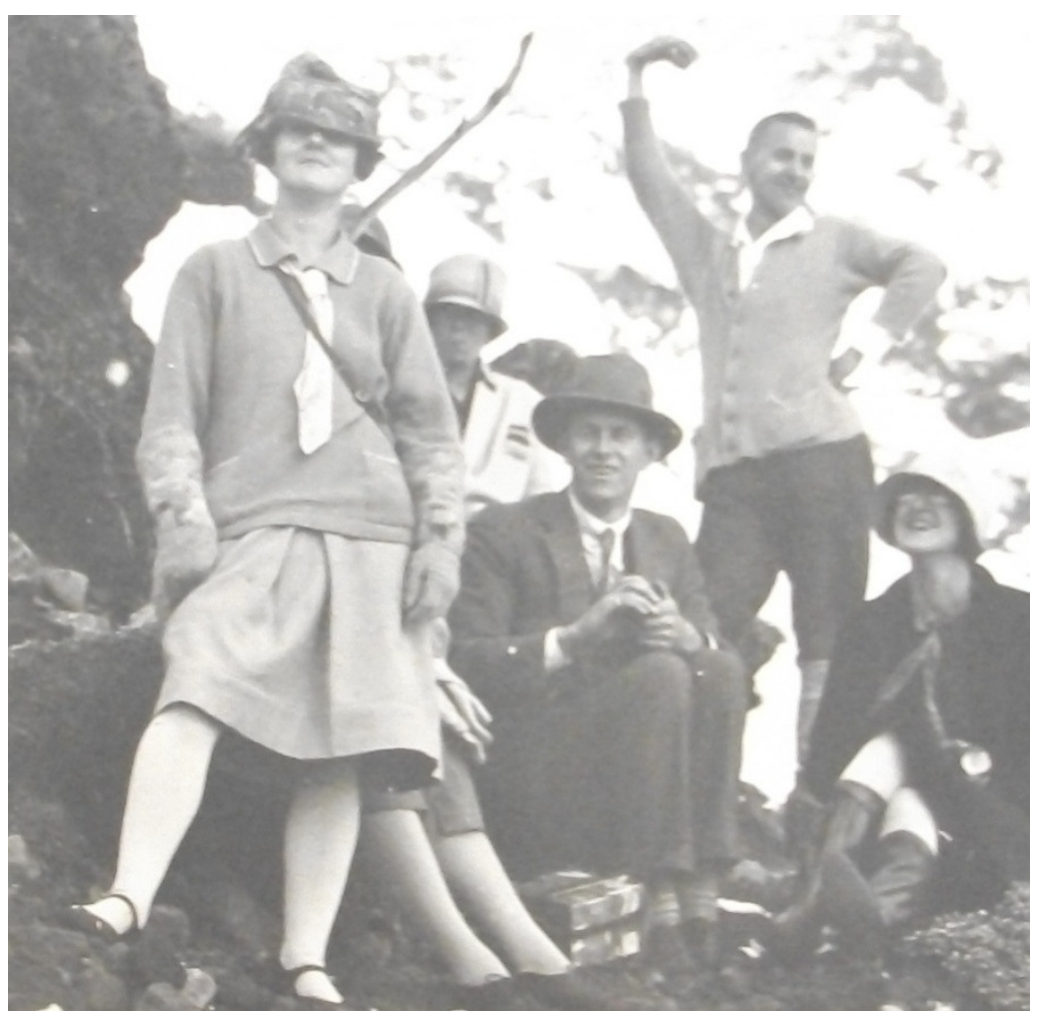

Figure 8. Cropped section of a photograph of the "NP [New Plymouth] Amateur Photographic Society at Egmont, 3 June 192[?]" Fred Butler is striking a pose at the back. The woman standing at the front with her hat tilted over her eyes is unnamed, but bears a resemblance to Hilda Haldane.

From Volume One of Fred Butler's Mount Egmont albums, Puke Ariki.

In light of discovering these photographs, I began to pursue a hypothesis that Fred's story was completely true and that Hilda Haldane had been the girl who died the day before the wedding. I did not choose to prioritise this hypothesis because it was the scenario I thought most likely (I was still inclined to think Fred had been lying about the death and maybe also about the engagement). I pursued it because it was a hypothesis that could easily be negated or confirmed. In other words, I made a strategic decision, one I was only able to make because of my pre-existing knowledge of bodies of records (and their availability and searchability) that would serve my purposes at this point in the enquiry. If Hilda had been the fiancée of whom Fred spoke, her death would have been recorded in the official New Zealand death registers. Whether that was the case would be easy to establish, and the question of whether she and Fred had been engaged would probably have then been easily answered too - a death notice in one of the local newspapers would almost certainly have included that information and would have been relatively easy to find once I had the date of death. 
As it turned out there was no record of Hilda having died in 1925 or anytime in the few years after. Out of curiosity I looked at the index to the marriage registers and there I found her. In 1928 she married Charles Victor Williams. This did not mean Hilda and Fred had not been close in 1924 and 1925, and possibly even engaged to be married. However, it also did not strengthen the hypothesis that they had been. Potentially it provided a reason why Fred might have destroyed the diary. If Hilda rejected him in favour of Charles Williams, Fred may have felt humiliated by the content of the diary. With this possibility in mind, I looked more closely at the photograph album to see when it had been compiled. What I found there was that the early photographs were not inserted in chronological order. Rather, photographs taken between 1924 and 1930 were intermingled, suggesting that the album may not have been compiled until 1930. I also noticed some annotations were in messy handwriting more typical of Fred's writing after 1930 than before. If Fred had destroyed the diary in 1925 or 1926 following a split with Hilda, would he not have also destroyed the photographs? Perhaps not; and perhaps by 1930 he was able to look back with more equanimity - though looking back with equanimity does not really seem characteristic of Fred's disposition. Certainly something must have happened because the Haldane sisters completely vanish from the albums after June 1925. Their disappearance called for an explanation.

Deciding I should not be too hasty in ruling out the possibility that Molly was Fred's love interest, I checked the indexes to the death and marriage registers for her name. I did not find her. I checked the birth indexes and learnt from them that Molly was born in 1905 and Hilda in 1901. This meant Molly was two years younger than Fred who was, in turn, two years younger than Hilda. This information about their respective ages told me nothing definite, though it did indicate that an intimate relationship between the twentythree year old Hilda and twenty-one year old Fred, while not impossible, would contravene the social norm. I began to wonder whether I had misinterpreted the significance of the photographs.

At a loss for how to explain the sisters' presence in, and disappearance from, the album, I started searching for 'ambient context', the context surrounding the Haldane sisters in 
1924 to $1925 .^{65}$ Not knowing what I was looking for, but knowing I would recognise it if I found it, I began a type of focused browsing. ${ }^{66}$

Whereas my browsing activity during the early stages of my research had focused on material known to be related to Fred, my browsing activity at this point focused on the digital finding aids of heritage collecting institutions. I was browsing through lists of 'hits' retrieved by means of keyword searching on the names and other information recorded in the annotations to the photographs, hoping I would chance upon that unknown something.

How would one explain such an information need to an archivist in a reference interview? How do you tell another person what you are looking for when you do not know yourself, and how do you trust them to look - or make decisions about where to look - on your behalf, when the thing you are looking for may reveal itself as meaningful only when it is seen in relation to the memory of some other thing which may, up until that moment, not have seemed significant? At the level of consciousness what I wanted to find was all material associated with anybody or anything identified in the annotations to the photographs that were taken during the time when Fred and the Haldane sisters were known to be in each other's company.

I searched for all the people identified in the annotations, firstly in Puke Ariki's database and then in the databases of a number of other collecting institutions. I found nothing useful. I looked again at the photographs to see if there were clues I had overlooked - and I found one. It was the words "Tahurangi House" in the annotation to the photograph of Mrs Haldane feeding hens (Figure 9). Because of the domestic character of the image, I believed Tahurangi House to be the name of the Haldanes' home.

\footnotetext{
${ }^{65}$ The term ambient context is borrowed from Chris Hurley. It was introduced in Chapter Three section 3.3.4. Hurley used it as a transitive dimension notion - it refers to the described context surrounding a provenance entity. I use it here to refer to the actual (intransitive dimension) context surrounding the people about whom I am seeking information.

66 This sentence paraphrases Hurley (2011) who claimed that archival descriptive methods enable "rummaging" in the archives "looking for the thing that you don't know you're looking for until you find it".
} 


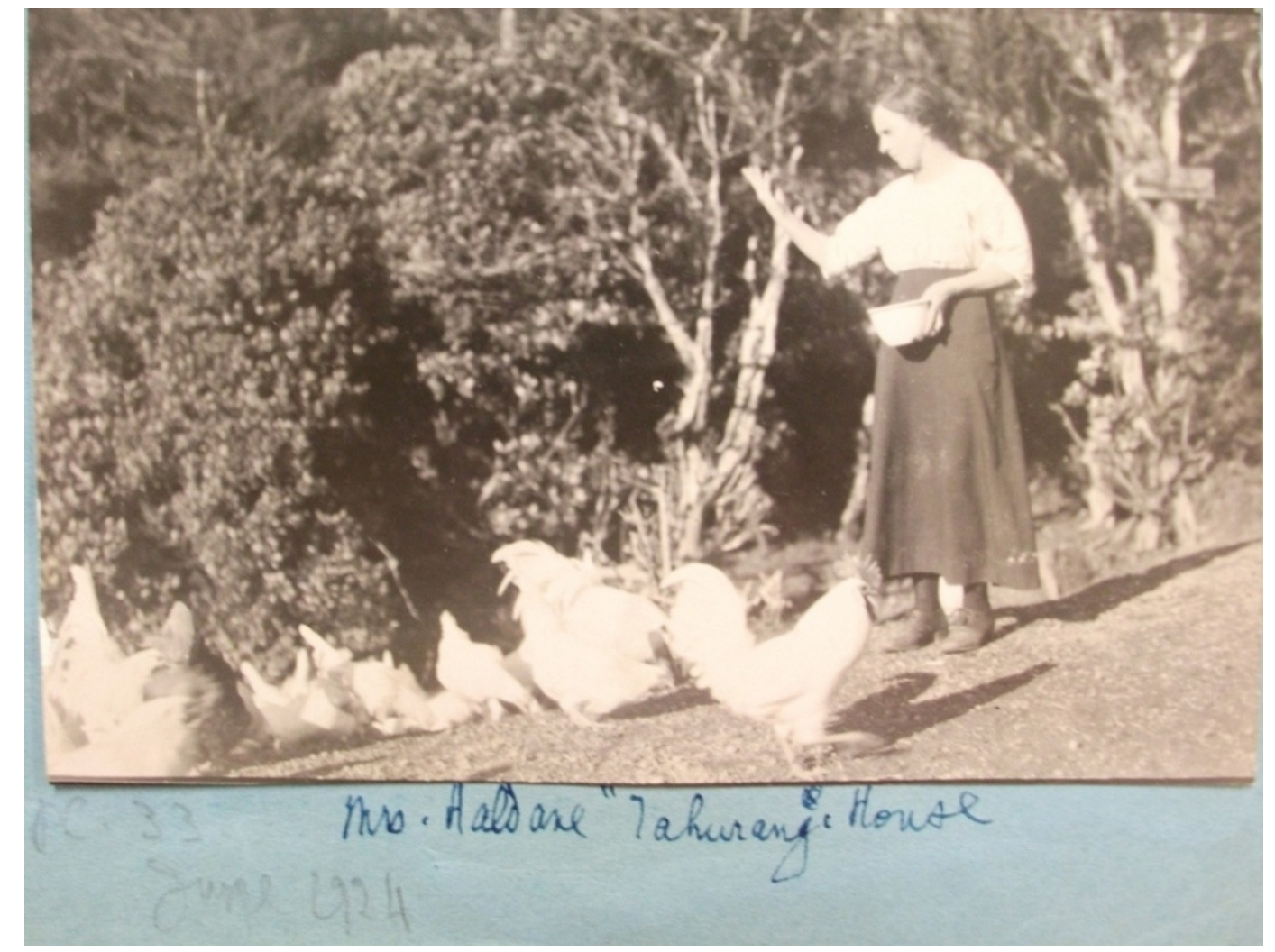

Figure 9. Mrs Haldane feeding hens at Tahurangi House. From Volume One of Fred Butler's Mount Egmont albums, Puke Ariki.

I had Collections Online, the publicly available database of the Museum of New Zealand Te Papa Tongarewa (hereafter Te Papa), open in my web-browser at the time, so I searched there first. I found a single image (C.003368) with next to no metadata. However, what little metadata there was told me something new - Tahurangi House might have been the Haldane's home, but it was also the hostel on the northern slopes of Mount Egmont. It now seemed my earlier assumption, that the photographs had been taken while Fred was a visitor at a private family home, was probably wrong.

Unfortunately, there seemed to be little more I could learn from C.003368. Frustratingly, the photograph was depicted in Te Papa's Collections Online in the way digital images of photographs often are in the databases of libraries and museums - it was a digital orphan, a single image with no apparent link to other documents or to provenance entities. ${ }^{67}$ Stripped of their space-time contingent context, digital orphans do not provide the pathways to potentially related material that are provided by aggregations of material described in accordance with the archives domain principles of provenance and

\footnotetext{
${ }^{67}$ The term digital orphan is borrowed from Sassoon (2007a, p. 139).
} 
documentary context. I searched elsewhere for material relating to Tahurangi House. I found bits and pieces which told me more about the history of the hostel, but I found nothing about the Haldane family. With no clues left, it seemed I had come to the end of the trail. Again I abandoned the idea of pursuing this line of enquiry.

However, some months later I resumed it because of a chance discovery while I was pursuing another line of enquiry.

I had been playing with the idea that Fred's "paranoic thing", as Shaw (2006, September 15) called it, might not have been paranoia so much as an understandable emotional response to a very real and negating experience of social exclusion. In order to investigate this hypothesis, I had attempted to establish whether there was truth in claims Fred made that staff at the Alexander Turnbull Library had borrowed negatives from him and not returned them (Butler, 1958, April 21). Unfortunately, the information I had about the negatives was not specific enough for me to be able to search effectively for them. However, shortly after giving up hope of tracing the negatives, it occurred to me that the annotation alongside a photograph of the Haldane's dog Roy provided a very straightforward way of checking the validity of at least one of Fred's many claims that others were publishing his intellectual property without his permission. In this annotation Fred wrote that A.B. Scanlan had used the image "in his Egmont book WITHOUT permission \& without acknowledgement". I borrowed a copy of Scanlan's Egmont: The Story of a Mountain from the Victoria University of Wellington Library and, in it, I found not only the photograph of Roy but also Hilda Williams (née Haldane) reminiscing about her days at Tahurangi House. She had been one of the people Scanlan had interviewed whilst conducting his research.

From reading Egmont: The Story of a Mountain I learned Hilda and Molly were the daughters of Andrew Haldane who was caretaker and guide at Tahurangi House between 1918 and 1927. Scanlan said, "Haldane's wife and his two daughters, Hilda and Molly, gave to the Old House ... qualities of hospitality, humour and helpfulness" and that "the two girls shared their father's love of the mountain and inherited his tireless energy" (Scanlan, 1961, p. 93). Apparently Hilda and Molly, like their father, acted as guides taking visitors up the mountain. In other words, for them the outings with Fred depicted in the 
photographs may have been just another day's work, and the playfulness on Hilda's face nothing more than a physical manifestation of her nature.

As for Fred's claim that his photograph of Roy had been used without acknowledgement, the evidence afforded by the book was irrefutable. The photograph is there (Scanlan, 1961, p. 128) and, even though the sources of most of the other images reproduced in the book are acknowledged, the source of the photograph of Roy is not. So, on this occasion I found what I set out to find and what every researcher hopes to find - evidence that proves a fact. I found objective evidence in a book in a library's lending collection, a thing which would not normally be thought of as a heritage object let alone as a record. This objective evidence was afforded by the book because it was its intransitive dimension (state of being) at the time of publication that was the focus of my attention. Does this mean Scanlan's Egmont: The Story of a Mountain can be thought of as a record? Certainly not if one's concept of record is traditional, but what if one works within the continuum paradigm and thinks of records as conceptual constructs? I explore the possibilities that way of thinking affords in Chapter Six. Of more interest in the immediate context is reflection on 'publication' in relation to intersubjectivity, and on both in relation to evidence emergence.

\subsection{Pluralisation - Processes of Making PUblic}

When a researcher is working with physical heritage objects, she is constantly interacting with the curators, archivists, and librarians responsible for those objects. Fred Butler was an intriguing character. To come in contact with the material he left behind is to discover stories one wants to tell and objects one wants to show. As my research progressed I frequently shared my 'finds' with staff who had worked with the Butler materials, and they would sometimes point out things they had previously noticed, but I missed. This linking of incomplete individual observations provided me, as I said in Chapter Four, with the means for richer inference and greater certainty in my inferences. We feed off each other's observations just as we feed off each other's ideas.

One example from my time at Puke Ariki occurred when I was browsing through the 'scrapbooks' which contain manuscript transcriptions of historic newspapers. I noticed different fountain pens had been used and, alongside each change of pen, the date and 
time of day was written in pencil in the margin. Often the change of pen occurred midsentence. My initial (and erroneous) interpretation drew on a perception of Fred as obsessively concerned with recordkeeping detail for its own sake, an idea I had encountered in Shaw (2006, September 15). It also drew on my memories of using a fountain pen as a child and the sense I had, whenever I bought a new pen, that each pen had its own way of writing. This inference provided grounds for yet another inference, which was that Fred was so obsessed with completing the mammoth task he had set for himself that he switched pens when the ink was running low rather than stop to refill the pen he was using.

I shared this 'insight' with Bill Howard, a research librarian at Puke Ariki who had previously worked with the 'scrapbooks'. Bill said he had not noticed the change of pen or the pencilled marginalia, but seeing it made him remember something he had previously noticed and I had missed. At the back of these volumes there were lists of names with sums of money entered alongside. After seeing the lists, I looked more closely at the handwriting of the transcriptions. I realised my idea that Fred was swapping pens revealed - or, to put that differently, evidenced or could be explained by - overeagerness on my part to find examples of technological agency. In reality, each time the pen changed, it seems the writer changed too. By noting the dates and times of the handover in the margins, Fred kept track of the hours he and his employees worked on the task. As for my feeling that Fred had an obsessive compulsion to stick with the task and work at high speed until it was completed, it still seems to me unusual - and 'telling' - that these changeovers so often occurred mid-sentence.

When one is engaged in an extensive research project with a human interest dynamic, there can come a point when those with whom one has interacted lead, rather than follow, the discovery process. This is how it came to be that when I decided enough was enough and that I would finally stop looking for evidence of Fred's love life, to my amazement, evidence came looking for me. In an email dated 3 November 2011 Frances Burton sent me an excerpt from Fred's 1925 diary:

Tuesday 30 June:- Last night fall snow. Ground all covered in morning but .... I decided to go for some fun in the snow Carl wouldn't dream of going - too cold. 
(but he really was too lazy) I persuaded Miss Hilda \& Miss Molly to come with me so that Carl will come [text transcribed as received].

These few sentences provide no definite evidence of whether there was a special relationship between Fred and either of the Haldane sisters. However, they do make it clear that time with "Miss Hilda" and "Miss Molly" was an attractive proposition for Carl Ramshaw, who was named as the photographer alongside many of the images depicting Fred with the sisters. This opened my eyes to a possibility I had not previously considered. Was Hilda's flirtatious look and Molly's apparent shyness (see Figure 6) more because of the young man behind the camera than the one posing with them in the photograph? One simply cannot be certain. The facts of the matter, the truth, the reality of what was happening - call it what you will - remain lost, and maybe always will be, in the continuum's fifth dimension - the dimension of the unknown (Upward, 2009, p. 207).

Like all the dimensions of Upward's continuum, the dimension of the unknown should be understood as contingent and variable, not as an actual space. What is known and what is unknown depends on who is doing the knowing - and when and in what circumstances. ${ }^{68}$ Things we want to find, but cannot find, have a way of coming to light. Long after I had finished my case study research, both Frances Burton and Andrew Moffatt (who was at the time the social history curator at Puke Ariki) emailed to tell me concrete evidence of a love interest in Fred's life had been found. It was in a letter book which Frances donated to Puke Ariki in 2012. When a volunteer at Puke Ariki began transcribing it, she found copies of letters Fred had written, in 1932, to a woman named Veda Sanders. It appears Fred and Veda planned to marry. What became of this relationship is, however, another mystery to be solved - or not.

I was told the letters to Veda begin and end in 1932, even though the letter book itself continues through to July 1934 . I checked the indexes to the death registers. There was no entry for Veda in the years between 1932 and July 1963 (the period I searched). That ruled out the possibility of a tragic death the day before the wedding. Out of curiosity, I checked the indexes to the marriage registers to see if Veda had ever married. I did not

\footnotetext{
${ }^{68}$ Also, of course, some things may be unknowable.
} 
find her, but I did find her name in the indexes to births: born Veda Merlin Sanders in 1905, she was two years younger than Fred.

\subsection{WHAT IS EVIDENCE? WHERE DOES IT COME FROM AND WHERE DOES IT GO?}

In Chapter Four I said evidence is always, in one way or another, constructed. When I made that comment I had in mind Brothman's claim that evidence cannot be deliberately constructed in the form of a record because evidence "arises out of processes of social negotiation after the fact" (Brothman, 2002, p. 334). Brothman, as I said in Chapter Three, made this claim because he saw a need for a corrective to an emerging and increasingly dominant archives domain discourse in which "archivists and other record keepers" had “begun to identify more closely with the record-maker's perspective and relinquish the record-user's perspective" (p. 327). Archival science's evidence-focused discourse had, he believed, assumed an objectivist stance which did not adequately account for subjectivity and temporal differences, in particular for the fact that "the identification of evidence signals the passing of time" (p. 335). In effect, he was claiming there to be a necessary relationship between the concept of evidence and the process of discovery - in the absence of that relationship evidence could not be said to exist. This understanding of the nature of evidence served as a corrective to the assumptions Brothman saw to be embedded in the domain's increasingly evidence-privileging discourse. It was the premise which enabled him to formulate an argument that the concept of record cannot be regarded as synonymous with the concept of evidence.

Discussions of evidence frequently privilege a discovery perspective (e.g., Furner, 2004; Schum, 1994). This is the natural stance a historian or a jury takes, but was Brothman (2002) correct in linking evidence's emergence and existence exclusively with discovery? With that question in mind, in this section I factor reflections on evidence's emergence, ephemerality, persistence, and social reach into a broader reflection on the nature of evidence.

In archival science evidence is commonly conceptualised in terms of relationships and sometimes as a relationship. Duranti (2002), for example, claimed evidence "is not an entity, but a relationship" (p. 9) and Meehan (2006) shared the same view. Furner (2004) and Yeo (2007), however, observed that thinking about evidence as a relationship is 
problematic because the word evidence is commonly used to refer to one of the component parts in a relationship rather than to the relationship itself. Furner (2004) suggested confusion could be avoided if, rather than speak of evidence as a relationship we speak of evidence as relational. Evidence, he said, exists in a particular type of relationship, one "that is conceived as linking $\mathrm{x}$ and $\mathrm{y}$, when $\mathrm{x}$ is treated as evidence for $\mathrm{y}$ ". Such a relationship, he added, should be referred to as evidential, not as evidence ( $p$. 248).

Furner's linguistic differentiation sits more comfortably with common language use of the word evidence. However, it takes us only a little way towards understanding what evidence is. It tells us evidence is an emergent phenomenon and that one of the things in which it is grounded is thought (because the relationship in which evidence emerges is conceived). Also, because discussions of evidence (including Furner's) frequently focus attention on the form evidence takes, we know evidence emerges from the meeting (in an evidential relationship) of the evidence perceiver's thought with either a physical object or some other thought. We know this because, as Furner said, the things we speak of as evidence may be "physical phenomena" or "mental phenomena" such as "ideas, thoughts and beliefs, and classes of such entities such as propositions" (Furner, 2004, p. 251). Furner is not alone in this view. Amongst those who study evidence, "the substantive variety of evidence" is widely agreed to be "nearly infinite" (Schum, 1994, p. 3). Therefore, evidence can be "generally and loosely defined as that which we consider or interpret in order to draw or infer a conclusion [emphasis in original] about some aspect of the world" (Furner, 2004, p. 247). Working from foundations laid in Chapter Four, evidence can, therefore, be understood as the intransitive dimension phenomena (including our own prior thoughts, but excluding our physical brain and sensory system) in which our reality-oriented (though not necessarily valid) perceptions and inferences are grounded - and of which we are consciously aware. ${ }^{69}$ Including the last phrase is important because the word evidence "has no complete signification of itself" (Bentham,

\footnotetext{
${ }^{69}$ I have used the term reality-oriented here rather than truth-directed, because in Chapter Four I connected the latter phrase with committed and open-minded striving towards an ideal of correspondence between transitive dimension knowledge and its intransitive dimension referent. In the societal totality, however, enquiry of this nature is not the norm, which is why I have chosen to use reality-oriented here. It recognises that, unless one is being deliberately fraudulent, one's claims that evidence exists of something are (in one's own mind, at least) reality-oriented.
} 
cited by Meehan, 2006, p. 136). It is a label we apply to things (of all possible types) in certain circumstances, and we do not apply linguistic labels to things of which we are not consciously aware. We may not even identify as evidence those physically present things on the margins of our attention. Yet both, as I pointed out in Chapter Four, may be contributing to how our perceptions and inferences are shaped.

This broad definition of evidence, which is in essence the same as Furner's, is the one with which I work. It allows neutrality with regard to the types of things that can serve as evidence and it makes no assumptions regarding the validity of the conclusions drawn from evidence. It also makes no assumptions regarding whether perceptions of evidence are intuitive or the outcome of consciously deliberative analysis, which is important given that in Chapter Four I argued intuitive meaning-making plays a significant part in even the most objective of enquiries. The only thing this definition requires of us is that we think of evidence as having a certain place in a certain type of relationship (i.e., an evidential relationship) - it is the $x$ that is treated as evidence for $y$.

Unfortunately, the idea that $\mathrm{x}$ is evidence because of the place it has in an evidential relationship, coupled with the idea that an evidential relationship is one where $\mathrm{x}$ is treated as evidence for $\mathrm{y}$, is tautological. It does not take us very far towards understanding what evidence is. A slightly different way of expressing that definitional formula is to say evidence is the $\mathrm{x}$ in a relationship where $\mathrm{x}$ evidences $\mathrm{y}$. Though the verb evidences is as vague as the noun evidence, focusing on the verb is helpful because it allows us to shift away from asking what evidence is and instead think about how $\mathrm{x}$ is acting within any given relationship where $\mathrm{x}$ is intuitively seen as serving an evidential purpose in relation to $\mathrm{y}$.

In archival science one of the most common ways in which evidence is said to act is as proof. Duranti (2002), for example, described evidence as "the relationship shown to the trier of a fact - a judge or jury - between a fact to be proven and a fact that proves it" ( $p$. 9); and Meehan (2006) suggested evidence could be understood as the relation between "a proposition to be proven and a proposition that proves" (p. 137). A conceptual link between evidence and proof has also been important in the development of recordkeeping standards where a primary objective of recordkeeping, and a primary 
functional requirement of recordkeeping systems, is that records are created, captured, and managed in such a way that their authenticity can be proven (e.g., International Organization for Standardization, 2001).

As my case study discussions have shown, there were occasions when my evidence acted as proof. However, mostly proof of the hypotheses I entertained was not found. Because this is commonly the case during discovery, Schum (1994) said, "we often make use of masses of inconclusive [emphasis in original] evidence" providing grounds for inferences that "can only be probabilistic in nature" (p. 2). This being the case, pinning the concept of evidence to the concept of proof does not adequately explain the nature of evidence.

Whereas today we commonly interpret any claim that a fact or proposition has been proven to mean there is no space for doubt that it corresponds with the reality about which it speaks, an older use of the verb to prove attributes it the meaning "to make trial of; to try, test" ("Prove", 2007). This provides scope for saying a thing serves as evidence (and, therefore, is evidence) if it is used to test a proposition, hypothesis, or purported fact. This fits more comfortably with contemporary knowledge paradigms and with discovery as we experience it. ${ }^{70}$ It also serves another useful explanatory purpose: it allows the concept of evidence to be used in relation to a process of enquiry rather than simply in relation to a conclusion. Whether the outcome of an enquiry establishes a hypothesis it tested to be correct, false, or still open to question is immaterial because whatever was used to test the hypothesis is always constituted as evidence in the context of that enquiry.

During my case study, for example, I used the index to the deaths registers to test the hypothesis that Hilda or Molly may have died shortly after the last photographs of them (in Fred's album) were taken. The index served as evidence by providing proof neither Hilda nor Molly died at that time. The outcome of my re-examination of the "Nudes" and "Nudists" 'scrapbooks' Pound (2006) saw as evidencing (i.e., as proving) the fact (purported by Pound) that Fred practised nudism - at least on occasion - was different. As a result of looking at those 'scrapbooks' in order to test Pound's interpretation of

\footnotetext{
70 Hereafter I avoid ambiguity by using the words prove and proof only when there appears to be correspondence between a knowledge statement and its referent.
} 
them, I formed the conclusion that, though one might contain evidence of an interest in nudism, the other did not, and neither provided grounds for claiming Fred practised nudism. So, were these 'scrapbooks' evidence? The answer can only be, it depends; and what it depends on is how one sees them relationally. I cannot see them as evidence if I consider them in relation to an indisputable conclusion that Fred practised nudism. However, I have no difficulty in thinking of them as evidence if I see them in relation to Pound's claim that Fred practised nudism. I also have no difficulty in thinking of them as evidence if I think about them in relation to my testing of Pound's claim. In short, very subtle relational variations can change our perception of a thing from being evidence to not being evidence.

Useful as the notion of testing is in thinking about how one thing acts when it is seen as evidencing another thing, it is not uniquely useful. The scenario just described reveals another way in which a thing can be acting when we see it as evidence - it may be providing grounds for doubting the validity of a prior belief or knowledge claim. Another way of expressing this would be to say a thing acts as evidence when it causes scepticism or suspicion.

Recognition that there are grounds for doubt may be the end point of an enquiry or may be the stimulus that begins an enquiry, which brings to attention another role a thing may be playing when it acts as evidence. It may, as Schum (1994) observed, be opening up a "line of argument or a chain of reasoning" (p. 22).

A chain of reasoning may be communicative, in which case it is structured as a line of argument leading to a conclusion already arrived at, or it may be investigative in which case it takes the form of a line of enquiry - or, more graphically apt, an inferential network (Schum, 1994, pp. 83-86) - where both the end result and the paths that will be travelled to that end are uncertain. For a line of enquiry to begin, there must be stimuli that focus attention on a problem to be explained and stimuli that point to at least the first steps that can be taken in a search for that explanation.

Things that do not fit the norm for the context in which they are found seem especially likely to call for explanation and to stimulate hypothetical explanations. Sereena, for example, recalled a problem which had previously puzzled her (why a diary had been 
destroyed) when she heard Frances say Fred had once been engaged. The hypothesis that Fred's engagement may have been during his twenty-first year emerged from that meeting of evidence that called for an explanation (the missing diary) and evidence that potentially provided an explanation (the tragic engagement story). My hypothesis that Hilda Haldane may have been Fred's fiancée emerged from an interaction between my observation of photographs and annotations in one of Fred's albums that deviated from the norm to which I had become accustomed and my memory of Sereena's hypothesis, which I intuitively saw as possibly explaining the anomaly I perceived. The story about Fred's engagement had previously captured my interest, but the details were so sparse I could not think of an effective way of pursuing any of the hypotheses that came to mind when I heard it. The evidence afforded by the first volume of Fred's albums solved that problem because, besides stimulating a hypothesis about who the fiancée might have been, it also stimulated awareness of ways to begin testing my hypothesis. Again, of course, the evidence in the album did not act alone in pointing a way forward. Rather, it acted in conjunction with my pre-existing knowledge of the availability and searchability of information resources that might yield further evidence pertinent to this newly formed hypothesis.

One does not necessarily take the first step in an enquiry with confidence that the enquiry can be brought to a definitive conclusion. Often one takes that first step simply in the hope of finding some new clue which will enable the enquiry to continue. In short, things can act as evidence by calling attention to a problem in need of explanation, by appearing to offer an explanation for a problem, or by pointing to a way of beginning or progressing an enquiry.

Another, and fundamentally important, way in which things may act when they are acting as evidence is by establishing relevance. As a line of enquiry unfolds various things become relevant to that line of enquiry but, at the end of the enquiry, not all of those things will necessarily be seen as relevant to whatever conclusion has been arrived at. One of the photographs which acted powerfully in leading me to form the view that Fred and Hilda were close provides an example. The photograph in question is that depicted in Figure 8. The annotation attached to this photograph states it depicts members of the New Plymouth Amateur Photographic Society but does not name the individuals. Also, it 
does not record the year clearly - what one sees is "3 June 192[?]". I construed this image as evidence relevant to the relationship between Fred and Hilda on the strength of a perceived resemblance between Hilda and the young woman in the hat and because the absence of the final numeral in the date gave me latitude to infer that it was likely to have been taken during Fred's twenty-first year. I did not, however, take the relevance of this photograph for granted. Rather, I invested considerable effort in attempting to establish whether the young woman in the hat and tie really was Hilda. The way I did this was by comparing her facial features with Hilda's. With hindsight it seems confirmation bias may have been shaping my research strategy at this stage because there are two things I did not do - and did not even realise I was not doing. I did not look for other photographs of a young woman in a hat and tie in Fred's album, and I did not look for other photographs of the New Plymouth Amateur Photographic Society. As it happened, there was another photograph of the New Plymouth Amateur Photographic Society in Fred's album and it included the young woman in question. I found it serendipitously while looking for something else and close to completing what I thought would be the final draft of this chapter.

The newly found photograph depicts a fairly large group of people. It was one I had taken a digital copy of when I was visiting Puke Ariki, so I was aware of its existence, yet somehow its relevance in relation to the photograph depicted in Figure 8 had escaped my attention. What caught my eye, as I was scanning through my collection of digital images, was that amongst those depicted was a young woman dressed the same as the young woman I had convinced myself was Hilda. I looked more closely, saw the annotation and realised that it was indeed the same young woman. This too was a photograph of the New Plymouth Amateur Photographic Society taken on 3 June - 3 June 1927. In the annotation Fred had recorded (from left to right) either the name of the person depicted or " $\mathrm{Mr}$ " or "Miss " when he did not know the name. The name of the young woman in the hat and tie is difficult to decipher, but what Fred appears to have written is "Miss Cater".

How did this photograph act when it acted as evidence in my enquiry? It prove another photograph I had believed to cast light on the nature of the relationship between Fred and Hilda had no such explanatory power because it was not relevant to that relationship. 
This example demonstrates how when the 'reality' under investigation is not selfevidently real, but merely purported or hypothesized to be real, a tendentious circularity can easily come into play whereby 'relevance' and 'reality' are co-constituted in a way which serves to 'confirm' some perceptual predisposition but actually bears no resemblance to realities - and realities of relation - in the intransitive dimension. In theorising relevance within an exploration of evidence, therefore, we cannot afford to think of relevance purely in relation to a line of enquiry or a conclusion one person forms or a group of people share at some point in time. Doing so constitutes relevance as purely determined by subject-centred perception or interest. Logically, in light of my argument so far, evidence can be said to sometimes exist in relation to an erroneous and subjective perception. However, looked at from a whole of spacetime perspective, the concept of evidence does not exist in order to affirm subjectivities and produce fictions. On the contrary, it is reality-oriented. Therefore, the way we conceptualise relevance must also be reality-oriented. To that end, we can say establishing relevance is ultimately a question of demonstrating that the perceived relatedness of things corresponds with the actual relatedness of those things. The precision required in making such connections can be very fine-grained as was demonstrated by the teasing juxtaposition of the snapshot of Fred swimming at Bell Falls and the diary entry claiming he was snapped in the nude.

Relevance is not much discussed in archival science but there is a concept conceptually connected with relevance that is regarded as being of fundamental importance in the archives domain's evidence-privileging discourse. That concept is authenticity.

In traditional archives domain discourse the record (understood to be a physically bounded object) is deemed to be authentic if the claims it makes for itself regarding its context of creation (e.g., dates and signatures), or the claims of that nature others make on its behalf, can be proven. Though language vests the quality of authenticity in the object, logically the concept of authenticity is concerned with the actuality of the relationship between an object that exists in the present and its context of creation. Because the physical characteristics of record objects change over time and their contexts of 'creation' are recognised as multiple in most contemporary archival science discourse, it makes sense to recognise that authenticity is a word of relation rather than one that signifies an absolute-and-true-for-all-contexts characteristic of an object. If we 
are able to reliably envisage an object from the past as it was when it was created - or when it was in use in some other context - we can say that it is authentic in relation to that context. If it is authentic in relation to a given context (regardless of whether it might be considered authentic in relation to other possible contexts), a researcher coming later can trust it to be relevant for evidential purposes in respect of that context. Clearly, the more objective the method for capturing evidence that a heritage object (or some part of it) is related to something else, the more trust a later user of that heritage object will be able to vest in it. Clearly also, the more numerous and fine-grained the relationality that can be captured, the more potential the object will have for adequately supporting lines of enquiry that may be of interest to future researchers. I discuss these matters further in Chapters Six and Seven.

In my discussion of relevance I referred to a need to think about evidence from a whole of spacetime perspective. The conceptual problems to which this chapter responds exist because of a pre-occupation with space-time situated understandings of evidence. In the flow of time different, sometimes competing, understandings of evidence exist. The reasons for this vary from the existence of differing needs for evidence to incompleteness and uncertainty of interpretation. Given this is the case, the only way to conceptualise evidence at a meta-level is to rise above the flow and look at its diversity as an objective (i.e., intransitive dimension) reality - diversity exists; it needs to be accounted for. In other words, if we want to begin understanding evidence as a meta-concept, we need to give thought to the question of where it comes from and where it goes - "theories", as Upward (2005a) said, "have to be rooted in formation, in process, in the becoming of things, rather than in their essential and abiding nature" (р. 89). In the remaining part of this section I return to the questions in response to which this theoretical discussion was framed.

Can evidence be deliberately constructed in the form of a record, or is it only constructed during discovery from traces unconsciously left in records? The case study experience demonstrated that, while often things are construed as evidence in the researcher's mind during discovery, there are also times when evidence comes to the researcher readymade. When evidence is construed in our minds, what we do is apply a conceptual overlay which does not change the intransitive dimension characteristics of whatever was 
there before (the thing construed as evidence does not cease being whatever it previously was). Rather, in the mind's eye, we see the thing as more than it was before and, perhaps also, as less than it was before. We see it as more because we see it in relation to something else so it takes on meaning by association. We see it as less because not all of its characteristics will necessarily be playing a part (or consciously seen to be playing a part) in its construction as evidence.

It is because these perceptions of evidential relatedness and significance are often communicated and re-used for the same or closely related evidential purposes that we can think of evidence coming to us already made. The transcribed diary entries and digitized photographs sent to me by Frances Burton, for example, came to me as evidence already made. The annotation in Fred's photograph album recording that a particular photograph of Roy had been reproduced without acknowledgement in Scanlan's Egmont, The Story of a Mountain was found by me as evidence already made - deliberately constructed and left in a place where it would be found (Fred's albums were amongst the items in his collection that he made available for the use of others). The indexes to births, deaths, and marriages are, of course, another clear example from the case study of evidence already made.

It is because the entities (physical objects, oral testimonies, etc) one person construes as evidence at some particular time tend to be richer in themselves and in their potential relatedness than they are required to be for the purposes of that one conceptual overlay, that those entities - perhaps records - can be seen to be cornucopias "of meanings" (Harris, 2001a, p. 41) or, as I prefer, cornucopias of evidential possibilities. Take Scanlan's book, for example. It acted as trace evidence - and as a primary source, or a "true and original" remnant "of the past" (Laborde, as cited in Moore, 2005, p. 216) - when my attention was centred on the photograph of Roy (Scanlan, 1961, p. 128) and the book's list of illustrations in relation to the question of whether Scanlan had published the photograph without acknowledging Fred as the photographer. When my attention was focused on the textual information provided by Hilda, it acted as testimonial evidence. Admittedly, it was 'hearsay' evidence, but so too is much of the testimonial evidence afforded by official records - whether contemporary health records or the witness statements in the court records of the Salem witchcraft trials (Yeo, 2010c, pp. 104-105). 
Needless to say, there are many other directions in which an object as complex as this book (once owned by John Pascoe, Chief Archivist of the National Archives of New Zealand between 1963 and 1972, as evidenced by an inscription on the title page) might stretch out as evidence. ${ }^{71}$ When Harris (2001a) described records as cornucopias of meanings, it was almost certainly with this type of 'stretching out' in mind. This was certainly what I had in mind when I suggested the phrase cornucopias of evidential possibilities might be more useful. What occurred to me only as I was writing this chapter is that records, and other things that serve as evidence, are cornucopias of evidential possibilities also in that they serve multiple evidential functions. Potentially, they prove assertions, test assertions, stimulate hypotheses, cause awareness of problems, point to ways of pursuing enquiries, provide grounds for probabilistic trust, etc.

How can we say that evidence exists when some people dispute the validity of an evidential relationship that others stand by? Can we say evidence exists if its relevance to a matter it was once believed to cast light on (i.e., its relatedness) is exposed as unfounded, or if the matter it was once believed to cast light on turns out to have been only a figment of imagination? These questions, which have been posed in order to problematize the possibility of conceptualising evidence as a meta-concept, lose their potency if we take an expansive view of evidentiality as being a fundamental feature of human existence, rather than a feature only of certain discourses. It dissipates further if we recognise that evidence exists in relation to fallible perceptions, inferences, and knowledge claims. If, in striving to define evidence as a meta-concept, we stop trying to reconcile what different people and groups of people standing at various points in the flow of spacetime have objectified as evidence and instead imagine ourselves into the hypothetical state of being able to see the whole of spacetime (all that ever was, is, or will be) then we objectify evidential relationships in relation to the subjects and the object-full 'subjectivity' responsible for their emergence. From the whole of spacetime perspective we can watch those relationships persisting or being abandoned, being communicated and accepted as valid (or not), being re-used, being sometimes inscribed in objects that

\footnotetext{
${ }^{71}$ The notion of records 'stretching out' is borrowed from continuum writing, where it has often been used (e.g., Upward \& McKemmish, 2001, p. 34; McKemmish, et al., 2009, p. 4457).
} 
persist and which may later be used for the same evidential purpose, for some other evidential purpose, or for some purpose which is not evidential at all.

In the whole of spacetime nothing is lost. Some particular perception or claim of evidential significance may be discredited and, therefore, fall out of use in the flow. However, from a whole of spacetime perspective, when considered in relation to its own context of emergence, spread, and duration, every evidential use, every perception or claim that an evidential relationship exists will always be what it always was. Pound's evidence was, is, and will continue to be his evidence in relation to the case he made for Fred Butler practising nudism (Pound, 2006). My different interpretation of those 'scrapbooks' does not change their status as evidence in the context of their earlier use by Pound. In the flow of time, my different perception may have some effect on the duration and spread of the belief that there is an evidencing relationship between the 'scrapbooks' singled out by Pound and Fred's purported nudism. However, there is no certainty even that will be the case, given how repeatable colourful stories with a scandalous edge are. Furthermore, in a world of diverse and uneven engagements with knowledge products, what is known and what is unknown varies so much from person to person that we can never assume universal perceptions of evidentiality exist even at a specific moment in the flow of time. Nevertheless, we can claim as a universal truth that what was was and what is is, even as we acknowledge that both the things that were and are, and our knowledge of them - and, therefore, our understanding of them as evidence - are always becoming.

Is evidence a relationship or relational? Taking Upward's whole of spacetime stance enables us to see each evidential relationship that ever was as static and fixed in its own space and time, yet also to see the component parts of that relationship potentially drifting apart and serving other evidential purposes. Also, it enables us to see how whole evidential relationships and chains of evidential relationships can themselves become the evidencing entity. This is because, as a line of enquiry stretches out, it becomes increasingly common for an evidencing-entity-coupled-by-reasoning-to-an-evidencedthing to become the evidencing entity in relation to some new evidenced thing. Indeed, complex networks of that nature are the norm because in real life situations - as opposed to "contrived abstract examples" - "single stage inductive reasoning" is rare (Schum, 1994, p. 33), as is also the experience of evidence coming to us with "already established 
credentials regarding its relevance, credibility, and force" (Schum, 1994, p. 67). In short, it is a mistake to debate whether evidence is a relationship or relational because it seems to be both. It seems that it is because certain relationships are seen to exist within or between empirically present things that we see those things as evidence by virtue of their perceived relationship with something that is not empirically available. Even the death index which served as evidence that Hilda did not die during the years when she and Fred associated can act in that way only because it is lent authority by the documents from which it emerged and by knowledge of the contexts and protocols associated with the creation of those documents. Though many individual users may not have that knowledge, those documents and that knowledge about them act evidentially in the background because it is from out of them that a socially situated habit of trust has emerged.

So, was the diary providing evidence of another diary kept during Fred's twenty-first year but subsequently destroyed - the diary spoken about by Sereena but not seen by me evidence from my perspective? In answering that question I confront a conceptual dilemma because I cannot think of it as my evidence but I also cannot deny its huge evidential significance in relation to the line of enquiry I followed. It was my experience that all that was demonstrated (in Chapter Four) to be at work during any meaningmaking process is also at work during historical research enquiry. Social identity, world views in the form of stereotypes and unverified generalisations, hazy memories, and things empirically present but on the periphery of our attention all act to produce perceptions and inferences along with - and in much the same way as - those physical and mental phenomena we typically think of as evidence. How we draw the boundary between the things we refer to as evidence and other actors at work in the perceptual or meaning-making process is interesting, especially in the case of mental phenomena. On the one hand, we seem to limit use of the word evidence to those empirically present things on which we centre our attention. This is why the things that evidence are sometimes "mental"; they are knowledge derived from engagements with the physical, not the engagement itself. ${ }^{72}$ It is also why we typically do not name as evidence things

\footnotetext{
72 The distinction between "mental" and "physical" evidence was made by Furner (2004) and was discussed earlier in the chapter. Up to this point his terminology has been workable. However, in the context of the
} 
that are empirically present and affecting our perceptions yet on the margins of our attention - things such as a file pin; a consistent recurrence of a type of paper, a colour of ink, and a handwriting style; a screen display; oral information provided by an archivist; or even the fact of being physically within an archival repository.

All this is a reminder that evidence is merely a word we sometimes use to refer to the things we are conscious of our thoughts being immediately grounded in. We tend to apply it to things which are present at the moment of thought because they existed before the thought. We do not apply it to the thought itself. In other words, evidence - even "mental" evidence - is always spoken of as object (i.e., an intransitive dimension phenomenon) in relation to the thought. However, we do not use the term evidence in reference to all the intransitive dimension phenomena from which the thought emerged. We do not call evidence those things we do not perceive acting to produce our ideas, or those things whose acting presence is taken for granted. We also do not use the word evidence to refer to things we do not want to acknowledge were acting - a predilection for tragic love stories or salacious gossip, for example, or perhaps a desire to fit into a social group, or shape a group identity. In other words, we seem to restrict our use of the word evidence to those things which (rightly or wrongly) we believe lend objective weight to our reality-oriented thoughts. Perhaps this is why the word evidence is used in reference to intransitive dimension phenomena even though the status of being evidence is acquired by those intransitive dimension phenomena only because of thought - and, therefore, as evidence they are always transitive dimension phenomena.

I am not sure what to make of this paradox. It is almost as though the word evidence, as we commonly use it, does not allow us to fully accept that the knowledge outcomes of our thinking processes are affected by anything other than the things we call evidence. Whatever the explanation may be, our talk about evidence only partially accounts for the objectivity of objects and the object-full 'subjectivity' of perception and inference that are

current discussion, the verbal dichotomy is problematic. Therefore, clarification of what Furner meant by "mental" phenomena seems warranted. Clearly he used this term in reference to those things that in critical realism would be termed transitive dimension phenomena - ideas, beliefs, knowledge claims, etc. These things, of course, would neither emerge nor be communicated if not for intransitive dimension phenomena such as the brain, technologies of inscription, and physical carriers. 
at play during meaning-making processes. There is a certain irony in this because it is by virtue of meaning-making processes that we construe things as evidence.

The intent of these final reflections is not to define evidence once and for all, but to raise a question. In what contexts is it useful to limit our thinking to concern with evidence and evidentiality, and in what contexts would it be more useful to expand our conceptual space so that we pay attention to all those things which act and all those ways of acting that have causal effects for perception and meaning-making? When thinking about records in relation to the accountability of the organisations that created them, paying close attention to legal discourse - particularly that concerned with tests of evidence makes sense. However, when the design of heritage sector knowledge enabling systems is under consideration, I suggest the expanded conceptual space is the more valuable. This is not to say no distinction should be made between good evidence and bad evidence. It is simply to say there is value in thinking broadly about the factors that affect how our perceptions are shaped and, therefore, how well we construe things as evidence and formulate knowledge from the evidence we discover.

\subsection{CONCLUSION}

This chapter has been primarily focused on exploring how evidence emerges during a historical research process (a recognised gap in archives domain thinking) and responding to problems (manifested or raised in archival science literature) in relation to how, or whether, evidence can be theorised as a meta-concept. The chapter was comprised of a case study which was used as a foundation for a theoretical discussion of the question: What is evidence, where does it come from and where does it go? This question set the stage for developing a concept of evidence which includes reflection on its emergence, ephemerality, persistence, and social reach. It was posed because the discourse analysis demonstrated problems exist in the domain in relation to conceptualising evidence due to a preoccupation with competing absolutes. This has led to arguments that evidence should be understood in one way and not in another; to arguments which homogenize through over simplification; and to arguments that the word evidence is used in so many different ways, and perceptions of evidentiality are so subjective, that a meta-concept may be impossible to achieve. My response was to argue that theorising evidence at a 
meta-level can be achieved if one adopts Upward's whole of spacetime perspective. Looking from that angle makes it possible to account for the diversity that exists in real life experiences of evidence instead of trying to erase that diversity through strained homogenization or by shutting out ideas that differ from one's own.

In the course of developing my argument, I focused close attention on the problem of understanding evidence in terms of relationships. I did this because various views have been expressed in the literature regarding whether evidence should be understood to be a relationship or an entity in a relationship. Drawing on my case study experience, I argued that evidence should be understood as an entity in a relationship, but that the entity itself seems to always be a relationship. This is something which may not be immediately apparent to archivists who work with a traditional object-privileging concept of record and are accustomed to thinking the physically single item is the smallest unit of interest.

Like Furner (2004), I take the view that a simple formula works if we want a high level understanding of the type of relationship within which an entity manifests as evidence: entity $\mathrm{x}$ is evidence when $\mathrm{x}$ is treated as evidence for $\mathrm{y}$. What this formula allows for is that entity $x$ might not be evidence in other types of relationship. This is useful, but the tautological character of the formula is obstructive. In order to get past that obstacle, I drew on my case study experience to explore how entities were acting at the times I perceived them as evidence or used them for evidential purposes. Many different ways of acting were identified, amongst them: proof of facts, stimuli for problem perception, stimuli for hypothesis formation, providing grounds for trusting (or being sceptical of) assertions in other items of evidence, establishing relevance, and pointing to ways in which an enquiry can be begun or continued.

In archival science literature evidential multiplicity is often thought of in terms of a record potentially being used as evidence in relation to many different topics of enquiry or being interpreted in many ways. That evidence can also be thought of in terms of a multiplicity of functional affordances enabling different types of awareness is an idea I have not encountered in the discipline's literature. Of particular interest to me was the fact that I felt no qualms about including (in my list of evidential ways of acting) the function of 
pointing to ways in which an enquiry can be begun or continued. In an evidence-focused discourse where proof has been privileged and user perspectives neglected, it seems radical to say that this is a way of evidencing. Yet, the reality of the research experience made it clear to me that evidence discovery is only possible because of the pointers, and that awareness of the pointer often co-emerges with awareness of the same entity serving some other evidential function. Logically when a thing acts as a pointer (or clue), it does so by stimulating a hypothesis - not an explanatory hypothesis in relation to the big question one is addressing, but a hypothesis that if one conducts a certain type of search or looks at a certain document, evidence that helps answer the big question might be found.

I pick up on this idea that the verb to evidence can be understood as a catch-all for a number of different ways in which things function during a research enquiry in Chapter Seven where I discuss the design of knowledge enabling systems. Also, in Chapter Seven I pick up on a conclusion I formed in the course of thinking about the current chapter's findings in relation to those reported in Chapter Four. This conclusion is that a broad focus on the things that play a part in shaping our perceptions and inferences may be more useful for informing the design of knowledge enabling systems than a narrower concern only with the types of things we are accustomed to thinking of as evidence.

As was the case with Chapter Four, although my theoretical discussion was framed by pre-existing archival science theory, my case study did not assume that theory to be of interest only in relation to the things archivists typically think of as records. This meant I could follow whatever paths and engage with whatever type of object seemed best for the purpose of finding evidence that might answer the questions intriguing me. A particularly interesting outcome of that approach was realising that the most compelling example of evidential proof to emerge during this part of my case study was found in a book in a library's lending collection. Books in library lending collections are not typically thought of as heritage objects, let alone as records. Indeed, in the archives domain's traditional discourse books are, as I pointed out in Chapter Three, the prototypical 'other' to record. Given that Scanlan's Egmont: The Story of a Mountain, served as objective evidence, can we say it was a record? The answer to that question undoubtedly depends on how we conceptualise records. Understanding records is the focus of my attention in 
Chapter Six. As was the case in this chapter, I concern myself with processes of formation. My intention is to explore and cast light on what it means to say records are logical entities or conceptual constructs. The work I do in Chapter Six allows me to return to a question relating to evidence which I did not explore in the current chapter. That question is whether evidence is a concept of such central importance to the concept of record that it should be regarded as definitional. 


\section{SEEING AND BEING: THE CONSTRUCTION OF RECORDS AND CORNUCOPIAS OF EVIDENTIAL POSSIBILITIES}

\subsection{INTRODUCTION}

In Chapter Three I said that amongst the archival science stimuli for this research were articles that have been critical of discourse that treats evidence as being of central importance to the concept of record (e.g., Brothman, 2002; Fisher, 2009; Harris, 2001a; Hobbs, 2010; Yeo, 2007). I argued in Chapter Three that gaps in the discipline's understanding of evidence and its understanding of records need to be addressed before there can be meaningful discussion about the relationship between records and evidence. The gaps I identified were: understanding evidence as a phenomenon that emerges during historical discovery; understanding evidence as a meta-concept; and understanding the continuum notion of records as logical entities (McKemmish et al., 2009, p. 4447) or as McKemmish (1994) had previously put it: "as conceptual constructs" that even when "captured in a medium that can be felt and touched ... do not coincide with records as physical objects" (p. 187). Chapter Five addressed the first two of these issues. In Chapter Six I turn my attention to the third. Drawing on my case study research and my discussion of perception and meaning-making in Chapter Four, I explore how records are constructed. The way I approach this exploration is unusual. Rather than positioning myself as an archivist whose understanding of the characteristics of records is grounded in vague notions of prototypical records, which is the way in which Yeo (2008) argued most archivists understand the notion of record, I adopt the stance of a historical researcher and I begin with a digital orphan - in Yeo's terms, a "boundary object" on the "fuzzy" edges of the category of record.

The term digital orphan was used by Sassoon (2007a) to refer to digital images which information systems present as single items without metadata relating them to their provenancial or former documentary contexts (p. 139). For many archivists such images do not warrant being thought of as records. At best they may be seen as decontextualised copies of records. At worst the 'originals' from which they were copied may themselves 
have been removed from their earlier recordkeeping contexts and, therefore, also barely warrant being called records. ${ }^{73}$ "This loss of an archival anchor", said Sassoon, "is magnified and long-lasting" (p. 139). When systems do not bind the parts together and reveal them to be bound together, digital orphans are the result - content without context, object without recordness.

Exploring the emergence as a record of the digital orphan at the heart of this chapter provides an opportunity to reflect on the relational nature of recordness and the circumstances in which it may be 'lost' and 'found' (I use inverted commas because sometimes 'loss' is a failure of perception rather than an absence in being). Licence for taking a historical researcher's perspective is provided by continuum theory's sensitivity to space and time and its consequent acceptance of variability. Conceptually, I have situated this research in the open space of the continuum's fourth dimension - the dimension of pluralisation and societal totalities where things do not always "adhere to rules laid out by professional practice, procedure and precedent" (Reed, 2005, p. 181). This allows me to argue the processes of capture (second dimension concept, as are the notions of record and evidence) that enable things to be seen as records may occur in the mind of a researcher, and may 'materialise' as a conceptual overlay rather than as a physical or digital object or physical or digital aggregation of objects. The case study experience I describe illustrates how this can happen even when formal recordkeeping systematization - Sassoon's "archival anchor" - is absent in the physicality of a collection and has not been consciously factored into the design of collection management systems. The insights provided by the case study experience suggest one should not be too hasty in making absolute claims that a thing is or is not a record; nor should one be too rigid in one's thinking about where records are centred or how they are bounded. The case study also casts light on the relationship between records and evidence - or, as I will argue is preferable when conceptual overlays affect understanding and categorisation of an entity, between recordness and evidentiality.

\footnotetext{
${ }^{73}$ The word original is problematized because the photographic object from which a digital image is derived may not be the original image in absolute terms. In this chapter I problematize the word original whenever the notion of being original is contingent, rather than absolute.
} 


\subsection{REDISCOVERING THE RECORDNESS OF A DIGITAL ORPHAN}

The digital orphan at the heart of this chapter came to my attention when I entered "Tahurangi House" into the search box of Te Papa's Collections Online. It was a serendipitous find when, faced with factual uncertainty and evidential sparseness, I was casting my net wide in the hope of learning more about Hilda and Molly Haldane. My search produced a single hit - a digitized version of item C.003368 in Te Papa's photography collection. A screen dump showing the web page at the time of the search is reproduced in Figure 10 below.

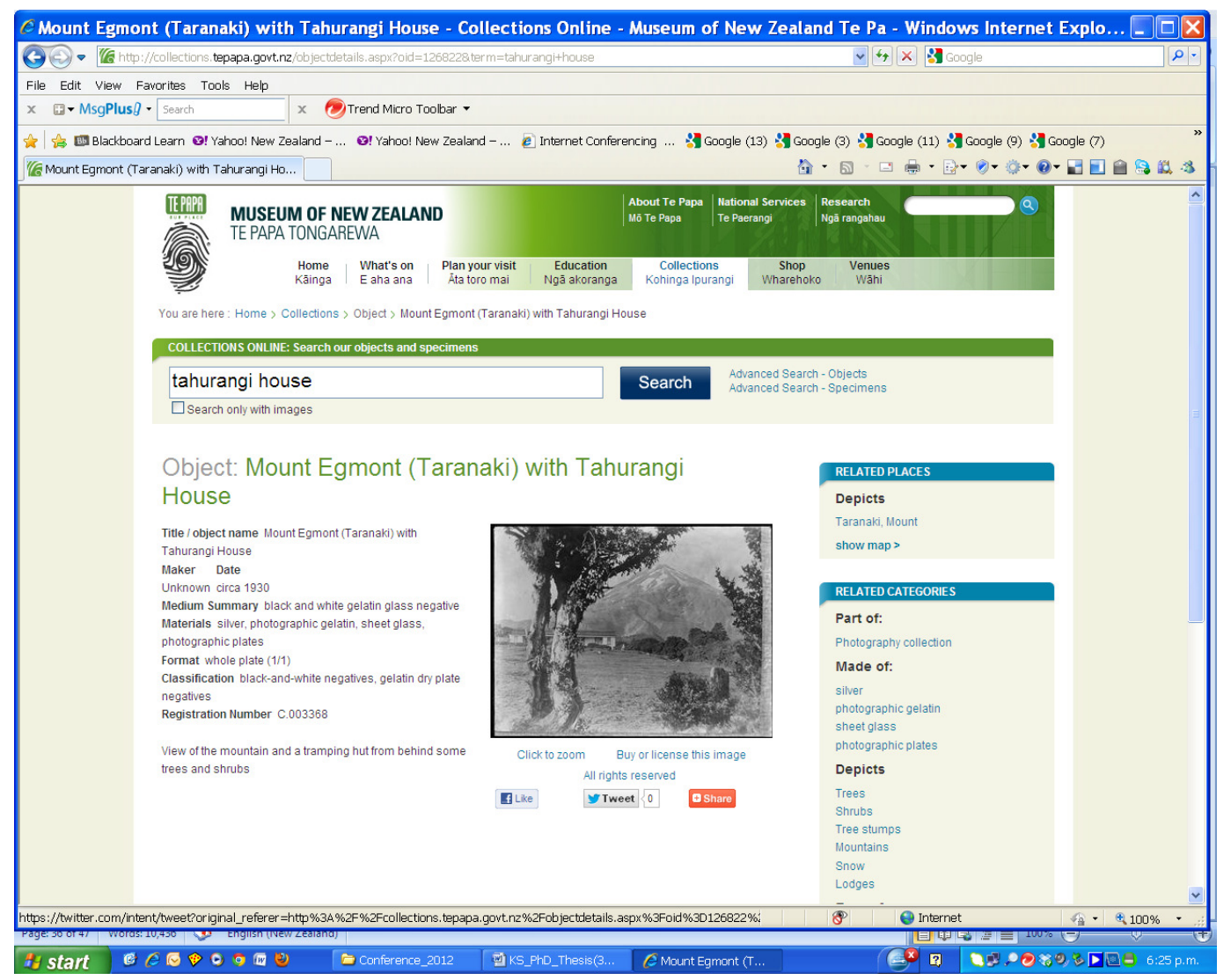

Figure 10. Screen dump of Te Papa's Collections Online display of item C.003368.

The metadata alongside the image revealed that the item described was a photographic negative - "silver, photographic gelatin, sheet glass photographic plate". It said the "Maker" was "Unknown". The date was supplied and an approximation - "circa 1930". There was no information about the negative's source of acquisition or its custodial history. In fact, there was nothing in the metadata that revealed anything about personal or organisational contexts in which the image might have previously existed. Therefore, except for referring to Tahurangi House as a "tramping hut", it provided no clues about 
any social context to which C.003368 might lend meaning or in relation to which it might be interpreted. On the right side of the screen "Related Places" and "Related Categories" were listed. Clicking on these allowed me to see C.003368 within assemblages which brought together descriptions (sometimes accompanied by visual representations) of items in Te Papa's collection composed of the same materials and produced using the same photographic technologies as this negative, or with the same terms as those which appeared in the metadata describing the photographic image component of C.003368; i.e., "Mount Taranaki", "trees", "shrubs", "tree stumps", "mountains", "snow", and "lodges". None of these assemblages showed the image as having a relationship with a personal recordkeeper or recordkeeping system, and the only organisational context described was Te Papa's photography collection, of which this glass plate negative was a part.

Most people looking at this image would have seen a digital orphan (though they would need to know that term before they used it to describe their perception), an isolated digital image with no "archival anchor". I, however, had a strong feeling this was one of Fred's photographs. This suspicion was quickly confirmed when I found the same image in the personal digital collection I had compiled by photographing documents associated with Fred while I was visiting Puke Ariki. There is a print of the Tahurangi House image in volume one of Fred's Mount Egmont albums. A handwritten annotation beneath the print in the album shows the negative number Fred assigned it and also the date the photograph was taken - 26 February 1928 (see Figure 11). Fred's annotation does not name the photographer. Therefore, based on the note he wrote inside the front cover of the album (see Figure 12), we can assume he took this photograph himself. Because Fred was working as a professional photographer in 1928, it seems reasonable to assume he was also likely to have been the creator of the print in the album. ${ }^{74}$ In all probability, he would have been the first and only custodian of the glass plate negative prior to its acquisition by the National Museum. ${ }^{75}$

\footnotetext{
${ }^{74}$ The 1928 Stone's Taranaki Directory lists Fred as a photographer operating from 288 Devon Street East, New Plymouth and the 1929 directory lists him as the proprietor of Crown Studio, 230 Devon Street East, New Plymouth.

${ }^{75}$ The National Museum and the National Art Gallery were united as a single entity by The Museum of New Zealand Te Papa Tongarewa Act, 1992. A new building housing both collections was opened in 1998.
} 


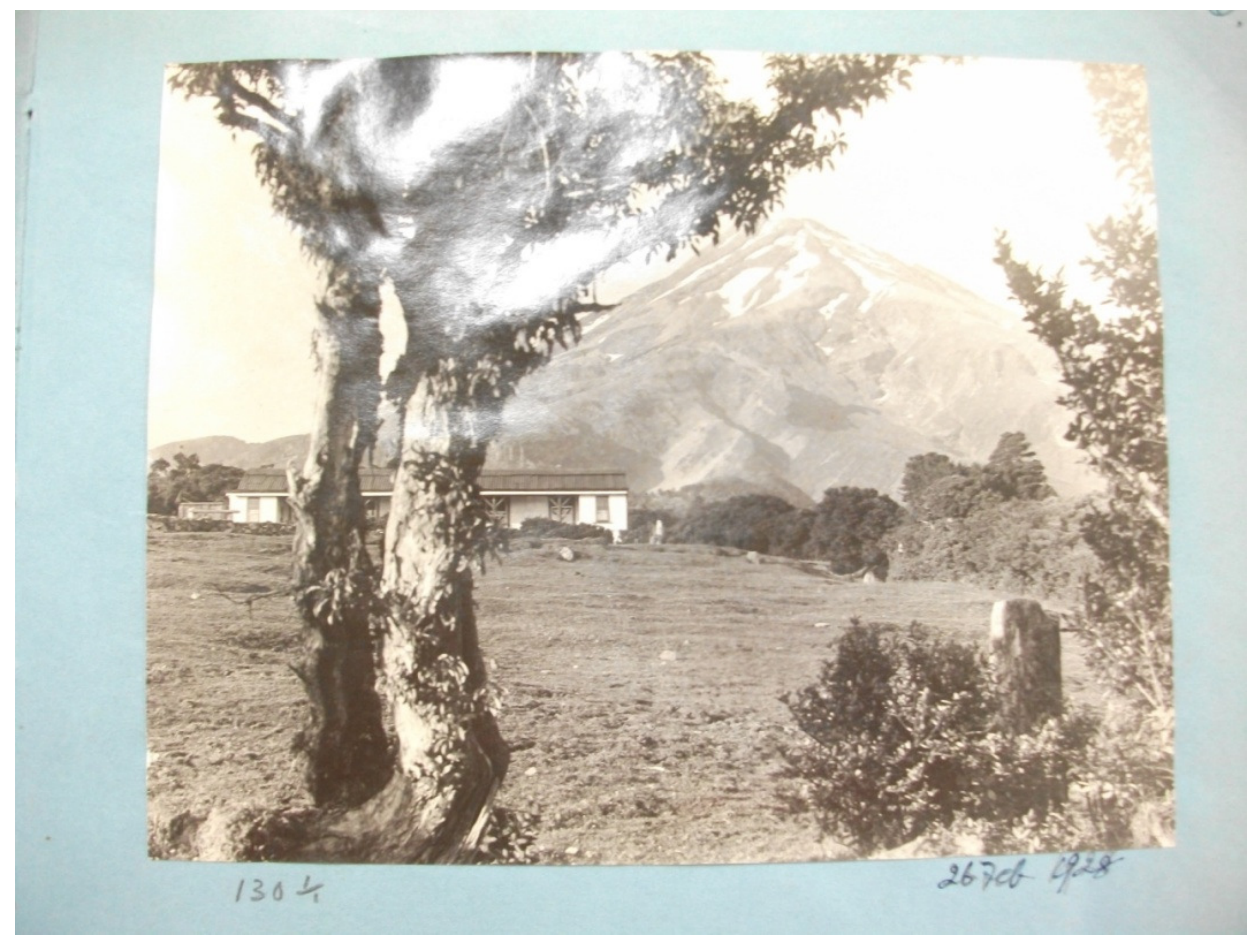

Figure 11. Print of Tahurangi House. From Volume One of Fred Butler's Mount Egmont albums, Puke Ariki.

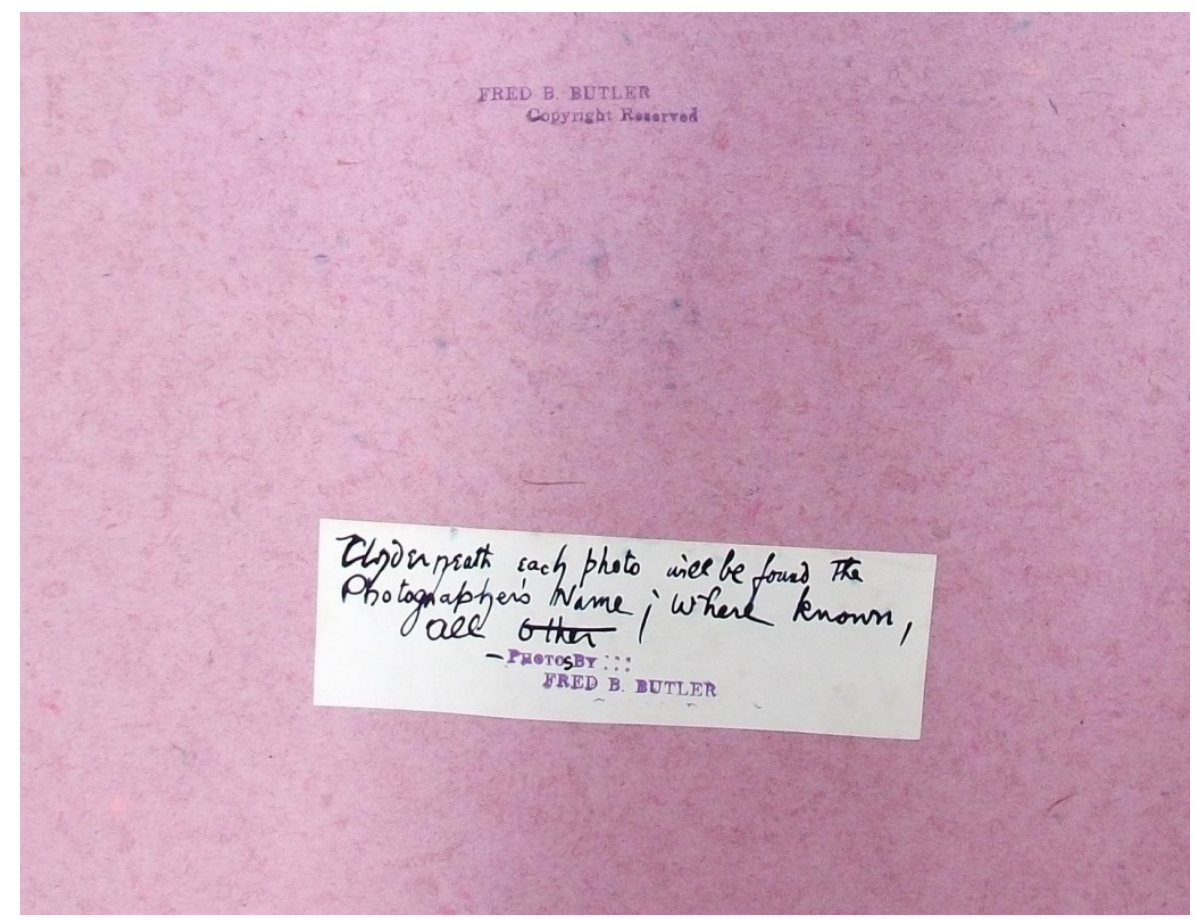

Figure 12. Notes regarding copyright ownership and identity of photographers inside the front cover of Volume One of Fred Butler's Mount Egmont albums, Puke Ariki. The stamp (top centre) reads "Fred B. Butler Copyright Reserved". The text on the label reads "Underneath each photo will be found the Photographer's Name; where known, all other Photos by Fred B. Butler". 
As an archivist with a deeply engrained habit of seeing the bond between a document and knowledge of its recordkeeping provenance as the essence of recordness, even though the metadata displayed in Te Papa's Collections Online showed a digital orphan, what I saw was a record.

When I returned to Te Papa's Collections Online for a second look at the Tahurangi House image (C.003368), I realised that this recordness did not exist only in my mind's eye. It was also inscribed in the image which had previously appeared to be a digital orphan. The whole glass plate had been digitised and, along the edge, were a few white markings. In the screen display (especially the thumbnail version) these markings appear to be faint meaningless squiggles. However, when the image was magnified they began to appear more deliberate, even if still undecipherable (see Figure 13).

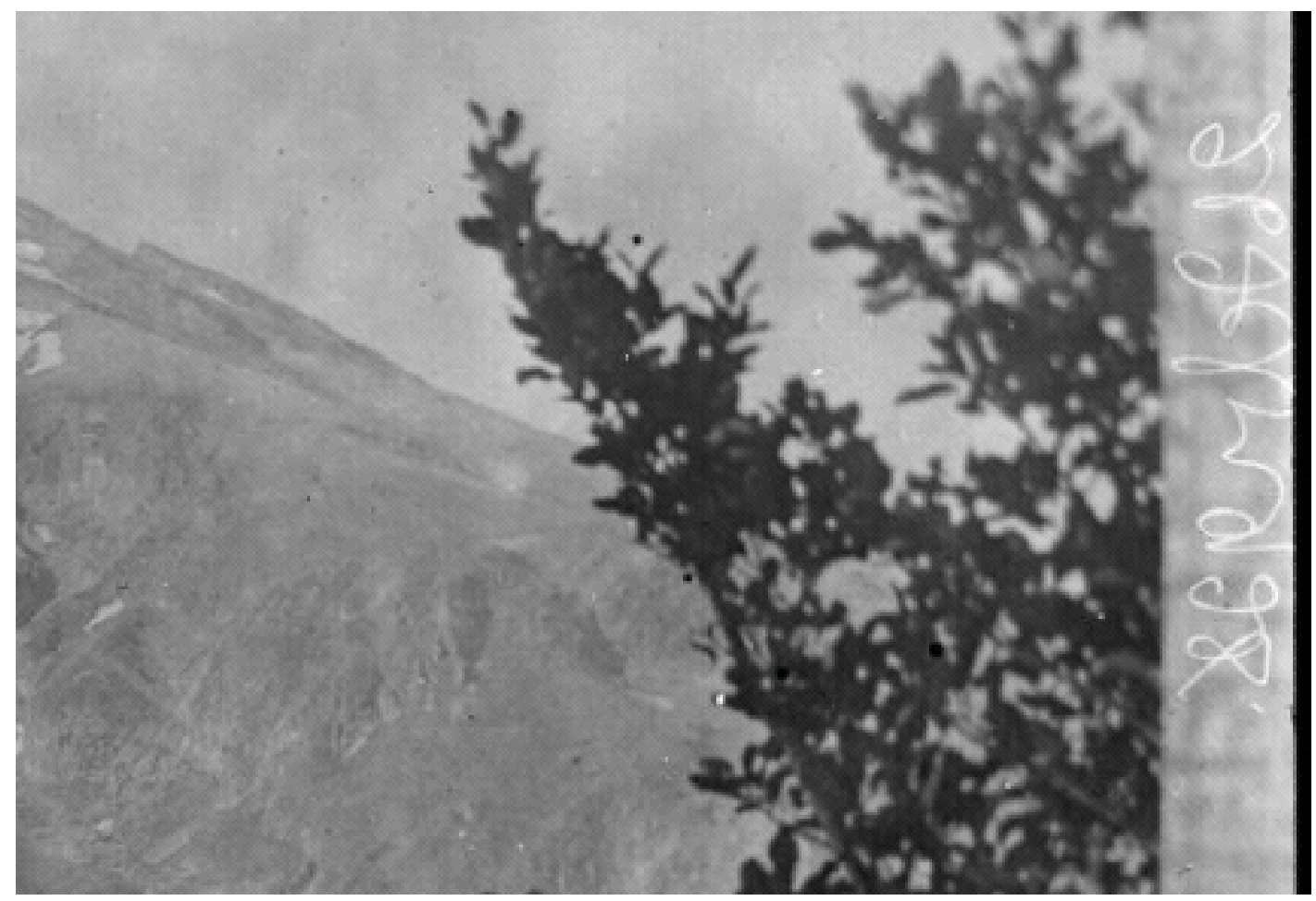

Figure 13. Magnified view of part of the digital image of item C.003368 depicted in Te Papa's Collections Online.

I turned the image ninety degrees and reversed it. The annotations were then readable. Clearly written in Fred's hand, were the date the photograph was taken and the negative number assigned by Fred. Both were perfect matches with the annotation in Fred's album at Puke Ariki (see Figures 14 and 15). In other words, material evidence of Fred's past recordkeeping presence was embedded in this supposed digital orphan, there for the 
seeing all along, but only able to be seen for what it was by somebody with relevant preexisting knowledge. This cautions us to be wary of pronouncing anything to not be a record. In reality - in the intransitive dimension - every human-made and human-used object transmitted through time has a context of creation and/or use and a custodial history. An object's bonds with these things that archivists customarily think of as conferring recordness can be broken and knowledge of them lost or obscured. However, as this example from my case study shows, that knowledge can sometimes be brought to light again. All that may be needed is somebody whose motivations and pre-existing knowledge enable them to see what others have not.

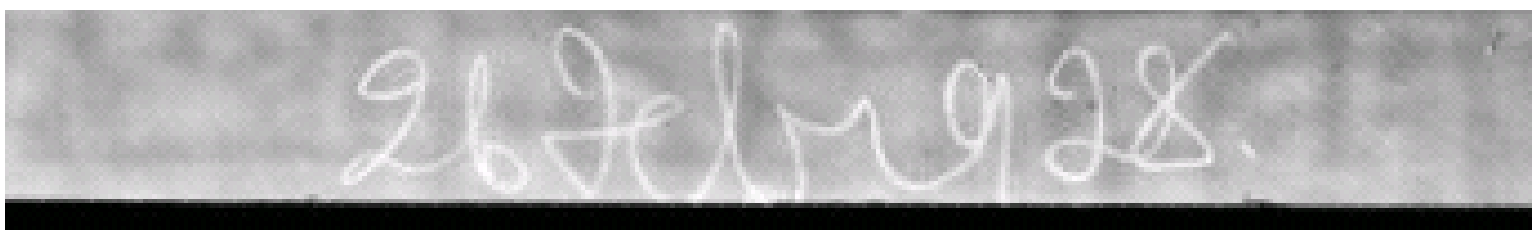

Figure 14. A reversed and rotated copy of the annotation near the top of the digital image of item C.003368 depicted in Te Papa's Collections Online.

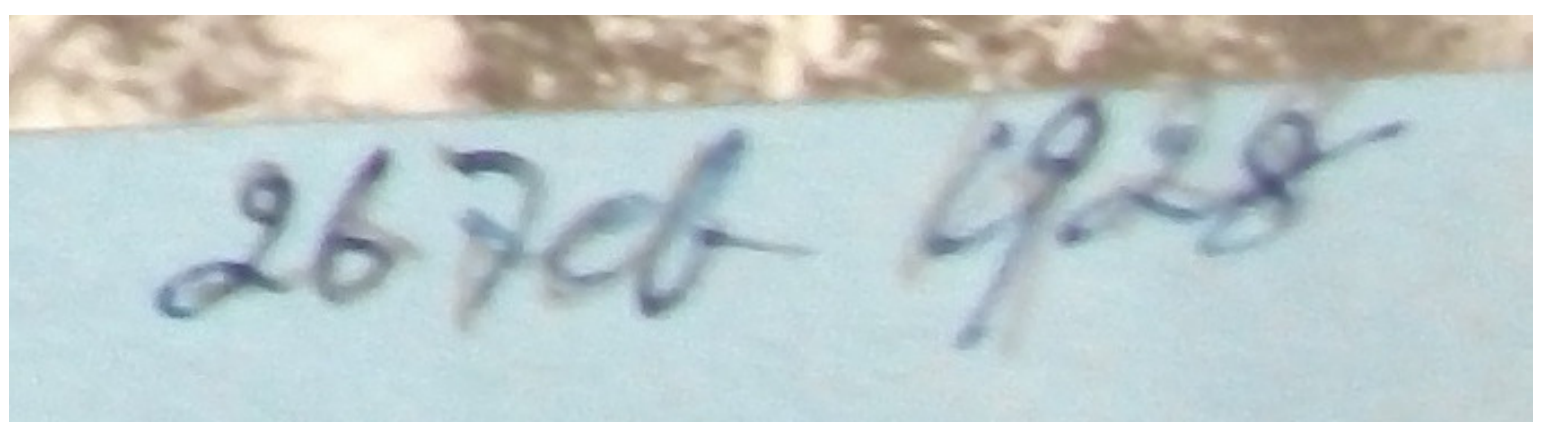

Figure 15. The annotation beneath the print of Tahurangi House in Volume One of Fred Butler's Mount Egmont albums at Puke Ariki.

\subsection{EXPANDING RECORDNESS}

Once I had established the Tahurangi House image's original provenancial context, I felt I had exhausted the potential of this image and metadata 'package' for enabling me to explore my research question, so I turned my attention to other things. However, about two weeks later an idea came to me during the night - a flash of inspiration, a moment of 
abductive suggestion. ${ }^{76}$ It occurred to me that, while the original provenance of the glass plate negative $\mathrm{C} .003368$ could be traced back to Fred, the original provenance of the digital image and metadata 'package' derived from that negative rested with Te Papa or, perhaps in part, with one of Te Papa's predecessor organisations. This justified a claim that the descriptive metadata and digital image together comprise a digital record which, though grounded in the glass plate negative, is distinct from that negative. That the digital package constitutes a new record is hardly novel in continuum discourse - Hurley (2013) has explained this by pointing to repurposing and recontextualisation as grounds for claiming that the copying of content may produce a new record. The situation can also be explained in critical realist terms - as Elder-Vass (2007) pointed out distinctive structure is what ultimately differentiates an emergent phenomenon from any of the phenomena in which it is grounded. An emergent phenomenon, therefore, can "exercise powers that are not possessed by its component entities either in isolation or in an unstructured aggregation" (p. 163). These two explanations, while not identical, are compatible.

It was the distinctive structure of the emergent phenomenon - the digital 'package' (or digital record) in Collections Online - that I put to work. It is axiomatic in the archives domain to say that records have both internal and external structure. This digital 'package' was no exception. It has a contemporary (if somewhat imperfect) recordkeeping context: the system created by Te Papa and known as Collections Online. Within that system, besides the documentary contexts that have been assigned for the purpose of enabling users of the system to aggregate metadata and digital images around themes deemed to be of potential interest by those who created the metadata, there is also a documentary context which seems to have been brought into existence purely for collection control purposes. This manifests in the registration numbers which are unique alpha-numerical object identifiers connecting each digital 'package' to an item in the physical collection. What I realised on waking to that abductive suggestion was that, if one of Te Papa's predecessor organisations had acquired other whole plate negatives from Fred along with C.003368, there was a strong chance the whole acquisition (of whole plate negatives) would be sequentially numbered and findable in Collections Online. In other words, I realised I might be able to use contemporary metadata records

\footnotetext{
${ }^{76}$ Abductive suggestion was discussed in Chapter Four.
} 
in a contemporary system to discover historical records created by Fred because Te Papa, in carrying the registration numbers into Collections Online, may also have unwittingly carried into that contemporary system evidence of an aggregation of Fred's records. ${ }^{77}$

The following day I discovered this to be the case. Returning to Te Papa's Collections Online, I began a series of searches where I entered the registration number as my search term. Beginning with C.003367, I worked my way backwards from C.003368 (the Tahurangi House (package') and then, beginning with C.003369, I worked my way forwards. Each search retrieved a very sparse metadata description of a whole plate negative. In most cases, no digital image was attached. Nevertheless, there were recurring patterns in the metadata which enabled me to identify a sequence of just over four hundred negatives (C.003114 to C.003520) which I was almost certain had all once been in Fred Butler's custody. ${ }^{78}$ The negatives described in these metadata packages were all dated between "circa 1920" and 1935. They were variously attributed to "The Crown Studio (New Plymouth)", William Oakley (who I already knew to have been a New Plymouth photographer), and "unknown". Many, but not all, of these metadata packages explicitly named New Plymouth or other well-known North Taranaki places.

The glass plate negative $\mathrm{C} .003368$ was now revealed as having an additional dimension of traditional recordness. Besides having known provenancial context and a past documentary context from which it had become separated (i.e., the album and other Butler material at Puke Ariki), it also had a past documentary context which had been carried into the present. In all respects it qualified as a record. Furthermore, all the items I had identified as being part of the same sequence, because of their documentary relationship with C.003368, could also be seen as records - they acquired provenancial context and documentary context by association. As for the 'packages' in Te Papa's

\footnotetext{
${ }^{77}$ I had previously considered searching the National Museum's physical accession registers in the hope of identifying other Butler material but was warned by a Te Papa curator that the accession registers were both voluminous and incomplete for the decades which were of interest to me. I deferred making a decision about combing through the old physical registers because, while such a search might have led to the discovery of more Butler material, it would have been time-consuming and also unlikely to yield any insights of value in relation to my research question.

78 I say "almost" only because I did not look at the metadata for every item in the sequence. Instead, I tested at intervals. Staff at Te Papa, when advised of this discovery, checked accession records which confirmed I was correct. Information about the source of acquisition was subsequently added to Collections Online.
} 
Collections Online, besides being records in their present context of creation and use, each inherited some of the recordness of the negatives their metadata described and from which their images had been derived. They could, therefore, be thought of as a record of Fred (a point I argue more strenuously in section 6.5 below).

\subsection{CONCEPTS, PERCEPTIONS, AND STATES OF BEING IN THE CONSTRUCTION OF RECORDS}

In this section I look at what the case study experiences described above suggest can be said about how records are constructed and, in particular, about the conceptual component of their construction. Ideas explored in Chapter Four regarding perception and meaning-making are put to use in the reflections that follow. In that chapter I argued that (at any moment of perception) the way one experiences an empirically present object, the meanings one ascribes to it, and the categories to which one assigns it result from an interplay of the object's characteristics, the context in which it is empirically situated, the activity in which one is engaged, and any knowledge previously acquired and concepts previously formed which one's brain selects as relevant to the situation. Building on this foundation one can say that to see an object as a record is to focus attention on those characteristics of that object (including present and past associations of which one is aware) that match one's concept of record. Similarly, one can say that if one creates a textual object or contextualises any object with the deliberate intent that it should serve as a record, a concept of record will be amongst the things that affect the character of the product resulting from that activity. That this is indeed what happens seems to be confirmed by the volume of archival science critical theory which has commented on the extent to which records have been conceptualised, and descriptive practices have been developed, in relation to a mental prototype of an unpublished paper textual document seen in relation to aggregations of similar documents created by provenance entities of a traditionally privileged type. ${ }^{79}$

Our individual conceptual spaces are, as I said in Chapter Four, intermeshed with the conceptual spaces of others. Therefore, the concepts each of us employs tend to have been significantly developed by others prior to our encountering them and modifying

\footnotetext{
${ }^{79}$ Relevant literature was discussed in Chapter Three.
} 
them in relation to our own experiences. In the case study example described above, for example, I made heavy use of the archives domain's common and long-lived practice of applying the term record to documents that can be seen to have a 'created by' relationship with a single provenance entity of the type traditional archives domain discourse thinks of as the creator.

I was applying this traditional concept when I argued that the physical negatives identified and described by the metadata sequence I found in Collections Online are records. I was able to do this because I had demonstrated that Fred had been the original aggregator and keeper of those negatives and - in the case of at least some -also their creator in a common language sense, their systematiser, and their user. This combination of ways of engaging with largely documentary aggregations is, as I argued in Chapter Three, typically what has qualified individuals and organisations to be referred to as creators in traditional archives domain discourse. I also applied this traditional concept of record when I argued that the packages of metadata (and packages of metadata with accompanying digital images) in Collections Online are records. When conceptualised in relation to the traditional paradigm, these packages are current records (i.e., still in the custody and use of their creator) whereas the physical negatives are archival records (i.e., no longer in the custody and use of their creator but still able to be seen in relation to that creator). Attributing record status to the digital packages and physical negatives in this way should be uncontentious (within the archives domain) because the practice of conceptualising records in relation to a 'creating' provenance entity of this type is privileged in the domain's traditional thinking and is also accepted by continuum theorists as grounds for claiming recordness to exist.

I am able to speak of the digital packages in Collections Online and the physical negatives as records because I recognise there is a match between the types of relationships the concept of record I am applying requires to be present if a thing is to be referred to as a record and the actual relationships that exist in the reality (the intransitive dimension) that surrounds and includes - or has surrounded and included - the objects I am thinking of as records. When we talk about the construction of records from a discovery perspective, therefore, records - like evidence - could be said to emerge from the layering of a (transitive dimension) concept over (intransitive dimension) entities that 
stand or have stood in certain relation to each other and in relation to whatever type of provenance entity the concept of record requires. Building on this, we can say that each negative, though physical in and of itself, is a physical-conceptual hybrid when seen as a record. In fact, because the metadata and digital images played such a significant part in causing me to perceive the negatives as records, the negatives when thought of as records could probably be even better described as physical-digital-conceptual composites.

This idea that heritage objects, when in use (whether conceptualised as records or as some other type of thing), are physical-digital-conceptual composites may be applicable to most researchers who use the systems and collections of heritage institutions. I say this because researchers rarely have access to acquisition records and superseded collection control systems or even the opportunity to interact at any one time with more than a few objects from the physical collections. This means their perceptions of relationships and assemblages are significantly dependent (particularly in the early stages of their research when their body of relevant knowledge is small) on the contextualising information brought to their attention by the (usually digital) 'finding aid' provided by the institution in which they are working. Naturally those digital 'finding aids' reflect the conceptual biases of those who created them and populated them with metadata, so even before the researcher brings his or her conceptual predispositions into play, the concepts of others are always already embedded in the mix.

Because the relationships (in the intransitive dimension) that correspond with the (transitive dimension) concept of record we apply at any given time seem to be already there at the time we see and categorise some object as a record, it is tempting to suggest that records are not conceptual constructs, but pre-exist the perception that leads to their categorisation. The problem we face when considering this question of whether records are always already there (and, therefore, purely intransitive dimension entities) or whether they are always hybrids or composites that emerge when certain intransitive dimension entities are selectively perceived and categorised in relation to that perception, is essentially the same problem as we face in conceptualising and speaking about evidence. In both cases the language we use predisposes us to not distinguish clearly between an abstract concept and the actual entities which we (commonly or 
occasionally) categorise with reference to that abstract concept. Ideas about categories and the characteristics of things included in them are always purely conceptual, even though they are deeply grounded in encounters with the physical and empirical. The actual entities we label with our categorising abstractions, on the other hand, are not purely conceptual but always also self-evidently physical or digital. Sometimes these actual entities come to us as records already made; in other words, we recognise them to have come into being in the course of some prior act that responded to a need for a record and a concept relevant to that need. Other times these actual entities are constructed as records through post-creation processes of selective perception which may or may not be accompanied by processes of physical or digital contextualisation. Whichever may be the case, a concept of record is always at play when something materialises in some context, or is recognised by somebody, as a record.

Because the answer to the question whether a record pre-exists perception or emerges during perception will always depend on the circumstances relevant to the specific space and time when the perception occurred, there seems nothing to be gained - at the level of meta-theory about the concept of record - from consciously or unconsciously attaching definitional significance to distinction between things originally and deliberately constructed as records and things created for other reasons but later used as records because they have been seen to have record characteristics relevant to a particular need. It is more useful to recognise that at whatever time and in whatever context of creation or use an object emerges as a record, its emergence as record is always grounded in the interplay of transitive and intransitive dimension phenomena. An entity with characteristics Yeo (2008) attributed to prototypical records might, from the point of view of mainstream archivists thinking in the abstract and in traditional terms, seem more deserving of classification as a record than a book in the lending collection of a library; but, if the record needed is one that provides objective evidence that Fred's photograph of Roy was used in Scanlan's Egmont: The Story of Mountain without acknowledgement, the book itself and the trace evidence it contains is that record. ${ }^{80}$ It is a far better record than Fred's handwritten assertion (which is testimonial evidence with un-established credibility), even if that assertion is in something more akin to a prototypical record; i.e.,

\footnotetext{
${ }^{80}$ This part of my case study was first discussed in Chapter Five section 5.2.
} 
in an unpublished photograph album kept with other Butler records in an archives repository. It is a better record because it is the product of the activity of interest, rather than an assertion about that activity.

In twenty-first century archives domain discourse the traditional practice of conceptualising records in relation to a custodial provenance entity has been somewhat displaced by a tendency to give greater prominence to a provenancial relationship between the record entity and the activities which have generated and shaped it. ${ }^{81}$ When one conceptualises records in this way, there is nothing particularly contentious about my claiming the book to be a record because of its provenancial relationship with an activity. It is only the lingering effects of traditional 'theory' that cause one to baulk at the notion and to suggest that this book, seen in this way, is an exception to the rule. On the contrary, it demonstrates the rule as understood from a continuum perspective. Continuum theory allows for anything to be a record by virtue of any of its provenancial relationships - whether something is seen as a record depends on whether it is being used for evidential purposes and whether it has qualities that enable it to function as evidence within the context of use. As McKemmish et al. (2009) said, "In records continuum professional discourse and practice, the differences between records on the one hand, and other forms of recorded information on the other, rest on their evidential qualities, purposes, and functionality" (p. 4447).

In summary, my case study experiences and arguments so far suggest that, when one looks from a discovery perspective (which is not only that of historical researchers, but also that often taken by archivists arranging and describing historical records), there are three equally important pre-conditions for record emergence - or three fundamental ingredients from which records are constructed. One is provenancial connectedness in reality (in the intransitive dimension). Another is a concept of record. The third is the motivation and ability to see correspondence between the intransitive dimension reality and the transitive dimension concept. This third pre-condition should not be lost sight of

\footnotetext{
${ }^{81}$ De-privileged custodial provenance and increased emphasis on transactional provenance is a well recognised feature of records continuum discourse (discussed in Chapter Three). Yeo (2008), though not a continuum thinker, took a similar stance when he proposed records could be characterised "as persistent representations of activities or other occurrents, created by participants or observers of those occurrents or by their proxies; or sets of such representations representing particular occurrents [emphasis in original]" ( $p$. 136).
} 
because, as the case study experience described above demonstrated, sometimes evidence of historical recordness is obscured. Though right before our eyes, we may not see it; though discoverable, we may have no idea how to find it and, possibly, not even think to look for it. ${ }^{82}$

\subsection{PACKAGES, PARTS, AND PROVENANCE IN THE CONSTRUCTION OF RECORDS}

In discussing the role of conceptual categories in the construction of records in the previous section I used a traditional and uncontentious concept of record on which to pin my claim that certain digital and physical objects controlled by Te Papa (but not managed in accordance with archival principles or recordkeeping standards) can justifiably be referred to as records. Even my claim that Scanlan's Egmont: The Story of a Mountain was a record used a relatively mainstream concept of record. Conceptualising records in these mainstream ways, however, was merely a writer's ploy. It was a way of creating a space where I could communicate my thoughts about basic ingredients present in the mix when we construct or construe a thing as a record without running too much risk that readers might miss the points I was making because they were distracted by, and perhaps dismissive of, the concept of record I was using. In this section, I move into more contentious territory. I explore an impulse to think of the digital packages and erstwhile digital orphans manifested in the screen displays of Collections Online, not just as current records of Te Papa, but also as historical records of Fred.

As I said in section 6.4, there is nothing particularly contentious about seeing these packages as current records of Te Papa. Seeing them as records of Fred, on the other hand, is unusual in terms of prevailing concepts of record in the archives domain. This is because these digital packages were not created, aggregated, owned, or used by Fred. This means they do not have the type of direct provenancial relationship with Fred that is privileged - and usually treated as necessary - in traditional and mainstream concepts of record. I use the word necessary here in the critical realist sense, which is to say that in the absence of such a relationship a thing cannot be a record.

\footnotetext{
${ }^{82}$ Possibly these three pre-conditions for the emergence of historical records are significant 'ingredients' in the mixes from which all records emerge. This is something that could be explored in future research concerned with theorising the nature of records.
} 
Many archivists might take the view that the mismatch between the 'concept' of record in my mind and mainstream notions of record justifies dismissing my idea as nothing more than the subjective and idiosyncratic meaning-making of a researcher concerned only with her own research interests. Concepts and ideas introduced in Chapter Four, however, provide an alternative way of understanding my perceptual and conceptual impulse. That alternative is to describe it as object-full subject-centred epistemic privileging. In other words, my 'concept', though it came to me in an intuitive manner, was grounded in objects I had encountered. Notably, it was grounded in the packages I found in Collections Online. In the paragraphs that follow I explore what it was about those packages that stimulated me to perceive them in the way I did, and I reflect on what this exploration reveals about the construction of records and the problem of conceptualising records and their provenance.

In order to carry out this exercise I unpack a single digital package and trace the provenance of its component parts when those parts are conceptualised in three different ways: as inscriptions embedded in digital or physical carriers, as texts (i.e., strings of words, spaces, punctuation marks, etc) transferrable between carriers, and as information or knowledge that may persist and spread even when the physicality and precise text associated with any prior inscription of that information or knowledge is not transferred. Hereafter I refer to these fragments of information or knowledge as transitive dimension content because my attention is on the transfer and continuity of knowledge about certain things. In contrast, when I use the terms inscription and text my focus is on a state of being at a particular time. When one unpacks the packages in this way, a multiplicity of provenances is exposed. Each unit of data is, one could say, a record within a record - and nearly always, it seems, a record of multiple different things because the context of first emergence can vary in accordance with how a data unit is conceptualised.

Let us look, for example, inside the package relating to the negative assigned the registration number C.003518. This package, which does not include a digital image, is (at the time of writing) comprised of the registration number and the following textual components: 
Title: Old Boys Football Team

Production: Unknown, 1928

Materials: photographic gelatin, silver, black-and-white film

Classification: gelatin silver negatives, black-and-white negatives

Format: whole plate $(1 / 1)$

Credit line: F B Butler/Crown Studios Collection. Gift of Frederick B Butler, $1971 .^{83}$

All these component parts when conceptualised as the texts that have been inscribed in, and now display in, Collections Online (i.e., when conceptualised as inscriptions) were self-evidently created by employees or other agents of Te Papa. This is self-evident because my definition of inscription revolves around a necessary relationship between a text and a single carrier - the inscription cannot exist apart from its carrier. If, however, we think of the component parts of this package as texts or purely as transitive dimension content, their provenance is more varied (and, at times, less certain). The materials, classification and format statements, for example, can be inferred to have been created as transitive dimension content either by staff at Te Papa, or (more likely) much earlier by National Museum staff. Either way, those who created and first inscribed that transitive dimension content would have been describing characteristics of physical objects they were observing at the time of description. In other words, besides being grounded in a particular set of curatorial activities and norms of practice associated with those activities, the transitive dimension content is equally - and, perhaps, more significantly - grounded in the physical reality of the negatives themselves. ${ }^{84}$ This transitive dimension content would have first emerged prior to or during the act when it was first inscribed. Assuming that first act of inscription was in a physical or digital system that preceded Collections Online, the transitive dimension content would have been transferred from one system to another. Possibly over time there have been multiple transfers. With each transfer a new inscription would have emerged. Even if the text has been transferred verbatim, each inscription can be reasoned to be different from any others because the inscribing and

\footnotetext{
${ }^{83}$ The credit line element was added to this package a considerable time after the case study experience I described earlier in this chapter.

${ }^{84}$ My use of the word significantly here relates to my discussion in Chapter Four of the epistemic importance of observations of phenomena in the domain of the empirical. I return to this in Chapter Seven.
} 
carrying technologies have changed. Yet the transitive dimension content is the same (assuming no epistemically significant errors were made during the transfer process). In other words, the emergence of the inscription we see in Collections Online today would be (and probably is) differently grounded to the emergence of the transitive dimension content we see.

If we translate the words emergence and grounded into terminology more widely used in the archives domain, we can say that the transitive dimension content communicated by the inscription has a different provenance to that of the inscription itself. Even if deliberate changes to the text (e.g., for the sake of terminological consistency) were made during the transfer, there would still be differences in provenance because the essence of the transitive dimension content we see in Collections Online at any given time would have pre-existed its later inscription and would be traceable back to the physical negative in which it was grounded. If an epistemically significant error was introduced during the transfer, however, one would have to take the view that new transitive dimension content had emerged during the act of inscription. The provenance of this new transitive dimension content would be different to that of its fellows in Collections Online because it emerged at a different time and in a different context. Significantly, it would differ from its fellows in that it would be neither immediately nor ultimately grounded in observation of the physical negative.

Where does Fred fit? In the case of the metadata elements discussed above, Fred gave rise to the physical negative in which the transitive dimension content is ultimately grounded. The physical negative is a different phenomenon to the transitive dimension content; yet, if not for Fred, that transitive dimension content would not exist because the negative would not exist. The presence of this causal link does not warrant thinking of Fred as a creator of the transitive dimension content. He was, however, highly significant in the historical ambience associated with that transitive dimension content's first emergence. As a consequence, that content reveals something about Fred - though only to those who have the contextual knowledge necessary to see the chain of connections that lead back to Fred. The transitive dimension content is, therefore, able to serve as evidence of Fred, evidence that is indisputably relevant (assuming I was correct in 
identifying Fred as the photographer). ${ }^{85}$ Some would call this transitive dimension content a record of Fred because of the strength of that evidential connection; others would not, but only because their concept of record is narrower.

The connection with Fred is much more direct in the case of this package's transitive dimension content regarding the title and date of production for this negative. In this case, the transitive dimension content would have been first inscribed on a physical carrier long before the negative was acquired by Te Papa, and Fred would almost certainly have been directly or indirectly responsible for that first inscription. In making the inscription, Fred or his employee - his proxy, if one borrows the term used by Yeo (2008) in his proposed definition of a record (p. 136) - would have been recording first-hand knowledge of the reality depicted in the image and surrounding the act of photographic image creation. This transitive dimension content, therefore, is grounded in that act. Its provenance is, therefore, different from that of the transitive dimension content regarding materials, classification, and format.

That the transitive dimension content regarding date and title would have been created as described above is a probabilistic inference based on norms of practice for professional photographers and curators in heritage collecting institutions during the twentieth and early twenty-first centuries. ${ }^{86}$ It is normal for the curators of photographic collections in heritage institutions to include in their physical and digital systems information about the dates individual photographs were taken. Also, often they include titles. However, it is

\footnotetext{
${ }^{85}$ This is a probabilistic inference. As I said earlier, Fred is known to have been working as a professional photographer in 1928. Also, as I previously said, there is a case for arguing that those negative images not attributed to named photographers (William Oakley and Crown Studio in the case of this sequence) were taken by Fred. Because Fred became the proprietor of Crown Studio in July 1928, it is possible that this photograph of the Old Boys' Football Team was taken by Fred prior to acquiring the Studio, or by Fred or an employee after acquisition. The possibility that the photograph was taken by Crown Studio prior to Fred's taking over cannot be ruled out. However, it seems unlikely because no other photographs attributed to Crown Studio (New Plymouth) in Collections Online were taken that late in the 1920s - all have precise dates, except for one (mistakenly, in my opinion) estimated to have been taken "circa 1930". Similarly, there is a possibility the photograph was taken by William Oakley, but again that seems unlikely to have been the case. In fact, there is a case to be made that some of the photographs attributed to William Oakley may actually have been taken by Fred. I discuss this further in Chapter Seven.

${ }^{86}$ The assertion I made earlier that the materials, classification and format transitive dimension content would have been created by staff members at the National Museum or Te Papa was also a probabilistic inference. It drew on my knowledge that it is normal for curators of photographic collections in large heritage collecting institutions to provide information of this type, in this detail, and in the standardised form that is self-evident if one scans numerous packages of metadata in the C. Series (all seem to be whole plate silver gelatine negatives). Fred's recording systems were, in contrast, inconsistent and incomplete.
} 
unusual for them to include precise information of either type without first viewing a reliable source where that information has been previously recorded. Often that source is the photographic product itself or the packaging in which it was received. Such information comes to curators in those ways because photographers - especially professional photographers - often make a note of the date a photograph was taken and the subject matter, of primary importance to the photographer, depicted in the image. Sometimes (particularly when formal group portraits are being taken) photographers include in the composition and, therefore, capture in the image some physical object carrying a text that states the name of the group and the year. The image of "Surf Life Saving Club members" depicted in Figure 3 is an example of this practice. It is also an example of the practice of carrying transitive dimension content, but not the precise text expressing that content, from one inscription to another: the text inscribed as metadata in Collections Online is "Surf Life Saving Club members", but the text captured in the image is "N.T. Royal Life Saving Society". ${ }^{87}$

The negative assigned the registration number C.003518 ("Old Boys Football Team") may be another example of such a self-describing group portrait. Without seeing it and in the absence of a digital image, I cannot be certain. Nevertheless, the metadata itself is enough to tell me an inscription communicating the date and the information now deemed to be the title was already there when the National Museum took custody of that negative. I know this because that information - as it appears today - is so precise that it must have first been inscribed at the time this photograph was taken or very soon after and almost certainly by the photographer or an employee of the photographer. This being the case, this transitive dimension content is likely to have been transferred largely verbatim from the image, from a physical container in which the negative was received, or from the edges of the negative, to a collection control system which preceded Collections Online and from there - either directly or via other systems - to Collections Online itself.

\footnotetext{
${ }^{87}$ The "N.T." would have been an abbreviation for North Taranaki, an inference one can make when one knows the identity of the photographer and the geographic area in which he operated. Because the person who created the metadata did not appear to have the contextual knowledge necessary to make this inference, the transitive dimension content in the metadata is less than that in the image. In that sense, it is different to that in the image; but, in another sense, it is the same because it does not falsify what is inscribed in the image.
} 
This link between the transitive dimension content provided by Collections Online regarding the title and date of production of C.003518 and Fred as the provenance entity responsible for the creation of that transitive dimension content can be argued to be sufficient to constitute it as a record of Fred. Admittedly, concepts of record which attach significance to the presence of a custodial relationship between an object and its 'creator' are difficult to apply to an entity that is understood to be a non-material abstraction - to an entity we 'see' to exist only because in encountering something that is physically present (the inscription), we 'see' (in the mind's eye) a chain of connections pointing to the fact that the knowledge contained in that physically present inscription probably came into being long before the inscription itself did and, therefore, seems to have a way of being that distinguishes it from the inscriptions in which it has at various times materialised and from the texts that have been component parts of those inscriptions.

Though the absence of physicality and of a custodial relationship between Fred and this transitive dimension content might be deemed problematic by archivists whose paradigms are informed by traditional notions of creator and record (and the traditional entanglements of those notions), it is less problematic when considered in relation to contemporary archival science literature which has commented on the extent to which the domain's traditional thinking has been limited by custodial concerns and habits of conceptualising records as physical objects. Increasingly records are spoken of as information about, evidence of, or representations of such things as actions, transactions, activities, events, and occurrents associated with their creation and use, rather than in terms of their physicality and custodianship. ${ }^{88}$ If one works with notions of record such as these, thinking the transitive dimension content communicated by the date and title inscriptions in Collections Online (and relevant to the negative C.003518) to be a record of Fred is relatively unproblematic even though the inscription itself was not created by Fred. Thinking about a record in this way, however, does call for a leap of imagination because it requires that an abstract notion of information (i.e., the transitive dimension content) be isolated in thought, that it be seen as something separate to its various

\footnotetext{
${ }^{88}$ Definitions with this orientation away from the physical and the custodial include that proposed by Yeo (2008, p. 136), and those included in the first and second editions of the international records management standard ISO 15489 (International Organization for Standardization, 2001, 2016). Records continuum theory, as discussed in Chapter Three, also has this orientation away from imagining physicality and custodianship to be centrally important to the concept of record.
} 
carriers, forms of inscription, and textual expressions. ${ }^{89}$ In effect, what we do when we take this leap of imagination is look from a whole of spacetime perspective in such a way that we see individual carriers and inscriptions as coming and going in the flow of time differently to the transitive dimension content they mediate. This is because we 'see' the transitive dimension content in terms of the totality of carriers and inscriptions and, therefore, as more broadly spread and potentially more persisting than any of those individual carriers or inscriptions.

\subsection{PACKAGED PACKAGES AND POINTS OF CONNECTION IN THE CONSTRUCTION OF RECORDS}

In section 6.5 I took as my start point - as the thing I was calling a record - a package of metadata associated with, but not including, a single photographic negative. I disassembled the package and traced the historicity of its parts to demonstrate that the context of emergence - the provenance, if you like - of the package was not necessarily shared by its parts. Additionally, I demonstrated that the contexts of emergence of some parts differed from those of others. One of the mechanisms I used to build this argument was to conceptualise each unit of metadata content (hereafter, data unit) in the package in three different ways (as inscriptions, as texts, and as transitive dimension content). What then became apparent was that the context of emergence of each part varied in accordance with how that part was conceptualised. Given this multiplicity of contexts of emergence, I argued there are logical grounds for thinking about this package as more than just a single record that exists in a present day context. It can also be thought of as a present day container of numerous historical records that are distinct from the record that contains - and is comprised from - them. It is worth noting at this point that the case for variable and complex provenance could have been made even if I had thought of the data units in the package only as inscriptions. This is because the credit line element was not a part of the C.003518 (Old Boys Football Team) package at the time I uncovered the sequence surrounding the Tahurangi House image. It was added about two years later when, following a public presentation of my findings, I made an early draft of this chapter

\footnotetext{
${ }^{89}$ The phrase isolated in thought is adapted from Sayer (1998). When we isolate "the components of a thing" "in thought", he pointed out, it becomes "possible to understand (albeit fallibly) the nature of that thing because we can trace where the component parts have come from." This "enables us to distinguish between changes in the nature of a thing and successive replacements of that thing" (pp. 123-124).
} 
available to Photography Collection staff at Te Papa. They then checked their acquisition records to confirm my findings and added credit line data to all the descriptions in the sequence I found as well as to descriptions of other negatives they had discovered to have been acquired from Fred. A Collections Online search on the phrase Frederick $B$ Butler now returns 1280 hits (1 September 2016) in contrast to my first search (ca. February 2011), which yielded only one hit after testing all possible variations on Fred's name.

Something I did not do in section 6.5 was draw attention to the fact that the package with which I began (the Old Boys Football Team metadata) was not only a package, but also itself a part. We could say it was a packaged package. It was, for example, part of a screen display. It was also part of the sequence of metadata pointing to, and digital images derived from, negatives once in Fred's custody and stretching out in both directions from the Tahurangi House 'digital orphan'. This sequence - or package - was itself part of a sequence of metadata packages in Collections Online which have registration numbers beginning with "C.O". That sequence intersects with another sequence, which is all the Collections Online descriptions of photographic material naming Fred in the credit line. All these sequences are (sometimes over-lapping) parts of a still larger package: the whole of Collections Online. Collections Online itself is part of a package comprised of all the heritage and related information resources Te Papa controls. The digital and the physical, though seemingly so different, are intricately enmeshed in this institution-wide package. The digital component, on the one hand, has inherited components of the physical collections and, on the other hand, lends additional functionality to items in the physical collections - the annotations on the edges of the glass-plate negatives, for example, are almost impossible to detect on the physical negative (even when one is looking for them) whereas they stand out clearly in the digital images.

In continuum terms, the Te Papa institution-wide package is a third dimension entity. The 'archive' in this dimension is imagined in terms of the organisation, its functions, and in terms of the 'memory' stores of that organisation. If we cross the threshold into the continuum's fourth dimension (the societal plurality, the 'archives' of 'collective memory'), we can 'see', if only in the mind's eye, the Te Papa institution-wide package as part of a multiplicity of encompassing packages. One would be a package comprised of all 
the heritage resources and all the information resources controlled by institutions in New Zealand. Puke Ariki's collections and databases are also part of that very large package of heritage resources and information resources controlled by institutions in New Zealand.

Within the Puke Ariki package there is a photograph album containing a print that carries an image duplicated in, and part of, the Tahurangi House 'digital orphan' package in Te Papa's Collections Online. This image is a point of intersection between two institutionwide packages. The point of intersection exists because, although these packages were created by two distinct 'primary' provenance entities, their interiority is comprised of entities with multiple and varying provenancial relationships, some of which are relevant to both institution-wide packages.

Another point of intersection between these two institution-wide packages is the text of the annotations on the edge of the negative and alongside the print. Still another is the material expression of those textual annotations - the manuscript annotation in the album and the manuscript annotation inherited by the digital image (from the negative of the print in the album) carry a trace of their writer and make it evident that the same person wrote both annotations. When packaged with other 'data' within the album, these historically connected annotations enable identification of the writer and show the writer to also have been the photographer. This trace would not be present if the annotations had been trimmed from the digital image and transcribed into the 'digital orphan's' metadata as text; it is there because the method of reproduction has preserved evidence of the inscription rather than just the text. Such points of intersection connect packages.

The lending collection in Victoria University of Wellington's library (from which I borrowed Scanlan's Egmont: The Story of a Mountain) is another part of that very large package which is the totality of the heritage resources and information resources controlled by institutions in New Zealand. An image of a dog named Roy is a point of intersection between this package and the Puke Ariki package because a print of that image of Roy also exists in the album in which the Tahurangi House print can be found. Moving even closer in, we can say that the image of Roy is a point of intersection between a physically bounded package with relatively prototypical record characteristics (the album) and a physically bounded package with characteristics that, from a traditional 
perspective, would place it outside the category of record (the book). Despite their seemingly fundamental differences, these two packages share some of the same provenancial relationships due to the presence of the same image in both.

The situation is interesting because, if the album and the book are seen in terms of their physical boundaries and physical packaging, they are necessarily conceptualised as different packages (one a record; the other, perhaps, not). However, they work together as a single logical package when seen in a provenancial relationship with an act of intellectual property infringement - in other words, when seen as a record evidencing such an act. In fact, working together in this way they come close to being a complete record, if one conceptualises a complete record as a package that is itself that about which it speaks. When one looks at the album and book as a complete record of an act of intellectual property infringement, attention focuses on the annotation in the album (testimonial evidence) and on the image of Roy in the album and as it reappears in the book. However, these parts are not in themselves sufficient to make the record complete because it is other parts of the album that identify the person who took the photograph and made the assertion, and because the second image of Roy can only be seen as evidence of an act of intellectual property infringement, if it is seen within the book.

This example, along with others discussed in this chapter, reveals that conceptually what is at work when somebody (mentally, physically, or digitally) constructs a record is a concept of the type of thing that can be a record coupled with a concept of significant provenance. How expansive 'the record' needs to be for it to be seen as complete depends on the purpose we need it to serve. When I saw Scanlan's book as the record that proved Fred's assertion to be true, the book was the complete record - it was all I needed, because I already had the rest. However, if I were to deed to the future a record that was complete in relation to that act of intellectual copyright infringement, the complete package would include the album containing the original print, Fred's assertion that the photograph was reproduced without his permission, Fred's assertion that he was the photographer, and the visual patterns (handwriting, images in related photographs, etc) that served as trace evidence lending weight to a probabilistic belief that Fred was indeed the photographer. 
Because entities can be conceptualised in different ways and at different levels of granularity, and because the provenance of those entities is virtually always complex, there is potential for logical records - or records as conceptual constructs - to emerge in many different ways. The way they emerge, when not determined by some pre-existing notion of what does and does not belong in the category, will be determined by need. In effect, the logical record is a bundling of entities that may simultaneously be part of some other bundle - or package - and that also may have previously been, and could in the future be, bundled in still other ways.

\subsection{OVERVIEW AND REFLECTIONS ON THE RECORD-EVIDENCE RELATIONSHIP}

In this chapter I have explored the question of how records are constructed. I began by arguing that the case study experience described in sections 6.2 and 6.3 provides grounds for claiming there are three equally important pre-conditions for record emergence - or three fundamental ingredients from which records are constructed. One is connectedness (structure) in reality (in the intransitive dimension). Another is a concept of record. The third is the motivation and ability to see correspondence between the intransitive dimension reality and the transitive dimension concept.

I argued that, from a discovery perspective, records are like evidence in that they emerge from the layering of a (transitive dimension) concept over (intransitive dimension) entities that stand, or have stood, in certain relation to each other and in relation to whatever type of provenance entity is required by the concept of record at work in the perceptual situation. This being the case, I argued that, besides using the terms logical objects and conceptual constructs to refer to records, one could also describe records as composites which always have a conceptual component, but which also always have a physical or digital component - and often have all three. I also suggested that there is little value, at the level of meta-theory, in distinguishing between things originally and deliberately constructed as records and things created for other reasons but later used as records because they have been seen to have record characteristics relevant to a particular need. Perception is variable; it is not uniform or universal. Therefore, we can never state that some things are and, from all perspectives and at all times, always will be records whereas other things are sometimes merely seen to be like records. However, we can say 
that whenever an entity emerges as a record, its emergence is always grounded in the interplay of transitive and intransitive dimension phenomena and that the phenomena we refer to as records are (or have previously been) structured in the intransitive dimension in a way that corresponds with the notion of record at play.

I used a traditional concept of record to build this first part of my argument. However, after laying the above foundations for understanding the composite character of records, I began exploring possibilities for conceptualising record entities in a variety of ways, at different levels of granularity, and in terms of a variety of different provenancial relationships.

By looking inside a small package of metadata in the sequence of negatives I found in Te Papa's Collections Online (having first argued that package to be a contemporary record) I built a case for claiming that each unit of metadata content in the package can be seen as a record in its own right whenever it does not have precisely the same set of provenancial relationships as the other units in the package or of the package itself, and if it is seen in relation to its own provenance rather than the provenance of the package. This means that a contemporary record may have contained within it various historical records which predate its own emergence. These historical records within the contemporary record lend aspects of their historicity to the contemporary record thereby endowing the contemporary record with multiple possible ways of stretching out its recordness (via provenancial and documentary relationships).

One of the means by which I constructed the above argument was by conceptualising the units of data content within a 'record package' in a variety of different ways. I worked with notions of inscription, text, and transitive dimension content. My intention was not to imply these should be understood as the only ways in which record entities can be conceptualised. Rather, I chose these concepts because they were pertinent to the largely textual contemporary record I chose from my case study, and because talk of records in archives domain discourse tends to sometimes assume the record to be structured text (or some other form of information) embedded in its carrier (inscription) and other times 
to be the structured text alone (text). ${ }^{90}$ Also, as far as I am aware, there has been little or no discussion in the domain's literature about whether when records are thought of as information, the term information is being used to refer to precise text or something more akin to my notion of transitive dimension content. ${ }^{91}$

The value of bringing these different conceptualisations into play rests in the fact that inscriptions, texts, and transitive dimension content, though highly interdependent, can become separated and, therefore, can spread differently through space and time. My analysis of the metadata package in Collections Online enabled me to argue that the sets of provenancial relationships associated with each unit of data content vary in accordance with how the unit is conceptualised. This enabled me to explain why it was that I intuitively saw the metadata package as a record of Fred. It was because when the units of metadata content in the package were conceptualised as texts, and even more when they were conceptualised as transitive dimension content, some could be traced directly to Fred as the source - or original creator - and others could be traced directly to objects Fred had created. Whether this justifies claiming the package, as opposed to some of its parts, is a record of Fred is a moot point - it would depend on one's concept of record. I believe it is consistent with McKemmish and Piggott's (2013) thinking on the nature of personal records because, in defining a "virtual personal archive", the only type of relationship they required to exist between records "in all forms, genres, and media" and the person whose archive they comprise is a "relating to" relationship (p. 133). Their text made it clear that the way in which the record relates to the person should be interpreted broadly.

The many and varied ways in which the parts of a 'record package' stretch out towards provenancial entities (a multiplicity that increases in accordance with the variety of ways

\footnotetext{
${ }^{90}$ Yeo $(2010 b)$ noted this ambiguity within a discussion of problems associated with attempts to identify the significant characteristics of records. He saw it as being significantly grounded in different understandings of the affordances of records. He did not mention continuum theory, but identified "the Australian recordkeeping school" (p. 103) as having a narrow concept of record (as evidence of the record creator's activity) and, therefore, tending to place less value on the material character (and broader societal and cultural contexts) of records than do Harris, Cook, and others Yeo identified as arguing the case for broader understanding of the affordances of records. Interestingly, Yeo (2010c) treated records as dematerialised structured text when he likened them to speech acts.

${ }^{91}$ Possibly this issue has been discussed in digital recordkeeping and digital curation literature. That body of literature is outside the scope of my current research, but future research building on my findings would bring it into focus.
} 
in which the parts are conceptualised and in accordance with how 'packaged' the package is) explains why it is that record entities - particularly those traditionally conceptualised as records (e.g., documents and files) - are cornucopias of evidential possibilities.

Following this exercise in identifying and conceptualising record entities at highly granular levels, I turned my attention to conceptualising record entities as packages within packages within packages (and so on) and also as perceived packages that can emerge when points of intersection between pre-existing packages (intersections that result from elements of shared provenance) are recognised. These points of intersection come into being because of the tendency for texts, images, and transitive dimension content to multiply and spread through spacetime. They are just as likely - perhaps more likely - to be found in entities not traditionally thought of as record entities (notably, books and other publications) as they are to be found in record entities of traditionally accepted types.

Barbara Reed has followed a similar line of logic in her reflections on issues in digital recordkeeping. She came to the conclusion that space-time situated relationships are the entity of primary importance for recordkeeping. "Recordkeeping", she said, "can potentially be recast to be all about relationships" (Reed in Cunningham, et al., 2013, p. 143). In other words (my words), recordkeeping is not about types of objects called records, because the recordness of the object is emergent from the relationships. Reed made this claim in the context of an argument that the time has come to stop conceptualising the phenomena of central importance for recordkeeping in light of the archives domain's traditional physical paradigm. Alluding specifically to the problem of managing the digital, she argued that, in addition to recasting recordkeeping "to be all about relationships", recordkeepers (including archivists) need to rethink the "granularity spectrum" from systems - and linked or collaborative systems - all the way down to the most basic data units from which those systems are comprised (pp. 140-141). My reflections in this chapter, though not focused on purely digital environments but on situations where the co-existence of the physical and digital is paramount, have lead me to conclusions very similar to Reed's: space-time situated relationships are of key importance, and our thinking about the size of the 'record' entities between which such relationships exist needs to be much more open. I have also suggested that we need to 
pay closer attention to how we are conceptualising and, often unreflectively, 'typing' the entities we constitute as records. This matters because the future affordances of those entities are affected by recordkeeping 'typing'. An inscription, for example, has different affordances to a text; and transitive dimension content, which is information that can serve only as testimonial evidence (never as trace), has little value if its circumstances of emergence and source are unknown (see discussion of testimonial evidence in Chapter Three, section 3.3.5).

What is interesting is that I arrived at the conclusion that this fine-grained space-time situated relational precision is important both in my reflections on the construction of records, amd also in my reflections on the emergence of evidence during historical research processes. Conceptually the continuum notion of record has much in common with the notion of evidence I developed in Chapter Five. Both are reality-oriented concepts sitting in that conceptually difficult space between intransitive dimension reality and transitive dimension knowledge about that reality. Both, therefore, value correspondence between perceived relationships and actual relationships. Furthermore, perceptions of both records and evidence emerge in contexts of epistemic privileging historical researchers privilege certain topics of enquiry; archivists typically privilege certain types of provenance entity and certain ambient entities.

Another similarity between my findings on the nature of evidence and the continuum concept of records is that both are open to the possibility that the thing referred to as the record or the evidence may be something very small or a structured aggregation of many things. Yet another similarity rests in the variety of substantive things that can serve as evidence or as record. ${ }^{92}$ Schum (1994) said the substantive variety of evidence is "nearly infinite" (p. 3), especially in the fields of law and history (p. 21). Though the variety of things that can serve as record in the archives domain's traditional paradigm is limited, it is infinite (or, at least, open and as yet unbounded) in the continuum paradigm. The same openness exists in the 'postmodern' paradigm advocated by Verne Harris and others who have followed his lead (e.g., Nelson Mandela Foundation, 2005; Sassoon, 2007b). The Nelson Mandela Foundation (2005), for example, described the Nelson Mandela archive

\footnotetext{
${ }^{92}$ The word substantive is used here to refer to things that can potentially be construed as evidence or as record.
} 
as an "infinite archive", which includes everything from documents authored by Mandela and government records relating to episodes in his life, to places Mandela lived or visited, and items connected with Mandela in very indirect ways; e.g., "the many structures ... named after him" and "the countless stories of people who have simply felt their lives touched by him" (p. 041).

Despite identifying all these similarities between evidence as it emerges during a research process and the continuum notion of record, my research suggests there is a difference that should be noted. Continuum thinkers, like most archivists, tend to accept as records only entities that have a provable (i.e., authentic) relationship with a provenance entity. A historical researcher, on the other hand (and in light of my case study experience), will accept as evidence anything that seems to be relevant to the matter into which the researcher is enquiring (even if that matter is a hypothesis that is being tested, rather than something known to have once occurred or been real) and will dismiss that thing as irrelevant and, therefore, not evidence only if its relationship with that matter is determined to have not existed in reality or if the hypothesis is dismissed. In other words, the way most historical researchers conceptualise evidence embraces uncertainty; the way most archivists conceptualise records does not. I have read no continuum literature which has led me to believe that continuum thinkers differ from other archivists on this matter. Logically, however, the notion of gradations of certainty fits within the continuum paradigm, so the discourse's silence on this matter may simply be because the issue has yet to be discussed.

Having acknowledged that difference, there is another important point to be made. This is that, by requiring certainty with regard to provenancial relationships and by engaging in practices consistent with that conceptual requirement, recordkeepers working at the front end of record creation and archivists receiving record entities that are already made privilege epistemically strong relationships which, when they correspond with a historical researcher's topic of enquiry, make it possible for the researcher to claim with certainty that her evidence is relevant to that enquiry. ${ }^{93}$ In the traditional paradigm there is a mismatch between the high-level and singular relationality on which archivists focused

\footnotetext{
${ }^{93}$ Actual practice can fall well short of this ideal.
} 
their definitions and descriptions of records (i.e., fonds or series related to a single provenance entity and a single ambient context) and the much more granular and complex relationality required by historians in order to establish relevance in relation to their enquiries. However, this mismatch would not be so extreme if the way in which records are conceptualised (and described) were very fine-grained as well as highly 'packaged'. This way of thinking is, as I said above, emerging in continuum discourse. Upward (2009) described archivists as "the clue providers, working at the level of small truths" (p. 122). The rich "web of relationships" (Upward, 2009, p. 218) envisaged by Reed and other continuum thinkers promises to provide many clues - in the form of many certainties - for researchers as they go about the business of building their "inference networks" (Schum, 1994, p. 131) at least in part from building blocks provided by recordkeepers.

Can we say, therefore, that evidentiality is so significant in relation to the concept of record that it can be taken as definitional? The answer would have to be, it depends. If one's concept of record is object-centric and predicated on the assumption that the category of record is bounded (even though the boundaries may be fuzzy), one could well argue as Yeo (2007) did that evidentiality is merely one of many affordances such objects have. However, if one's concept of record is relationship-centric and grounded in the continuum notion that recordness is not a property of a certain type of object but can emerge (in many possible ways) as a characteristic of any entity by virtue of its internal and external relationships, recordness and evidentiality are very closely aligned concepts indeed. They are so closely aligned that, in this paradigm, evidentiality can justifiably be argued to be the defining characteristic of records because, if not for its (internal or external) evidence enabling relationships, no entity could ever be a record.

The question begged by the juxtaposition of the traditional and continuum concepts of record is not what concept is correct, but what concept of record is most fit for purpose in any given situation. The situation of concern in this thesis is cross-domain discussion about collaboration and convergence in the design of knowledge enabling systems. The concept fit for that purpose would be both relationship-centric and also totally open in terms of how both 'record entities' and 'provenance entities' are conceptualized. An open and relationship-centric concept such as that advocated by continuum theorists has 
potential for allowing objects and aggregations (which we may or may not choose to call records) to be presented in digital systems as cornucopias of evidential possibilities.

\subsection{CONCLUSION}

This chapter has tackled two tasks set in Chapter Three. The first was to cast further light on what it means to say, as continuum theorists do, that records are logical entities or conceptual constructs. This notion has been previously articulated primarily in the context of contemporary digital recordkeeping. By exploring the question of how records are constructed from a discovery perspective and in relation to physical objects as well as digital, I have attempted to illustrate the continuum notion of record in ways that are meaningful to collecting archivists as well as others working in the cultural heritage sector. The second task undertaken in this chapter was to take what I had learnt about the question of how records are constructed and consider it in relation to what I had previously learnt about how evidence emerges during historical research (discussed in Chapter Five) in order to address the question of whether evidentiality is of central importance to the concept of record. I concluded that in the continuum paradigm where space-time situated relationships (rather than types of physical or digital entities) are seen as the entity of primary importance for recordkeeping, the case is very strong though it would be more true to say that the continuum concept of record corresponds with a reality-oriented notion of relevant evidence (i.e., correspondence between the perceived relatedness of things and the actual relatedness of those things) than with a broader notion of evidence that would include evidence cited in support of a flawed knowledge statement or evidence that is used at one point in an enquiry, but abandoned as irrelevant at a later stage.

These findings led me to reiterate a point I first made in Chapter Three, which is that the continuum notion of record has more potential for enabling effective cross-domain collaboration in the design of knowledge enabling systems than does the archives domain's traditional concept of record. That potential derives in part from the fact that the continuum notion is relationship-centric and, therefore, able to be completely open with regard to the nature of the phenomena that can be records and also with regard to the question of what those phenomena can be records of. 
In Chapter Seven I discuss my research findings in relation to my research question and objectives. I include reflections on lessons learnt, from the research, about the design of knowledge enabling systems. I conclude the thesis by bringing to attention discourses that were of interest to me in the early stages of my research, but which did not find their way into my thesis, and by making suggestions for future research. 


\section{THE DESIGN OF KNOWLEDGE ENABLING SYSTEMS AND CONCLUDING COMMENTS}

\subsection{INTRODUCTION}

This chapter concludes the thesis. It begins by discussing what was learnt from the research about the design of knowledge enabling systems. It then looks, from two perspectives, at the contributions to knowledge made by the thesis: firstly, with reference to the research objectives as originally articulated in section 1.4.2; and, secondly, with reference to problems and gaps in the body of archival science literature which gave shape to the thesis (discussed in Chapter three). It closes by introducing some of the discourses outside the archives domain which attracted my attention in the early stages of my research, but did not find their way into my thesis. I draw attention to points of commonality with continuum recordkeeping thinking and make suggestions for future research.

\subsection{REFLECTIONS ON THE DESIGN OF KNOWLEDGE ENABLING SYSTEMS}

\subsubsection{Introductory comments on relevant research objectives.}

Two of the research objectives I introduced in section 1.4 .2 focused on practice and systems design. These were:

- to contribute to understanding of how the theoretical concepts and idealised practices of the archives domain work to facilitate the emergence of evidence;

- to contribute to understanding of how actual practices and technologies facilitate - or possibly hinder - the emergence of evidence.

Because Fred Butler's former collection has been widely dispersed, I anticipated that my case study would provide ample opportunity for exploring both objectives. Unfortunately, what I found was that, except for Puke Ariki, institutions that had acquired items from Fred's collection rarely included references to him in their digital finding aids. Indeed, it is only in relatively recent times that Puke Ariki has begun to address a similar gap in their public finding aid. As a consequence, the research yielded relatively little insight into how actual practices and technologies facilitate - or possibly hinder - the emergence of 
evidence. For this reason, the discussion that follows is primarily focused on the first of the two objectives above. This objective was speculative in that it assumed the possibility of using actual experience as a foundation for imagining a different type of experience, one where systems design and practice would be more informed by the 'idealised' practices advocated by archival science's 'postmodern' and continuum theorists.

Despite claims to the contrary (discussed in Chapter Three), the ideal practices imagined in 'postmodern' theory (e.g., Duff \& Harris, 2002) differ little in intent from those imagined by continuum theorists. The major point of difference is that continuum theorists have paid more attention to the question of what realizing the ideal means in practice. In reflecting on my case study experiences of evidence emergence (and nonemergence), I came to see great value for historical researchers in the 'descriptive' practices advocated by members of the continuum community. Therefore, continuum thinking is fore-grounded in the discussion below. My discussion of continuum practice is, however, limited. As I said in section 2.7 .3 , I did not include writing directly relevant to Monash University's metadata projects in the body of literature with which I engaged. Also, I included only a small proportion of continuum literature produced after 2010.

\subsubsection{The ability to witness and (continuum-informed) recordkeeping functionality}

Reed (in Cunningham, et al., 2013) said "recordkeeping can potentially be recast to be all about relationships" (p. 143). More precisely, it is all about "persistent stable relationships" (p. 143), about the challenge, "in a dynamic world" (p. 143), of providing "observation platforms" (Upward, 2009, p. 20) that enable records to be seen in "timebound, evidential cocoon[s] of meaning" (Hurley, 1998, p. 74). In other words, the identification and fixing of actual space-time situated relationships - of the 'nodes' and the 'connectors', and of the period of duration - affords things (which some call records) the ability to function as evidence of perhaps one thing, or of many things.

Harris (2001b) asked, "Why should the capacity to witness through personal records depend on the degree of "functionality'" (p. 12)? My research suggests that the capacity to witness through records (whether personal or not) is afforded almost entirely by the functionality afforded by the fixing of relationships of the type described above. 
Fixity allows the 'record' (however, it might be seen to be centred and bounded) to 'speak' for itself - to object to what others say about it - if necessary over and over again. If the 'record' cannot object, it cannot witness effectively - human perception is too selective and incomplete; human inferences are too often narrowly conceived or coloured by confirmation bias; and second-hand witnessing (even truth-directed story-telling such as that in my thesis) communicates only a portion of what was actually seen and experienced, and sometimes embellishes that.

Fixing the 'record' does not mean simply fixing an object. It also means fixing the object's ways of being related. Continuum recordkeeping practice revolves around relationships that are space-time situated, authentic, and specific. In the absence of such relationships the 'record's' relevance to the matter at hand is open to question. This research has shown that, if the 'record' is not empowered to say what it has witnessed or how it stands in relation to other 'records' which may be able to provide that information, its utility in truth-directed enquiry is severely compromised. Continuum theorists do not claim this functionality exists only because of deliberate recordkeeping actions; they simply argue that it is the role of professional recordkeepers to deliberately and consciously do what they can to ensure such functionality is enabled. In engaging with notions of scalability and provenancial multiplicity, they have paved the way for bringing recordkeeping metadata increasingly close to correspondence with the types of relationships that are of interest to researchers as they seek out and explore the relevance and meaning of evidence in the course of their enquiries. This case was argued in Chapters Five and Six.

\subsubsection{Pathways through time and points of interaction}

Reflecting on my case study experience, I am aware of two fundamentally different ways in which I interacted (in a cognitive sense) with the evidence that came to my attention. There were times when I was focused on moving from one thing to another thing to which the first 'pointed'; and there were times when what mattered to me was the ability to see (whether in my mind's eye, on paper, or on a screen) aggregations of related things.

Focused and deliberate movement from one thing to another was sometimes enabled by the fact that the thing already seen pointed explicitly to something else (e.g., Fred's 
annotation which pointed to Scanlan's book). More often, it was knowledge I already had that enabled me to 'see' one thing pointing to another (e.g., the dates the photographs of the Haldane sisters were taken 'pointed' to the indexes to New Zealand's official marriage registers; the image of Tahurangi House depicted in Collections Online 'pointed' to Fred's album). If others are like me, then it would seem there are a number of reasons why one seeks out the thing to which the 'pointer' 'points': in order to explore the meaning and truthfulness of assertions made in the 'pointer', to test one's own hypotheses (regarding the relevance and meaning of things already seen), and to locate more material that may be directly relevant to some aspect of one's enquiry. This last reason for seeking out an object to which a 'pointer' 'points' serves the purpose of building up a body of evidence relevant to the enquiry in a relatively broad sense. This is important because, except in those rare cases where ultimate proof of some matter of interest to a researcher is found, an abundance of relevant evidence is a significant enabler of a researcher's ability to formulate truth-directed interpretations of the evidence she has to hand and to reach well-grounded probabilistic conclusions. 'Pointers' serve this purpose because they 'point' to something in the intransitive dimension ambience. By intransitive dimension ambience I mean the ambience that actually surrounded one's topic of enquiry, rather than the ambience of which Hurley has spoken, which is comprised of descriptions of such things, and which is, therefore, comprised of transitive dimension entities that describe entities in the unbounded intransitive dimension. When following 'pointers' for this reason, one moves from the known to the relatively unknown. I say the thing or things to which one moves are relatively unknown because the presence of the thing that is 'pointed to' is anticipated, rather than certain, and because one also anticipates that one may find unknown things associated with that thing that are relevant to one's enquiry. Serendipitous discoveries happen in such circumstances - one is actively seeking out information relevant to one aspect of one's enquiry when, because there is an actual (i.e., intransitive dimension) connection, one finds something relevant to some other aspect of the enquiry. Such connections are not always direct. Hilda's reminiscences in Scanlan's Egmont: The Story of a Mountain, for example, enabled me to better understand the snapshot of Fred, Hilda, and Molly sliding in the snow (Figure 7). Similarly, my discovery of the Tahurangi House 'digital orphan' was the first step towards uncovering a wealth of material casting light on aspects of Fred's life of which I had previously been unaware. In 
short, the ability to trace entities to which 'pointers' 'point' serves many important roles in research.

Metadata functions as a 'pointer'. It points to things curators have intended it to point to, and it 'points' to things researchers 'see' it to point to and would like to find. One of the frustrations I encountered in my research was finding it impossible to trace back to source metadata I saw to be 'pointing' to something that had previously existed. It seems to me that in the eyes of archivists (and other curators) metadata is authoritative information about an object, but not about all aspects of an object, only about those seen to be significant by the archivist and which the archivist can 'read'. During research, however, metadata is sometimes seen more as testimonial evidence - its completeness, its trustworthiness, and its meaning may all be open to question. I am not suggesting that the historical researcher responds to all metadata in this way. Rather, my experience suggests, this way of seeing the metadata occurs occasionally, when the metadata seems discordant with other things one knows or when it stimulates questions and hypotheses. In such circumstances one wants to see how the metadata is grounded, how it stands in relation to that about which it 'speaks'. If the metadata cannot be traced to source and the source cannot be viewed, it may be impossible to answer questions of importance to the researcher that have been stimulated by the metadata.

This point can be illustrated by looking at the sequence of metadata packages I found in Te Papa's Collections Online, and in particular those ascribed to William Oakley. The entire sequence intrigued me when I first uncovered it. As I said in Chapter Six, three "makers" (photographers) were named: unknown, William Oakley, and Crown Studio New Plymouth. This stimulated me to seek out more information about Crown Studio and Oakley because I wanted to know how Fred had come to acquire their photographs. That line of enquiry led to my learning Fred had practised as a professional photographer, for a short time under his own name (which lent weight to my suspicion that the unknown photographer was, in all cases, Fred), and subsequently as the proprietor of Crown Studio in New Plymouth. This explained how Crown Studio negatives had come into his possession. ${ }^{94}$ Fred's relationship with Oakley, however, remained hazy. My searches led

\footnotetext{
${ }^{94}$ This was not known to curatorial staff dealing with the photography collections at Puke Ariki and Te Papa.
} 
to information about Oakley, but not about his relationship with Fred. The only connections of which I was aware were the fact Fred had acquired photographs taken by Oakley and a vague recollection of having seen something in one of Fred's 'scrapbooks' which said Fred had (at a time I do not recall) run an antiques business from the building from which Oakley was operating as a photographer. I surmised Fred had probably acquired Oakley's photographs for his collection after Oakley's death in 1942.

However, a quite different possibility was brought to my attention at a later stage in my research. In April 2014 I was invited to join Frances and Sereena Burton, Ann Shelton, and Ann's husband, Duncan, on a visit to Te Papa for the purpose of viewing some of the negatives held in the photography collection. Frances and Sereena had brought with them several boxes of glass-plate negatives and envelopes of film negatives which had been passed down to them by Fred. The negatives were still in the packaging in which Fred had kept them. The film negatives were in pre-printed envelopes from Oakley's studio. On the envelopes were hand-written notes recording where the photographs had been taken. Ann Shelton very quickly recognised the hand-writing was Fred's. Quite reasonably, she took this to mean Fred had been the photographer and Oakley had merely processed the film (and, perhaps, made prints). This points to the possibility that all (or some) of the negatives attributed to Oakley in Collections Online may, in fact, have been taken by Fred. Unfortunately, original packaging is typically replaced and destroyed. When that happens, any 'information' materially embedded in texts the packaging carries, and able to be 'read' only by those with relevant knowledge and motivation, is also destroyed - part of the text may be replaced, but the cornucopia is lost.

Objective practice would allow the objects to object to what has been said about them, but the objects cannot object when they no longer exist. It interests me that many of the metadata packages pointing to Oakley as the "maker" say the negative to which they point depicts a building or place in the New Plymouth area. Fred (as local historian and compiler of a local history resource) frequently used photography as a means of recording the physical character of the city and surrounding areas. Did Oakley share that interest, or did he just process the films? 
The central importance continuum theory attaches to transactionality and provenance translates into a practical focus on capturing metadata that enables tracing backwards through time - ideally such metadata would link an entity to the interaction (or series of interactions) out of which it emerged, and to the entities present and 'acting' at moments of interaction. By this means the pathway each 'actor' follows through time can be made explicit, and information about other 'actors' (including technological tools and processes of production) that may have played a part in determining its state of being (and, therefore, its potential evidential affordances) can be recorded. Rich recording of the 'actors' present during an interaction and of the pathways followed by those 'actors' through time would make systems more useful in relation to diverse potential topics of enquiry.

Interpretation activities seem to call for metadata of the same type - metadata that assists in recognition of pathways through time, points of intersection and interaction, knowledge about states of being at moments in time, and knowledge about 'actors" ways of 'acting'. Setting aside (for the moment) the problem of explaining the ways of acting of human actors, it should be noted here that the ways of acting of technological 'actors' can be important during interpretive activities. There were multiple occasions during my case study research when I drew on my own knowledge of how different tools of inscription work, and there were also occasions when I sought professional advice about relatively obscure aspects of their working in order to explore hypotheses I was considering.

Always, it seems, when one is 'reading' a heritage object one needs to read it in terms of its structure and in terms of the possible ways of acting afforded by that structure - the snapshot of Fred swimming at Bells Falls and the diary entry recording the event evidence differently because they stand differently in relation to the actual event. That difference results to a significant extent from their ways of acting as 'tools' for recording. Often, it seems to me, we read material evidence intuitively. I did this repeatedly. If my experience is typical, it would seem we do not waste time questioning every observation and exploring the validity of every small perception. Rather, we do these things only in response to dissonance or when we are aware that our pre-existing knowledge is an inadequate foundation on which to build a conclusion. Archives domain practices have tended to let the materials speak for themselves with regard to technological provenance. 
Material evidence, however, 'speaks' only tacitly. One needs relevant knowledge to understand what is being 'said'. Including information about the tools and processes of production in provenance metadata would not only make that information accessible, but might also go some way towards stimulating those who are not intuitively mindful of the effects of technological 'actors', or who are unaware of the limitations in their preexisting knowledge about those 'actors', to reach more valid conclusions than they otherwise would. Efficiency and completeness in recording this type of provenance metadata seems to call for collaboration and connectivity.

\subsubsection{Authority, objectivity, and interoperability}

Providing metadata that explains the ways of acting of a person is a less straight-forward matter. Some might argue such explanations are too subjective to warrant inclusion in knowledge enabling systems. As far as I am aware, this issue has not been discussed in continuum recordkeeping discourse. However, the emphasis in Hurley's work, as in traditional archival science, has been on object-full, highly structured, descriptions of empirically observed phenomena. Explanations of a person's behavioural habits or state of mind at a particular time hardly seem to fit into that paradigm because they emerge from processes of inference and are often speculative. Nevertheless, my research experience suggests such explanations can play a significant part in broadening one's understanding of explanatory possibilities. Sometimes they are affirming, which, in truthdirected enquiry, is not necessarily a good thing. On other occasions they disrupt certainty and present new evidence, which can deepen enquiry. I, therefore, see value in recording inferred and speculative explanatory possibilities as metadata. Their inferential and possible (rather than observed and certain) character, however, should be transparent. Also, as I have previously argued for all metadata, the provenance of the explanation should be stated. This 'secondary' metadata would ideally identify empirically available evidence in which the inference is grounded and explain the process of reasoning.

Logically, divergent views on a person's behavioural tendencies (in general or at a specific time) are no different to divergent views on whether a somewhat illegible word transcribed into metadata should be understood to be one set of letters or another. Proof one way or the other might not always be possible, but expanding the body of 
explanatory possibilities, supporting arguments, and evidence would, I believe, aid rather than hinder those who are seriously truth-directed (and perhaps also those who are seeking truth, but lack research experience and advanced evidence assessment skills). The argument I am making here is consistent with continuum thinking - Upward (2009) has argued, "single sources of decision-making can no longer be trusted". This means, he said, that the neutrality and authority of archival systems should be seen as coming from openness to the "the plurality of the archives where diversity flourishes" rather than from claiming neutrality and authority for a closed system that "irons out diversity" (p. 144).

Hurley's thinking is essentially the same. He has argued that metadata describing "different perspectives on the past - contrasting, conflicting even, but nevertheless authentic [which I interpret to mean the metadata is what it purports to be and its provenance is correctly identified] - would provide (or, at least, attempt to provide) the whole contextual meaning, as well as enriched discovery pathways" (Hurley, 2005b, p. 85). Also, data in the ambient context that is external to the provenance data supplied by any single institution helps to enable "external validation of [that] provenance data" (Hurley, 1995a, p. 21).

Thinking along much the same lines as the critical realists Morgan and Olsen, whose views on the nature of objectivity were discussed in Chapter Four, Hurley (2013) argued that for users to make sense of ambience populated by descriptions coming from many sources, a reference point "outside the description" is needed. This "Datum [capitalized in original]" would tell "the user about the describer's point of view" and would "allow the described entity to be positioned in relation to other entities". Following Morgan and Olsen's line of reasoning, I would go a step further and say that the described entity should always have a separate identity to the identity assigned to the description. Recognising that the entity to which a knowledge statement refers is distinct from the knowledge statement itself, is a foundational premise for objective practice in a third way paradigm. Within the context of developing epistemically adequate converged systems, observing this practice would mean that descriptive metadata so dissimilar that it cannot be integrated might, at least, be brought into relation via relationships with the described object. Such relationships would improve findability as well as intelligibility. 
Based on the work I did in Chapter Six, I would say packaging, rather than dissimilarity, is the cause of interoperability problems. This is because it is when individual items of metadata are identified only in relation to their package that they are prevented from connecting externally with the same, or closely related, items of metadata in other packages. In theory, these problems would be overcome if, in addition to assigning described objects identities that distinguish them from descriptions, the component parts of a description were assigned identities that distinguish them from the package of which they are a part.

My reading has been broad and, therefore, not deep in certain areas. Contemporary recordkeeping and digital curation literature, in particular, has been largely outside my scope. Similarly, literature relevant to the development of semantic web infrastructure has been outside my scope. I believe, however, that ideas such as I have suggested above have been promoted in that context; and I think it quite likely they will have found their way into, at least, the thoughts of continuum thinkers such as Barbara Reed. I flag them as matters of interest for further research.

\subsubsection{Aggregations, flexibility, and scalability - patterns, intuitive 'reading', and user interfaces.}

There were many times during my research when I would have liked to have been able to 'call up' an aggregation of things surrounding a document or other entity of interest. For example, when I was investigating the nature of Fred and Hilda's relationship, I imagined the possibility of being able to do a series of searches which centred the Tahurangi House area and 30 June 1925, and which brought into view descriptions of material (in the systems of all institutions which had such material) relevant to increasingly wide date spans. This is the kind of ambience Hurley has imagined as possible, if the problem of parallel provenance were to be overcome - a shared system would bring all described material into relation and would have the flexibility and scalability necessary for the researcher to determine the object of central interest and the extent of the ambience surrounding that object. This vision seems like a day-dream in light of my actual experience with systems; nevertheless, it would be a lovely way to search, particularly when one is just looking about for those things that may or may not exist, but which one will recognise if one should find them. 
Thinking about the possibility of doing a search such as the one I imagined centring Tahurangi House made me aware that place and time tend to be difficult to search in the systems of heritage collecting organizations. This difficulty exists because of the nature of the information typically entered into these fields. If places are described at all, they tend to be described somewhat haphazardly, usually in terms of place names (which can be variable) rather than spatial co-ordinates. Dates are more consistently described, but the way in which date metadata is typically structured in descriptive systems seems to me to assume that the purpose of date information is always to describe an object (or aggregation) one is already viewing and never to enable possibilities for finding that object. I can imagine years, months, days, hours, minutes, and even seconds being recorded in separate (but related) fields. This would enable the type of scalability I have imagined. The question of how to deal with uncertainty is more complex - "n.d." is not a terribly useful clue for searching. Approximations seem better, but I find myself wondering whether approximated date ranges (again structured so the opening and closing dates are in different fields) might be more searchable that approximated single dates - how likely, for example, is it that a photograph described as having been taken "circa 1930" (but actually taken in 1926) would be missed in a search simply because a single digit has positioned it in the wrong decade?

The representation of space and time as metadata warrants further research. I have not read extensively in the digital humanities, but I know digital representation of space and time has attracted research interest in that field (e.g., Greengrass and Hughes, 2008). Such research would be a useful foundation for further recordkeeping research concerned with capturing and structuring date and place data, particularly now that digital technologies are affording opportunities for much more specific identification of space and time in relation to the born-digital.

The other noteworthy occasion when I would have liked to been able to call up an aggregation of descriptive metadata related to a metadata package I had seen, and which had stimulated a hypothesis, was when I wanted to see if the metadata package describing the Tahurangi House image (in Collections Online) was part of a sequence of metadata packages describing negatives received from Fred at the same time. As it was, I had to search for each package by its registration number, then click on the initial 
metadata view (a small selection of data from the whole package and, in a few cases, also a thumbnail image) in order to see the full package of metadata. This was very timeconsuming, even though I only sample-searched, first to establish there was a pattern, then to establish the pattern seemed to be continuing, and finally to identify a change in the pattern (which I read as being the two ends of the sequence). In contrast to the multiinstitutional place-and-time centred search I imagined when looking for information that might cast light on Fred and Hilda's relationship, my imagining of being able to call up an aggregation of sequentially numbered metadata descriptions within a single organisation seems more achievable. All that would be needed is for relationships currently implicit in the system to be made explicit; and for the researcher to be allowed to identify the type of relationship that is of interest (sequentially numbered, in this case), how far out from the item at the centre of interest (the registration number assigned to the Tahurangi House package, in this case) the search should extend, and which fields should be displayed on the screen when hits are returned.

The question of which fields should be displayed leads to another point of interest. When I was conducting the search which enabled me to identify the extent of this sequence, I became tired of clicking to see the full metadata package; so, as long as the partial package first displayed was consistent with the pattern I had identified, I moved straight from that screen display to a new registration code search. One reason why I did this was because none of the full metadata displays I had viewed in the early stages of the process (when I was ascertaining that there was, in fact, a pattern) displayed a field relevant to the source of acquisition. Therefore, I assumed that information was never made available in the system. In fact, it is made available when data has been recorded in the field (the credit line field, in Collections Online). Because of the assumption I had made and because I was sampling, I 'misread' the point where the sequence ended. As it happened, towards one end of the sequence some negatives that were entirely unrelated to Fred had been assigned registration numbers which 'slotted' them into the sequence before it actually ended. Soon after finding this sequence I decided that I would spend a research grant on having a sample of the negatives scanned (at considerable expense) so that I could see whether they were annotated in Fred's hand in the same way in which the Tahurangi House negative was. It was only after the scans were returned to me that I 
became aware of the 'strays'. I became aware of them because the credit line field was included in the metadata supplied with the images, and the information in that field made the source of acquisition explicit.

Notions of wholeness and integrity recur in archives domain discussions of the nature of records and the role of metadata. This was one of the themes to which I drew attention in Chapter Three. In the archives domain the notion of a whole tends to be understood as absolute in relation to an aggregation that exists at a certain point in time. My experience in uncovering the sequence surrounding the Tahurangi House 'digital orphan' points to the value of this notion. To make good choices, one needs to know what factors must be taken into account. To work that out, one needs to see the whole of the fields potentially usable in the description of the type of item on which one's attention is focused. As a new user of Collections Online, it was difficult to get a feel for precisely what that whole was. This was partly because empty fields were not displayed when hits were returned and partly because the credit line field was not included in the advanced search option, which allows one to specify the data one is looking for in specific fields. In other words, the credit line field, though present, is largely out of view - there is a whole, but it is hard to see. I am not suggesting here that every hit should display every potentially relevant field. On the contrary, for visualization work and pattern recognition, one needs sparse displays. What I am suggesting is that the researcher should be the one to decide what fields should be included in sparse displays - and what I am saying is that one needs to see the whole-that-is in order to make wise choices about the nature of the whole one wishes to see.

One final point worth making in relation to my discovery of the Collections Online sequence is that anybody could potentially have the opportunity to seek out 'lost' sequences such as the one I found. As Denard (2012) said, "A visualization may at once embody deep and complex specialist knowledge and at the same time make the contours of that knowledge intuitively accessible to a non-expert audience" (p. 71). I discovered the sequence by applying specialist knowledge, but that knowledge has broad applicability - individual heritage objects have often been assigned unique identifiers by their curators and, while aggregations are often split because of differences in format, it is relatively common for items in the parts to be assigned sequential identifiers. Whenever 
that has been the case, the possibility of retrieving these partial aggregations exists. It is not always the case, so one cannot assume that any item of interest that is found will have a provenancially related sequence stretching out from it. I tried a similar search in Tapuhi (the Alexander Turnbull Library's system at the time I conducted my case study) without success, but in that case the item around which I was searching was the description of a photographic print. I know (from having worked in the Alexander Turnbull Library) that many of its prints were not assigned individual identifiers, but were physically filed by subject (e.g., a place name or personal name). I, therefore, predicted that I would be unsuccessful. Negatives (especially glass-plate negatives) are quite different in that they are not made readily available for public use and, in pre-digital times, their images were so difficult to 'read' that requests to view them were rare. It can, therefore, be predicted that searches for sequences of negatives surrounding a negative of interest will be successful reasonably often. A month ago, out of curiosity, I entered the search terms "Roy" and "dog" in Collections Online. One hit came back - B.027310, "Roy the Famous Dog", "Unknown", January 1925. I conducted the same kind of search on registration numbers as I had previously and, as could be predicted, each search retrieved a metadata package describing a negative acquired from Fred. I can imagine a system which generated a 'pop-up' along with each hit on the description of a negative (or perhaps of anything). The 'pop-up' would suggest the user might like to view sequentially numbered items surrounding the one retrieved, and would explain that this can be rewarding because, in the past, items related by provenance have often been numbered sequentially.

\subsection{THE CONTRIBUTIONS OF THE THESIS}

\subsubsection{Two perspectives}

In reflecting on the contributions to knowledge made in this thesis it is important to remember that the research was envisaged as contributing to two disciplinary discourses: archival science and an emerging cross-domain discourse concerned with the epistemic adequacy of heritage sector theory, practices, and systems. It is also important to remember that the research question and objectives articulated in Chapter One (section 1.4) were intended only to set a general sense of direction for the research. Given that the research was to be conceptually open and exploratory, an element of vagueness was 
deliberately embedded in both. This was because the critical discourses from which the research paradigm drew suggested that, as the research progressed, there were likely to be changes in my understanding of what mattered most and would, therefore, be most usefully explored in depth and prioritized in the structure of the thesis. Because this is indeed what happened, I look at the contributions of the thesis from two perspectives: firstly, with reference to the research objectives as originally articulated; and, secondly, with reference to problems and gaps in the body of archival science literature which gave shape to the thesis.

\subsubsection{Discussion of contributions with reference to the research objectives}

The research question I posed was:

What can be leant about archives domain thinking, heritage objects and their evidentiality, and the design of knowledge enabling systems by exploring how evidence emerges during a historical research process?

The objectives underpinning this question were:

- to contribute to knowledge about the nature of evidence, especially how it emerges during a historical research process;

- to contribute to understanding of how the theoretical concepts and idealised practices of the archives domain work, or could work, to facilitate the emergence of evidence;

- to contribute to understanding of how actual practices and technologies facilitate - or possibly hinder - the emergence of evidence;

- and to contribute to understanding of the fitness of archives domain concepts and terminology for cross-domain communication and the development of a discourse which cuts across the domains.

The first of these objectives has been significant throughout the research because, in addition to being of interest from a cross-domain perspective, it is also a matter of interest within archival science's body of theoretical writing. I discuss my contribution to knowledge about the nature of evidence in section 7.3 .3 below. 
The second and third objectives were explicitly addressed only in this chapter. However, foundations for the discussion in section 7.2 above were laid in my thick descriptions of evidence emergence as I experienced it during my case study. As I noted in section 7.2, the case study I chose was more useful for exploring the second objective than the third. In general, my case study experiences endorsed the descriptive methods advocated by Chris Hurley, the continuum thinker with whose work on description I engaged most deeply, although I went further in suggesting that attention needs to be given to representing place as a provenance entity and time so that it is a more searchable entity. I also went further (than Hurley) in suggesting that a broad focus on the things that play a part in shaping our perceptions and inferences may be more useful for informing the design of knowledge enabling systems than a narrower concern only with the representation and transmission of evidence.

Two dynamics were at work in the fourth objective, which was to contribute to understanding of the fitness of archives domain concepts and terminology for crossdomain communication and the development of a discourse which cuts across the domains. On the one hand, this objective was oriented towards concepts; on the other hand, it was oriented towards terminology. The remaining paragraphs of this section, in which I discuss the most important way in which my research contributed to understanding of this nature, are largely concept-focused. This is because, in the course of the research, I learnt it is a good deal easier to assess the fitness for purpose of concepts and to contribute to the development of a cohered and shared conceptual space than it is to assess the fitness for purpose of words, let alone predict what words might be most effective in future imagined scenarios. Indeed, I found that even individuals who are in conceptually similar spaces can append different connotations to a word and, therefore, react in quite different ways. Nevertheless, comments on vocabularies and audiences (informed by my reading and critical self-reflection) are included in the primarily conceptfocused discussion below.

Chapter Three played an important role in addressing this fourth objective. That chapter explored the conceptual foundations and ontological ramifications of existing formal and informal theory manifested in the body of literature with which I was most deeply engaged. My analysis of the manuals authored by the domain's most influential 
foundational thinkers exposed variable stances in relation to the research phenomena and also many epistemic inadequacies, in particular in the conceptualisation of records. I found that in both the foundational manuals and contemporary non-continuum discourse records tend to be treated as the phenomena around which the domain is cohered. Yet, agreed understandings of the nature of records have been elusive because most archivists ground their thoughts, about what does and does not belong in the category, in mental prototypes which differ from community to community. Therefore, in allowing, or not allowing, non-prototypical objects into the category, decisions can be made with reference to varying prototypical record characteristics (Yeo, 2008). If a domain's understanding of its core concept is so fuzzy that it cannot be explained in an ontologically consistent manner, it seems to me the domain has a fundamental problem which will work against effective cross-domain communication.

What I came to realise in the course of my analysis of existing theory, and have both argued and demonstrated throughout the thesis, is that continuum theory is conceptually well placed for effective cross-domain communication and collaboration. By focusing on processes of formation and by privileging the abstract over the physical, it has opened the way for diverse, but logically coherent understandings and categorisations of the same object. This means that any object can potentially be managed to simultaneously serve multiple functions. It also means that, if one of the functions that object serves is evidential, its evidentiality (or recordness) can be managed to stretch out, via space-time situated relationships, in multiple directions rather than just one.

Something many archivists do not appear to understand about continuum theory is that, despite having been generated within the archives domain, its notions of monistically diverse spacetime and of multi-polarity make it more a trans-domain, trans-disciplinary meta-theory than an archives domain theory. This is not only true for continuum theory in its entirety, but also true for the much discussed component depicted in the records continuum model. In transcending the domain and discipline from which it emerged, continuum theory could be said to be theory for a different discipline and a different profession to the one from which it emerged. Its ontological premises are different and its vision is different - in transforming 'archival thinking', it has not so much generated a new theory relevant to the old archives and records management professions, as asked the 
scholars and practitioners associated with those old professional groups to see themselves in relation to, and as part of, a possible meta-field which could be united by a common concern for the adequacy of knowledge.

In seeing continuum theory as having this broad reach, Upward (its primary theorist) has not been making hegemonic claims for his own work and words and those of his colleagues. On the contrary, he and other major continuum thinkers see the theory itself within the continuum. This makes continuum theory no different, in fundamental respects, to the recorded information about which it speaks -as the theory moves out from its point of creation, it comes into relation with increasingly diverse viewpoints and other ways of thinking, which may or may not be as logically defensible as continuum theory and which may or may not use the same language. Continuum theory, when looked at as being within the archives domain (one could say within the third dimension, given that the boundaries of the continuum dimensions are fluid) co-exists with widely spread discourses that have actively misconstrued continuum theory or passively othered it by ignoring its existence. It has struggled to be taken seriously and understood in this environment. Its efforts to demonstrate relevance by using terms already familiar to archivists (e.g., record, transaction) with the intention that they should be understood in slightly different ways to how they have customarily been understood have, to a considerable extent, 'back-fired' because the old connotations have spoken more loudly than the new theory. The fact that continuum discourse was for more than a decade largely focused on contemporary recordkeeping issues magnified the effect (see Chapter Three).

Continuum theorists' efforts to explain the new theory by using terms borrowed from philosophy, with which most in the archives domain are unfamiliar, have also been largely unsuccessful (Piggott, 2012, p. 181). The philosophical language of continuum discourse, however, may be more useful in the societal plurality (the continuum's fourth dimension) than it has (so far) been within the archives domain. It is well-suited to theory building and can be anticipated to be relatively meaningful for others addressing similar problems and working from similar philosophical foundations. I was reasonably comfortable with it, but only after I had grappled with critical realism and made the conceptual leap necessary for continuum thinking. 
Having joined a theory-building enterprise, I have complexified continuum theory by introducing concepts and terms from critical realism which I have found useful and which do not appear to have direct equivalents in continuum discourse. Those I have found most useful are epistemic privileging and the critical realist notion of a transitive dimension that is, depending on one's perspective, either inside or outside an intransitive dimension. Also, I have brought some of Latour's concepts into relation with the continuum concepts of interiority and exteriority, though I have tweaked his terminology a little. I am thinking here of entanglements of object-full objects, subject-full objects, and object-full subjects (as discussed primarily in Chapter Four). In these ways I have gone beyond simply contributing to understanding of which parts of archives domain discourse are fit for the purpose of cross-domain communication by pointing out that continuum theory has that capability; I have also contributed to the development of continuum theory by introducing new concepts. I believe these concepts to have significant explanatory power and, therefore, to be important contributions.

It is my hope that (directly or indirectly) my thesis will also help practitioners become better continuum thinkers. A PhD thesis is not the best tool for this job. Nevertheless I believe my thesis makes a useful contribution of this nature, certainly one that could be reformulated and made public in more palatable ways. It does this in four ways. Firstly, I have fore-grounded monistic diversity, multi-polarity, and Upward's concept of spacetime in my outline of continuum logic. These concepts were critically important for enabling my own 'break-through' moments in understanding continuum theory. It is reasonable to assume that my explanation of how they work together logically (section 3.3.3) and demonstrations of them at work (in Chapters Four to Six) may enable others to make the same conceptual leap. Secondly, I have shown that continuum theory allows for perspectives other than that of the manager of contemporary organisational records. In adopting the perspective of a historical researcher, I have used that licence in quite a radical way. That radicalism will, I hope, clearly demonstrate the theory's versatility. Thirdly, I have placed things that are marginalized and othered in most archives domain discourse at the centre of attention. Finally, I have been mindful of the dryness of academic language and the difficulty it presents for comprehension by those who are not accustomed to it. In the hope of countering this to some extent, I have explained 
concepts carefully (even though the explanations cannot always be simple) and used engaging story-lines from my case study to show them at work.

One last observation, before ending discussion of my fourth objective, is that I have found the terms provenance and documentary context to be problematic. Though both denote indisputably important concepts, both are also burdened with conceptual problems. A tendency to not think of documents as provenance entities is one of those problems. In Chapter Six (section 6.5) I argued that, from the point of view of a historical researcher, it may be more important for metadata to record the fact that one document is grounded in an earlier document than to record the name of the person or organisation who 'created' the later document. Another problem relating to the conceptualisation of provenance is a tendency for it to be spoken about primarily with reference to the social, the human, and the deliberate and intentional. Natural world phenomena (most significantly, geographic location) and the tools and technologies of inscription are commonly not treated as provenance entities. Looking at the situation from a critical realist perspective or in light of Latour's work, this seems unfortunate as metadata describing things that have been significant in the 'becoming' of a record, and which may need to be understood if the record's evidential affordances are to be understood, may not be captured. Reed (in Cunningham, et al., 2013) spoke about diachronic and synchronic relationships (p. 143), not about provenance and documentary context. These more open concepts seem more valuable.

\subsubsection{Discussion of contributions with reference to problems and gaps in archival science literature}

My research approached the problem of contributing to the development of epistemically adequate cross-domain discourse (as a pre-cursor for development of converged knowledge enabling systems) by critically examining, re-using, deconstructing, extending, or repurposing archives domain concepts with that objective in mind. For this reason, my thesis makes contributions to the discipline of archival science as well as to emerging cross-domain discourse.

The specific problems and gaps in archival science which became primary matters of concern for the theory-building component of my research were identified in Chapter 
Three. One of those problems was a widespread lack of understanding of continuum theory's core logic, flexibility, and explanatory power in relation to diverse matters of concern in archival science. Because I had found there were significant synergies between continuum theory and critical realism, I saw that my research (and thesis) could be directed towards the objective of addressing that problem. By grounding my research in the collecting archives and cross-domain cultural heritage space, I had created potential for communicating continuum concepts in ways that would be meaningful to a community, within the archives domain, which has largely failed to see relevance in continuum theory and has often felt marginalised in mainstream archives discourse more generally. This is one of my contributions to archival science.

In Chapter three I identified a number of specific issues within archival science theory that warranted close attention in my research. The over-arching issue I set out to address was the question of how the concept of record stands in relation to the concept of evidence. My reading had led me to the view that there is contention on this matter for three reasons. One is because the distinct nature of the continuum concept of record is not widely appreciated. Another is because the domain's discourse on the nature of evidence is unbalanced due to the fact that evidentiality has been discussed primarily from the perspective of recordkeepers concerned with the creation, capture, and management through time of contemporary records. The discovery perspective (that of the historical research and, up to a point, the archivist working with historical records) has been relatively neglected. Also, the problem of understanding evidence as a meta-concept has attracted relatively little research attention. The third reason for contention is because much of the domain's late twentieth and early twenty-first century discourse has been shaped by polarized epistemological paradigms. In particular, I noted that much of the literature disputing claims that evidentiality is central to the concept of record has (in addition to failing to engage with the continuum concept of record) juxtaposed a postmodern and subjectivist concept of record against a positivist and (traditional) creator-privileging notion of evidence.

These are the issues I addressed in Chapters Four to Six. My findings in each case are original, perhaps significant (that is for others to judge), contributions to the continuum 
community's body of theoretical writing and to archival science theory more generally. Those findings are briefly outlined in the remaining part of this section.

By closely analyzing how meaning emerges at the interface between the complexity of a subject and the complexity of the objects the subject encounters during a historical research process, I built a case for claiming objectivity and subjectivity warrant being understood in more relational and nuanced ways than the domain's traditional and 'postmodern' discourses have allowed. In building this case I made extensive use of critical realist concepts and ontologically compatible concepts borrowed from Latour's writing on actor-network theory (discussed as contributions to continuum theory in section 7.3.2 above). I also drew attention to the ontologically compatible continuum notion of interiorised exteriorities and exteriorised interiorities, which I encountered in Upward and McKemmish (2001). Because I became aware of that notion in a late reading of that article, and because my engagement with continuum literature has been limited, there may be potential for future research to develop the work I have done on this subject more fully in relation to continuum theory.

The question around which I framed my discussion of evidence was: What is evidence, where does it come from, and where does it go? This enabled me to theorise the nature of evidence by taking into account its emergence, ephemerality, persistence, and social reach. I built a case for arguing that evidence should be understood as an entity in a relationship, but that the entity itself seems to always be a relationship. I also built a case for arguing that evidential multiplicity should be understood in terms of multiple functional affordances (e.g., proof of facts, stimuli for problem perception, stimuli for hypothesis formation, providing grounds for trust, establishing relevance, and pointing to ways in which an enquiry can be begun or continued) in addition to being understood (as is usual in archival science) in terms of a record potentially being used as evidence in relation to many different topics of enquiry or being interpreted in many different ways. I also argued that Upward's spacetime thinking provides intellectual tools that make it possible to theorise evidence as a meta-concept. A significant finding was the conceptual synergy I perceived to exist between evidential relevance (which I argued to be realityoriented) and authenticity (which I argued to be relational). Another significant finding was my perception that, except in those rare cases when evidence comes to the enquirer 
ready-made, it is constructed through meaning-making processes. Both these findings have implications for descriptive practice and the design of knowledge enabling systems (discussed in section 7.2 above).

Following my discussion of the concept of evidence, I turned my attention to the concept of record. In doing this, I privileged the concept-privileging continuum notion that records are "logical entities" or "conceptual constructs". I contributed to relevant discourse by building a case for arguing that records are composites which always have a conceptual component, but which also always have a physical or digital component (and often have all three). I also argued record entities can be conceptualised as both intransitive dimension and transitive dimension entities, at different levels of granularity, and in terms of different provenancial relationships. I drew attention to the many points of commonality between this conceptualisation of records (compatible with continuum theory) and the conceptualisation of evidence I had previously developed, but noted one point of difference. That difference is that my concept of evidence was more open to relational uncertainty than is the concept of record (as I found it to be usually discussed in the body of literature with which I engaged). Of greater interest was my finding that the authenticity-privileging relationship-centric continuum concept of record corresponds with a reality-oriented notion of relevant evidence. The 'descriptive' practices advocated by continuum theorists such as Hurley and Reed, therefore, can be argued to be of fundamental importance for the emergence of knowledge in future contexts of enquiry.

This end-to-end argument is (to my knowledge) a unique and important contribution to continuum discourse and to archival science theory. It was significantly enabled by critical realist concepts and by critical realism's requirement that researchers give serious attention to competing theories relevant to their research phenomena. If not for that requirement, I may not have discovered continuum theory's explanatory power. My demonstration of critical realism's conceptual and methodological utility is, therefore, another important contribution of my research.

My engagement with critical realist literature, as with the other bodies of literature informing my research, has been partial. My discussion of archival science theory (whether traditional, contemporary, or continuum) is grounded in a certain body of 
literature examined from a certain perspective. My findings should, therefore, be regarded as provisional. They are certainly extensible; and, because encounters with new bodies of knowledge frequently cause us to revise our prior understandings, they should also be regarded as fallible. In so far as that may be the case, they should be treated as corrigible because, in the critical realist paradigm, the advancement of knowledge is viewed as an on-going joint venture. This is also the case in the continuum paradigm. As Upward (2009) pointed out "what we say and do depends upon levels of understanding of the complexities in the particular times and places in which our statements and actions are made or take place" (p. 10). Therefore, "adequacy is the best one can claim for statements within continuum theory and thinking" (Upward, 2005a, p. 88).

\subsection{THOUGHT AND PRACTICE IN THE SOCIETAL PLURALITY - INTERSECTIONS AND POTENTIAL WAYS OF BECOMING}

One good way to end a thesis arguing the case for continuum thinking is by going back to its beginnings and drawing attention to the paths that were not followed, but which still beckon. In the planning phase of my research (2009) I became aware of semantic web thinking and technological development. It was a serendipitous discovery when I was searching for literature that might give me some idea of how systems developers with museum orientations found working with archivists to be (I have never worked in a museum, so had no experience-based understanding). This led me to articles published by Martin Doerr and various of his colleagues who have been associated with the development of the CIDOC CRM (the Conceptual Reference Model created by the International Council for Museums' International Committee for Documentation). Up to that point I had been cynical of the possibility that cross-domain convergence could be achieved without significant loss of archival functionality. From working in libraries I had come to think of convergence as entailing significant compromise, at best; and, in the worst cases, forced use of systems designed for different kinds of information work. Doerr's writing opened my eyes to a quite different approach, one which saw attention to ontological and epistemological matters as essential for semantic definition, and which saw semantic definition to be essential for the successful integration of data generated in different domains. Such systems, Doerr (2003) argued, need to be "property-centric" (p. 75). This, translated into recordkeeping terms, means they need to place relationships at 
the centre of attention and they need to be precise in the semantic definition of relationship-types. Doerr envisaged convergence in terms of heterogeneity, not (in words borrowed from Upward, 2009, p. 3) the distribution of professional sameness. A heterogeneous information resource that functioned adequately for knowledge purposes, however, would not be achieved by aggregating existing domain models, but by first examining the assumptions and semantics embedded in those models in order to assess their epistemic adequacy and identify points of conceptual intersection with other models.

For a short time, after discovering Doerr's work, I began reading more widely about semantic web technologies. I wondered whether I could bring them into play in my research (which I was still planning), but decided I did not have the necessary technological competence, so set that idea aside.

Later in my research journey (early 2011) I had the opportunity to listen (from Wellington) to a series of lectures on Thingformation, which Costis Dallas (whose background is in archaeology, digital humanities, and cultural heritage, and who is one of those associated with the development of the CIDOC CRM) was giving at the University of Toronto (Dallas, 2011, March 22 - April 5). At that time, I was at a point in my research journey where I felt intellectually isolated. The ideas I had been developing, and to which I was becoming committed, seemed radical and eccentric in relation to the archives domain norms with which I was familiar (at that time my understanding of continuum theory's flexibility was relatively limited). Recognising that Dallas was in a conceptually similar space, I began to wonder whether I could integrate some of his work into my thesis. However, realising that the literature base underpinning my research was already vast and broad, and that limitations were needed if the task was to be completed, I abandoned that idea. I pulled back into my pre-defined closed-off space and tried to shut the outside out.

At least, for the most part, I focused on shutting the outside out. One small indulgence I allowed myself was joining the Semantic Web and Linked Open Data groups on LinkedIn. For several years now I have been following Kingsley Uyi Idehen, Founder and CEO at OpenLink Software, who had caught my attention because he argues the necessity of provenance data for all information on the Web. I see his arguments as external 
validation of the case continuum thinkers make that 'recordkeeping' practice is important for all information resources, not just those of a closed and traditional domain of archivists and organisational recordkeepers.

About a month ago Idehen argued the case for provenance data again. Stimulated by the impact 'fake news' has been claimed to have had on the Brexit vote and the 2016 presidential election in the USA, he wrote:

Our basic Identity problem [in Web architecture] is that we aren't identifying entities [e.g., people, places, and events] unambiguously en route to creating documents; even worse, we lack the basis for creating provenance-oriented document metadata that unveils the Who, What, Where, and When dimensions of any chunk of information (i.e., Who was Where When they wrote What).

You cannot determine "Why did they write it?" if you don't possess complementary information (metadata) regarding the Who, What, Where, and When of the writing. It simply isn't possible, and therein lies the kernel of this problem, now massively scaled up to and by the Web.

Proprietary identifiers and opaque "Black Box Algorithms" do not offer any useful magic for addressing this fundamental challenge; they simply worsen the problem, as the "Fake News" problem demonstrates. (Idehen, 2016, November 28)

Earlier this year, Dallas published in Archival Science. This was, I believe, his first publication in an archives domain journal. In this article - "Digital curation beyond the wild frontier': A pragmatic approach" - Dallas (2016) argued there is a disconnection between the normative approaches to digital curation that currently dominate the field of digital curation and the "rich historical traditions of museum curatorship where the notion of curation originated" (p. 421), and that there is also

A tension ... between a custodial paradigm of digital curation firmly rooted on the normative and instrumental knowledge of the information disciplines, and actual practice involving creators and users of digital information, with their diverse and potentially conflicting needs and priorities. (p. 435) 
Dallas called for "a formal reconceptualization of digital curation, adequate knowledge representation of its objects, evidence-based research on curation practices, and establishment of curation-enabled digital infrastructures suitable for curation in the continuum" (p. 421).

Dallas's use of the word continuum can be read as pointing to his argument that the notion of a "wild frontier" beyond which digital curation is poorly practiced is an epistemically inadequate foundation on which to build this reconceptualization. It can also be read as pointing to records continuum theory. Adequacy is variable and should be understood in relation to needs and priorities. What is needed is an approach to digital curation that privileges "the multiplicity of contexts, processes, and actors of digital curation practice, its actuality, contingency, pervasiveness, end-to-end applicability beyond the life cycle, reach beyond the custodial fold, and pragmatic and epistemic entailments" (p. 441). This way of thinking, he said, "resonates with records continuum thinking" (p. 441).

As I end my thesis, it seems that - continuum-style - things that have been separated are coming together. My research, which at first seemed strangely conceived, is far from 'wild' when seen in relation to these discourses which place primary value on the epistemic adequacy of knowledge-related practices. I can dive into the middle of the sentence quoted from Dallas (2016) in the paragraph above and point to my research as having been concerned with the "epistemic entailments" of archives domain thought and practice and to have been particularly concerned with "end-to-end applicability" of actual practice in heritage sector institutions and the practices 'imagined' by continuum thinkers. It contributes in a small way, perhaps an idiosyncratic way, to a much larger agenda - or, more aptly, a set of conceptually overlapping agendas.

Now that the 'outside' has found its way back into my thesis, I am reminded of the limitations of my research, the things intentionally and unintentionally shut out.

One absence in the end-product which was not anticipated in the planning is prototypical 'museum-type' objects. Though my case-study was chosen to allow them in, perhaps by privileging archives domain thinking and practice, I shut them out. Future research could be designed to bring such objects into sharper focus, perhaps by combining continuum- 
grounded recordkeeping thinking with the thinking that has been emerging in critical cultural heritage discourse and which underpins Dallas's thinking. Such an approach would probably both identify points of conceptual overlap and also identify silences in the respective discourses which can usefully be filled by things the other has to say.

An epistemic bias in my work is that I privileged archives domain thinking in the thought that lent shape to my historical research experience and in my writing about my case study experience. This was deliberate because the thing I was most interested in understanding was the utility of recordkeepers' and archivists' practices and of the systems in which they embed those practices for those who use those systems during historical research activity. However, as my research advanced, I became increasingly aware that seemingly mundane activities such as my own recordkeeping practice (e.g., annotation and 'filing') were playing a part in my meaning-making processes. This awareness brings to mind Schum's work on strategies for marshalling evidence. I read that part of Schum (1994) only lightly, but suspect it could be worth revisiting. Again, I would suggest a broad cross-disciplinary approach, one which takes into account work Dallas and various of his colleagues have done on scholarly research activity (Bernardou, Dallas, Constantopoulos, \& Gavrilis, 2010a, 2010b) and other relevant work which may have been conducted in the digital humanities.

An early interest which was side-lined in the execution of my thesis was personal records and personal recordkeeping. Again, I come back to Dallas. One of the discourses on which he has drawn is cultural-history activity theory. This is a still-evolving body of theory with its roots in the work of the Russian psychologists Leo S. Vygostsky, A.N. Leontiev and A.R. Luria in the 1920s and 1930s. Its chief concern is the dialectical relation between social life, individual subjectivity, and material tool production (Stetsenko \& Arievitch, 2004). Reading a little in this field and listening to a few lectures was another indulgence I have allowed myself. Setting aside the fact that this body of theory has broad applicability, I can see that it would be a particularly interesting way of approaching the issue of structure in relation to personal records and personal recordkeeping. Being grounded in psychology, it may potentially speak more directly on these matters to archivists, such as Catherine Hobbs, who have had difficulty connecting with continuum discourse. One could expect that continuum discourse itself would be enriched by the process. 
I have already drawn attention to epistemic bias in my engagement with archival science literature (sections 2.7.3, 2.7.4, and 7.4). Given the direction my research led me, I am particularly aware of having read very little about the recordkeeping metadata schema developed by continuum thinkers, and the thinking underpinning that work. These schema have been argued to be appropriate for personal recordkeeping (McKemmish, Acland, Ward, \& Reed, 1999). If this has not been empirically explored, it should be. Such exploration could be particularly interesting if it drew on the findings of the research with cultural-history activity theory, which I suggested above.

Also of interest to me is the question of whether the recordkeeping metadata schema are adequate for purposes of evidence discovery in real-life contexts of enquiry and in relation to topics of enquiry other than those recordkeepers consciously and deliberately record. I wonder whether the CIDOC CRM (positioned more in the opening-out realm of the continuum's fourth dimension) might be better equipped to handle that need. With that possibility, and the nature of the CIDOC CRM in mind, I think research that looked at the recordkeeping models in relation to the CIDOC CRM would be interesting. Could the recordkeeping models be integrated into the CIDOC CRM (bearing in mind that such integration would allow the recordkeeping models to maintain a distinct identity)? Are there ambiguities in the recordkeeping models that would be identified and addressed as part of the process? Would the recordkeeping models add richness to the CIDOC CRM and the range of concepts it makes available for the use of all? Would concepts already in the CIDOC CRM enrich recordkeeping thought and practice? I think they would. In particular, work has been done there which addresses issues Hurley has argued call for further research; namely a need to conceptualise provenance and creators more clearly, and a need to identify relationship types more thoroughly (Hurley, 2005b, 2012, 2013). In light of the indefinite divisibility of the continuum of recorded information and the fact that perceptual variations and different forms of abstraction (e.g., the minor distinctions between a text, an inscription, and the transitive dimension content they carry) account for much of that indefinite divisibility, I think there is also a need to more thoroughly identify the types of things that can be modelled as records. Previous work conducted in the context of the CIDOC CRM is likely to also be helpful for this. 
Finally, and perhaps most 'dear to my heart', I would like to see practical research focused on the development of visualization tools along the lines I suggested at the end of section 7.3. What I envisaged there were systems which apply the knowledge we already have about processes of aggregation within different types of institutions and in relation to different types of objects in order to suggest to users searches and opportunities for visual pattern detection which they might not think of themselves, but which are sometimes richly rewarding. Functionality of this type would make systems more actively knowledge enabling. 


\section{REFERENCES}

Allen, R. (1961, June 22). Letter to Clyde Taylor. In folder labelled "Butler, Frederick Burdett)" amongst unprocessed archival materials, Puke Ariki, New Plymouth.

Archer, M.S. (1998). Introduction: Realism in the social sciences. In M.S. Archer, R. Bhaskar, A. Collier, T. Lawson \& A. Norrie (Eds.), Critical realism: Essential readings (pp. 189-205). London: Routledge.

Archer, M.S. (2013). Morphogenic society: Self-government and self-organization as misleading metaphors. In M.S. Archer (Ed.), Social Morphogenesis (145-166). London: Springer.

Archer, M. S., Sharp, R., Stones, R., \& Woodiwiss, T. (1998). Critical realism and research methodology. Opening remarks at the Second Plenary, CCR Conference, Essex.

Atherton, J. (1986). From life cycle to continuum: Some thoughts on the records management-archives relationship. Archivaria, 21, 43-51. Retrieved from http://archivaria.ca/index.php/archivaria

Bacon, F. (1998-2005). On the advancement of learning. (R.S. Bear, ed.). (Original work published 1605). Retrieved from Scholars Bank, University of Oregon website: https://scholarsbank.uoregon.edu/xmlui/handle/1794/646?show=full.

Bartlett, N. (2011). The complication of color in an academic archive. In T. Cook (Ed.), Controlling the past: Documenting society and institutions: Essays in honour of Helen Willa Samuels (pp. 111-149). Chicago: Society of American Archivists.

Bearman, D. (1992). Documenting documentation. Archivaria, 34, 33-49. Retrieved from http://archivaria.ca/index.php/archivaria

Bearman, D. (1994). Electronic evidence: Strategies for managing records in contemporary organizations. Pittsburgh: Archives and Museum Informatics.

Bearman, D., \& Lytle, R. H. (1986). The power of the principle of provenance. Archivaria, 21, 14-27. Retrieved from http://archivaria.ca/index.php/archivaria 
Benton, T. (2004). Critical Realism. In Michael S. Lewis-Beck, A. Bryman, \& Tim Futing Liao (Eds.), The SAGE Encyclopedia of Social Science Research Methods. (pp. 222-224). Thousand Oaks, CA: Sage Publications, Inc. doi: 10.4135/9781412950589.n197

Benton, T. (2007). Forward. In J. Frauley \& F. Pearce (Eds.), Critical realism and the social sciences: Heterodox elaborations. Toronto, Buffalo, \& London: University of Toronto Press.

Bernardou, A., Dallas, C., Constantopoulos, P., \& Gavrilis, D. (2010a). A conceptual model for scholarly research activity. Retrieved from IDEALS: Illinois Digital Environment for Access to Learning and Scholarship website: https://www.ideals.illinois.edu/bitstream/handle/2142/14945/benardou.pdf?seq uence $=2$

Benardou, A., Constantopoulos, P., Dallas, C., \& Gavrilis, D. (2010b). Understanding the information requirements of arts and humanities scholarship. The International Journal of Digital Curation, 5(1), 18-33. doi:10.2218/ijdc.v5i1.141

Berners-Lee, T. (2009). The next web. Retrieved from TED website: http://www.ted.com/talks/tim_berners_lee_on_the_next_web

Bhaskar, R. (1998a). General introduction. In M. Archer, R. Bhaskar, A. Collier, T. Lawson \& A. Norrie (Eds.), Critical realism: Essential readings (pp. ix-xxiv). London and New York: Routledge.

Bhaskar, R. (1998b). The possibility of naturalism: A philosophical critique of the contemporary human sciences (3rd ed.). London \& New York: Routledge.

Bhaskar, R. (2013). The consequences of the revindication of philosophical ontology for philosophy and social theory. In M. Archer, \& A. Maccarini (Eds.), Engaging with the world: agency, institutions, historical formations. (pp. 11-21). (Ontological explorations). London: Routledge.

Bilalić, M., \& McLeod, P. (2014). Why good thoughts block better ones. Scientific American, 310(3), 58-63. 
Blok, A., \& Jensen, T. E. (2011). Bruno Latour: Hybrid thoughts in a hybrid world. London: Routledge.

Book row: Collection on the move (1978, July 11). [Clipping from Truth]. In ARC 20021031. Puke Ariki, New Plymouth.

Brothman, B. (1991). Orders of value: Probing the theoretical terms of archival practice. Archivaria, 32, 78-100. Retrieved from http://archivaria.ca/index.php/archivaria

Brothman, B. (1993). The limit of limits: Derridean deconstruction and the archival institution. Archivaria, 36, 205-220. Retrieved from http://archivaria.ca/index.php/archivaria

Brothman, B. (2002). Afterglow: Conceptions of record and evidence in archival discourse. Archival Science, 2, 311-342. doi:10.1007/BF02435627

Brubaker, R.L. (1966). Archival principles and the curator of manuscripts. American Archivist, 29(4), 505-514. doi:10.17723/aarc.29.4.8538576776w21r71

Bunn, J. (2011). Multiple narratives, multiple views: Observing archival description. (PhD), University College London, London.

Burton, F., \& Burton, S. (2007, July 26). Interview by Diana Gibbons [Sound recording]. (ARC 2007-117). Puke Ariki, New Plymouth.

Butler collection, (n.d.). Retrieved from Archaeopedia New Zealand website: http://archaeopedia.com/wiki/index.php?title=Butler_Collection

Butler, F. B. (1942). Early Days Taranaki. New Plymouth: Author.

Butler, F.B. (1958, April 21). Statement by F.B. Butler, witnessed by A.L. Low and A.M. Nicholson, regarding purported loan of photographic plate negatives to the Alexander Turnbull Library in 1947. In ARC 2002-1031, Puke Ariki, New Plymouth.

Carlsson, S. (2009). Critical realist information systems research. Encyclopedia of Information Science and Technology (2nd ed., pp. 811-817). doi:10.4018/978-160566-026-4.ch132 
Chandler, J., Davidson, A. I., \& Johns, A. (2004). Arts of transmission: An introduction. Critical Inquiry, 31(1), 1-6. Retrieved from http://criticalinquiry.uchicago.edu/

City Council buys historical items. (1970, February 5). [Clipping from Taranaki Daily News]. In unprocessed archival material, Puke Ariki, New Plymouth.

City gains a treasure: Tauranga Museum's priceless collection. (1977, May 28). Bay of Plenty Times. p. 7.

Collier, A. (1994). Critical realism: An introduction to Roy Bhaskar's philosophy. London \& New York: Verso.

Collins, S. G. (2009). Library of walls: The Library of Congress and the contradictions of information society. Duluth, Minnesota: Litwin Books.

Cook, T. (1994). Electronic records, paper minds: The revolution in information management and archives in the post-custodial and post-modernist era. Archives and Manuscripts, 22, 300-328.

Cook, T. (1997). What is past is prologue: A history of archival ideas since 1898 and the future paradigm shift. Archivaria, 43, 17-63. Retrieved from http://archivaria.ca/index.php/archivaria

Cook, T. (2001a). Archival science and postmodernism: New formulations for old concepts. Archival Science, 1, 3-24. doi:10.1007/BF02435636

Cook, T. (2001b). Fashionable nonsense or professional rebirth: Postmodernism and the practice of archives. Archivaria, 51, 14-35. Retrieved from http://archivaria.ca/index.php/archivaria

Cook, T. (2011). The archive(s) is a foreign country: Historians, archivists, and the changing archival landscape. American Archivist, 74(2), 600-632. doi:10.17723/aarc.74.2.xm04573740262424

Cunningham, A. (2005). Archival institutions. In S. McKemmish, M. Piggott, B. Reed \& F. Upward (Eds.), Archives: Recordkeeping in society (pp. 21-50). Wagga Wagga: Charles Sturt University, Centre for Information Studies. 
Cunningham, A., L. Miller, \& B. Reed (2013). Peter J. Scott and the Australian 'series' system: Its origins, features, rationale, impact, and continuing relevance. Comma: International Journal on Archives, 2013(1), 121-144.

Dalgleish, T., Dunn, B., D., \& Mobbs, D. (2009). Affective neuroscience: Past, present, and future. Emotion Review, 1(4), 355-368. doi:10.1177/1754073909338307

Dallas, C. (2011, March 22 - April 5). Thingformation: Informing thing cultures, curating digital heritage. Spring lecture series, Digital Curation Institute, University of Toronto. Retrieved from University of Toronto website: http://current.ischool.utoronto.ca/events/2011/thingformation-informing-thingcultures-curating-digital-heritage-3

Dallas, C. (2016). Digital curation beyond the 'wild frontier': A pragmatic approach. Archival Science, 16, 421-457. doi:10.1007/s10502-015-9252-6

Danskin, A. (2009). Statement of objectives and principles for RDA. Joint Committee for the Development of RDA. Retrieved from http://www.rda-jsc.org/docs/5rdaobjectivesrev3.pdf.

Day, R. E. (2004). The erasure and construction of history for the information age: Positivism and its critics. In L. Rabinovitz \& A. Geil (Eds.), Memory bytes: History, technology, and digital culture (pp. 76-76). Durham and London: Duke University Press.

Day, R. E. (2008). Works and representation. Journal of the American Society for Information Science and Technology, 59(10), 1644-1652. doi:10.1002/asi.20875

Denard, H. (2012). A new introduction to the London Charter. In Bentkowska-Kafel, Denard, \& Baker (Eds.), Paradata and transparency in virtual heritage (pp. 57-72). Farnham, Surrey: Ashgate.

Derrida, J., \& Prenowitz, E. (1995). Archive Fever: A Freudian Impression. Diacritics, 25(2), 9-63. doi:10.2307/465144 
Dingwall, G. (2010). Life cycle and continuum: A view of recordkeeping models for the postwar era. In T. Eastwood \& H. MacNeil (Eds.), Currents of archival thinking (pp. 139-161). Santa Barbara, California: Libraries Unlimited.

Dobson, P. J. (2002). Critical realism and information systems research: Why bother with philosophy? Information Research, 7(2). Retrieved from http://informationr.net/ir/7-2/paper124.html.

Dobson, P. J., Myles, J., \& Jackson, P. (2007). Making the case for critical realism: Examining the implementation of automated performance management systems. Information Resources Management Journal, 20(2), 138-152. Retrieved from http://www.igi-global.com/journal/information-resources-management-journal$\mathrm{irmj} / 1073$

Doerr, M. (2003). The CIDOC CRM: An ontological approach to semantic interoperability of metadata. Al [Artificial Intelligence] Magazine, 24(3). Retrieved from http://www.aaai.org/Magazine/magazine.php

Duchein, M. (1983). Theoretical principles and practical problems of respect des fonds in archival science. Archivaria, 16, 64-82. Retrieved from http://archivaria.ca/index.php/archivaria

Duff, W. (2010). Archival mediation. In T. Eastwood \& H. MacNeil (Eds.), Currents of Archival Thinking (pp. 115-136). Santa Barbara, Denver, Oxford: Libraries Unlimited.

Duff, W., \& Harris, V. (2002). Stories and names: Archival description as narrating records and constructing meanings. Archival Science, 2(3-4), 263-285. doi:10.1007/BF02435625

Duff, W., \& Johnson, C.A. (2003). Where is the list with all the names? Informationseeking behaviour of genealogists. American Archivist, 66(1), 79-95. doi:10.17723/aarc.66.1.1375uj047224737n 
Duff, W., Monks-Leeson, E., \& Galey, A. (2012). Contexts built and found: A pilot study on the process of archival meaning-making. Archival Science, 12(1), 69-92. doi:10.1007/s10502-011-9145-2

Duranti, L. (1993). Origin and development of the concept of archival description. Archivaria, 35, 47-54. Retrieved from http://archivaria.ca/index.php/archivaria

Duranti, L. (2002). The concept of electronic record. In L. Duranti, T. Eastwood \& H. MacNeil (Eds.), Preservation of the integrity of electronic records (pp. 9-22). Dordrecht: Kluwer Academic Publishers.

Eastwood, T. (2010). A contested realm: The nature of archives and the orientation of archival science. In T. Eastwood \& H. MacNeil (Eds.), Currents of archival thinking (pp. 3-21). Santa Barbara, California: Libraries Unlimited.

Eisenhardt, K. M. (1989). Building theories from case study research. The Academy of Management Review. 14(4), 532-550. doi:10.5465/AMR.1989.4308385

Elder-Vass, D. (2007). Re-examining Bhaskar's three ontological domains: The lessons from emergence. In C. Lawson, J. Latsis \& N. Martins (Eds.), Contributions to social ontology (pp. 160-176). London and New York: Routledge.

Elder-Vass, D. (2010). [Review of the book Critical realism and the social sciences, Frauley \& Pearce (Eds.)], British Journal of Sociology, 61(1), 200-202. doi:10.1111/j.14684446.2009.01308_4.x

Elger, T. (2010). Critical Realism. In Albert J. Mills, G. Durepos, \& E. Wiebe (Eds.), Encyclopedia of Case Study Research. (pp. 254-258). Thousand Oaks, CA: SAGE Publications, Inc. doi:10.4135/9781412957397.n95

Evans, J., McKemmish, S., \& Reed, B. (2009). Archival arrangement and description Encyclopedia of Library and Information Sciences (Third ed., pp. 130-140). New York: Taylor \& Francis. doi:10.1081/E-ELIS3-120043720 
Fairclough, N., Jessop, B., \& Sayer, A. (2004). Critical realism and semiosis. In J. Joseph \& J. M. Roberts (Eds.), Realism discourse and deconstruction. (pp. 23-42). London and New York: Routledge.

Findlen, P. (1997). Francis Bacon and the reform of natural history in the seventeenth century. In D. R. Kelley (Ed.), History and the disciplines: The reclassification of knowledge in early modern Europe. (pp. 239-260). Rochester, New York: The University of Rochester Press.

Fisher, R. (2009). In search of a theory of private archives: The foundational writings of Jenkinson and Schellenberg revisited. Archivaria, 67, 1-24. Retrieved from http://archivaria.ca/index.php/archivaria

Fox, S. (2009). Applying critical realism to information and communication technologies: A case study. Construction Management and Economics, 27(5), 465-472. doi:10.1080/01446190902842292

Fritzsche, P. (2005). The archive and the case of the German nation. In A. Burton (Ed.), Archive stories: Facts, fictions, and the writing of history (pp. 184-208). Durham \& London: Duke University Press.

Furner, J. (2004). Conceptual analysis: A method for understanding information as evidence, and evidence as information. Archival Science, 4(3-4), 233-265. doi:10.1007/s10502-005-2594-8

Gee, J. P. (2005). An introduction to discourse analysis: Theory and method. (2nd ed.). London \& New York: Routledge.

Giddens, A. (2005). The constitution of society: Outline of the theory of structuration: Elements of the theory of structuration. In G. M. Spiegel (Ed.), Practicing History: New Directions in Historical Writing after the Linguistic Turn (pp. 121-142). New York \& London: Routledge.

Gilbert, C. D., \& Wu, L. (2013). Top-down influences on visual processing. Nature Reviews: Neuroscience, 14(May), 350-363. doi:10.1038/nrn3476 
Gilliland, A.J., \& McKemmish, S. (2004). Building an infrastructure for archival research. Archival Science, 4(3-4), 149-197. doi:10.1007/s10502-006-6742-6

Gilliland-Swetland, A. J. (2000). Archival research: A "new" issue for graduate education. American Archivist, 63(2), 258-270. doi:10.17723/aarc.63.2.6226636045t48543

Ginzburg, C. (2013). Our words, and theirs: A reflection on the historian's craft today. Cromohs: Cyber review of modern historiography, 18, 97-114. Retrieved from http://www.fupress.net/index.php/cromohs/article/view/14122

Greengrass, M., \& Hughes, L. (Eds.). (2008). Virtual representation of the past. London: Ashgate Publishing Limited.

Groff, R. (2004). Critical realism, post-positivism and the possibility of knowledge. London: Routledge.

Hand, M. (2008). Making digital cultures: Access, interactivity, and authenticity. Aldershot: Ashgate Publishing Limited.

Hardiman, R. (2009). En mal d'archive: Postmodernist theory and recordkeeping. Journal of the Society of Archivists, 30(1), 27-44. doi:10.1080/00379810903264591

Harris, V. (1997). Claiming less, delivering more: A critique of positivist formulations on archives in South Africa. Archivaria, 44, 132-141. Retrieved from http://archivaria.ca/index.php/archivaria

Harris, V. (2001a). Law, evidence and electronic records: A strategic perspective from the global periphery. Comma: International journal on archives, 1(2), 29-43.

Harris, V. (2001b). On the back of the tiger: Deconstructive possibilities in "Evidence of me". Archives and Manuscripts, 29(1), 8-21.

Hayles, N. K. (1999). How we became posthuman. Chicago: University of Chicago Press.

Hayles, N. K. (2012). How we think: Digital media and contemporary technogenisis. Chicago: The University of Chicago Press. 
Henry, L. J. (1998). Schellenberg in cyberspace. American Archivist, 61(2), 309-327. doi:10.17723/aarc.61.2.f493110467x38701

Historic material lost. (1970, January 17). The Daily News. In "History - Taranaki", Research Centre, New Plymouth.

Hobbs, C. (2010). Reenvisioning the personal: Reframing traces of individual life. In T. Eastwood \& H. MacNeil (Eds.), Currents of archival thinking (pp. 313-241). Santa Barbara, California; Denver, Colorado; Oxford, England: Libraries Unlimited.

Horsman, P. (1999). The last dance of the phoenix, or the de-discovery of the archival fonds. Archivaria, 48, 1-23. Retrieved from http://archivaria.ca/index.php/archivaria

Horsman, P., Ketelaar, E., \& Thomassen, T. (2003). Introduction to the 2003 reissue $A$ manual of archive administration (2nd ed., pp. v-xxxiii). Chicago: Society of American Archivists. (Reprinted from: 1968).

Hoskin, S. (2004). Fred Butler: Eccentric man of mystery. Retrieved from the Puke Ariki website: http://pukeariki.com/Learning-Research/Taranaki-ResearchCentre/Taranaki-Stories/Taranaki-Story/id/432/title/fred-butler-eccentric-man-ofmystery

Hurley, C. (1994). The Australian ('series')system: An exposition. In S. McKemmish \& M. Piggott (Eds.), The records continuum: Ian McLean and Australian Archives first fifty years (pp. 150-172). Clayton, Australia: Ancora Press in association with Australian Archives.

Hurley, C. (1995a). Ambient functions: Abandoned children to zoos. Archivaria, 40. Retrieved from http://archivaria.ca/index.php/archivaria

Hurley, C. (1995b). Problems with provenance. Archives and Manuscripts, 23(2), 234-259.

Hurley, C. (1998). The making and keeping of records: (1) What are finding aids for? Archives and Manuscripts, 26(1), 58-77. 
Hurley, C. (2005a). Parallel provenance: Part 1: What, if anything, is archival description? Archives and Manuscripts, 33(1), 110-145.

Hurley, C. (2005b). Parallel provenance: Part 2: When something is not related to everything else. Archives and Manuscripts, 33(2), 52-91.

Hurley, C. (2008). What, if anything, is the Australian ('series') system? Retrieved from Chris Hurley's Stuff website: http://www.descriptionguy.com/description.html

Hurley, C. (2012). Some things archivists do... Description and arrangement. Paper presented at Pre-Congress Workshop on Description at ICA Congress, Brisbane, August 2012. Retrieved from Chris Hurley's Stuff website: http://www.descriptionguy.com/images/WEBSITE/some-things-archivists-doarrangement\&description.pdf

Hurley, C. (2013). In pursuit of provenance: When societal met parallel with a view to relationships. Paper given at an Australian Society of Archivists' symposium on societal provenance, Adelaide 21 June 2013. Retrieved from Chris Hurley's Stuff website: http://www.descriptionguy.com/images/WEBSITE/What-is-PP.pdf

Idehen, K. I. (2016, November 28). The 'fake news' meme. Retrieved from Linkedin website: $\quad$ https://www.linkedin.com/pulse/fake-news-meme-kingsley-uyiidehen?trk=mp-reader-card

International Council on Archives (1994). ISAD(G): General international standard archival description, 1st Edition. Ottawa. Retrieved from http://web.mclink.it/MD1431/sito/isaargrp/isad\%28g\%29e.html\#0

International Organization for Standardization (2001). ISO 15489:2001 - Information and Documentation - Records Management - Part 1: General, ISO, Geneva.

International Organization for Standardization (2007). ISO 23081:2007 - Information and Documentation - Records Management Processes - Metadata for Records - Part 2: Conceptual and Implementation Issues, ISO, Geneva. 
International Organization for Standardization (2016). ISO 15489:2016 - Information and Documentation - Records Management - Part 1: Concepts and Principles, ISO, Geneva.

Jenkinson, H. (1922). A manual of archive administration including the problems of war archives and archive making. Oxford: Clarendon Press.

Jimerson, R.C. (2002). The nature of archives and manuscripts, OCLC Systems \& Services: International digital library perspectives, 18(1), 21-23. doi:10.1108/10650750210424788

Jimerson, R.C. (2011). How archivists 'control the past'. In T. Cook (Ed.), Controlling the past: Documenting societies and institutions: Essays in honor of Helen Willa Samuels (pp. 363-379). Chicago: Society of American Archivists.

Johnson, C. A., \& Duff, W. M. (2005). Chatting up the archivist: Social capital and the archival researcher. American Archivist, 68(1), 113-129. doi:10.17723/aarc.68.1.h1/2r87kl1846417

Jones, H.G. (2003). Introduction to the 2003 reissue. In T.R. Schellenberg, Modern archives: Principles and techniques (xi-xiii). Chicago: Society of American Archivists. (Original work published 1956).

Jones, M. (2004). Critical realism, critical discourse analysis, concrete research. In J. Joseph \& J. M. Roberts (Eds.), Realism discourse and deconstruction (pp. 43-67). London \& New York: Routledge.

Joseph, J., \& Roberts, J. M. (Eds.). (2004). Realism discourse and deconstruction. London \& New York: Routledge.

Kaplan, E. (2002). 'Many paths to partial truths': Archives, anthropology, and the power of representation'. Archival Science, 2(3-4), 209-220. doi:10.1007/BF02435622

Ketelaar, E. (2001). Tacit narratives. Archival Science, 1(2), 131-141. doi:10.1007/BF02435644 
Koponen, E. (2008). The development, implementation and use of e-learning: critical realism and design science perspectives. (PhD), University of Tampere, Finland. Retrieved from http://acta.uta/fi/pdf/978-951-44-7590-0.pdf.

King, A. (2010). The odd couple: Margaret Archer, Anthony Giddens and British social theory. The British Journal of Sociology, 61(s1), 253-260. doi:10.1111/j.14684446.2009.01288.x

Kirschenbaum, M. G., Farr, E. L., Kraus, K. M., Nelson, N., Peters, C. S., Redwine, G., \& Reside, D. (2009). Digital materiality: Preserving access to computers as complete environments.

Latour, B. (1996). On actor-network theory: A few clarifications. Soziale Welt, 47(4), 369381. Retrieved from http://www.jstor.org.helicon.vuw.ac.nz/stable/40878163

Latour, B. (2004). Why has critique run out of steam? From matters of fact to matters of concern. Critical Inquiry, 30(2), 225-248. Retrieved from http://criticalinquiry.uchicago.edu/

Latour, B. (2005). Reassembling the social: An introduction to actor-network-theory. Oxford: Oxford University Press.

Latour, B., \& Sánchez-Criado, T. (2007). Making the 'Res Public'. Ephemera: Theory and Politics in Organization, 7(2), 364-371. Retrieved from http://www.ephemerajournal.org/sites/default/files/7-2latour-sanchez-criado.pdf

Lawson, T. (1998). Economic science without experimentation / Abstraction. In M. Archer, R. Bhaskar, A. Collier, T. Lawson \& A. Norrie (Eds.), Critical Realism: Essential Readings. (pp. 144-186). London and New York: Routledge.

Le Boeuf, P. (2005). Is it possible to organise all information? Library viewpoint. Paper presented at the Bibliotheca Universalis: How to Organise Chaos? Satellite Meeting to the 71st World Library and Information Congress, Jarvenpaa, Finland. Retrieved from: http://www.fla.fi/frbr05/2005_Jarvenpaa_LeBoeufw.pdf 
Light, M. (2008). The endangerment of trees. Paper presented at the EAD@10 Symposium, San Francisco. Retrieved from https://www.archivists.org/publications/proceedings/EAD@10/Light-EAD@10.pdf

Lytle, R.H. (1980a). Intellectual access to archives: I. Report of an experiment comparing provenance and content indexing methods of subject retrieval. American Archivist, 43(1), 64-75. doi:10.17723/aarc.43.1.31031523737j16n7

Lytle, R.H. (1980b). Intellectual access to archives: II. Report of an experiment comparing provenance and content indexing methods of subject retrieval. American Archivist, 43(2), 191-207. doi:10.17723/aarc.43.2.c4777576733114rp

Maclean, I. (1959). Australian experience in record and archive management. American Archivist, 22(4), 387-418. doi:10.17723/aarc.22.4.cu4242717578022t

MacNeil, H. (2008). Archivalterity: Rethinking original order. Archivaria, 66, 1-24. Retrieved from http://archivaria.ca/index.php/archivaria

MacNeil, H. (2009). Trusting description: Authenticity, accountability, and archival description standards. Journal of Archival Organization, 7, 89-107. doi:10.1080/15332740903117693

Manoff, M. (2006). The materiality of digital collections: Theoretical and historical perspectives. Libraries and the Academy, 6(3), 311-325. doi:10.1353/pla.2006.0042

McGann, J. (2001). Visible and invisible books in n-dimensional space. Radiant Textuality. Literature after the world wide web (pp. 167-191). London \& New York: Palgrave Macmillan.

Mclntyre, M. E. (1999). Lucidity, science, and the arts: What we can learn from the way perception works. Paper presented at the Fourth Symposium on Human Development, Kobe, Japan. http://www.atm.damtp.cam.ac.uk/people/mem/kobe-lecture.pdf 
McIntyre, M. E. (2007). On thinking probabilstically. Paper presented at the "Aha Huliko": A Workshop on Extreme Events., University of Hawaii.

McKemmish, S. (1994). Are records ever actual? In S. McKemmish \& M. Piggott (Eds.), The records continuum: Ian McLean and Australian Archives first fifty years (pp. 187203). Clayton, Australia: Ancora Press in association with Australian Archives.

McKemmish, S. (1996). Evidence of me .... Archives and Manuscripts, 24(1), 28-45.

McKemmish, S. (December 4, 2000). Cook and Harris on the continuum. Retrieved from Aus-archivists discussion list: http://www.asap.unimelb.edu.au/asa//ausarchivists/msg00484.html

McKemmish, S., Acland, G., Ward, N., \& Reed, B. (1999). Describing records in context in the continuum: The Australian recordkeeping metadata schema. Archivaria, 48, 337. Retrieved from http://archivaria.ca/index.php/archivaria

McKemmish, S., \& Gilliland, A. (2013). Archival and recordkeeping research: Past, present and future. In K. Williamson \& G. Johanson (Eds.), Research methods: Information systems, and context (pp. 79-112). Prahram, Vic.: Tilde Publishing.

McKemmish, S., \& Piggott, M. (2013). Toward the archival multiverse: Challenging the binary opposition of the personal and corporate archive in modern archival theory and practice. Archivaria (76), 111-144. Retrieved from http://archivaria.ca/index.php/archivaria

McKemmish, S., Piggott, M., Reed, B., \& Upward, F. (Eds.). (2005). Archives: Recordkeeping in society. Wagga Wagga, New South Wales: Centre for Information Studies, Charles Sturt University.

McKemmish, S., Upward, F., \& Reed, B. (2009). Records continuum model. Encylopedia of Library and Information Sciences (Third ed., pp. 4447-4459). New York: Taylor and Francis. doi:10.1081/E-ELIS3-120043719

Meehan, J. (2006). Towards an archival concept of evidence. Archivaria, 61, 127-146. Retrieved from http://archivaria.ca/index.php/archivaria 
Milligan, J. S. (2005). "What is an Archive?" in the history of modern France. In A. Burton (Ed.), Archive stories: Facts, fictions, and the writing of history (pp. 159-183). Durham and London: Duke University Press.

Mingers, J. (2002). Real-izing information systems: Critical realism as an underpinning philosophy for information systems. In ICIS 2002 Proceedings (pp. 295-303). Retrieved from the Association for Information Systems Electronic Library (AISeL) website:

http://aisel.aisnet.org/cgi/viewcontent.cgi?article=1119\&context=icis2002

Mingers, J. (2004). Critical realism and information systems: Brief responses to Monod and Klein. Information and Organization, 14, 145-153. doi:10.1016/j.infoandorg.2004.02.003

Mingers, J., Mutch, A., \& Willcocks, L. (2013). Critical realism in information systems research. MIS Quarterly, 37(3), 795-802. Retrieved from http://www.misq.org/

Moore, L. J. (2008). Restoring order: The École de Chartes and the organization of archives and libraries in France, 1820-1870. Duluth, Minnesota: Litwin Books.

Morgan, J., \& Olsen, W. (2007). Defining objectivity in realist terms: Objectivity as a second-order 'bridging' concept. Part one: Valuing objectivity. Journal of Critical Realism, 6(2), 250-266. doi: 10.1558/jocr.v6i2.250

Morgan, J., \& Olsen, W. (2008). Defining objectivity in realist terms: Objectivity as a second-order 'bridging' concept. Part two: Bridging to praxis. Journal of Critical Realism, 7(1), 107-132. doi:10.1558/jocr.v7i1.107

Muller, S., Feith, J. A., \& Fruin, R. (1940). Manual for the arrangement and description of archives (A. H. Leavitt, Trans. 2nd ed.). New York: The H.W. Wilson Company.

Murtomaa, E. (2000). Could this be the beginning of a beautiful friendship: A comparison of the description and access to the object of interest between the libraries and archives. Paper presented at the 66th IFLA Council and General Conference, Jerusalem, Israel. Retrieved from http://archive.ifla.org/IV/ifla66/papers/125164e.htm. 
Nellhaus, T. (2004). From embodiment to agency. Journal of Critical Realism, 3(1), 103132. doi: $10.1558 / j c r . v 3 i 1.103$

Nelson Mandela Foundation. (2005). A prisoner in the garden: Opening Nelson Mandela's prison archive. Camberwell, Vic.: Viking.

Nesmith, T. (2002). Seeing archives: Postmodernism and the changing intellectual place of archives. The American Archivist, 65(1), pp. 24-41. doi:10.17723/aarc.65.1.rr48450509r0712u

Nesmith, T. (2005). Reopening archives: Bringing new contextualisation into archival theory. Archivaria, 60, 259-274. Retrieved from http://archivaria.ca/index.php/archivaria

New Plymouth City Council Finance Committee. (1970, January 19). Minutes. In unprocessed archival material, Puke Ariki, New Plymouth.

Oliver, G. (2010). Transcending silos, developing synergies: Libraries and archives. Information Research, 15(4). Retrieved from: http://InformationR.net/ir/154/colis716.html

Oliver, G. (2014). International records management standards: The challenges of achieving consensus. Records Management Journal, 24(1), 22-31. doi:10.1108/RMJ-01-2014-0002

Prove. (2007, September). In Oxford English Dictionary Online ( $3^{\text {rd }}$ ed.).

Pederson, A. (Ed.). (1987). Keeping Archives. Sydney: Australian Society of Archives Inc.

Piggott, M. (2012). Archives and societal provenance: Australian essays. Oxford: Chandos Publishing.

Pound, F. (2006). The reflecting archive. Retrieved February 24, 2011, from Ann Shelton website: http://www.annshelton.com/texts-and-media/a-library-to-scale/thereflecting-archive/

Quiroga, R. Q., Fried, I., \& Koch, C. (2013). Brain Cells for Grandmother. Scientific American, 308(2), 24-29. 
Rabinovitz, L., \& Geil, A. (Eds.). (2004). Memory bytes: History, technology, and digital culture. Durham, NC: Duke University Press.

Reed, B. (2000, December 4). On Theory and Strategy [Posting to Aus-archivists listserv]. Retrieved from http://www.asap.unimelb.edu.au/asa//ausarchivists/msg00485.html

Reed, B. (2005). Beyond perceived boundaries: Imagining the potential of pluralised recordkeeping. Archives and Manuscripts, 33(1), 176-198.

Reed, B. (2015, July 10). Navigating the shoals of ISO standards. Retrieved from Image and Data Manager (IDM) website: https://idm.net.au/article/0010536-

Rekrut, A. (2005). Material literacy: Reading records as material culture. Archivaria, 60, 11-37. Retrieved from http://archivaria.ca/index.php/archivaria

Robinson, D. (2014). In bed with an elephant: Some experiences in cross-sectoral training initiatives, 1991-2004. Archives and Records: The Journal of the Archives and Records Association, 35(1), 13-27. doi:10.1080/23257962.2013.853173

Robinson, E. (2010). Touching the void: Affective history and the impossible. Rethinking History, 14(4), 503-520. doi:10.1080/13642529.2010.515806

Rolan, G. (2015). Towards archive 2.0: Issues in archival systems interoperability. Archives and Manuscripts, 43(1), 42-60. doi:10.1080/01576895.2014.959535.

Sargent, L. T. (2012). Herbert Sutcliffe and Radiant Living: Self-help and new thought in New Zealand. Utopian Studies, 23(1), 2-27. doi:10.5325/utopianstudies.23.1.0002

Sassoon, J. (1998). Photographic meaning in the age of digital reproduction. LASIE: Library Automated Systems Information Exchange, 29(4), 5-15.

Sassoon, J. (2007a). Beyond chip monks and paper tigers: Towards a new culture of archival format specialists. Archival Science, 7(2), 133-145. doi:10.1007/s10502007-9045-7

Sassoon, J. (2007b). Sharing our story: An archaeology of archival thought. Archives and Manuscripts, 35(2), 40-54. 
Sayer, A. (1998). Abstraction: A realist interpretation. In M. Archer, R. Bhaskar, A. Collier, T. Lawson \& A. Norrie (Eds.), Critical Realism: Essential Readings. (pp. 120-143). London and New York: Routledge.

Sayer, A. (2000). Realism and social science. London: SAGE Publications.

Scanlan, A. B. (1961). Egmont: The story of a mountain. Wellington: A.H. \& A.W. Reed.

Schellenberg, T. R. (1956). Modern archives: Principles and techniques. Chicago: University of Chicago Press.

Schellenberg, T. R. (1965). The management of archives. New York: Columbia University Press.

Schum, D. A. (1994). The evidential foundations of probabilistic reasoning. New York: John Wiley \& Sons, Inc.

Schwartz, J. M. (2000). "Records of simple truth and precision": Photography, archives, and the illusion of control. Archivaria, 50, 1-40. Retrieved from http://archivaria.ca/index.php/archivaria

Schwartz, J. M. (2002). Coming to terms with photographs: Descriptive standards, linguistic "othering," and the margins of archivy. Archivaria, 54, 142-171. Retrieved from http://archivaria.ca/index.php/archivaria

Scott, P. J. (1966). The record group concept: A case for abandonment. American Archivist, 29(4), 493-504. doi:10.17723/aarc.29.4.y886054240174401

Sewell, W. H. J. (2005). The concept(s) of culture. In G. M. Spiegel (Ed.), Practicing history: New directions in historical writing after the linguistic turn. (pp. 76-95). New York \& London: Routledge.

Shaw, P. (2006, September 15). Interview by B. Howard [Sound recording]. (ARC 2006116). Puke Ariki, New Plymouth.

Shelton, A. (n.d.). A library to scale: Part 1. Retrieved from Ann Shelton website: http://www.annshelton.com/works/a-library-to-scale-part-1/ 
Shipherd, A.L. (1970, January 16). Letter to His Worship the Mayor, New Plymouth. In unprocessed Butler archival materials, Puke Ariki, New Plymouth.

Shipherd, A.L. (1970, January 21). Letter to His Worship the Mayor, New Plymouth. In unprocessed Butler archival materials, Puke Ariki, New Plymouth.

Shipherd, A.L. (1970, October 2). Letter to General Manager, Taranaki Savings Bank. In unprocessed Butler archival materials, Puke Ariki, New Plymouth.

Shipherd, A.L. (1970, October 14). Letter to General Manager, Taranaki Savings Bank. In unprocessed Butler archival materials, Puke Ariki, New Plymouth.

Shipherd, A.L. (1970, October 23). Letter to The Librarian, Hocken Library. In unprocessed Butler archival materials, Puke Ariki, New Plymouth.

Shipherd, A.L. (2000, February 2). Interview by Mary Donald [Sound recording]. (ARC 2007-51, Tape 12). Puke Ariki, New Plymouth.

Smail, D. L. (2008). On deep history and the brain. Berkeley and Los Angeles: University of California Press.

Smiraglia, R. P. (2001). The nature of "a work": Implications for the organization of knowledge. Lanham, Maryland \& London: The Scarecrow Press, Inc.

Smith, M. L. (2006). Overcoming theory-practice inconsistencies: Critical realism and information systems research. Information and Organization, 16, 191-211. doi:10.1016/j.infoandorg.2005.10.003

Sold outside Taranaki. (1970, January 17), Taranaki Herald. In "History - Taranaki", Research Centre, Puke Ariki, New Plymouth.

Stace, H. (n.d.-a). School of Radiant Living. New Zealand History Online. Retrieved September 23, 2013, from http://www.nzhistory.net.nz/culture/radiant-living

Stace, H. (n.d.-b). Sutcliffe, Herbert. Te Ara: The Encyclopedia of New Zealand. Retrieved September 23, 2013, from http://www.teara.govt.nz/en/biographies/5s55/sutcliffe-herbert 
Stetsenko, A., \& Arievitch, I. M. (2004). The self in cultural-historical activity theory. Theory \& Psychology, 14(4), 475-503. doi:10.1177/0959354304044921

Suarez, Michael F. (2003-4). Historiographical problems and possibilities in book history and national histories of the book. Studies in Bibliography, 56, 140-170. doi:http://dx.doi.org/10.1353/sib.2007.0002

Taranaki history goes to Tauranga. (1977, March 31). [Clipping from Taranaki Herald]. In ARC 2002-1031. Puke Ariki, New Plymouth.

Taylor, C.R.H. (1961, June 20). Letter to Rigby Allen. In folder labelled "Butler, Frederick Burdett)" amongst unprocessed archival material, Puke Ariki, New Plymouth.

Taylor, C.R.H. (1961, August 20). Report and valuation of items in the Butler collection recommended for purchase by the New Plymouth City Council. In ARC 2002-1031, Puke Ariki, New Plymouth.

Tononi, G., \& Cirelli, C. (2013). Perchance to prune. Scientific American, 309(2), 26-31.

Trace, C. B. (2002). What is recorded is never simply 'what happened': Record keeping in modern organizational culture. Archival Science, 2(1-2), 137-159. doi:10.1007/BF02435634

Turner, M. J. (2012). Lies, damned lies and visualizations: Will metadata and paradata be a solution or a curse? In A. Bentkowska-Kafel, H. Denard \& D. Baker (Eds.), Paradata and transparency in virtual heritage (pp. 135-144). Farnham, England: Ashgate.

Upward, F. (1994). In search of the continuum: Ian Maclean's 'Australian experience' essays on recordkeeping. In S. McKemmish \& M. Piggott (Eds.), The records continuum: Ian Maclean and Australian Archives first fifty years (pp. 110-130). Clayton, Australia: Ancora Press in association with Australian Archives.

Upward, F. (1996). Structuring the records continuum, part one: Postcustodial principles and properties. Archives and Manuscripts, 24(2), 268-285.

Upward, F. (1997). Structuring the records continuum, part two: Structuration theory and recordkeeping. Archives and Manuscripts, 25(1), 10-35. 
Upward, F. (2005a). Continuum mechanics and memory banks: (1) Multi-polarity Archives and Manuscripts, 33(1), 84-109.

Upward, F. (2005b). Continuum mechanics and memory banks: (2) The making of culture. Archives and Manuscripts, 33(2), 18-51.

Upward, F. (2009). Managing the flicker: Continuum concepts and the formation of archives. (PhD), Monash University, Melbourne.

Upward, F., \& McKemmish, S. (1994). Somewhere beyond custody. Archives and Manuscripts, 22(1), 136-149.

Upward, F., \& McKemmish, S. (2001). In search of the lost tiger, by way of Saint-Beuve: Re-constructing the possibilities in 'Evidence of me'. Archives and Manuscripts, 29(1), 22-42.

Van der Weel, A. (2011). Changing our textual minds: Towards a digital order of knowledge. Manchester and New York: Manchester University Press.

Vandendorpe, C. (2009). From papyrus to hypertext: Toward the universal digital library. (P. Aranoff \& H. Scott, Trans.). Urbana \& Chicago: University of Illinois Press.

Vitali, S. (2008). Context is everything: Sharing knowledge among archives, libraries and museums. State Archives of Latvia: Archive of Publications, 2008.3, 32-44. Retrieved from http://www.arhivi.gov.Iv/index.php?1\&1310\&view=article\&art_id=927

Wellington, S. (2013). Building GLAMour: Converging practice between gallery, library, archive and museum entities in New Zealand memory institutions. (PhD), Victoria University of Wellington, Wellington.

Wight, C. (2004). Limited incorporation or sleeping with the enemy: Reading Derrida as a critical realist. In J. Joseph \& J. M. Roberts (Eds.), Realism Discourse and Deconstruction (pp. 201-216). London \& New York: Routledge. 
Wikgren, M. (2004). Critical realism as a philosophy and social theory in information science? Journal of Documentation, 61(1), 11-22. doi:10.1108/00220410510577989

Williams, C. (2006). Managing archives: Foundations, principles and practice. Oxford: Chandos Publishing Ltd.

Wynn, D., \& Williams, C. K. (2012). Principles for conducting critical realist case study research in information systems. Management Information Systems Quarterly, 36(3), 787-810. Retrieved from http://misq.org/

Yakel, E., \& Torres, D. A. (2003). Al: Archival intelligence and user expertise. American Archivist, 66(1), 51-78. doi:10.17723/aarc.66.1.q022h85pn51n5800

Yakel, E., \& Torres, D. A. (2007). Genealogists as a "community of records". American Archivist, 70(1), 93-113. doi:10.17723/aarc.70.1.II5414u736440636

Yeo, G. (2007). Concepts of record (1): Evidence, information, and persistent representations. American $\quad$ Archivist, 315-343. doi:10.17723/aarc.70.2.u327764v1036756q

Yeo, G. (2008). Concepts of record (2): Prototypes and boundary objects. American Archivist, 71(1), 118-143. doi:10.17723/aarc.71.1.p0675v40tr14q6w2

Yeo, G. (2009). Custodial history, provenance, and the description of personal records. Libraries \& the Cultural Record, 44(1), 50-64. Retrieved from http://www.utexaspressjournals.org/loi/lcr\#

Yeo, G. (2010a). Debates about description. In T. Eastwood \& H. MacNeil (Eds.), Currents of archival thinking (pp. 89-114). Santa Barbara, Denver \& Oxford: Libraries Unlimited.

Yeo, G. (2010b). 'Nothing is the same as something else': Significant properties and notions of identity and originality. Archival Science, 10(2), 85-116. doi:10.1007/s10502-010-9119-9 
Yeo, G. (2010c). Representing the act: Records and speech act theory. Journal of the Society of Archivists, 31(2), 95-117. doi:10.1080/00379816.2010.506782

Yeo, G. (2012a). The conceptual fonds and the physical collection. Archivaria, 73, 43-80. Retrieved from http://archivaria.ca/index.php/archivaria

Yeung, H. W. (1997). Critical realism and realist research in human geography: A method or a philosophy in search of a method? Progress in Human Geography, 21(1), 5174. doi:10.1191/030913297668207944

Yin, R. K. (2009). Case study research: Design and methods $\left(4^{\text {th }}\right.$ ed.). London: SAGE Publications. 